Universidad de Lima

Facultad de Ingeniería y Arquitectura

Carrera de Ingeniería Industrial

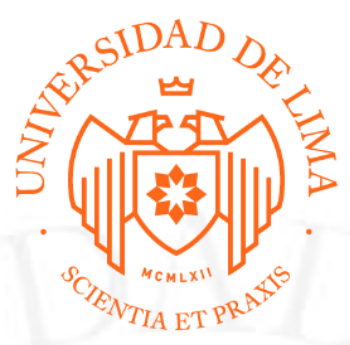

\title{
ESTUDIO DE PREFACTIBILIDAD PARA LA INSTALACIÓN DE UNA PLANTA PRODUCTORA DE CACAO FINO EN EL PERÚ
}

Trabajo de investigación para optar el Título Profesional de Ingeniero Industrial

\section{Brian Del Aguila Llaque}

Código 20140407

José Carlos Pastor Rodríguez

Código 20133051

Asesor

Martín Fidel Collao Díaz

$$
\text { Lima - Perú }
$$

Noviembre de 2019 
PREFACTIBILITY STUDY FOR THE INSTALLATION OF A FINE COCOA PRODUCTION PLANT IN PERU 


\section{TABLA DE CONTENIDO}

RESUMEN EJECUTIVO..........................................................................................XVI

EXECUTIVE SUMMARY .....................................................................................XVIII

CAPÍTULO I: ASPECTOS GENERALES ..........................................................1

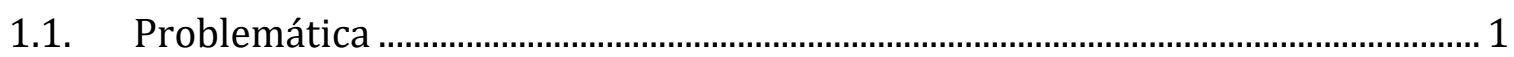

1.2. Objetivos de la investigación.................................................................................... 2

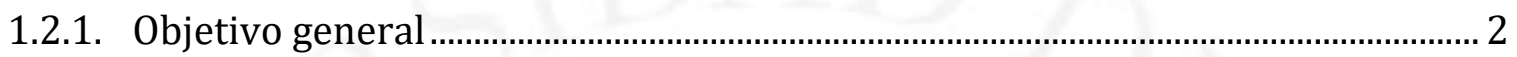

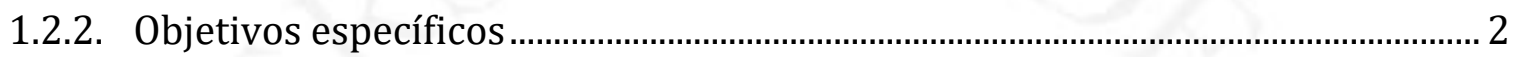

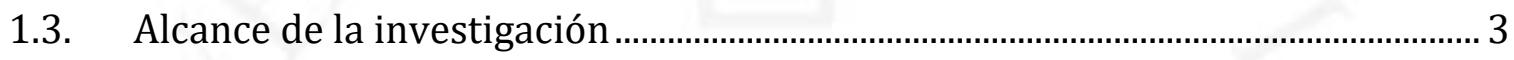

1.4. Justificación del tema ..............................................................................................

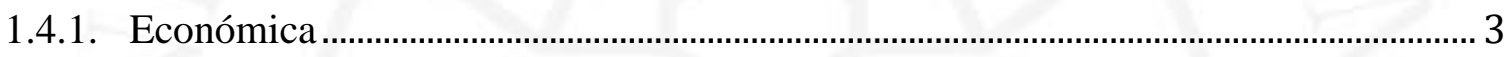

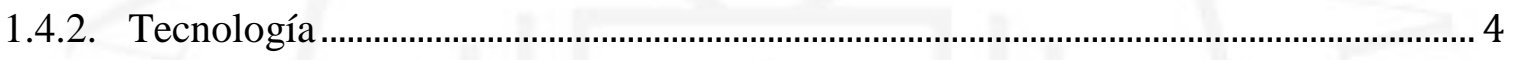

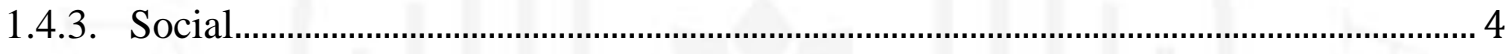

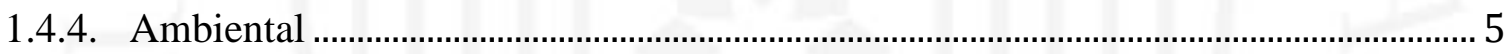

1.5. Hipótesis de trabajo.................................................................................................

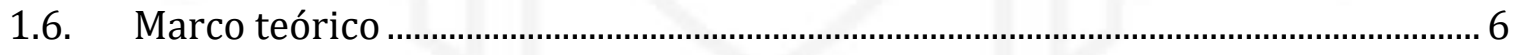

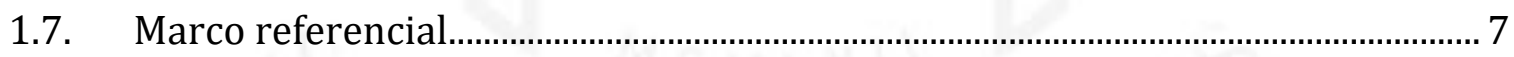

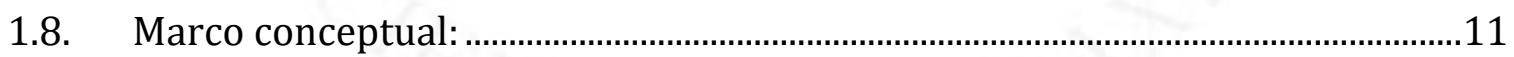

CAPÍTULO II: ESTUDIO DE MERCADO .............................................................13

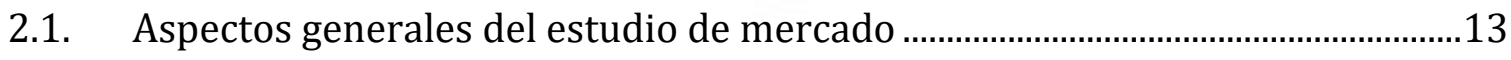

2.1.1. Definición comercial del producto............................................................................14

2.1.2. Usos del producto, bienes sustitutos y complementarios ....................................16

2.1.3. Análisis del sector industrial..................................................................................18

2.1.4. Modelo de negocios ....................................................................................................22

2.2. Metodología a emplear en la investigación de mercado ………………………......23 


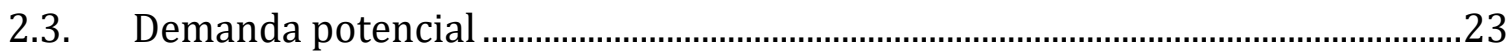

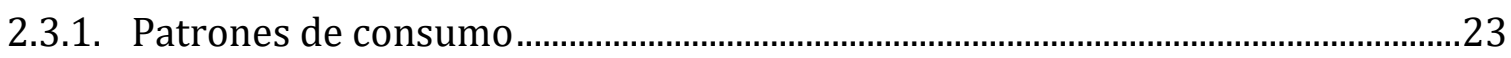

2.3.2. Determinación de la demanda potencial....................................................................24

2.4. Determinación de la demanda de mercado en base a fuentes secundarias o

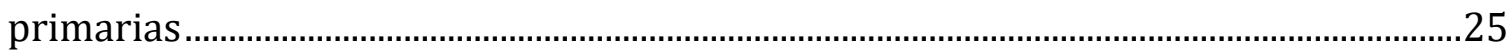

2.4.1. Demanda del proyecto en base a data histórica ......................................................25

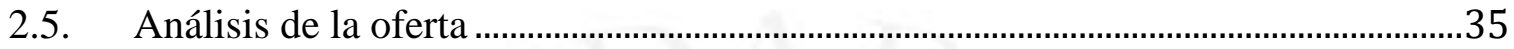

2.5.1. Empresas productoras, importadoras y comercializadoras .........................................35

2.5.2. Participación de mercado de los competidores actuales ..............................................35

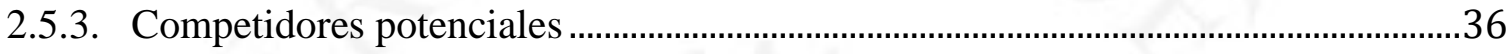

2.6. Definición de la estrategia de comercialización ..................................................................36

2.6.1. Políticas de comercialización y distribución ....................................................................36

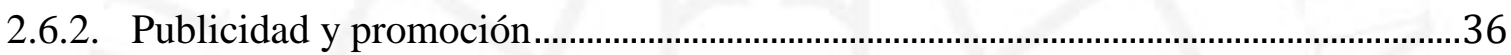

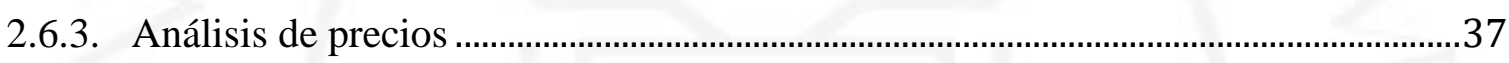

CAPÍTULO III: LOCALIZACIÓN DE PLANTA .............................................................. 40

3.1. Identificación y análisis detallado de los factores de localización ......................40

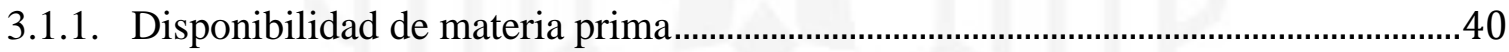

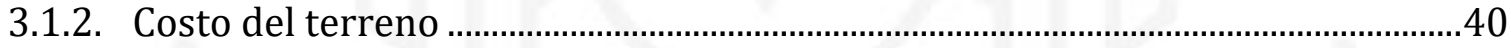

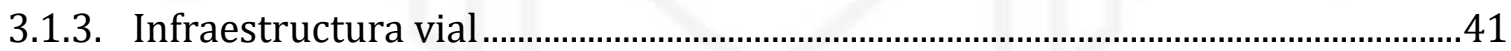

3.2. Identificación y descripción de las alternativas de localización .................................45

3.3. Evaluación y selección de localización.........................................................................46

3.3.1. Evaluación y selección de la macro localización ............................................................46

3.3.2. Evaluación y selección de la micro localización................................................................48

CAPÍTULO IV: TAMAÑO DE PLANTA ............................................................................5 52

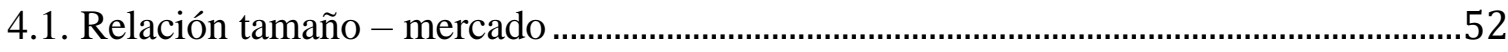

4.2 Relación tamaño-recurso productivo …………............................................................53

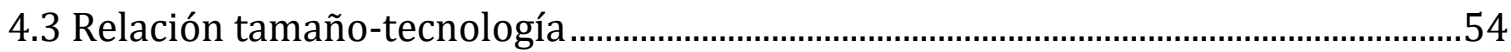




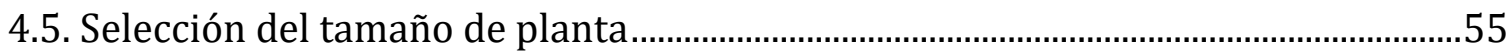

\section{CAPÍTULO V: INGENIERÍA DEL PROYECTO ..................................................56}

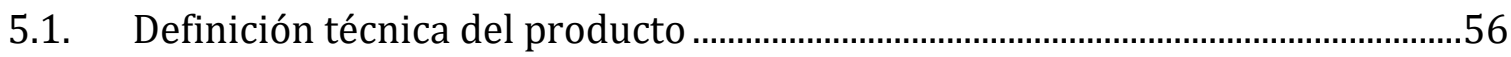

5.1.1. Especificaciones técnicas, composición y diseño del producto ..............................56

5.1.2. Marco regulatorio para el producto ……….................................................................58

5.2. Tecnologías existentes y procesos de producción..........................................................59

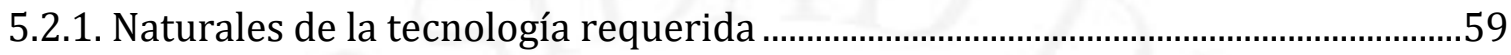

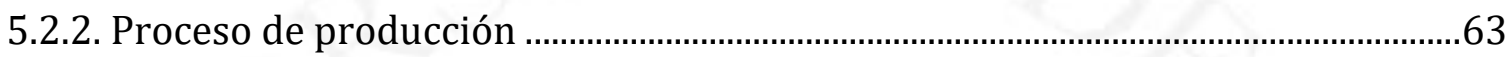

5.3 Características de las instalaciones y equipos ...............................................................

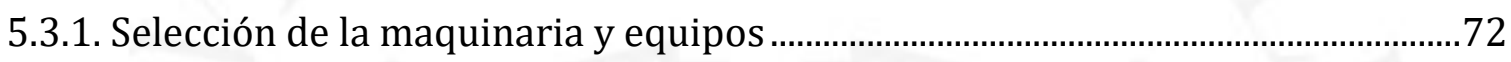

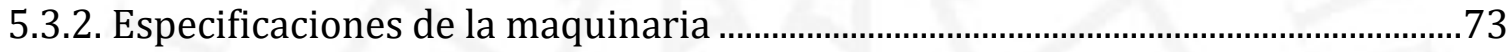

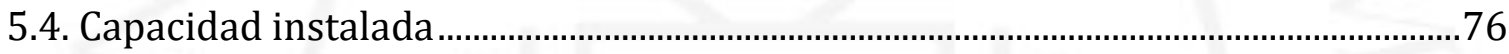

5.4.1. Cálculo detallado del número de máquinas y operarios requeridos ......................76

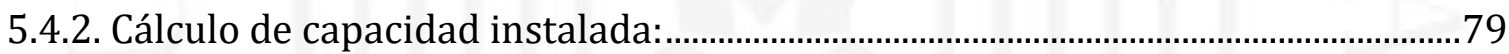

5.5. Resguardo de la calidad y/o inocuidad del producto ............................................80

5.5.1. Calidad de la materia prima, de los insumos, del proceso y del producto

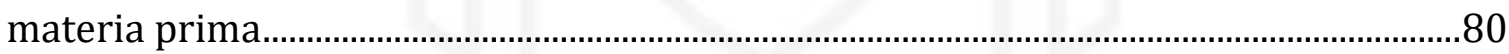

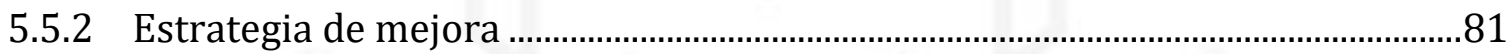

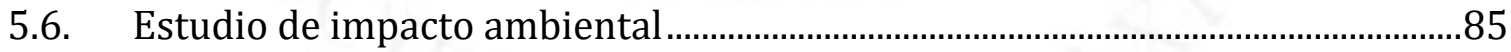

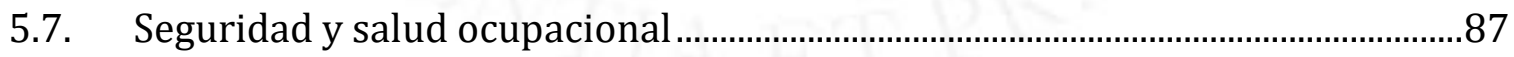

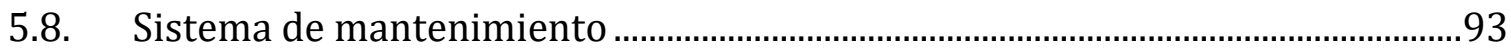

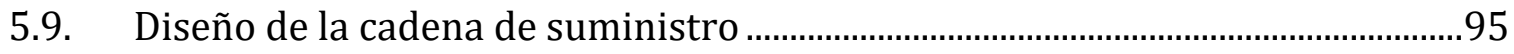

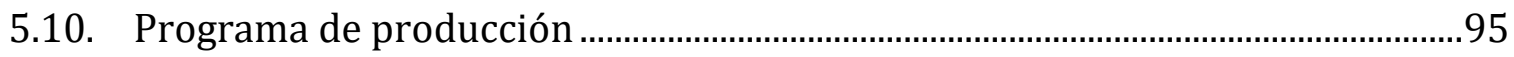

5.11. Requerimiento de insumos, servicios y personal indirecto ..................................97

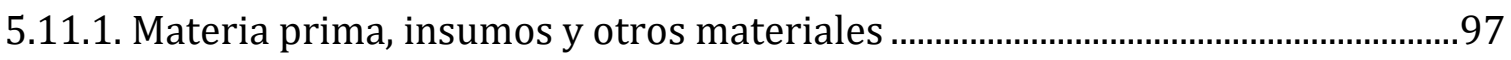


5.11.2. Servicio: energía eléctrica, agua, vapor, combustible, etc. . .99

5.11.3. Determinación del número de trabajadores indirectos .......................................100

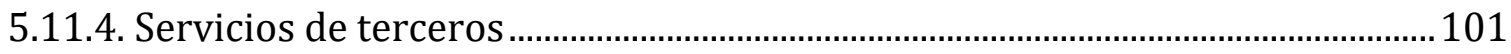

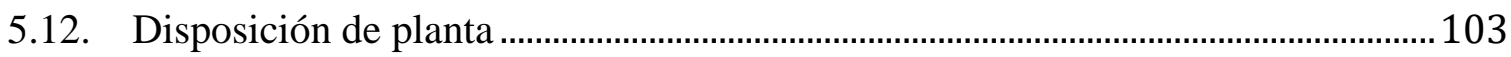

5.12.1 Características físicas del proyecto …………............................................................ 103

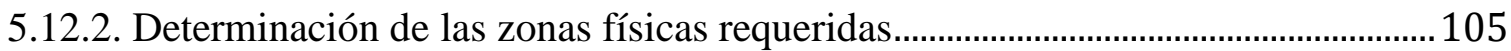

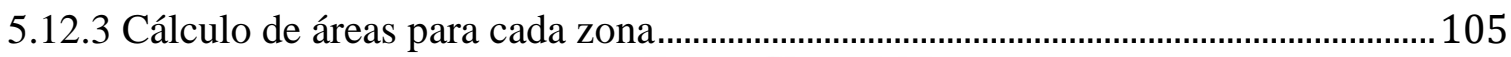

5.12.4 Dispositivos de seguridad industrial y señalización ...................................................112

5.12.5 Disposición de detalle de la zona productiva ...........................................................116

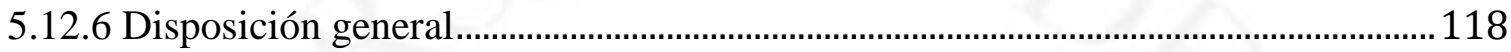

5.13 Cronograma de implementación del proyecto .............................................................. 124

CAPÍTULO VI: ORGANIZACIÓN Y ADMINISTRACIÓN ..................................... 125

6.1 Formación de la organización empresarial ........................................................................125

6.2. Requerimiento de personal directivo, administrativa y de servicios; y funciones generales de los principales puestos

6.3. Esquema de la estructura organizacional 129

CAPÍTULO VII: PRESUPUESTO Y EVALUACIONES DEL PROYECTO.........130

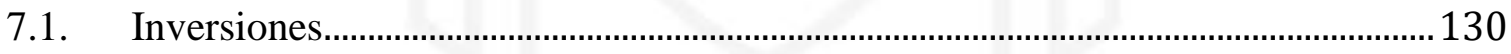

7.1.1. Estimación de las inversiones de largo plazo (tangibles e intangibles) ....................130

7.1.2. Estimación de las inversiones de corto plazo (Capital de Trabajo) ...................134

7.2 Costos de producción 135

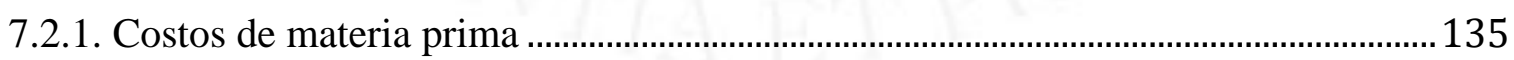

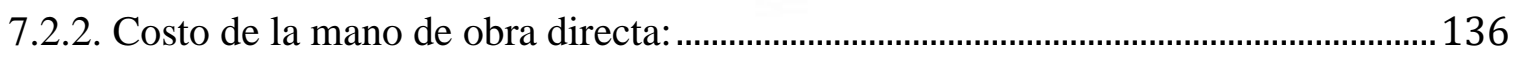

7.2.3. Costo indirecto de fabricación (materiales indirectos, mano de obra indirecta y

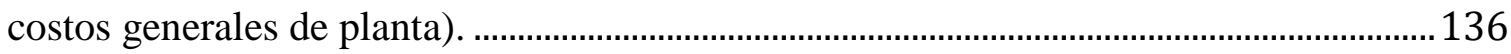

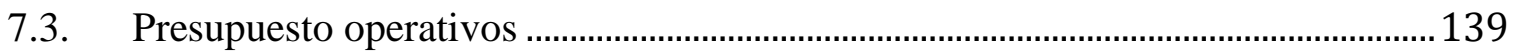

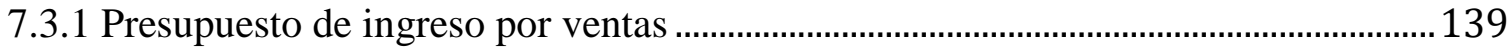

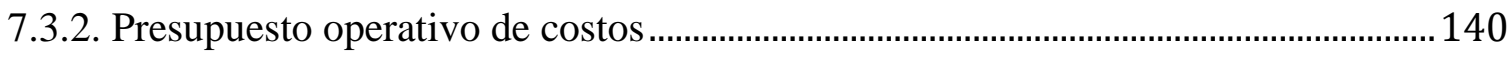


7.4. Presupuestos financieros

7.4.1. Presupuesto de servicio a la deuda

7.4.2. Presupuesto de estado de resultados 145

7.4.3. Presupuesto de estado de situación financiera 146

7.4.4. Flujo de fondos netos (Económico y Financiero). 150

7.5. Evaluación económica-financiera. 153

7.5.1. Evaluación económica: VAN, TIR, RBC, PR. 153

7.5.2. Evaluación financiera: VAN, TIR, RBC, PR 154

7.5.3. Análisis de ratios (liquidez, endeudamiento, rentabilidad, cobertura). 155

7.5.4. Análisis de sensibilidad del proyecto 156

CAPÍTULO VIII: EVALUACIÓN SOCIAL DEL PROYECTO. 157

8.1. Identificación de las zonas y comunidades de influencia del proyecto 157

8.2. Análisis de indicadores sociales (valor agregado, densidad de capital, intensidad de capital, relación producto - capital y productividad de mano de obra) 157

CONCLUSIONES 160

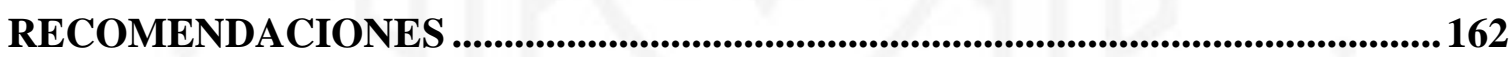

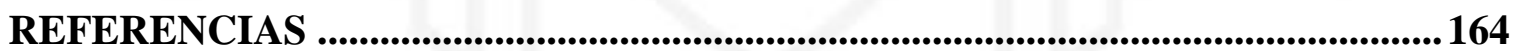

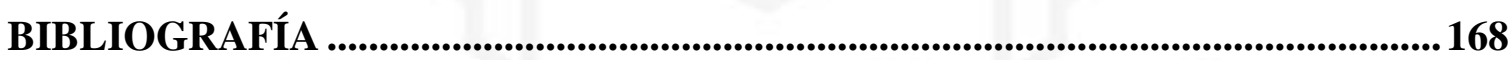

ANEXOS 169 


\section{ÍNDICE DE TABLAS}

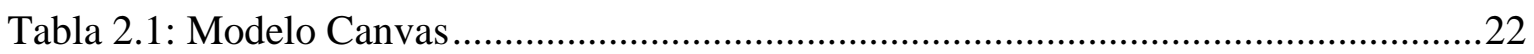

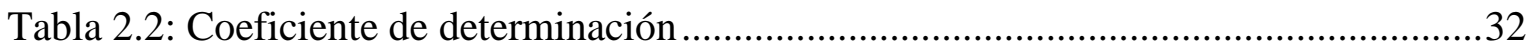

Tabla 2.3: Proyección de la exportación nacional de cacao ...................................................32

Tabla 2.4: Exportación de cacao fino proyectada.....................................................................33

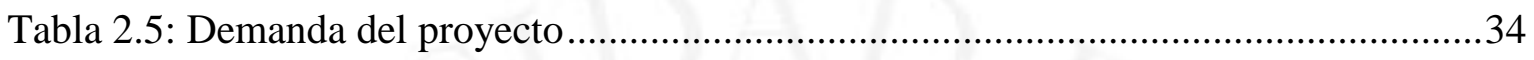

Tabla 3.1: Temperatura promedio anual por departamento ............................................43

Tabla 3.2: Humedad relativa promedio por departamento ................................................44

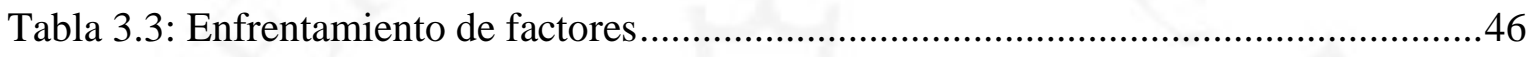

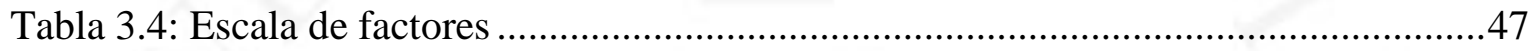

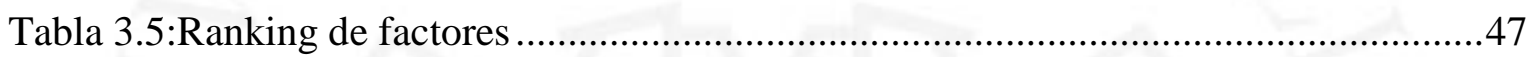

Tabla 3.6: Infraestructura vial por provincia .............................................................. 48

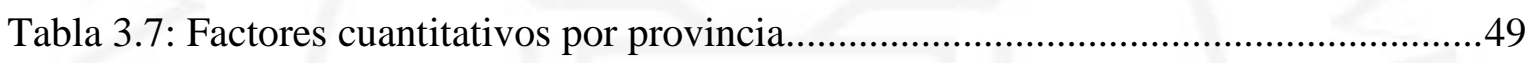

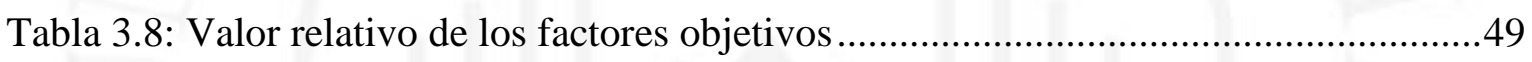

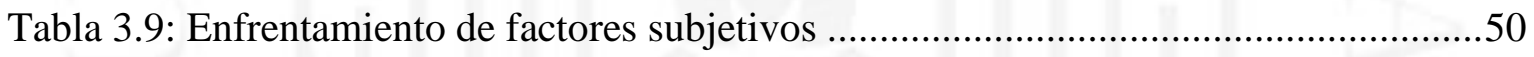

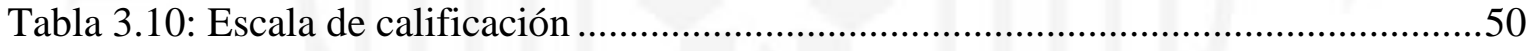

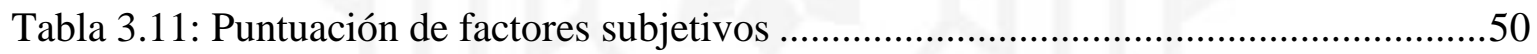

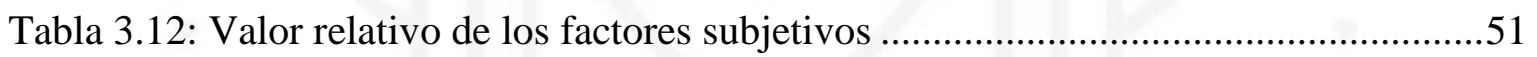

Tabla 3.13: Medida de preferencia de la localización ........................................................51

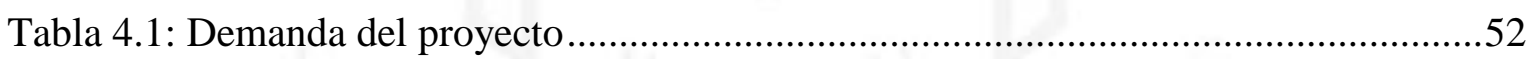

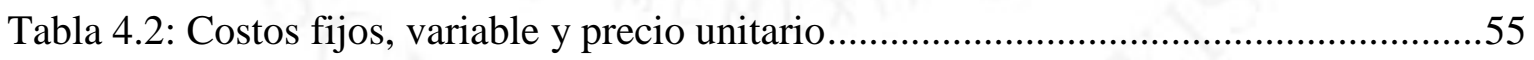

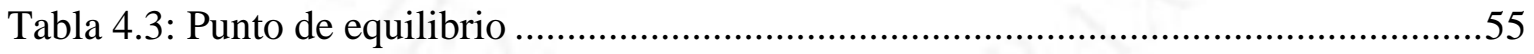

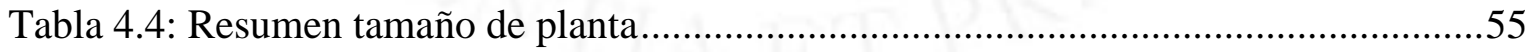

Tabla 5.1: Principales características del grano de cacao...................................................57

Tabla 5.2: Principales NTPs relacionadas al grano de cacao ...........................................58

Tabla 5.3: Especificaciones de las actividades semi-automáticas y automáticas.................72

Tabla 5.4: Especificaciones técnicas de la máquina despulpadora de cacao.......................73

Tabla 5.5: Especificaciones técnicas de la máquina lavadora por inmersión.......................73

Tabla 5.6: Especificaciones técnicas de la máquina secadora de granos automática...........74

Tabla 5.7: Especificaciones técnicas de la máquina de selección de granos por tamaño y

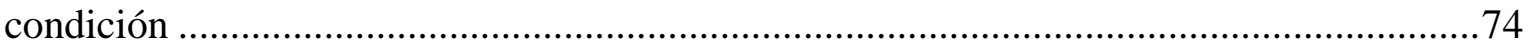


Tabla 5.8: Especificaciones técnicas de la máquina peladora de cacao .75

Tabla 5.9: Especificaciones técnicas de la máquina ensacadora de cacao ..........................75

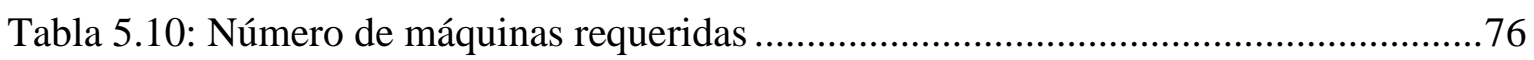

Tabla 5.11: Número de operarios requeridos área de plantación ........................................77

Tabla 5.12: Número de operarios requeridos área de producción ........................................78

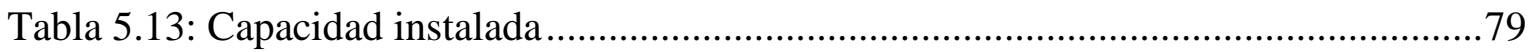

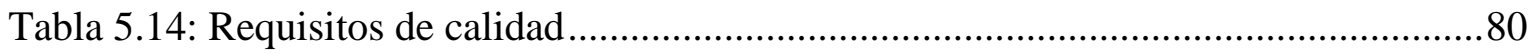

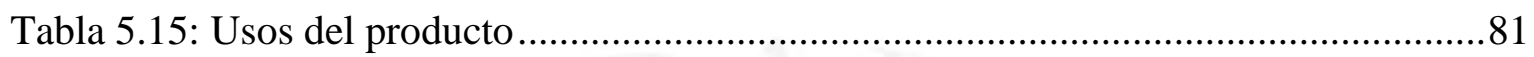

Tabla 5.16: Matriz HACCP-Identificación de puntos críticos de control ............................82

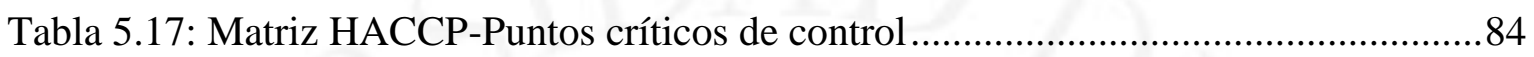

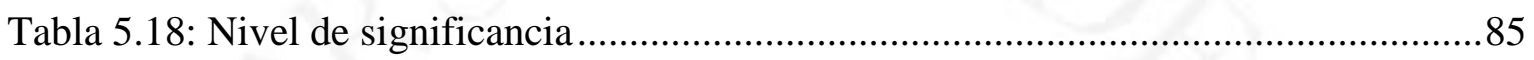

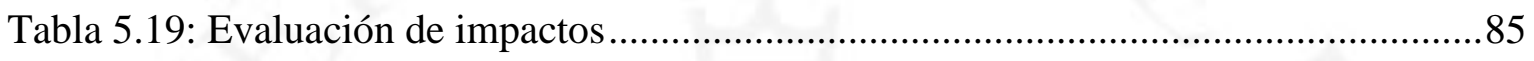

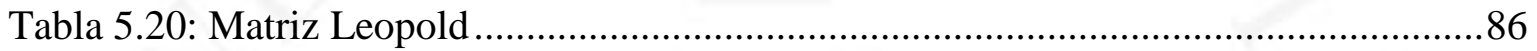

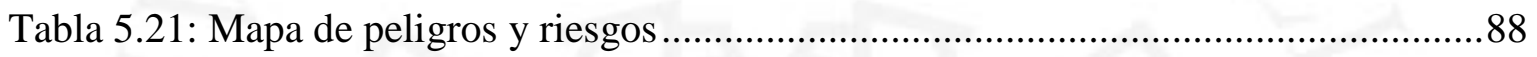

Tabla 5.22: Puntajes para el análisis de la matriz IPERC ….............................................. 89

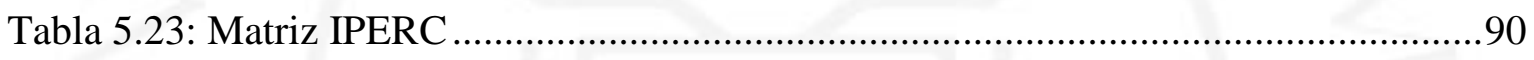

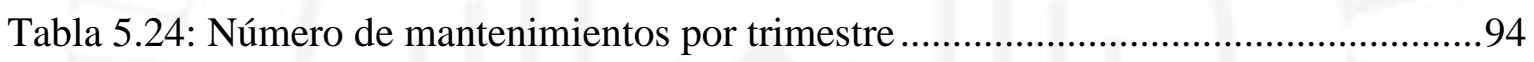

Tabla 5.25: Cronograma de implementación de los mantenimientos ..................................94

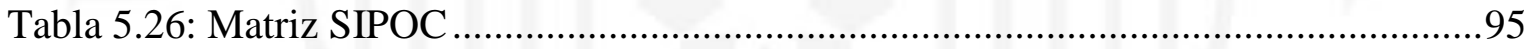

Tabla 5.27: Programa de producción anual .........................................................................96

Tabla 5.28: Programa de producción mensual ..............................................................97

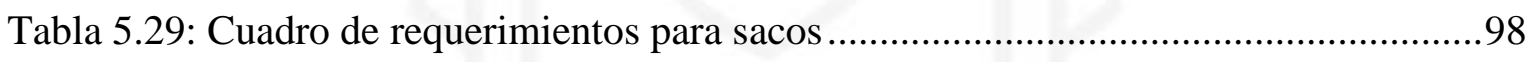

Tabla 5.30: Cuadro de requerimientos para mazorcas ...................................................... 98

Tabla 5.31: Cuadro de insumos para plantación................................................................99

Tabla 5.32: Cálculo de H-Máquina al año........................................................................99

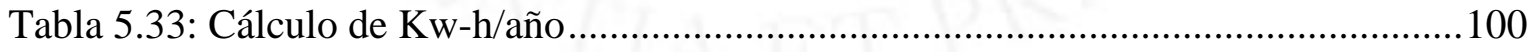

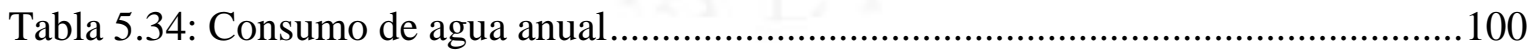

Tabla 5.35: Principales puestos y funciones de trabajo indirectos ...................................101

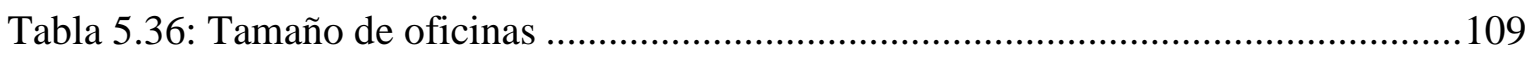

Tabla 5.37: Resumen metraje de las áreas................................................................... 112

Tabla 5.38: Análisis de Guerchet- elemento estático ....................................................... 116

Tabla 5.39: Análisis de Guerchet- elementos móviles ..................................................... 117

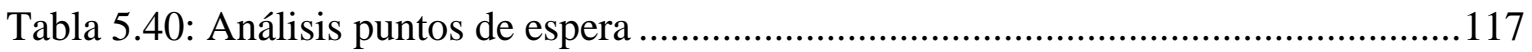

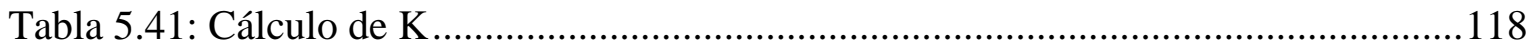


Tabla 5.42: Dimensiones de la zona de producción

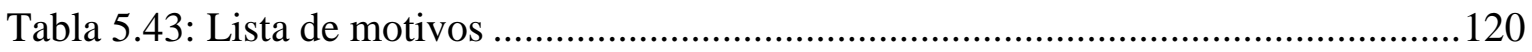

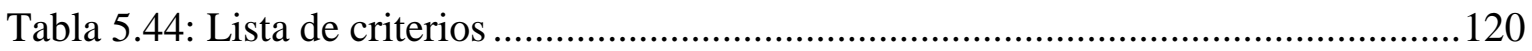

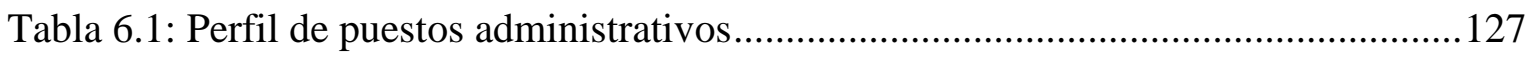

Tabla 6.2: F unciones de puesto administrativos........................................................... 128

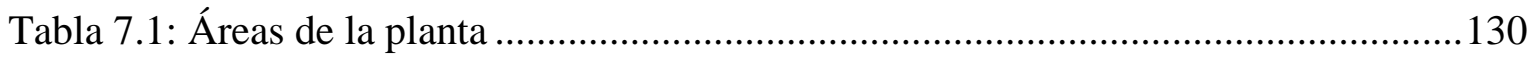

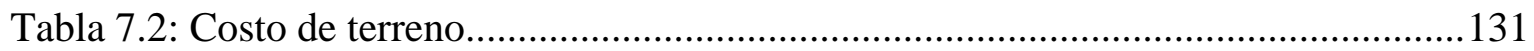

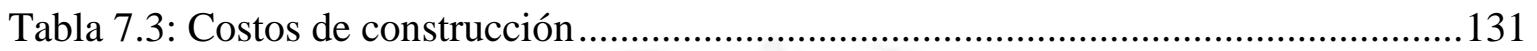

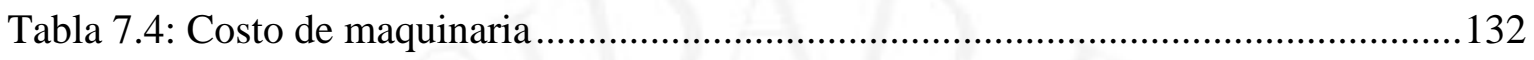

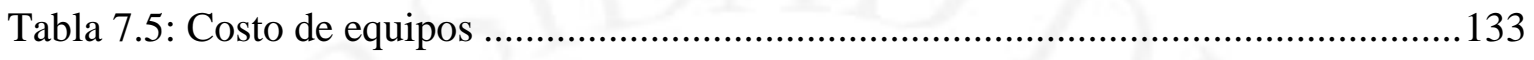

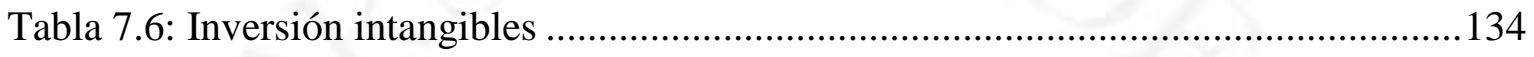

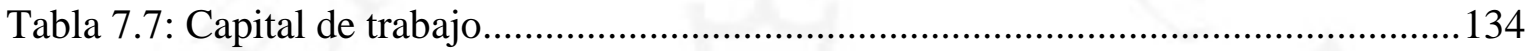

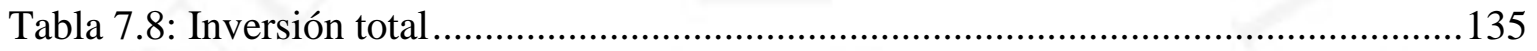

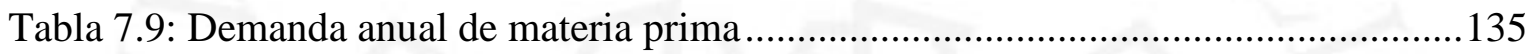

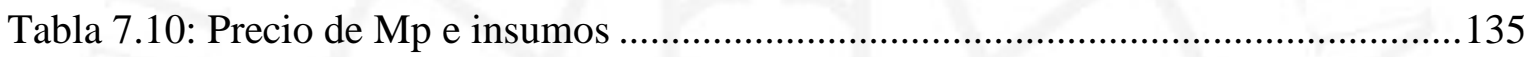

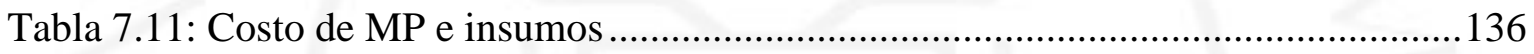

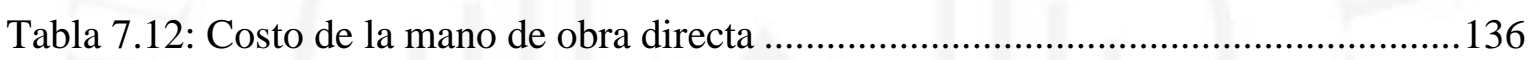

Tabla 7.13: Costo de la mano de obra indirecta .............................................................. 137

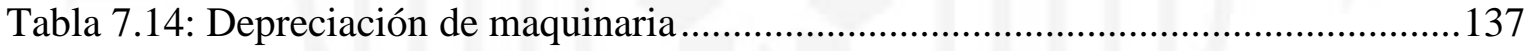

Tabla 7.15: Depreciación de equipos productivos ............................................................ 137

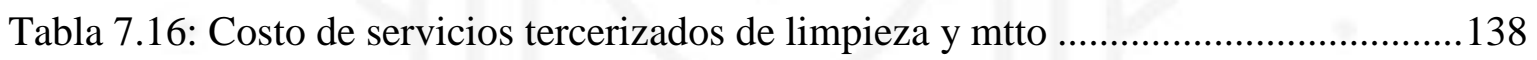

Tabla 7.17: Costo de servicios tercerizados para la plantación .........................................139

Tabla 7.18: Presupuesto de ingreso por ventas anuales.................................................. 139

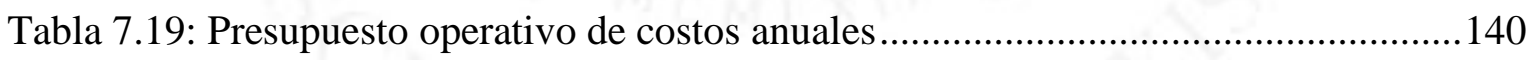

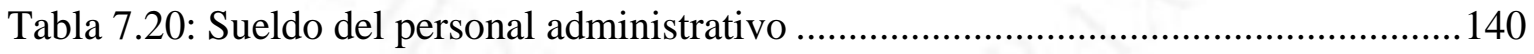

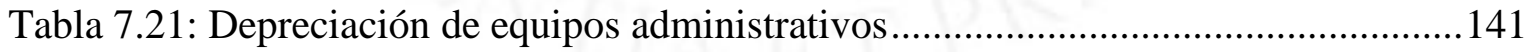

Tabla 7.22: Depreciación de intangibles ......................................................................... 141

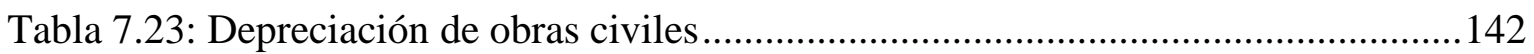

Tabla 7.24: Consumo de agua (No destinada a la producción) ..........................................143

Tabla 7.25: Consumo de energía en zona adm. y otras zonas no destinadas a la

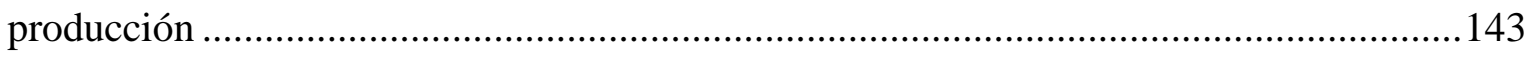

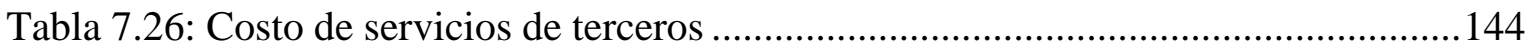

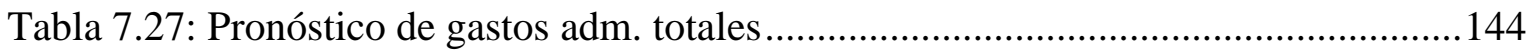

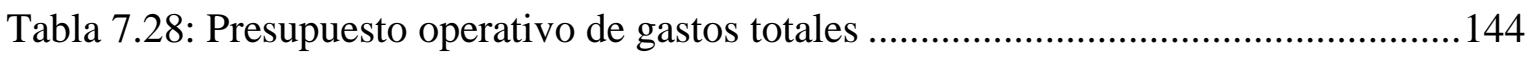


Tabla 7.29: Detalles del endeudamiento 145

Tabla 7.30: Cronograma de servicio a la deuda (Cuotas Crecientes) 145

Tabla 7.31: Presupuesto de estado de resultados al 2024 ................................................ 146

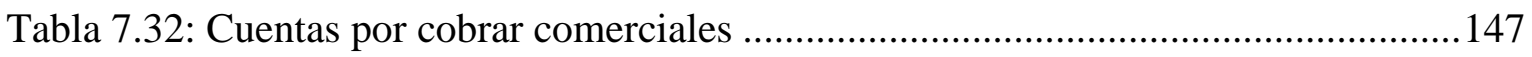

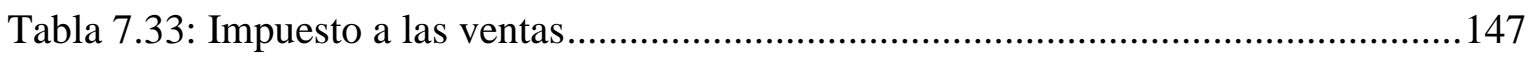

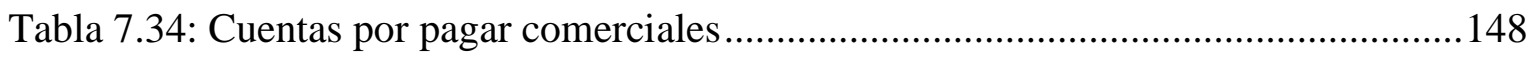

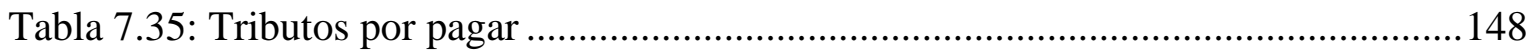

Tabla 7.36: Flujo de caja por concepto de materia prima ............................................ 149

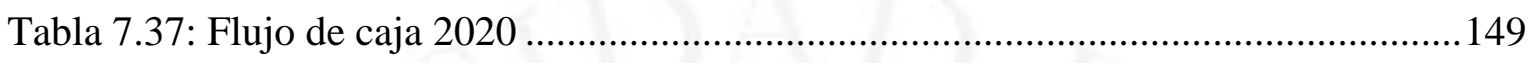

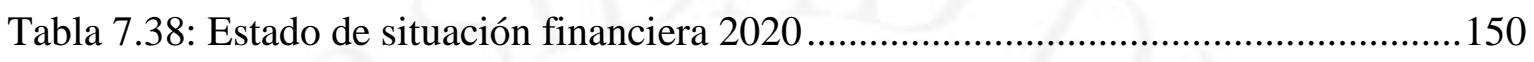

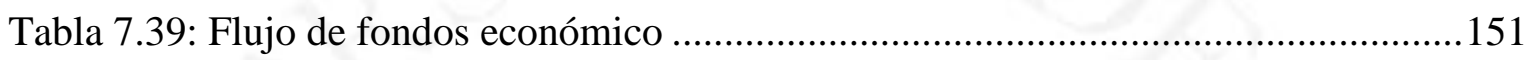

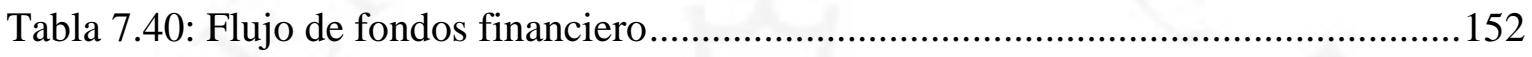

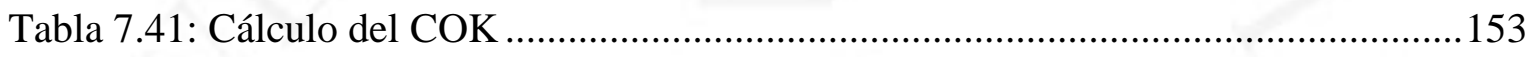

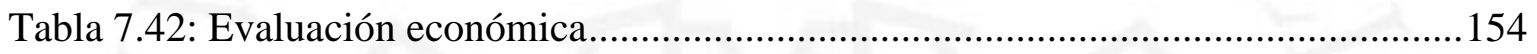

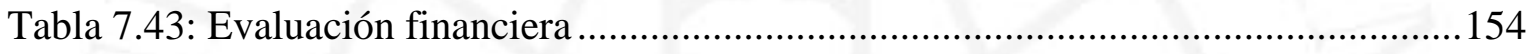

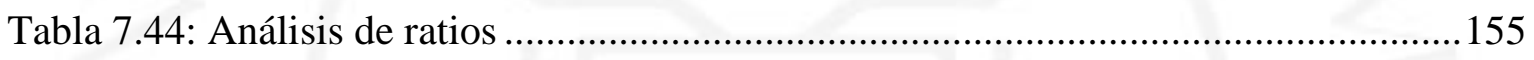

Tabla 7.45: Análisis de sensibilidad de precios de cacao fino en el Perú ......................... 156

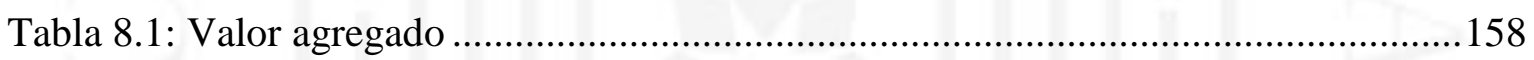

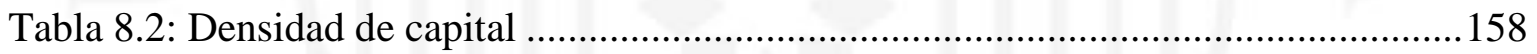

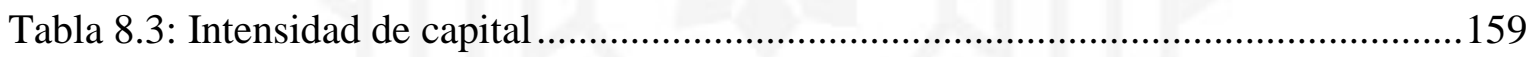

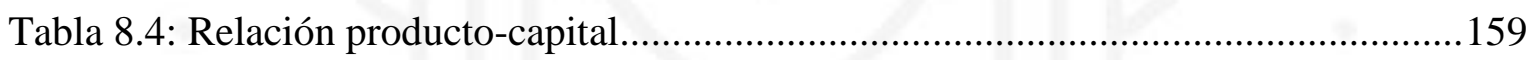

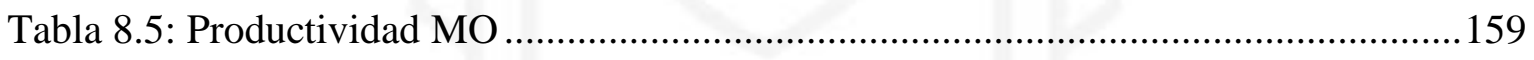




\section{ÍNDICE DE FIGURAS}

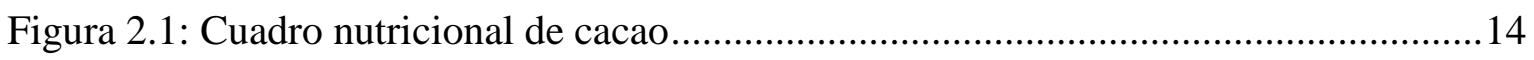

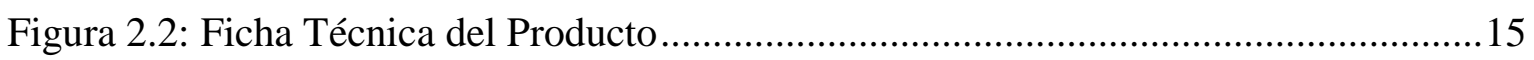

Figura 2.3: Ubicación de Plantaciones en San Martin........................................................ 17

Figura 2.4: Demanda y producción mundial de cacao ......................................................24

Figura 2.5: Exportaciones de cacao en grano crudo del 2000 al 2015 ..............................25

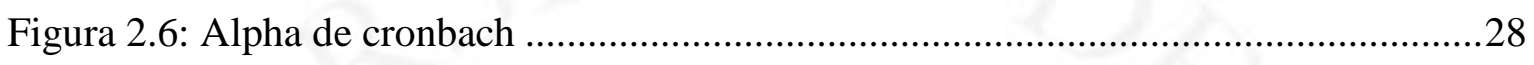

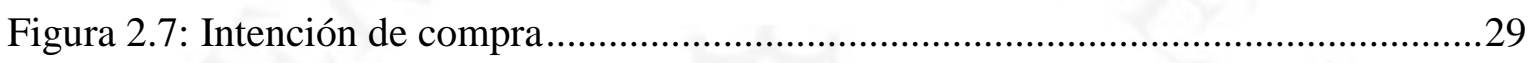

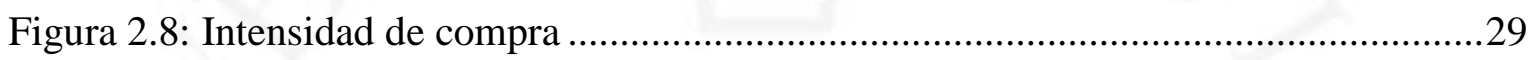

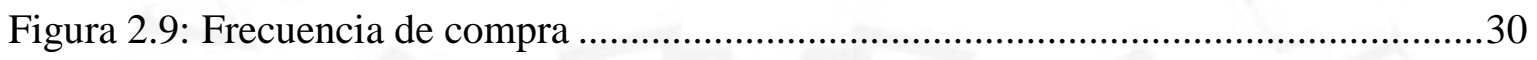

Figura 2.10: Data histórica de la exportación de cacao en Perú ........................................... 31

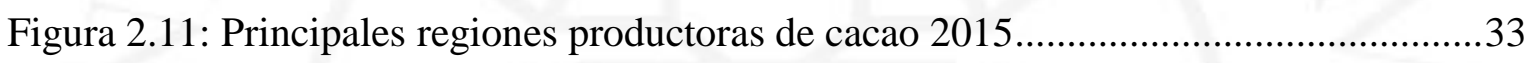

Figura 2.12: Principales empresas productoras de cacao en Perú ........................................34

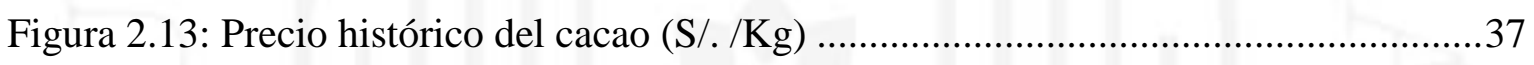

Figura 2.14: Precio promedio internacional al contado de cacao (Puerto EEUU Y UE)....38

Figura 3.1: Suministro de agua potable por departamento ............................................... 41

Figura 3.2: Suministro de energía eléctrica por departamento .........................................42

Figura 4.1: Exportaciones vs producción nacional de cacao ..............................................54

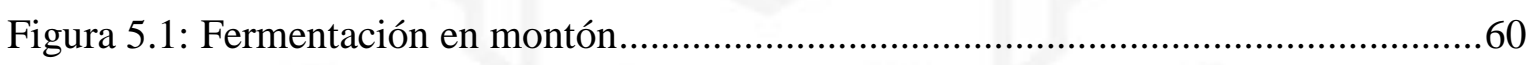

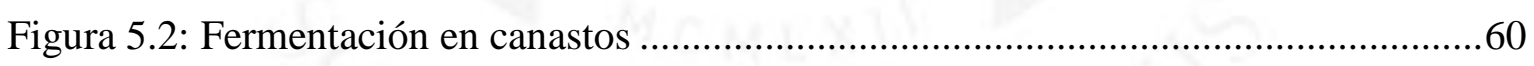

Figura 5.3: Fermentación en cajones de cascado ............................................................61

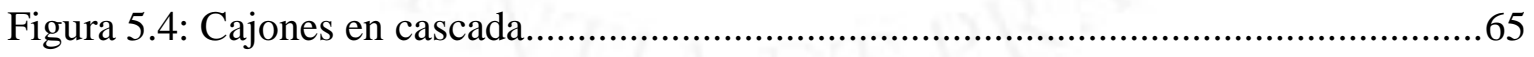

Figura 5.5: Temperaturas de fermentación por día.........................................................66

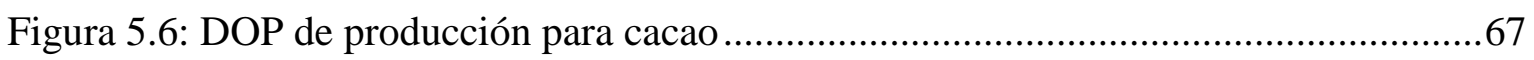

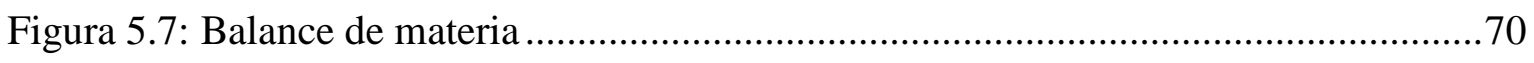

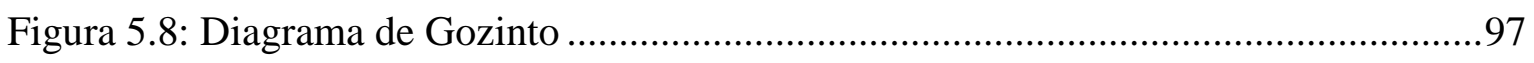

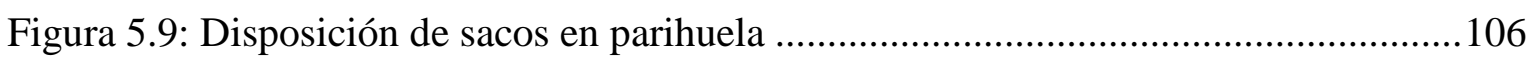

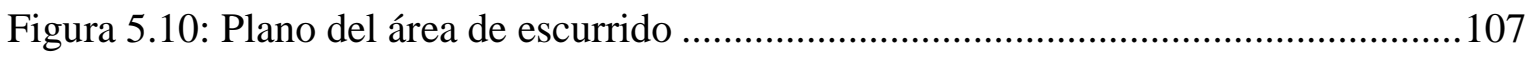

Figura 5.11: Plano de almacén de producto terminado ................................................. 108

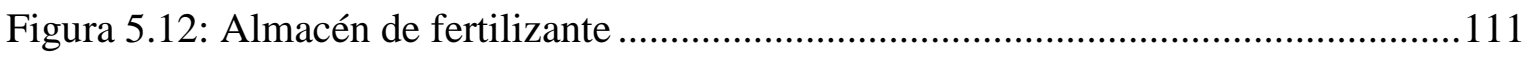




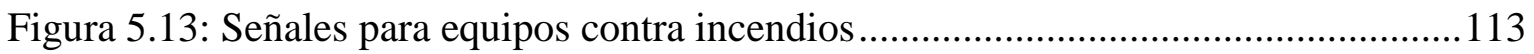

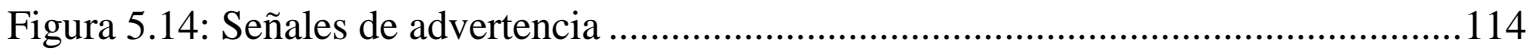

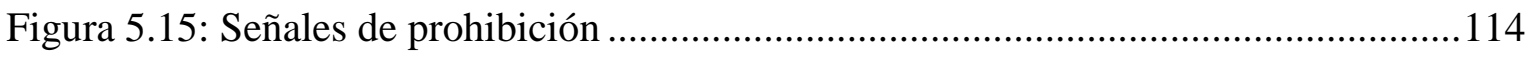

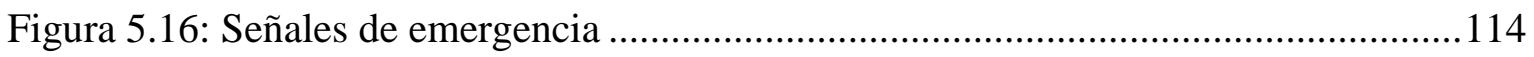

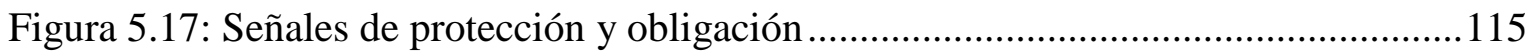

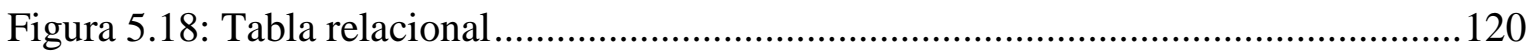

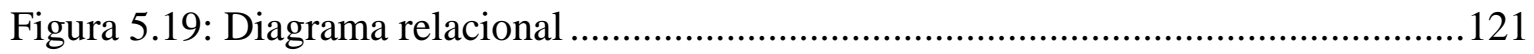

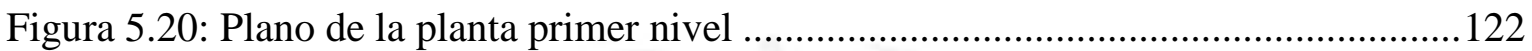

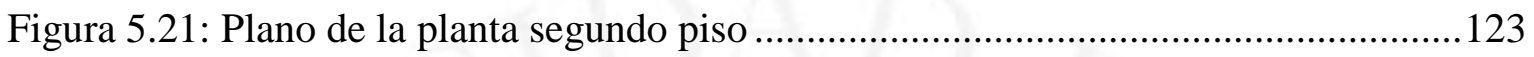

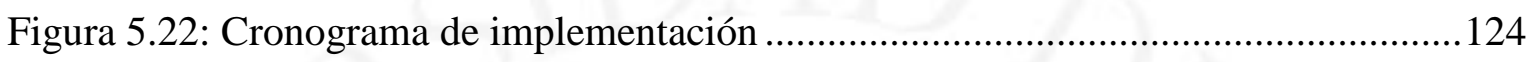

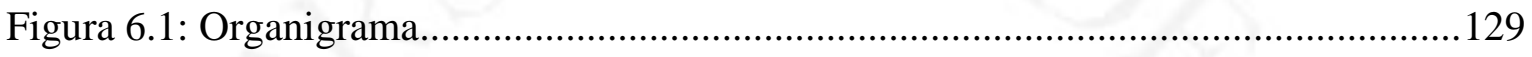




\section{ÍNDICE DE ANEXOS}

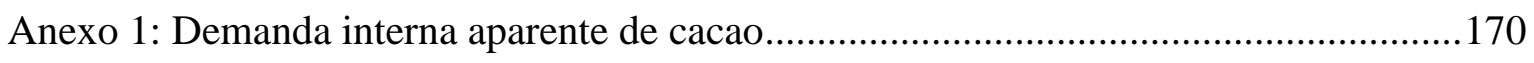

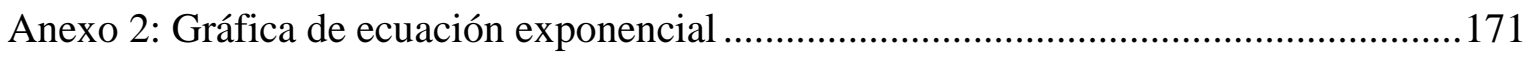

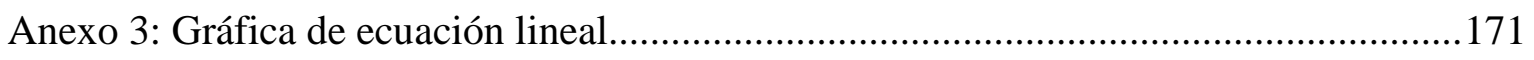

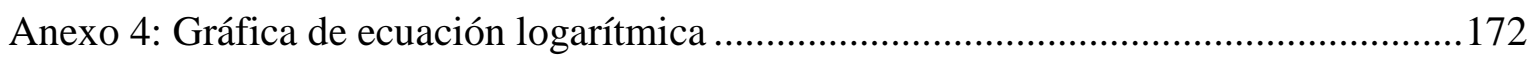

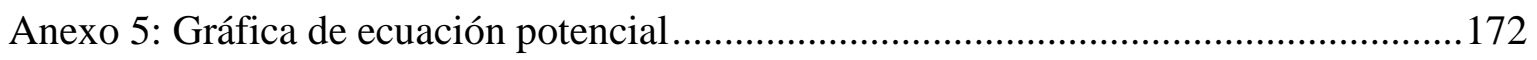

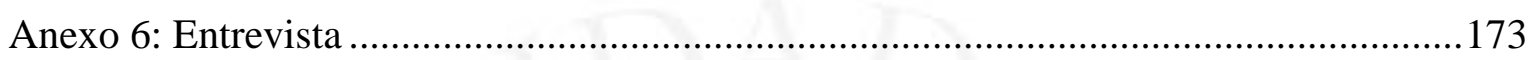

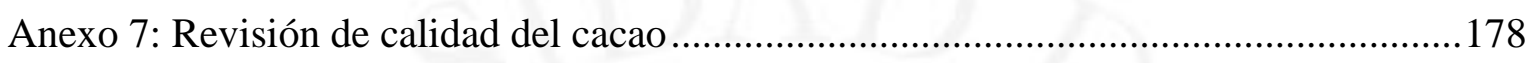

Anexo 8: Proceso de transformación de los residuos sólidos en el biodigestor .................181

Anexo 9: Caracterización del proceso de producción ........................................................ 182

Anexo 10: Tamaño de muestra para inspección de calidad..............................................187

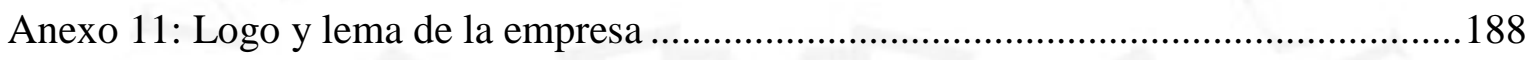




\section{RESUMEN EJECUTIVO}

El presente estudio de prefactibilidad evaluará la viabilidad económica, financiera, técnica, comercial y ambiental de la implementación de una planta productora de cacao fino en un ambiente de fermentación controlado.

Inicialmente, se realizó el estudio de mercado para poder analizar y verificar que una planta productora de cacao fino en sacos será acogida de manera positiva por los clientes. Luego, se analizó los patrones de consumo para determinar la demanda del proyecto, los cuales validan la posibilidad comercial del estudio de prefactibilidad aquí expuesto.

Además, se realizó una investigación a fondo para determinar la viabilidad técnica del proyecto. Para esta investigación se utilizó el método de Ranking de Factores y el método de Brown y Gibson la macro localización de la planta y la microlocalización de la misma en el lugar más conveniente. Dando como resultado el departamento de Tocache en la región San Martín.

A su vez, se evaluaron factores como el tamaño de mercado, tamaño de recursos productivos, punto de equilibrio y tamaño de tecnología. En línea con ello, se obtuvo que el factor limitante es la relación tamaño-mercado con 11,689 sacos de cacao de $60 \mathrm{~kg}$ al año.

También, el presente trabajo muestra la evaluación de la ingeniería necesaria para el proyecto, brindando como resultado el requerimiento de calidad, la ficha técnica del producto, maquinaria necesaria y la sostenibilidad del medio ambiente. De la misma manera, se determinó el número de colaboradores necesarios tanto para el área de plantación como el área productiva.

Finalmente, se estableció la viabilidad económica, financiera, técnica, comercial y ambiental. Se estimó la inversión, costos, gastos e ingresos de producción para obtener los estados financieros con los que se elaboraron tanto los ratios económicos y financieros. Luego del análisis, se concluye que: el 52\% de la inversión será financiada, el VAN 
económico es de S/. 501,142.07 y la TIR económica de 22.81\%. Respecto al análisis financiero, se obtiene un VAN financiero de S/. 719,278.25 con una TIR financiera de $32.87 \%$ y un valor agregado social de S/. 16, 538,193.

Palabras Clave: Planta Productora de Cacao Fino , Macro y Micro Localización de una planta productora de Cacao en Perú, Evaluación Económica y Financiera del Proyecto, Mercado Cacaotero Insatisfecho, Análisis del Sector Cacaotero en Perú y Tamaño de Planta. 


\section{EXECUTIVE SUMMARY}

This study evaluates the economic, financial, technical, commercial and environmental viability when installing a cacao bean production plant, controlling fermentation sub process.

First, the market study was carried out in order to analyze and verify that a fine cocoa production plant will be received positively by customers. Then, the consumption patterns were analyzed to determine the project demand, which validates the commercial possibility of the present prefeasibility study.

Additionally, an in-depth investigation was made to determine the technical feasibility of the project. This investigation used the Factor Ranking Method and the Brown and Gibson Method to determine the macro and micro location of the plant in the most convenient place. As a result, the optimal installation area is Tocache, San Martin.

In this project, factors such as market size, size of productive resources, break-even point and size of technology were evaluated to determine the limiting factor. As a result, the market-size relationship was chosen, producing 11,689 bags of $60 \mathrm{~kg}$ of cocoa beans per year.

Furthermore, this investigation portraits the main engineering requirements to install the plant in Tocache. These requirements are: quality requirement, the product data sheet, machinery and environmental sustainability. In the same way, the number of workers needed for both the plantation area and the productive area were determined.

Finally the main investment, costs, expenses and production income were estimated to obtain the financial statements. In conclusion: $52 \%$ of the investment will be financed, the economic NPV is S /. 501,142.07, the economic IRR is $22.81 \%$. On the other hand, the 
financial NPV is $\mathrm{S} / .717,278.25$, the financial IRR is $32.87 \%$ and the social added value is S /. 16, 538, 193.

Keywords: Fine Cocoa Plant, Macro and Micro Location of a Cocoa production plant in Peru, Economic and Financial Evaluation of the Project, Unsatisfied Cocoa Market, Analysis of the Cocoa Sector in Peru and Plant Size. 


\section{CAPÍTULO I: ASPECTOS GENERALES}

En el capítulo 1, se analizarán diversos aspectos para definir a detalle la problemática del proyecto. El proyecto inicia estableciendo el objetivo general y los específicos para determinar la ubicación estratégica de la planta, las amenazas al sector de producción de chocolate, la demanda potencial y real del cacao, el tamaño de planta y la correcta distribución de sus máquinas. Una vez determinados los objetivos, se analizará económica y financieramente el proyecto para evaluar si este es rentable.

\subsection{Problemática}

Estudios previos realizados por la Organización Internacional del cacao (ICCO) muestran que, mientras la demanda de cacao aumenta sostenidamente, la producción crece en menor tasa, afectada por problemas políticos, culturales, climatológicos y enfermedades asociadas con el cacao. Asimismo, la ICCO realizó proyecciones en base a la oferta y demanda mundial de cacao, para mostrar cómo es que la demanda de este producto desde el 2017 hasta el 2023 será mayor que la oferta mundial. En consecuencia, los precios proyectados crecerán sostenidamente hasta por encima de los $\$ 3,700.00 /$ tonelada (Agricultura, 2016, pág. 29).

Actualmente, las hectáreas de cacao producidas en Perú no son utilizadas al máximo. Esto se debe a que los agricultores no cuentan con la capacidad técnica para generar nuevos métodos de fermentación y secado que permitan mejorar el entorno de producción y la presencia de enfermedades graves para el cacao como la Moliphthora Roreri, capaz de erradicar más del 50\% de la producción anual.

El cacao fino se divide en dos especies: el cacao criollo y trinitario, las cuales presentan características organolépticas de sabor, textura y olor. El cultivo de este grano en Perú es muy puntual, dado que requieren de

cuidados estrictos en la etapa de plantación para mantener sus características principales. 
A consecuencia de la escasez de este tipo de cacao, los agricultores optan por sembrar plantas de cacao del tipo forastero o realizan cruces híbridos de plantas, ahorrando en costos, obteniendo un producto similar.

\subsection{Objetivos de la investigación}

\subsubsection{Objetivo general}

Determinar la viabilidad técnica, económica, financiera, social y ambiental para la instalación de una planta productora de cacao en el Perú a partir del clon criollo o nativo de este grano.

\subsubsection{Objetivos específicos}

1. Determinar la ubicación estratégica de la instalación de la planta productora de cacao fino para obtener un producto terminado óptimo que cumpla con los estándares de calidad de exportación.

2. Identificar las posibles amenazas de nuevos ingresos a la industria del chocolate para evaluar una diferenciación de producto estratégica.

3. Determinar la demanda real de cacao fino, tomando en cuenta la frecuencia, intención e intensidad de compra.

4. Determinar la producción real del proyecto implementando el concepto de MRP1 y MRP2.

5. Determinar el tamaño óptimo de planta para atender la demanda del proyecto.

6. Determinar la distribución de las máquinas y estaciones de trabajo en la planta para aumentar la productividad.

7. Realizar un análisis económico financiero para determinar la rentabilidad del proyecto. 


\subsection{Alcance de la investigación}

El presente trabajo busca determinar los beneficios, económicos, sociales y ambientales obtenidos de la implementación de una planta de producción de granos de cacao fino bajo un control riguroso en dos de los ambientes más críticos del proceso, siendo estos el secado y fermentado. Entiéndase así que, el grano de cacao será el producto final ensacado que a su vez será entregado a los clientes para su posterior comercialización. Asimismo, se analizará la necesidad de implantar cacao en grano, las oportunidades y amenazas del sector en el que se desenvuelve el producto, las fortalezas y debilidades de ingresar a este sector, el lugar óptimo para ubicar la planta en el Perú, los costos asociados con la puesta en marcha de la planta, así como el beneficio - costo obtenido, el periodo de recupero de inversión y el método de financiamiento más adecuado para iniciar el proyecto.

\subsection{Justificación del tema}

\subsubsection{Económica}

En primer lugar, el proyecto busca generar valor agregado al cacao mediante el control de los factores que intervienen el sub proceso de fermentación de éste grano, como son la temperatura y la humedad dentro del proceso de fermentado y la exigencia de un adecuado riego de las plantaciones de nuestros proveedores, ya que esto evitará la aparición de enfermedades fúngicas que ocasionarían pérdidas en más del $50 \%$ de la producción.

Según datos obtenidos de la Organización Internacional del cacao (ICCO), la demanda mundial también se encuentra insatisfecha por la baja producción del insumo debido a problemas políticos de sus mayores productores (Costa de Marfil con el 35\% de la producción mundial del grano) y la baja producción de países latinoamericanos por problemas de industrialización del proceso y enfermedades que destruyen la producción del grano de cacao, permitiendo analizar la posibilidad de exportación este producto, dando paso a nuevos competidores capaces de satisfacer la escasez, generando mayores ingresos debido al alza de precios ocasionado por este déficit. 


\subsubsection{Tecnología}

Según estudios realizados por MINAGRI, la producción del cacao en el Perú se realiza con métodos muy rudimentarios, poco industrializados, por lo que la aparición de enfermedades fúngicas como la Moliphthora Roreri es elevada y no está siendo controlada adecuadamente hoy en día.

En la actualidad, existen tres métodos para el control de las enfermedades del cacao. En primer lugar, se tiene al cruce genético entre dos especies de plantas. Una de ellas es la planta del cacao y la otra es una planta autoinmune a los efectos del hongo. Sin embargo, encontrar plantas con afinidad al cacao y resistentes al hongo es un problema, pues las diferentes variedades de este y las condiciones climáticas donde se desarrollan, ocasionan que estos cruces no siempre sean efectivos en cualquier ambiente. Otra opción es el uso de fungicidas que actualmente generan daños al medio ambiente y no presentan una solución a largo plazo, pues el hongo con el tiempo vuelve a aparecer. El tercer método es el constante mantenimiento del ambiente que rodea la plantación, donde se manipula la humedad relativa del suelo, cuyo valor recomendado es de aproximadamente 85\% (Leandro-Muñoz, 2017).

\subsubsection{Social}

El fortalecimiento de nuevos métodos de producción de cacao abre nuevas rutas para los agricultores peruanos. Según testimonios brindados en la conferencia de Cacao y Chocolate en el 2014, son muchos los agricultores que han dejado la producción de cocaína, que es muy intensa en el Perú y han optado por la inserción de cacao como principal producto de cosecha en sus terrenos, lo que ha permitido mejorar su calidad de vida y producción. Más aún, les permitió integrarse a la economía del país y generar mejores ingresos para su región y familias (Lorenzetti, 2014, pág. 17). La implementación de una planta productora de cacao fino no generaría ningún tipo de residuo al momento de implementarlo ni al cultivarlo, sino más bien, reduciría la cantidad de fungicidas aplicados a las plantaciones de cacao que utilizan las demás empresas productoras o agricultores. 


\subsubsection{Ambiental}

Según el reglamento $N^{o} 488 / 2014$ de la comisión europea (12/05/2014) que modifica el reglamento $\mathrm{N}^{\mathrm{o}} 1881 / 2006$ en lo que respecta al contenido máximo de cadmio en los productos alimenticios, este no debe ser mayor a $0.8 \mathrm{ppm}$. Sin embargo, estudios recientes demuestran que el contenido de cadmio en el cacao peruano, excede en más del $70 \%$ permisible, haciendo este un producto no apto para la exportación. (Ministerio de Agricultura y Riego, 2016, p. 14). Este problema se origina por realizar una mala práctica en el agua de riego (Calderon y Concha, 2000) y esto se podría revertir si se aplica materia orgánica en los suelos con problemas de contaminación de cadmio, dado que las propiedades de esta permite a la planta realizar una menor absorción de este metal (Caracterización del Contenido de NPK en la cascar de cinco clones de cacao del jardín interclonal de la Universidad Nacional de Ucayali, 2014).

La producción cacaotera solo aprovecha económicamente las almendras de cacao, que representan el 10\% del peso del fruto fresco (Barazarte, 2008, pág. 66). Esto genera terribles daños al medio ambiente debido a la aparición de olores fétidos y deterioro del paisaje. Cuando los desechos están conformados por las cáscaras de cacao, se pueden utilizar para preparar abonos orgánicos y sembrar un mejor cacao.

Este proyecto busca reducir los niveles de cadmio mediante la plantación consiente del 5\% de la demanda real en un ambiente óptimo y el acopio del restante explicando y exigiendo la utilización de métodos adecuados para obtener cacao libre de esta concentración de agentes dañinos.

\subsection{Hipótesis de trabajo}

La instalación de una planta productora de grano de cacao fino, con estándares de calidad es factible técnica, financiera, económica, comercial y socialmente. 


\subsection{Marco teórico}

El presente trabajo aborda la investigación para la instalación de una planta productora de cacao fino en el Perú. Durante el periodo de enero a septiembre de 2017, la producción nacional tuvo un crecimiento de $3.18 \%$, dato mayor al esperado por los agentes económicos que proyectaron un $3.10 \%$. De este crecimiento, el cacao tuvo una participación del 33.4\%, representando un total de 98 meses de crecimiento contínuo, según datos proporcionado por el Instituto Nacional de Estadística e Informática (INEI) en el año 2017.

El Perú está clasificado como el segundo país productor y exportador de cacao fino después de Ecuador (Convenio Internacional de Cacao 2010 ICCO). Es por este motivo que desde hace algunos años, empresas chocolateras de todo el mundo visitan nuestro país con el fin de cerrar contratos directamente con los productores de cacao, lo que permite que el agricultor tome conciencia y mejore sus buenas prácticas agrícolas y manufactureras en toda la cadena de valor, ofreciendo un producto de mejor calidad (Agricultura, 2016, pág. 21).

Sin embargo, José Iturrio Director de la Asociación de Cacao en el Perú declaró que:

"El cacao, no es un producto que ha alcanzado su potencial de producción ya que podría llegar a representar el 9\% de la oferta mundial, sin embargo, actualmente solo representamos el $1.8 \%$ del total y esto se debe a que el sector está en manos de pequeños productores y no hay mecanismos suficientes para aprovechar los beneficios del mercado” (Iturrio, 2014, pág. 1).

Entre las características de la producción local, se puede determinar que la mayoría de productores de cacao son pequeños, los que tienen una capacidad de producción menor a 5 hectáreas. Además, la elaboración se realiza de manera individual y se estima que el $70 \%$ de producción no está organizada. A esto, se le suma el manejo del cultivo, el cual se hace principalmente con tecnología tradicional y sin asistencia técnica. Asimismo, los niveles de tecnología son heterogéneos y no corresponden en algunos casos a las condiciones naturales de la zona. En consecuencia, predominan en zonas marginales hay 
predominio de cacao criollo por falta de asistencia técnica para incentivar la siembra de cacao mejorado como el clon CCN-51. (Felipa, 2015, pág. 116).

Por este motivo, muchos emprendedores tienen la idea de industrializar este recurso. Un claro ejemplo, es el caso del Presidente Ejecutivo de Sierra Exportadora, Alfonso Velázquez Tuesta, quién anunció, su apuesta por la industrialización y desarrollo del mejor cacao del mundo, pues el reporte de la Asociación Regional Exportadora (AREX) informa, que San Martín es la única región que registra exportaciones de Cacao, pero con una participación muy escasa. (Sierra Exportadora, 2014, pág. 2).

\subsection{Marco referencial}

Effects of microclimatic variables on the symptoms and signs onset of Moniliophthora roreri, causal agent of Moniliophthora pod rot in cacao

Autor: Mariela E. Leandro-Muñoz, Philippe Tixier, Amandine Germon, Veromanitra Rakotobe, Wilbert Phillips-Mora, Siela Maximova, Jacques Avelino

Fecha: Agosto 28, 2017

Similitud: Esta investigación es muy importante para el estudio debido a que explica a detalle qué es la Moliophthora Roreri, cuáles son las faces que presenta la enfermedad en el cacao y los factores desencadenantes para la proliferación del hongo en las plantaciones. A su vez, el presente artículo muestra las variables detonantes para el esparcimiento de las esporas del hongo, el rango de temperatura que favorecen su desarrollo y el nivel de humedad requerido para formar un excelente caldo de cultivo para el hongo.

Diferencia: El presente artículo está centrado en determinar los factores más resaltantes para la incubación y posterior desarrollo del hongo en las plantaciones de cacao, mientras que el proyecto estará centrado en usar estos datos para crear un ambiente controlado en San Martin y así poder determinar el área de cultivo óptimo para realizar la inversión. 
Estrategias de control de Moniliophthora roreri y Moniliophthora perniciosa en Theobroma cacao L.: revisión sistemática

\author{
Autor: Paola Andrea Tirado-Gallego, Andrea Lopera-Álvarez, Leonardo Alberto \\ Ríos-Osorio
}

Fecha: Mayo 12, 2016

Similitud: Esta investigación es importante para nuestro estudio ya que, los métodos de regulación y/o eliminación del hongo Moniliasis en la planta del cacao son los que se aplicarían en la posible planta instalada en el Perú. También, muestra información muy detallada de cada método tanto cultural como químico, lo cual nos da la posibilidad de evaluar todos los métodos y elegir el más conveniente para nuestro proyecto.

Diferencia: Este estudio analiza a detalle las enfermedades y se desvía por la rama química. Si bien es importante esa información, no indica todos los materiales, maquinaria y detalles esenciales para el proceso de cada método.

\title{
ESTUDIO DE PREFACTIBILIDAD PARA LA EXPORTACIÓN DE CACAO EN GRANO TOSTADO AL MERCADO ESTADOUNIDENSE
}

Autor: Chávez Castillo Rodolfo Antonio Juscamaita Sánchez Martín José

Fecha: Abril 2013

Similitud: Esta tesis busca generar nuevos trabajos como un punto de justificación social, afirmando un crecimiento sostenido en la compra de cacao en el mercado externo. Asimismo, da mención de los procesos necesarios para producir cacao en grano.

Diferencias: Busca dirigirse netamente al mercado Norte Americano, específicamente al penúltimo grupo de la cadena de abastecimiento conformado por empresas productoras de Chocolate y Derivados. 


\section{IDENTIFICACIÓN Y CONTROL DE LA MONILIASIS DEL CACAO}

Autor: Fundación Hondureña de Investigación Agrícola

Fecha: Noviembre 2003

Similitud: En la investigación en análisis, se conoce información acerca de métodos efectivos que han sido comprobados en el pasado para controlar la Moniliasis en el cacao. Es posible adquirir maquinaria y todos los materiales para poder instalar una planta que reduzca el porcentaje de plantas infectadas con este hongo y se pueda aumentar la producción de materia prima (cacao) y exportarlo a los principales productores de chocolate en el mundo.

Diferencias: Si bien son contados los métodos de control de este hongo, no todos son tan eficientes como se espera, debido a que es difícil mantener las condiciones epidemiológicas constantes y también se requiere de una inversión grande para suministrar constantemente los materiales y maquinaria para el método empleado.

Efecto in vitro de aceites esenciales de tres especies de Lippia sobre Moniliophthora roreri (Cif. y Par.) Evans et al., agente causante de la moniliasis del cacao (Theobroma cacao L.)

Autor: Betty Stefany Lozada, Laura Viviana Herrera1, Janeth Aidé Perea, Elena Stashenko, y Patricia Escobar

Fecha: Junio 5, 2012

Similitud: El presente artículo nos muestra las pruebas antifúngicas de los aceites de Lippia para la Moniliophthora Roreri. Estos datos serán de mucha importancia para determinar si efectivamente dicho proyecto puede aplicarse a campo con la finalidad de obtener datos exactos de las propiedades antifúngicas de estos aceites.

Diferencia: El proyecto muestra los resultados in vitro de las propiedades antifúngicas en ambientes controlados. Sin embargo, el ambiente regular de plantación 
de cacao en Perú presenta factores que podría interferir con el efecto anti- fúngico, como la humedad, la temperatura y tipo de suelo característico de la zona.

\section{Selección de genotipos de cacao (Theobroma cacao $L_{\text {.) }}$ con resistencia a escoba de bruja (Moniliophthora perniciosa) en Los Ríos, Ecuador}

Autor: Freire, Omar Miguel Tarqui; Cantos, Ignacio Antonio Sotomayor; Mendoza, Teresa de Jesús Casanova; Zamora, Gladys Angélica Rodríguez; Avellán, Luis Fernando Plaza

Fecha: Junio 1, 2017

Similitudes: Este artículo describe el proceso de selección y producción de nuevos híbridos capaces de resistir la enfermedad fúngica producida por la moniliophthora perniciosa, la cual afecta a brotes jóvenes, cojinetes florales, yemas vegetativas y frutos, que combinada con la Monilla (Monilophthora Roreri), causan pérdidas anuales que superan en ocasiones el 50\% de la producción y en casos extremos llega hasta el $90 \%$. Dato semejante al percibido por la institución Minagri en la producción Peruana con pérdidas cercanas al $60 \%$.

Diferencias: El presente artículo muestra pruebas realizadas para combatir la enfermedad fúngica ocasionada por la moniliopthora perniciosa, mientras que el tema de estudio del presente proyecto abarca la investigación de procesos nuevos para combatir la Moniliophthora Roreri. De igual manera las pruebas realizadas en el presente artículo se hicieron en la ciudad de Ecuador, en la vía Quevedo-El Empalme, donde las temperaturas son de $24.1^{\circ} \mathrm{C}$ y se encuentra a una altitud de $85 \mathrm{msnm}$. Mientras que, en Perú, las zonas aptas para el cultivo de cacao, presenta temperatura que oscilan entre 23$24^{\circ} \mathrm{C}$ llegando inclusive a los $31^{\circ} \mathrm{C}$ en época de verano, a su vez la altura óptima para plantaciones, tomando como referencia la zona de San Martín donde abunda el cultivo de cacao, se encuentra a $860 \mathrm{msnm}$. 


\title{
ESTUDIO DE PRE-FACTIBILIDAD PARA LA INSTALACIÓN DE UNA PLANTA DEDICADA A LA PRODUCCIÓN DE CHOCOLATE CON CACAO ORgÁnico PERUANO Seminario de Tesis. Universidad de Lima, Lima, Perú.
}

\author{
Autor: Salazar y Bustamante
}

Este estudio se enfoca en la producción de chocolate a base de cacao orgánico. Detalla los beneficios de utilizar una materia prima de alta calidad, beneficiando la salud del ser humano.

Similitudes: El estudio de tesis puede servir mucho de apoyo para analizar la industria del chocolate, y en base a esos resultados poder segmentar el público objetivo, determinar la demanda potencial y real y determinar el precio adecuado para vender el grano de cacao fino a los acopiadores.

Diferencias: Este proyecto no representa el proceso completo de granos de cacao fino aptos para ser exportados, sino únicamente la utilización de este producto como materia prima para producir chocolate.

\subsection{Marco conceptual:}

Glosario de Términos:

- Cacao:

Planta proveniente del Árbol de América de la familia de las esterculiáceas, cuyo fruto se utiliza como materia prima del chocolate (Sanchez, 1989, pág. 9).

- Enfermedades fúngicas:

Una infección fúngica, es una enfermedad que se desencadena del hongo (Quindos, 2011, pág. 16). 
- Hongos:

Un hongo es un heterótrofo, el cual carece de hojas y raíces. Este se reproduce por esporas, siendo un parásito sobre la materia orgánica que está en el proceso de descomposición (Loor, 2018, pág. 14).

- Moniliophthora roreri

Moniliophthora roreri es un hongo que causa la enfermedad de la Moniliasis, enfermedad que se genera de la mazorca en el cultivo de Theobromacacao. Esta enfermedad puede llegar a generar drásticas pérdidas en la cosecha (Loor, 2018, pág. 14). 


\section{CAPÍTULO II: ESTUDIO DE MERCADO}

En el presente capítulo, se determinará la demanda y oferta en el Perú para el grano de cacao fino. El cacao es un producto utilizado principalmente como materia prima para producir chocolate. Para obtener un grano de cacao fino apto para los exportadores, este debe de pasar por un proceso riguroso y controlado en la fermentación, dado que es importante mantener un producto terminado con humedad de $7 \%$.

Este producto cuenta con sustitutos como el algarrobo y harina de café, como también productos complementarios como los insumos de sus derivados, tal y como la leche, la harina y el azúcar. Por este motivo, se analizarán las principales Fuerzas de Porter para identificar las amenazas en el sector y mediante estrategias de precio y calidad, brindar una propuesta de valor para lograr la diferenciación en el mercado.

Se determinará la demanda del proyecto considerando la demanda mundial y peruana del cacao que luego mediante un análisis de las encuestas realizadas a empresas acopiadoras de cacao, se determinará el porcentaje de la demanda que se desea atender. Una vez se cuente con el dato de la demanda del proyecto, se determinará la oferta por los primeros cinco años.

\subsection{Aspectos generales del estudio de mercado}

La fermentación es un proceso esencial en la producción de cacao fino, debido a que este es el responsable de generar los cambios químicos que permitirán pasar de una almendra violeta, color propio de un grano de cacao, carente de sabor, textura y olor, en una almendra marrón con características agradables y necesarias para la elaboración de chocolate de alta gama.

De esta manera, se explica que el cacao que se producirá y se entregará a las empresas comercializadoras será un producto de alta calidad, el cual respetará las normas de calidad en el producto final siguiendo la NTP-ISO 2451:2016 para determinar un adecuado método de ensayo muestra y rotulado para granos de cacao, la NTP-ISO 
2292:2016 para un análisis a profundidad el método inminente para determinar la humedad contenida en los granos de cacao y la NTP 208.017:2015/COR 1:2016 para analizar de forma gravimétrica los compuestos presentes en el cacao, considerando en conjunto el Reglamento CE $\mathrm{N}^{\circ} 1881 / 2006$ que determina las cantidad máxima de cadmio en el producto para producir una grano apto para mercados externos de alta exigencia.

\subsubsection{Definición comercial del producto}

A continuación, se detallan los niveles de producto en base a las tres definiciones de Kotler:

a) Producto básico

El producto básico es el cacao, cuyo nombre científico es Theobroma Cacao. Este producto contiene e un alto aporte nutricional, como se puede observar en la siguiente tabla que explica el aporte nutricional en $100 \mathrm{gr}$ de cacao en grano.

Figura 2.1: Cuadro nutricional de cacao

\section{APORTE NUTRICIONAL $100 \mathrm{~g}$}

\begin{tabular}{|c|c|c|}
\hline $\begin{array}{c}\text { Energía } \\
496,25 \mathrm{Kcal}\end{array}$ & $\begin{array}{c}\text { Potasio } \\
\mathbf{4 8 1 , 0 0} \mathbf{~ m g}\end{array}$ & $\begin{array}{l}\text { Vitam. A } \\
16,71 \mu \mathrm{g}\end{array}$ \\
\hline $\begin{array}{l}\text { Proteínas } \\
7,09 \mathrm{~g}\end{array}$ & $\begin{array}{c}\text { Fósforo } \\
273,25 \mathrm{mg}\end{array}$ & $\begin{array}{l}\text { Vitam. B1 } \\
\mathbf{0 , 0 8} \mathrm{mg}\end{array}$ \\
\hline $\begin{array}{c}\text { Hidratos } \\
60,23 \mathrm{~g}\end{array}$ & $\begin{array}{c}\text { Fibra } \\
5,03 \text { g }\end{array}$ & $\begin{array}{c}\text { Vitam. B2 } \\
\text { o,39 mg }\end{array}$ \\
\hline $\begin{array}{l}\text { Agua } \\
\mathbf{2 , 1 5} \mathrm{g}\end{array}$ & $\begin{array}{c}\text { Grasa } \\
24,10 \mathrm{~g}\end{array}$ & $\begin{array}{l}\text { Vitam. B3 } \\
\mathbf{2 , 9 8} \mathrm{mg}\end{array}$ \\
\hline $\begin{array}{c}\text { Calcio } \\
\mathbf{1 8 0 , 2 5} \mathbf{~ m g}\end{array}$ & $\begin{array}{l}\text { Colesterol } \\
16,50 \mathrm{mg}\end{array}$ & $\begin{array}{l}\text { Vitam. B6 } \\
\text { o,09 mg }\end{array}$ \\
\hline $\begin{array}{c}\text { Hierro } \\
\mathbf{1 , 0 0} \mathrm{mg}\end{array}$ & $\begin{array}{c}\text { AGS } \\
14,54 \text { g }\end{array}$ & $\begin{array}{l}\text { Vitam. B9 } \\
\mathbf{1 1 , 2 5} \mu \mathrm{g}\end{array}$ \\
\hline $\begin{array}{c}\text { Yodo } \\
\mathbf{5 , 0 3 \mu g}\end{array}$ & $\begin{array}{c}\text { AGM } \\
7,91 \mathrm{~g}\end{array}$ & $\begin{array}{c}\text { Vitam. B12 } \\
\mathbf{0 , 3 3} \mu \mathrm{g}\end{array}$ \\
\hline $\begin{array}{l}\text { Magnesio } \\
70,00 \mathrm{mg}\end{array}$ & $\begin{array}{c}\text { AGP } \\
0,90 \mathrm{~g}\end{array}$ & $\begin{array}{l}\text { Vitam. C } \\
0,45 \mathrm{mg}\end{array}$ \\
\hline $\begin{array}{c}\text { Cinc } \\
\mathbf{1 , 3 7} \mathrm{mg}\end{array}$ & $\begin{array}{c}\text { Carotenos } \\
\mathbf{0 , 0 0} \mu \mathrm{g}\end{array}$ & $\begin{array}{l}\text { Vitam. D } \\
0,00 \mu \mathrm{g}\end{array}$ \\
\hline $\begin{array}{l}\text { Selenio } \\
\mathbf{3 , 3 3} \boldsymbol{\mu g}\end{array}$ & $\begin{array}{c}\text { Retinol } \\
\mathbf{1 1 , 2 5 ~ \mu g}\end{array}$ & $\begin{array}{l}\text { Vitam. E } \\
\mathbf{0 , 8 1} \mu \mathrm{g}\end{array}$ \\
\hline $\begin{array}{c}\text { Sodio } \\
172,75 \mathrm{mg}\end{array}$ & & \\
\hline
\end{tabular}

Fuente: Sierra Exportadora (2017) 
El cacao es utilizado como materia prima para la producción de chocolate y derivados en la industria chocolatera a nivel mundial. Este producto satisface la necesidad de un sabor característico del chocolate que luego, mediante la adición de otros insumos, se produce el chocolate con los niveles de cacao deseados por el mercado.

b) Producto real:

El caco proveniente de la planta se distribuirá en sacos de yute de $60 \mathrm{~kg}$, el cual contara con el logo de la empresa, el número de lote y la fecha de ensacado.

Figura 2.2: Ficha Técnica del Producto

\begin{tabular}{|l|l|l|l|}
\hline \multicolumn{5}{|c|}{ Ficha técnica de especificación } \\
\hline Nombre de producto: & Cacao fino en grano (Theobroma Cacao) & Descripción del empaque: & Sacos limpios de Yute de 60kg cada uno \\
\hline Descripción: & Granos secos de cacao fino para exportación & Largo: & 1 metro \\
\hline Origen: & Tocache, San Martin & Ancho: & 0.60 metros \\
\hline & & Altura relativa: & 0.40 metros \\
\hline Características & & Peso: & $60 \mathrm{~kg}$ \\
\hline Fisico químicas & & Color de saco: & Marrón claro \\
\hline \% humedad: & C-7\% & Cosecha: & Marzo - Julio \\
\hline Físico sensorial & & Fecha máx. de consumo: & Seis meses posteriores a la recepción del PT en el almacén \\
\hline Color grano de cacao fino: & Marrón oscuro (café) & \\
\hline & & &
\end{tabular}

Elaboración propia

c) Producto aumentado

La empresa contará con una línea de comunicación con sus clientes para determinar el estado de su pedido, como también una página web donde se podrá observar la producción de la empresa y las normas de calidad con las que cuenta. El producto terminado contará con un código QR, el cual facilitará al comprador a contabilizar los sacos, como también a tener las especificaciones técnicas de estos. 


\subsubsection{Usos del producto, bienes sustitutos y complementarios}

\subsubsection{Usos del Producto}

El cacao fino es un producto usado alrededor del mundo por utilizado por empresas de todo tamaño en la fabricación de chocolate amargo, chocolate con leche, licor de cacao, manteca de cacao y sus subsecuentes derivados. A su vez, este producto también es usado por la industria cosmética, ya que fabrican productos hechos a base de cacao para tratar la celulitis y combate los síntomas del estrés, con un olor agradable para el consumidor. Un tercer uso del cacao es en la industria farmacéutica, ya que ciertas propiedades del producto son beneficioso para combatir la tos y disminuye el riesgo de las enfermedades cardiacas.

\subsubsection{Sustitutos}

Los bienes sustitutos presente en el mercado capaces de acaparar el mercado actual de cacao fino, y desplazarlo como un bien secundario para el actual sector, puede resumirse en los siguientes 3 productos comerciales:

Algarrobo: Es una vaina color marrón, que suele medir aproximadamente treinta centímetros. Esta contiene una pulpa de consistencia gomosa y brinda un sabor dulce y agradable, que se asemeja al del cacao.

Baya de Acai: Este fruto puede llegar a reemplazar al chocolate ya que tiene un ligero sabor a ello y quizá por ese motivo, sea una posible razón por la cual se comercializa a nivel mundial y a gran escala. Tiene varias propiedades medicinales esenciales así como importantes antioxidantes para la prevención y curación de algunas enfermedades.

Harina de café: Esta harina varía de un sabor común del café, ya que no está hecha de granos, contiene altos niveles de fibra y minerales y presenta un sabor afrutado, permitiendo así incorporarla en comidas dulces. 


\subsubsection{Complementarios:}

Los bienes complementarios del cacao son todas las otras materias primas e insumos de sus derivados, tal y como la leche, la harina y el azúcar.

\subsubsection{Determinación del área geográfica que abarcará el estudio}

El área geográfica en donde se realizará el estudio de mercado es en el departamento de San Martín, Perú, específicamente en la zona de Huallaga Central, a las principales empresas acopiadoras y productoras de cacao fino. Se seleccionó esta región, pues presenta tierras aluviales con aptitudes para el desarrollo agrícola, siendo considerada como uno de los suelos más fértiles del trópico; a su vez, más del 30\% de la exportación Peruana proviene de la región de San Martin, lo que hace de esta zona un lugar óptimo y altamente productivo en cuanto a la producción de cacao.

Los factores antes mencionados, hacen que las empresas de este sector tengan una alta productividad y a su vez cumplan con los estándares de calidad requeridos para exportar. Y es de estas empresas con alto conocimiento tanto del proceso como de calidad de producto donde se realizara el estudio de los factores más importantes para una planta productora de cacao Fino.

Figura 2.3: Ubicación de Plantaciones en San Martin

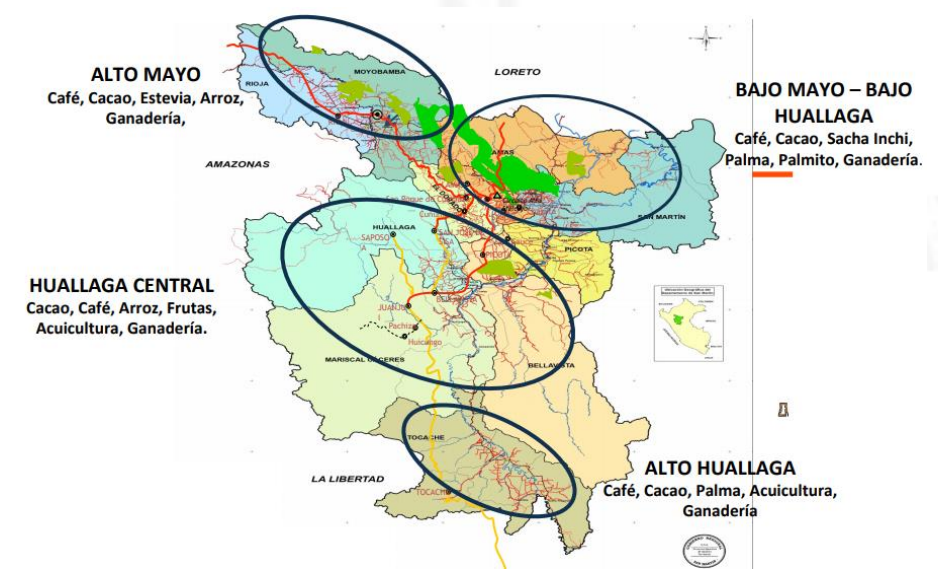

Fuente: Gobierno Regional de San Martin (2016) 


\subsubsection{Análisis del sector industrial}

Para poder determinar las variables que afectar de manera directa al modelo productivo se utilizará el modelo basado en las 5 fuerzas de Porte, las cuales analizará: Amenaza de nuevos competidores, amenaza de sustitutos, poder de negociación de proveedores, rivalidad de la industria y poder de negociación de los compradores.

\subsubsection{Amenaza de nuevos ingresos en el sector}

El riesgo de nuevo ingreso de competidores en el sector cacaotero, está relacionada con las barreras de entrada como: políticas locales, economías de escala, certificaciones, curvas de aprendizaje técnicas y sociales.

Para un sector commodities como lo es el cacao el manejo de las utilidades está fuertemente relacionada con los costos relacionados a producción y su volumen. Los compradores buscan zonas y empresas que garanticen tanto estabilidad como volumen de pedido. De esta manera, para poder cumplir con esas expectativas se debe innovar en mejoras tecnológicas y aumento del área a cultivar. Para este último tema, la búsqueda de zonas que protejan las áreas verdes de la deforestación y brinden autorizaciones para la siembra es un factor limitante. Por lo que se puede asegurar este motivo como una barrera moderada para el ingreso de nuevos competidores.

Por otro lado, la política nacional y local influencia mucho a este sector; por ejemplo: política de desarrollo productivo local, política de erradicación de coca y políticas de inversión tributaria. Si bien es cierto, las condiciones en el Perú promueven el desarrollo de negocios en el sector cacaotero por las políticas de erradicación de coca, al mismo tiempo están fomentando el trabajo en cooperativas. Esto afecta a las políticas de gobierno regional donde se desea sembrar. Formándose así, una nueva barrera de entrada al sector.

Un dato a favor de este sector es que se puede iniciar modelos especializados en abastecer nichos específicos del mercado cacaotero. Ya que, el volumen y el cliente (mercado) al que se dirigen, es pequeño y su exclusividad se pierde al fragmentarse. Perú, 
tiene una gran diversidad de clones de cacao por lo que el modelo para nichos podría implementarse sin mucha dificultad.

Otro punto para diferenciar los nuevos modelos que ingresen al sector, va de la mano con las certificaciones, las cuales gozan de una amplia variedad y son específicas para cada aspecto de la cadena productiva. Esto es importante, pues se ve una tendencia a exigir cada vez más certificaciones por parte de los compradores. Esto se debe tener en cuenta para el nuevo modelo a implementar si se está buscando una mayor participación en el mercado. Sin embargo, esto forma una barrera moderada pues, los costos para mantener esta certificación son elevados y su diferenciación en precios a veces no justifica el gasto.

Finalmente, para hablar de la curva de aprendizaje técnica, se debe tener claro cuál será el modelo a implementar y para qué mercado, ya que de esto dependerá la selección adecuada del clon de cacao a cultivar. A su vez, este tipo de seleccionado debe estar relacionado con el objetivo del negocio, pero al mismo tiempo, debe tener en cuenta los aspectos productivos y la calidad del mismo; así como también, se debe tener especial cuidado al momento de seleccionar el clon, ya que este debe ser resistente a enfermedades y condiciones de cultivo propias de la ubicación del negocio. Así que se debe tener mucho cuidado ya que de la selección adecuada del mercado dependerá toda la cadena productiva, siendo así este aspecto una barrera alta para el sector.

\subsubsection{Competidores en sector industrial}

En cuanto a la rivalidad del sector, se tiene a modelos basados en cadenas productivas de cacao que compiten por participación de mercado, recursos y hectáreas de siembra.

En primer lugar, la participación de mercado no presenta un factor influyente debido al déficit actual de este recurso a nivel mundial, aunque se debe tener en cuenta que los precios a los que se acuerde la venta dependerán de la calidad del grano, las características del mismo y las certificaciones que se tengan.

En segundo lugar, la atracción de fondos es muy fuerte, pues los modelos conformados por cooperativas compiten mucho con negocios privados para obtener 
fondos no rembolsables del estado. Donde, mientras los primeros lo utilizan en su mayoría para fortalecer el vínculo entre cada miembro de las cooperativas, los segundos lo utilizan para aumentar el ara de cultivo que tiene.

De los modelos antes mencionados, cooperativas y negocios privados, el primero tiene un enfoque más social que es promovido por el Estado para disminuir la pobreza y aumentar el sector agrario del país. Estos cuentan con beneficios tributarios, acceso a créditos especiales y fondos muchas veces no reembolsables provenientes de las cooperativas. Por lo tanto, si dejamos de lado este sector, se puede apreciar una rivalidad alta del sector privado por acaparar mayor mercado y financiamientos.

\subsubsection{Poder de negociación de los proveedores}

Los proveedores del sector cacaotero, están conformados por personas u empresas que ofrecen materiales y servicios necesarios para el funcionamiento del sector.

En primer lugar, hablaremos de los grupos financieros, ya que, aunque es limitado muchas entidades como las cajas rurales y micro financieras ve mucho potencial en el desarrollo agrícola, por lo que al estar más interesados en realizar prestamos su poder de negociación no se considera de mucho impacto al sector.

En segundo lugar, los proveedores de MP del sector cacaotero, conformado por agricultores que proveen mano de obra y terreno, se puedo observar en estudio de campo que existe una disposición a subsidiar sus activos. Es decir que el productor espera que cualquier nuevo comprador financie parte de la producción de cacao, esto ya sea de manera monetaria o mediante insumos necesarios para la plantación. Asimismo, los agricultores no dan indicios de preferencias en cuanto a la venta de cacao, ellos simplemente eligen a aquel comprador que ofrezca mayores beneficios. Por lo que, el poder de negociación impuesto por los proveedores de MP puede ser considerado como moderado. 


\subsubsection{Poder de negociación de los clientes}

En la industria cacaotera, los compradores están conformados por empresas procesadoras de grano y las empresas gourmet de Chocolate, que son las que influencian en las preferencias al crear nuevos productos y sabores. Por lo que, ellos son los que definen la variedad clonal de cacao a sembrar y reconocen las características propias de cada clon o sub especie. Son ellos, los que transfieren estas exigencias a los consumidores y ellos a su vez hacia cada eslabón de la cadena productiva, evidenciándose por ejemplo en las exigencias cada vez mayores por, certificaciones y productos orgánicos cada vez más en aumento. Por estos motivos, se puede concluir que los clientes ejercen una fuerte influencia en el modelo.

\subsubsection{Amenaza de sustitutos}

Los negocios sustitutos del sector cacaotero están conformados por empresas u organizaciones gubernamentales, que tiene un modelo de integración vertical ya que ocupan toda la cadena productiva. Se encargan de conectar todos los puntos del sector desde la producción de MP, hasta la elaboración y posterior comercialización tanto de productos elaborados como semielaborados.

Este tipo de empresas trabaja con un modelo que se ajusta mejor a su estrategia de negocios, el cual al integrar todos los procesos de la cadena productiva de cacao y derivados responde mejor a las exigencias y las tendencias del mercado. Es así que, en ayuda de este sector, el Gobierno peruano implemento un sistema de cooperativas que favorece el desarrollo del sector agrícola y su estrategia contra la pobreza.

Sin embargo, debido a la alta inversión realizada por las empresas en sus modelos, el costo para migrar a nuevos modelos sustitutos, seria excesivamente elevado, lo que conllevaría en el ínterin a una perdida en calidad, seguridad en el volumen de pedidos y por ende una pérdida de credibilidad. Por lo que se puede determinar que la amenaza de sustitutos no es muy alta. 


\subsubsection{Modelo de negocios}

Tabla 2.1: Modelo Canvas

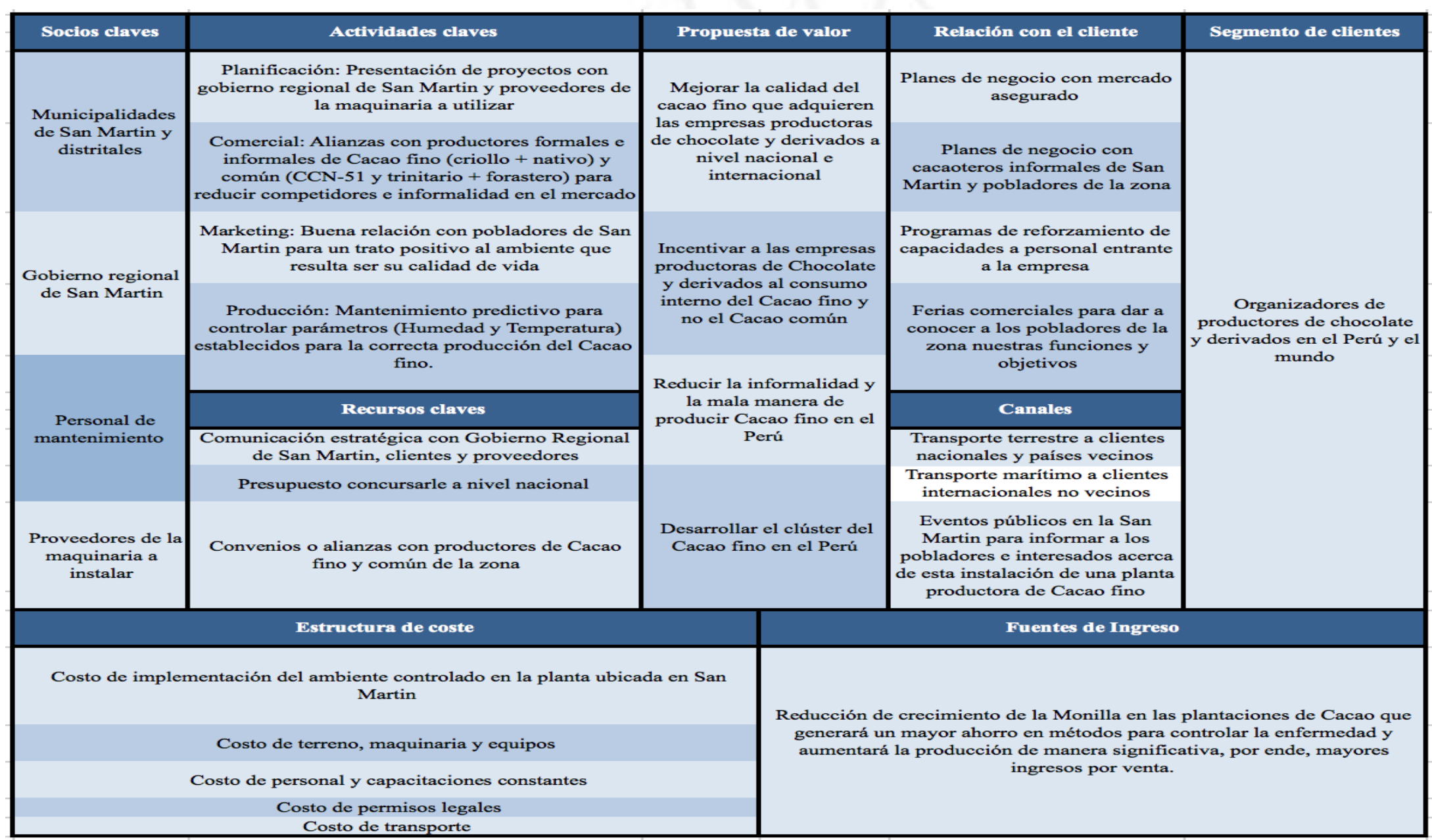

Elaboración Propia 


\subsection{Metodología a emplear en la investigación de mercado}

La metodología a utilizar en esta investigación será tanto primaria como secundaria. La fuente primaria será una entrevista a profundidad dirigida hacia productores de cacao fino tanto a nivel nacional como internacional. Se determinó que el mejor método de recopilar información para este estudio era realizando una entrevista a profundidad, ya que es una manera óptima de adquirir información del mercado objetivo.

Por otro lado, las fuentes secundarias que serán empleadas para adquirir información acerca de los productos sustitutos que tiene el cacao; de esta manera se podrá identificar las tendencias de los consumidores y tomar esos datos como referencia para un posterior análisis. También se utilizarán para obtener información acerca de la producción de los diferentes tipos de cacao tanto a nivel nacional como internacional.

\subsection{Demanda potencial}

\subsubsection{Patrones de consumo}

En cuanto a la demanda de caco en grano, que se mide en base a las moliendas rastreadas por la ICCO, muestra una evolución estable y con tendencia creciente impulsada por el mercado mundial de confitería de chocolate, en especial de la industria chocolatera de los países desarrollados. Así, el consumo de cacao en grano ha pasado de 1 millón de toneladas a 4,2 millones en los últimos años.

Las causas principales del aumento en las moliendas han sido: la fuerte demanda de manteca de cacao para abastecer la existencia de los almacenes de los stocks internacionales; el aumento en el consumo de chocolate en los mercados emergentes (nuevos países industriales); y el cambio en el hábito de consumo de chocolate en los mercados tradicionales, con el incrementó en el consumo de productos con mayor contenido de cacao (Agricultura, 2016, pág. 32). 


\subsubsection{Determinación de la demanda potencial}

El proyecto busca satisfacer los estándares de calidad exigidos por empresas internacionales. Y debido a que actualmente el mercado de cacao presenta un amplio mercado insatisfecho, la demanda Potencial será toda el mercado insatisfecho mundial de cacao fino que utilizada como materia prima al cacao para la producción de sus derivados o por centros acopiadores de este producto.

Según la International Cacao Organization, la demanda mundial de cacao está muy por encima de la oferta de este producto, actualmente este mercado insatisfecho presenta un margen creciente que según proyecciones para el 2024 será de 97, 000 toneladas de Cacao.

Figura 2.4: Demanda y producción mundial de cacao

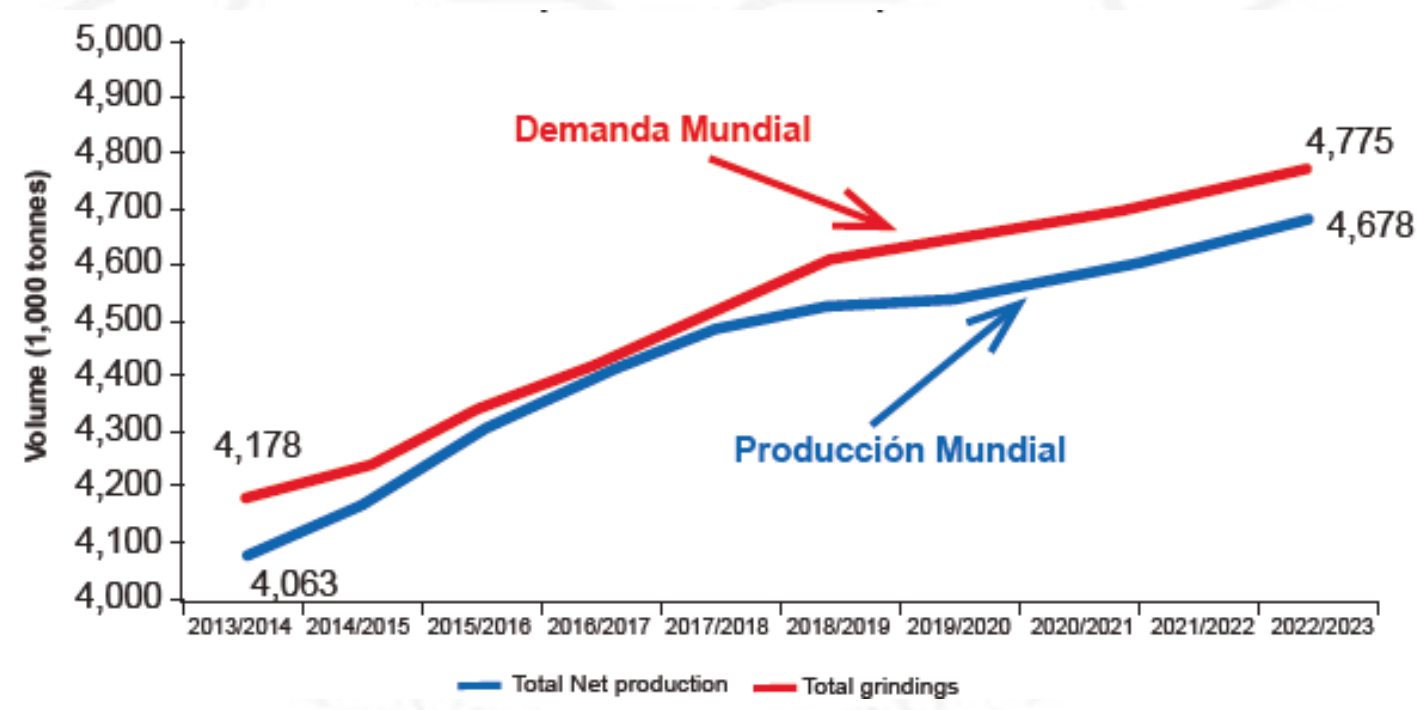

Fuente: International Cacao Organization (2016) 


\subsection{Determinación de la demanda de mercado en base a fuentes secundarias o primarias}

\subsubsection{Demanda del proyecto en base a data histórica}

\subsubsection{Exportaciones de cacao}

Si bien es cierto, según datos bridados por la SUNAT, las exportaciones de cacao en grano presentaron cifras marginales durante los primeros años del siglo 20. Desde el 2013 la tasa de crecimiento de exportaciones se mantiene en aumento, siendo esta de un $87 \%$ en el 2015, con un volumen record de 56.5 mil toneladas. Entre los años 2000 y 2015 se estima que las exportaciones se han incrementado en un 62\% por año. (Agricultura, 2016, pág. 26). A continuación, se presenta las exportaciones de cacao en grano crudo desde el año 2000 al 2015.

Figura 2.5: Exportaciones de cacao en grano crudo del 2000 al 2015

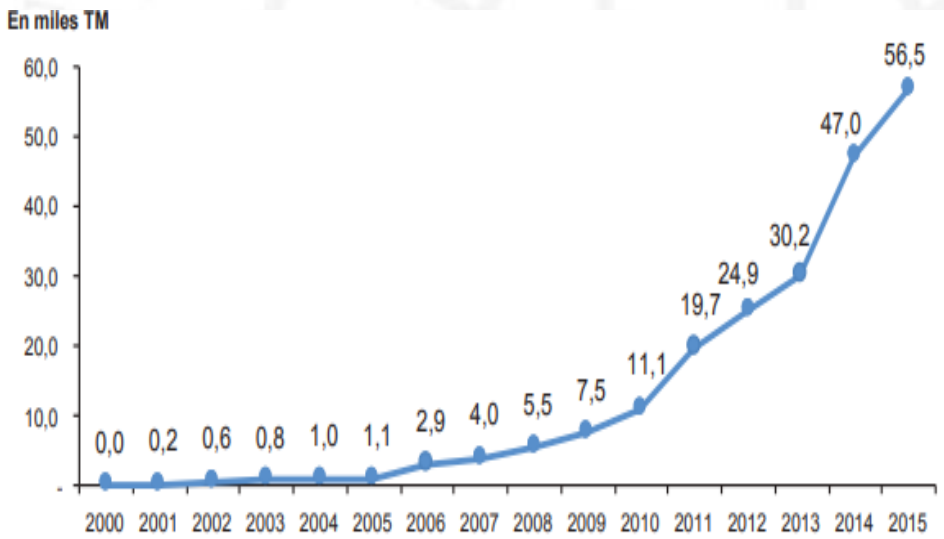

Fuente: MINISTERIO DE AGRICULTURA (2016)

\subsubsection{Definición del mercado objetivo teniendo en cuenta criterios de segmentación}

El presente proyecto se encuentra centrado en aquellas empresas que deseen utilizar como materia prima al grano de cacao. Por lo tanto, dentro de este Rubro se encuentran las empresas acopiadoras de Cacao para exportación, empresas productoras de chocolate y las industrias productoras de derivados de Chocolate. 


\subsubsection{Diseño y aplicación de la entrevista a profundidad}

Para el presente trabajo se realizaron entrevistas, como método de recolección datos cualitativos, esto debido a que algunas empresas muestran resiliencia a brindar determinados tipo de información sobre el método de producción que tienen.

Consideramos que las entrevistas son el mejor método de recolección de información, pues son más íntimas y flexibles (Maggi Savin-Baden, 2013, pág. 2). De por sí, se definen como una reunión para conversar e intercambiar información entre una persona (El entrevistador) y otra (el entrevistado).En la entrevista a través de preguntas y respuestas se logra una comunicación significados respecto a un tema (Janesick, 1998).

La entrevista se de tipo semi estructurada, debido a que se basan en una guía de preguntas donde el entrevistador tiene la libertad de introducir preguntas adicionales para precisar u obtener mayor información. (Sampieri, 2014, pág. 82). La entrevista que puede observase en Anexos 6 tiene la siguiente distribución:

\subsubsection{Experiencia en el mercado}

Con las preguntas 1-3, ubicadas en la página 169, se espera obtener información acerca de las empresas acopiadoras de Cacao y determinar el grado de experiencia que tiene en el mercado nacional.

\section{Conocimiento de factores de producción de Cacao:}

Las preguntas 4-10, encontradas en las páginas 169, buscan conocer a detalle tanto las enfermedades a las que la planta de Cacao está expuesta en un ambiente no controlado, como también las condiciones adecuadas de temperatura, humedad, $\mathrm{pH}$, altura y otros parámetros que el entrevistado crea importante en la producción de este producto. 


\section{Estacionalidad del cacao}

La pregunta 11 presente en Anexos 6 página 170, busca conocer cuál es la estacionalidad del Cacao, en qué meses se produce más, para que así con ayuda de las subsiguientes preguntas se pueda determinar si los factores medioambientales, $\mathrm{pH}$ del suelo, altura son decisivos durante este periodo.

\section{Enfermedades del cacao y Métodos de Solución a planta infectadas}

Con las preguntas 12-17 presentes en las páginas 170-171, se busca determinar cuáles son los males que aquejan con mayor frecuencia a las plantaciones de Cacao, que actividades preventivas se usan actualmente para contrarrestarlos y qué hacer en caso de que las plantaciones se encuentran infectadas.

\section{Estándares de Calidad}

Con las pregunta 18-21, presente las páginas 172-173, se busca conocer qué actividades realizan las empresas actualmente para determinar estándares de calidad del grano, de acuerdo al mercado al que se dirigen (Nacional o internacional) y que proceso es el más problemático de la empresa, de tal manera que si este es ocasionado por problemas originados por la calidad con el grano, se podrá proponer mejoras en la producción de ambiente controlado y así permitir al cliente acelerar su proceso originado mayor fidelización con el cliente hacia nuestro producto.

\section{$\underline{\text { Introducción a plantación de Ambiente Controlado }}$}

Las preguntas 22-24, ubicadas en la página 173, brindará información a las empresas acerca de lo que es un ambiente controlado y cuán importante es este para tener una pérdida de casi $0 \%$ en la producción por la exposición de las enfermedades que pueden llegar a causar entre 30-40\% de pérdidas de producción. 


\section{Preguntas para determinar Intensidad, Intención y Frecuencia de Consumo}

Finalmente, las preguntas 25-27, ubicada las páginas 176 y 174, se obtendrá la intención, intensidad y frecuencia de compra de nuestro producto bajo las condiciones de un ambiente controlado y el producto de los tres factores, se multiplicará por la demanda interna aparente calculada anteriormente, para así obtener la demanda del proyecto.

\subsubsection{Resultados de la encuesta: intención e intensidad de compra, frecuencia, cantidad comprada}

De la encuesta previamente realizada, se calculó el Alfa de Cronbach para evaluar la fiabilidad de los datos recopilados en las entrevistas. Si el valor de este coeficiente es mayor a 0.7 , significa que la fuente de datos recopilados es fiable. Para obtener este coeficiente, se utilizó el programa SPSS, obteniendo un valor de 0.709, llegando a la conclusión de que la fuente de datos es fiable.

Figura 2.6: Alpha de cronbach

\begin{tabular}{|} 
Reliability statistics \\
\begin{tabular}{|r|rr|}
\hline $\begin{array}{c}\text { Cronbach's } \\
\text { Alpha }\end{array}$ & N of & Items \\
\hline .709 & & 27 \\
\hline
\end{tabular}
\end{tabular}

Fuente: Programa SPSS (2019)

\subsubsection{Intención}

La pregunta 25 de la encuesta está relacionada con la variable de Intención. Con ella determinamos el porcentaje de empresas que tiene la intención de comprar cacao producido en ambiente controlado. 
Figura 2.7: Intención de compra

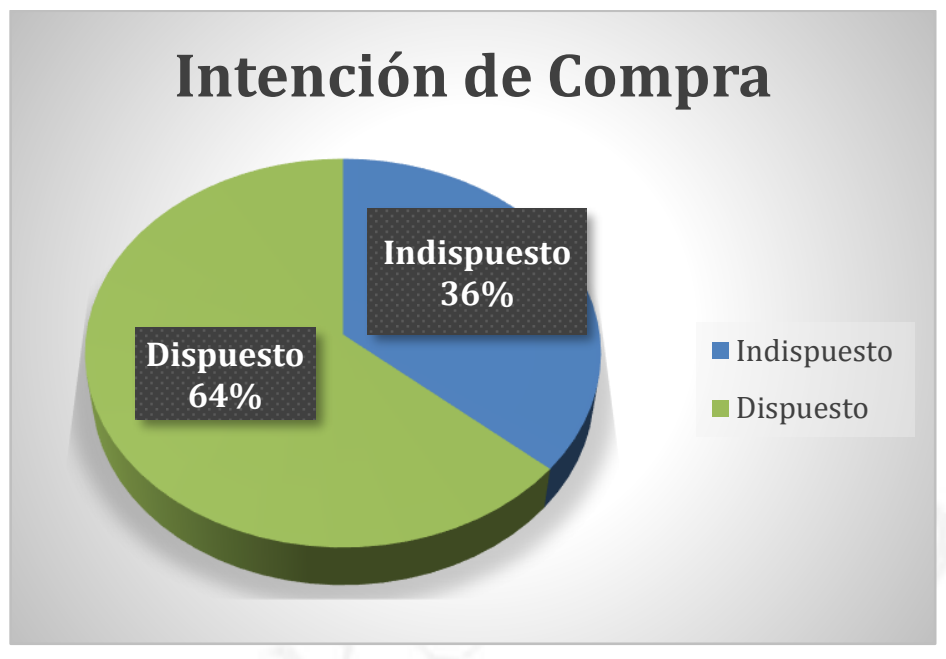

Elaboración Propia

De la gráfica anterior se puede observar que el 64\% del mercado está dispuesto a comprar cacao fino producido en ambiente controlado.

\subsubsection{Intensidad de compra}

La pregunta 26 está relacionada con este factor de intensidad, con ella determinaremos que porcentaje del mercado está dispuesto a comprar el cacao fino inmediatamente salga al mercado.

Figura 2.8: Intensidad de compra

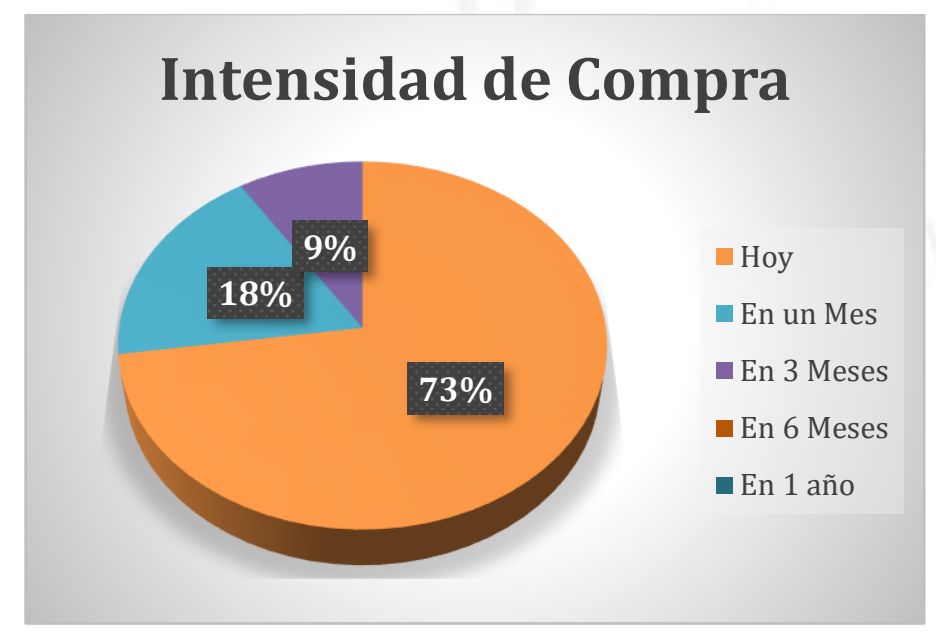

Elaboración Propia 
De la gráfica anterior observamos, que el $73 \%$ del mercado desea comprar inmediatamente el producto, mientras que el $37 \%$ del mercado prefiere hacerlo dentro de 1 mes. Esto según José Bartra, Gerente de Producción de las palmas se debe a que inicialmente ellos prefieren comprar un lote pequeño y determinar si los estándares ofrecidos son los que su cliente final desea, de ser así recién se observa si es viable la compra a gran escala, y el tiempo promedio entre el acopio y él envió de cargamento aproximadamente es de 1 mes.

\subsubsection{Frecuencia de compra}

Con la pregunta 27 de la encueta, se determinó la frecuencia de compra, esto nos permitirá determinar el tiempo entre compra que se realizará a la empresa.

Figura 2.9: Frecuencia de compra

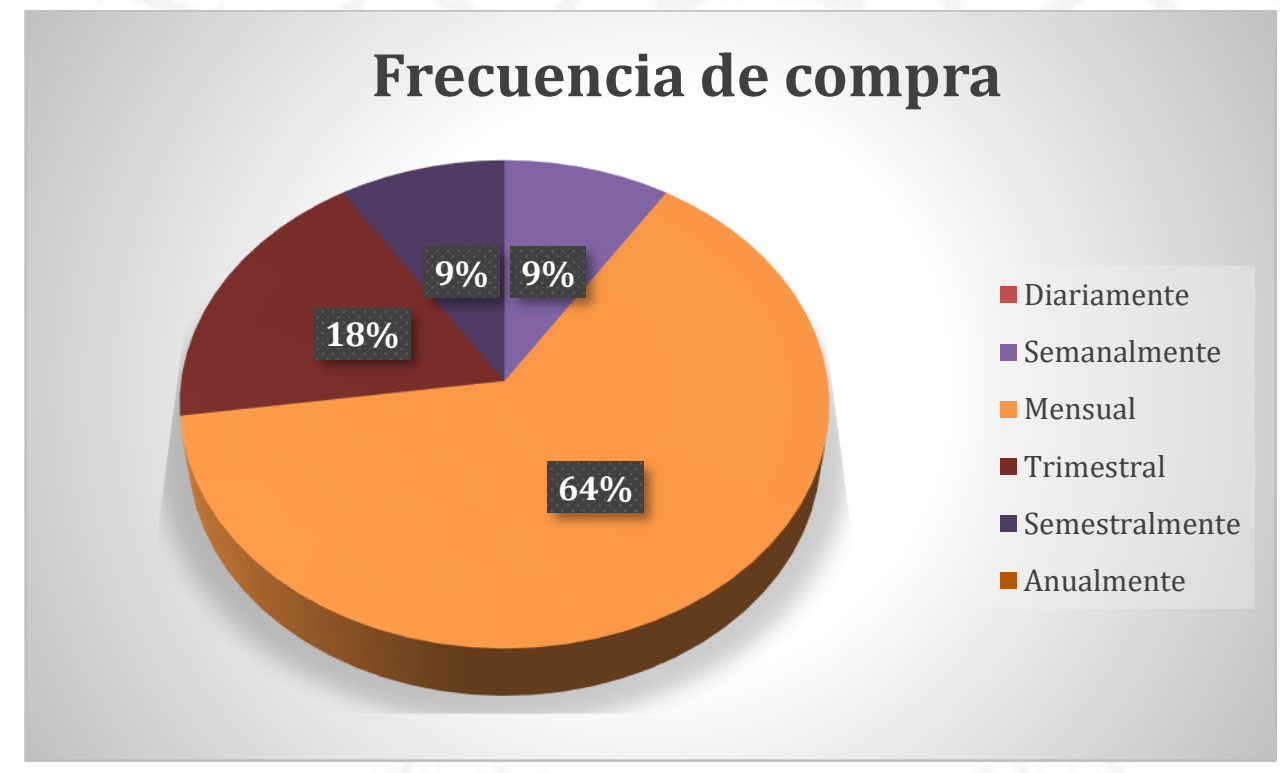

Elaboración Propia

De la gráfica anterior, se observa que le $64 \%$ de empresa compraría el cacao mensualmente y el $18 \%$ lo haría trimestralmente, este mercado es el que nos interesa pues, el grano de caco seco no puede ser conservado más de 3 meses según lo indica Lutheran Worl Relief en su Guía Número 8: Cosecha, Fermentación y Secado del Cacao. 


\subsubsection{Determinación de la demanda del proyecto}

La demanda del proyecto se determinará inicialmente analizando los datos de exportación de cacao peruano, por los principales centros acopiadores y cooperativas del país, posteriormente se reducirá el mercado centrándonos exclusivamente en el caco fino y finalmente, determinaremos la participación de mercado con respecto a las empresas posicionadas actualmente.

En primer lugar, y gracias a la información proveniente de "Agrodata", "Minagri” y la "Sunat", se logró obtener información histórica de las exportaciones durante los 18 años anteriores al estudio (2000-2019). Con ello, se procedió a analizar la data y determinar la tendencia que esta presenta.

Figura 2.10: Data histórica de la exportación de cacao en Perú

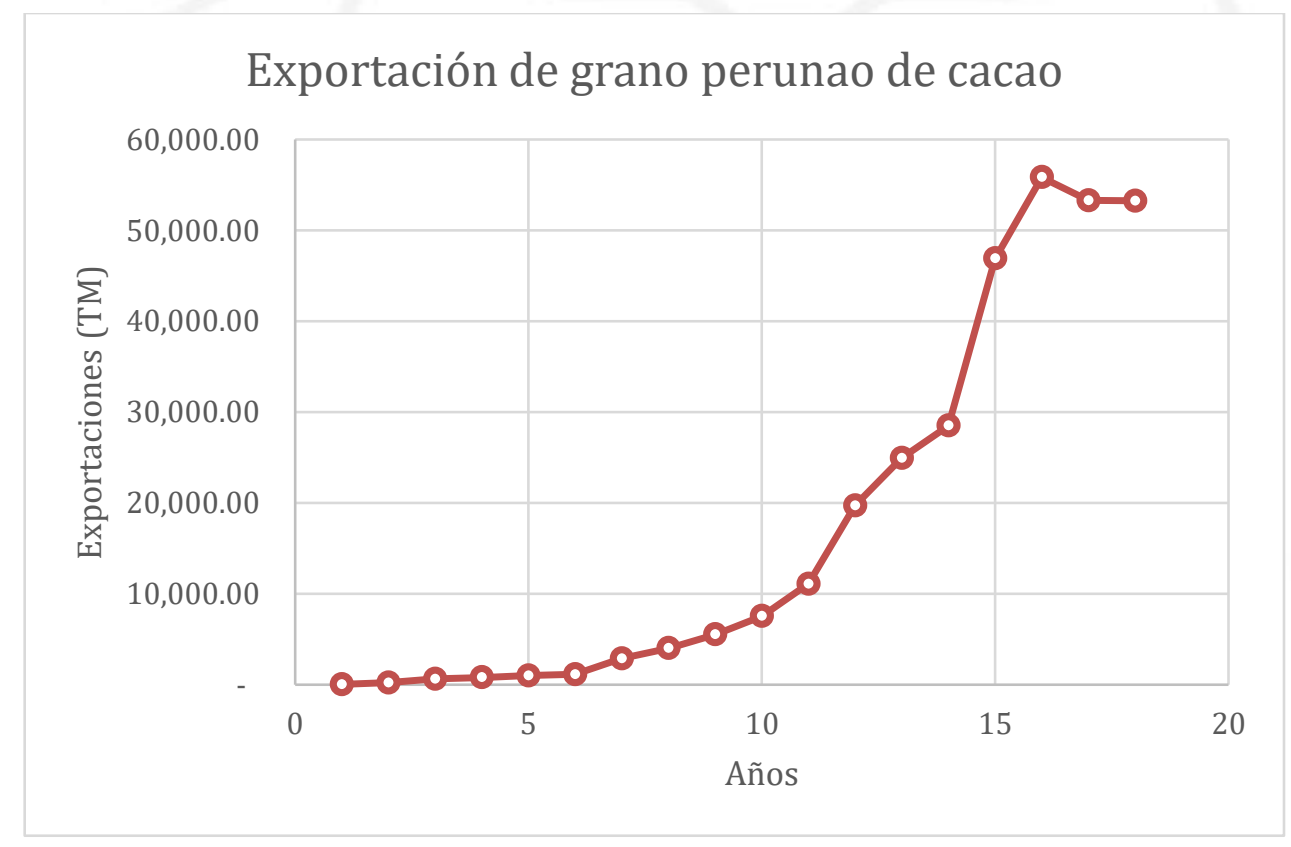

Fuente: Ministerio de Agricultura y Sunat (2015)

Para ello analizamos el coeficiente de determinación para 4 modelos diferentes, teniendo en cuenta un suabizamineto para los años 2016 y 2017, debido a un sobre stock de cacao en mercados extranjeros por las malas cosechas de Costa de Marfil durante estos periodos. De esta manera se analizó la tendencia de la data histórica, obteniendo un coeficiente de determinación para las ecuaciones presentes en anexos 2-5 de: 
Tabla 2.2: Coeficiente de determinación

\begin{tabular}{c|c} 
Ecuación & $\boldsymbol{R}^{2}$ (Coef.de determinación) \\
\hline Exponencial & 0.9143 \\
Lineal & 0.9159 \\
Logarítmica & 0.7639 \\
Potencial & 0.8556
\end{tabular}

Elaboración Propia

Con un coeficiente de determinación de $91.59 \%$, se determinó que la conducta de las exportaciones peruanas tiene una tendencia lineal. Cuya ecuación representativa es la siguiente:

$$
y=11,807.7273 x+400,250
$$

De la ecuación anterior procedemos a proyectar las exportaciones de cacao para los próximos 5 años:

Tabla 2.3: Proyección de la exportación nacional de cacao

\begin{tabular}{|c|c|}
\hline Año & $\begin{array}{c}\text { Exportación } \\
\text { en (TN) }\end{array}$ \\
\hline $\mathbf{2 0 2 0}$ & $134,486.82$ \\
\hline $\mathbf{2 0 2 1}$ & $146,294.55$ \\
\hline $\mathbf{2 0 2 2}$ & 158.102 .27 \\
\hline $\mathbf{2 0 2 3}$ & 169.910 .00 \\
\hline $\mathbf{2 0 2 4}$ & 193.525 .45 \\
\hline
\end{tabular}

Elaboración Propia

A continuación, para poder determinar la demanda del proyecto, el ministerio de agricultura informa que en el país, la distribución de cacao está conformada de la siguiente manera el 44\% de las áreas corresponde al cacao fino, es decir 37119 hectáreas; mientras que el cacao común (CCN-51) corresponde al 53.6\% de los cultivos y los grupos Trinitario y Forastero representa el 2.2\% (Agricultura, 2016). Los datos mencionados anteriormente nos sirven para determinar con mayor precisión el porcentaje de cacao fino que se exportará. 
Tabla 2.4: Exportación de cacao fino proyectada

\begin{tabular}{|c|c|}
\hline Año & $\begin{array}{c}\text { Exportaciones de } \\
\text { Cacao Fino (TN) }\end{array}$ \\
\hline $\mathbf{2 0 2 0}$ & $59,174.20$ \\
\hline $\mathbf{2 0 2 1}$ & $64,369.60$ \\
\hline $\mathbf{2 0 2 2}$ & $69,565.00$ \\
\hline $\mathbf{2 0 2 3}$ & $74,760.40$ \\
\hline $\mathbf{2 0 2 4}$ & $85,151.20$ \\
\hline
\end{tabular}

Elaboración Propia

Con ayuda del capítulo 3 de Macrolocalización, se determinó que el mejor lugar para colocar la planta será el departamento de San Martin. A su vez, este dato nos permitirá centrar la demanda y compararla con la producción de esta zona.

Figura 2.11: Principales regiones productoras de cacao 2015

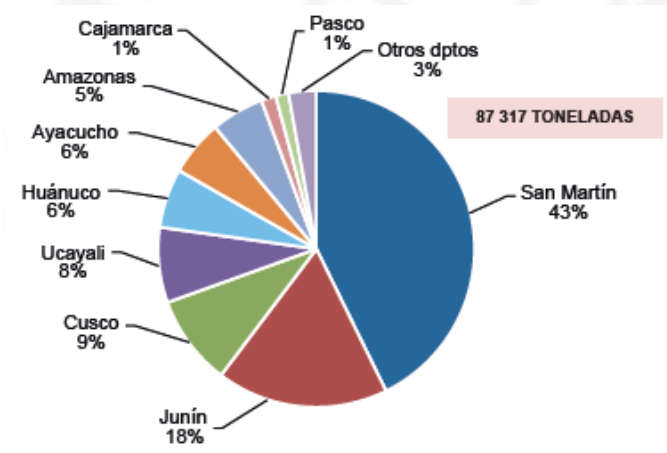

Fuente: MINISTERIO DE AGRICULTURA (2015)

Es así que, con la información del Ministerio de Agricultura, se pudo determinar que la participación de San Martín en la producción de cacao es del 43\% a nivel nacional.

Como penúltimo paso para determinar la demanda del proyecto, se analizará la participación de las empresas y asociaciones cacaoteras más importantes del país para determinar la participación que tienen: 
Figura 2.12: Principales empresas productoras de cacao en Perú

\begin{tabular}{|c|c|c|}
\hline $\begin{array}{c}\text { Empresa } \\
\text { Total Exportado }\end{array}$ & $\begin{array}{c}\text { Peso Neto } \\
\text { (t) } \\
\mathbf{5 6 8 5 1} \\
\end{array}$ & $\begin{array}{c}\text { Yalor FOB } \\
\text { (Miles US5) } \\
187633 \\
\end{array}$ \\
\hline Empresas & 46096 & 147164 \\
\hline $\begin{array}{l}\text { Sumaqao Sociedad Anónima Cerrada } \\
\text { Amazonas Trading Perú S.A.C. }\end{array}$ & $\begin{array}{r}10112 \\
9363\end{array}$ & $\begin{array}{l}31386 \\
29361\end{array}$ \\
\hline Cafetalera Amazónica S.A.C. & 8538 & 28948 \\
\hline Machu Picchu Coffee Trading S.A.C. & 6613 & 22467 \\
\hline Exportadora Romex S.A. & 6271 & 18928 \\
\hline $\begin{array}{l}\text { Casa Luker del Perú S.A.C. } \\
\text { Tropical Forest Peń S.A.C. }\end{array}$ & 1836 & 5388 \\
\hline Tropical Forest Perú S.A.C. & 1344 & 4277 \\
\hline $\begin{array}{l}\text { Selvacacao Sociedad Anonima Cerrada } \\
\text { Inka S Commodities Trading S.A.C. }\end{array}$ & $\begin{array}{l}375 \\
250\end{array}$ & $\begin{array}{r}1151 \\
755\end{array}$ \\
\hline Aquarius Trading Perú S.A.C. & 151 & 481 \\
\hline Inversiones Campo Verde Sac & 150 & 501 \\
\hline Agromayo Scrl & 150 & 443 \\
\hline Coffeecoa Perú S.A.C. & 148 & 481 \\
\hline Otras Empresas & 795 & 3585 \\
\hline Asociaciones & 2124 & 7225 \\
\hline Asociación de Productores Cacao Alto Hu & 1170 & 3889 \\
\hline Asociación de Productores Cacao Vrae & 805 & 2730 \\
\hline Asociación de Productores Cacaoteros Y C & 150 & 806 \\
\hline Cooperativas & 8309 & 28703 \\
\hline Cooperativa Agraria Cacaotera Acopagro & 4040 & 14133 \\
\hline Cooperativa Agroindustrial Tocache Ltda & 1153 & 3569 \\
\hline Cooperativa Agraria Norandino Ltda.Coop.Norandino & 987 & 3639 \\
\hline Coop Agrar Cafetalera Oro Verde Ltda & 779 & 2626 \\
\hline Cooperativa Agraria Cafetera Divisoria Ltda & 425 & 1449 \\
\hline Coop Agraria Cafet Valle Río Apurímac & 324 & 1149 \\
\hline Coop Agraria Cafetalera El Quinacho L 78 & 199 & 719 \\
\hline Cooperativa Agraria Industrial Naranjill & 155 & 481 \\
\hline Cooperativa Agraria El Gran Saposoa L & 151 & 522 \\
\hline Cooperativa Agraria Cafetalera Pangoa Lt & 116 & 415 \\
\hline
\end{tabular}

Fuente: Superintendencia Nacional de Aduanas y de Administración Tributaria (2015)

Gracias a la información proveniente de la SUNAT, se pudo determinar que las principales empresas exportadores tienen una participación entre el $11.03 \%$ y $17.78 \%$. $\mathrm{Si}$ bien el margen entre estas empresas es amplia, inicialmente nosotros planteamos ingresar con una participación del 5\%, la cual será susceptible a cambios dependiendo de la aceptación que tenga nuestro producto en el mercado.

Finalmente, el estudio de mercado muestra que las empresas presentan actualmente intención de compra del 64\%, intensidad de compra del $73 \%$ y la frecuencia de compra del $82 \%$. Con estos datos se pudo determinar que la demanda del proyecto será de:

Tabla 2.5: Demanda del proyecto

\begin{tabular}{|c|c|}
\hline Año & $\begin{array}{c}\text { Demanda del } \\
\text { proyecto (Ton) }\end{array}$ \\
\hline 2020 & 487.40 \\
\hline 2021 & 530.19 \\
\hline 2022 & 572.98 \\
\hline 2023 & 615.78 \\
\hline 2024 & 701.36 \\
\hline
\end{tabular}

Elaboración Propia 


\subsection{Análisis de la oferta}

A continuación se analizarán las empresas productoras, importadoras y comercializadoras de cacao, para luego enfocarse en el análisis de los competidores.

\subsubsection{Empresas productoras, importadoras y comercializadoras}

En PERÚ la importación del cacao es muy escaso debido a que, hay una producción constate e intensiva de este recurso, en la zona de San Martin, Junín y Cusco. Sin embargo, no son las únicas provincias que producen cacao, también lo hacen los departamentos de Ucayali, Huánuco, Ayacucho, Amazonas, Cajamarca y Pasco pero con una participación mucho menor a las tres anteriores regiones mencionados.

Como se puede ver la producción de este insumo en el país es intensivo; no obstante, la mayoría de los productores de cacao son pequeños productores con menos de 5 hectáreas de cultivo. La mayoría de la producción se realiza de manera individual estimándose que alrededor del $70 \%$ de estos productores no están organizados (Felipa, 2015, págs. 129-156)

Si bien es cierto la importación de este producto commodity para el Perú es escaso, ese no es el caso de las exportaciones, que de acuerdo a la SUNAT, el cacao en grano si bien es cierto registraba en los primeros años del nuevo siglo cifras marginales, desde el 2013 ha mantenido una tasa de crecimiento porcentual: siendo esta de un $87 \%$ en el 2015 , con un volumen record de 56,5 mil toneladas. Estimándose así que las exportaciones se han incrementado en un $62 \%$ por año. (Armado, 2016, pág. 23)

\subsubsection{Participación de mercado de los competidores actuales}

Como se mencionó anteriormente, los competidores actuales están conformados en un $70 \%$ por pequeños productores no organizados y el resto pertenece a algún tipo de organización. Sin embargo, los niveles tecnológicos son heterogéneos y no corresponden en algunos casos a las condiciones naturales de la zona. Y es esta fragmentación y 
atomización de la propiedad la que no permite aprovechar economías de escala. (Felipa, 2015, pág. 39).

\subsubsection{Competidores potenciales}

Actualmente no se encuentran competidores potenciales en la producción de cacao. Sin embargo debido al aumento de las exportaciones de Cacao y un mercado creciente de este recurso. Cabe señalar que es de vital importancia analizar la probabilidad de integración hacia atrás por parte de las empresa exportadoras en Perú.

\subsection{Definición de la estrategia de comercialización}

\subsubsection{Políticas de comercialización y distribución}

Es importante tener suficiente liquidez en el corto plazo para poder cumplir con los mantenimientos preventivos que se necesitarán implementar para mantener estables las condiciones controladas del fermentado. Por este motivo, se venderá al crédito (30 días) con un pago a proveedores cada 30 días.

Tener una producción controlada implica regular factores propios tanto del cultivo como del proceso, ya que esto permite tener una producción estable del cacao, evitando enfermedades y disminución de calidad del producto.

\subsubsection{Publicidad y promoción}

Se busca promocionar el proyecto mediante ferias, eventos públicos en países clave y a través de las redes sociales como Facebook e Instagram, ya que se orientará la producción al exterior y se tomará en cuenta Europa como principal mercado.

Se plantea ingresar al mercado con una diferenciación, debido a que los productores locales aumentan el precio del producto en los meses pico (junio- agosto) que son donde se concentra el $70 \%$ de las ventas anuales del Perú y de esta manera nos permitirá aumentar la participación de mercado. Es por esto que se venderá un cacao fino de alta 
calidad y se hará un cercano seguimiento de su producción, desde el sembrío hasta la venta al cliente.

\subsubsection{Análisis de precios}

\subsubsection{Tendencia histórica de los precios}

La evolución de los precios del cacao en el Perú entre los años 2000-2015 ha sido muy inestables pero crecientes, debido a posibles picos de producción como también caídas drásticas, creando así una tendencia estacional. En el año 2001, el precio del cacao estaba en aproximadamente $S / .2 .00 / \mathrm{kg}$, siendo el más bajo para los próximos quince años y en el 2015 se registró un valor récord de aproximadamente S/. 7.09/kg. A continuación, se observa la tendencia del precio promedio anual del cacao en el Perú.

Figura 2.13: Precio histórico del cacao (S/. /Kg)

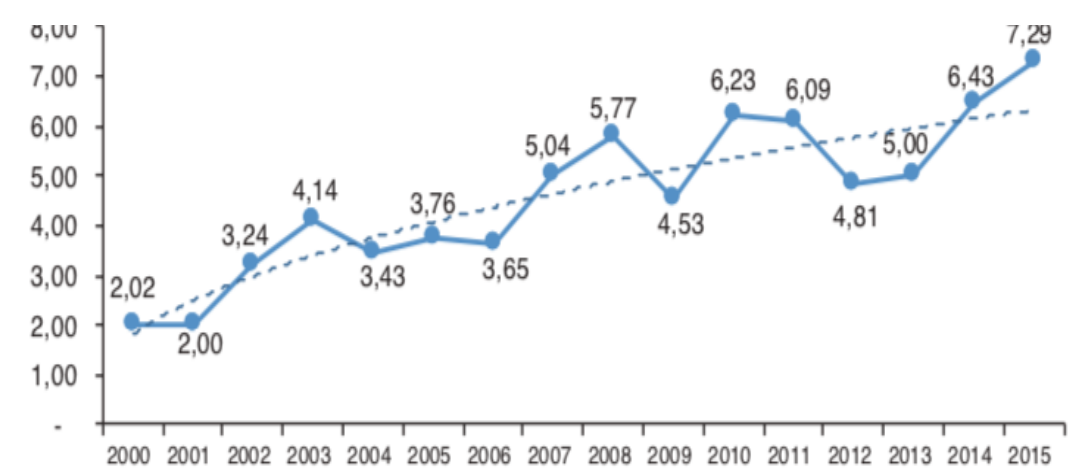

Fuente: Ministerio de Agricultura (2015)

Según Indexmundi, el precio promedio del cacao para los años 2016 y 2017 fueron de S/. 9.74/kg y S/. 6.62/kg respectivamente. Se puede notar que si bien el precio es muy inestable conforme pasan los años, sigue creciendo de manera rápida y esto puede impactar a las empresas acopiadoras del cacao en este país, obligándolas a reducir su producción debido al incremento del costo de adquisición.

Por otro lado, el comportamiento de los precios del cacao en el mundo es similar a la tendencia de precios a nivel nacional, ya que como se puede observar en el gráfico 2, los precios también presentan un comportamiento estacional creciente. En el 2001 se 
registró el precio más bajo de USD 1.09/kg y un valor pico en el año 2015 de USD $3.04 / \mathrm{kg}$.

Figura 2.14: Precio promedio internacional al contado de cacao (Puerto EEUU Y UE)

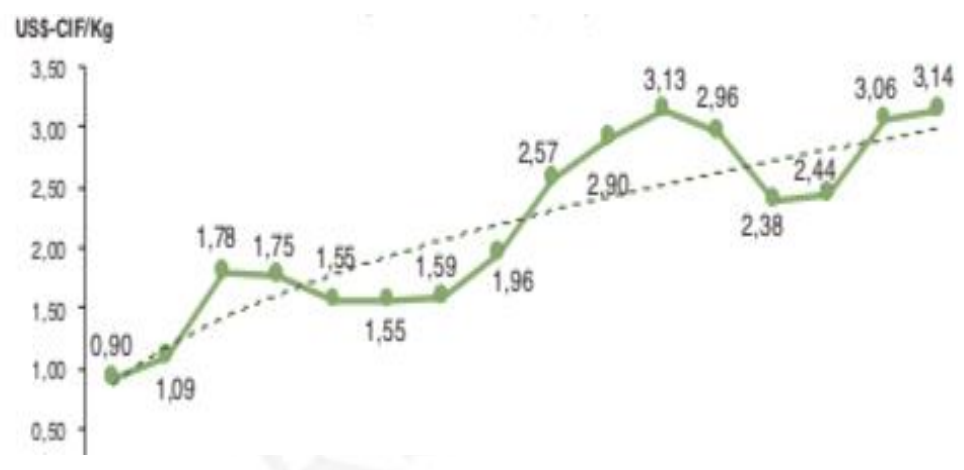

Fuente: Ministerio de Agricultura (2015)

\subsubsection{Precio actuales}

En agosto 2019, el precio promedio del cacao en el Perú fue de aproximadamente S/. 7.82/kg (INDEXMUNDI, 2019, p. 2). Según el periódico inglés BBC News, “Costa de Marfil y Ghana, son responsables de más de la mitad del cacao del mundo. Un informe reciente del Instituto de Genómica Innovadora de la Universidad de California (EEUU) pronostica que el cambio climático reducirá significativamente la cantidad de tierra apta para cultivar cacao en las próximas décadas" (5 razones por las que el chocolate está en peligro en todo el mundo, 2018). De cumplirse este pronóstico, el precio mundial del cacao podría verse afectado, pues Costa de Marfil y Ghana dominan el mercado mundial según lo mencionado líneas arriba, por lo que es difícil establecer el precio que tendrá este commodity. Lo que sí puede predecirse es que el precio tendrá una tendencia positiva conforme pasen los años. Es por este motivo, que se asumirá que el precio por kilogramo que se visualiza en la figura 14 será el precio de venta que los acopiadores de cacao utilizarán para hacer llegar el producto al extranjero. Para el presente proyecto, se considerará un margen de ganancia Precio - Costo del 15\%, obteniendo un precio de venta de S/. 8.16 / kg (Espinoza, 2018). 


\subsubsection{Estrategia de precio}

Se brindará un producto de alta calidad que cumpla con los estándares requeridos por las normas de calidad para poder ingresar al mercado europeo y otras partes del mundo. Se establecerá un precio que no varíe con la estacionalidad del Cacao para así aumentar volumen de ventas y poder recuperar la inversión en el menor tiempo posible. Al ofrecer un precio constante a las principales empresas acopiadoras de cacao fino, se estará incrementando la participación de mercado y a su vez, uniformizará la producción de aquellos clientes, ya que se reduciría la tendencia estacional que presentan hoy en día por los ineficientes procesos de producción del cacao fino en la selva del país. 


\section{CAPÍTULO III: LOCALIZACIÓN DE PLANTA}

Para instalar una planta de producción, se deben tomar en cuenta varios factores de localización; entre ellos está la disponibilidad de materia prima, el costo del terreno, la infraestructura vial, suministro de agua potable, suministro de energía eléctrica, temperatura promedio y la humedad relativa. El adecuado análisis de estos factores a través del método de Ranking de Factores y Brown Gibson, se podrá determinar la ubicación óptima de la planta.

\subsection{Identificación y análisis detallado de los factores de localización}

\subsubsection{Disponibilidad de materia prima}

Un factor a tomar en cuenta es la disponibilidad de materia prima cerca de la planta productora de cacao. La planta debe tener un constante suministro de las semillas de cacao a un costo mínimo para cumplir con la demanda de los posibles acopiadores y productores. Este factor será evaluado en toneladas producidas de cacao en la región elegida, tomando como referencia la Figura 3.11 ubicada en la página 40. Por lo tanto, los tres departamentos que produzcan la mayor cantidad de cacao en el país serán tomados en cuenta para el análisis de macro localización.

\subsubsection{Costo del terreno}

De los tres departamentos que produzcan la mayor cantidad de cacao en el Perú, se optará por elegir la localización que presente la disponibilidad del terreno al menor costo. Según Urbanía, en el 2018, los costos promedio del metro cuadrado en San Martín, Cusco y Junín son de S/. 48, S/. 56 y S/. 51 respectivamente. 


\subsubsection{Infraestructura vial}

La infraestructura vial es importante al momento de evaluar la calidad y accesibilidad de las carreteras y otras vías de transporte entre la ciudad y la planta a instalar. Según el Ministerio de Transportes y Comunicaciones, para el periodo del 2011-2016, San Martín superó los S/. 1,800 millones, Cusco los S/. 4,800 millones y Junín superó los S/. 2,000 en inversiones de un conjunto de obras estratégicas y otros proyectos integrales en vías de comunicación.

\section{Suministro de agua potable:}

La disponibilidad de agua potable es importante para la planta pues se monitoreara la humedad relativa del suelo, para determinar si es la adecuada. Por este motivo la necesidad de regar correctamente las plantaciones cuando estas las necesiten hace que la disponibilidad de este insumo se imprescindible. A continuación, se muestra la población que consume agua proveniente de red pública, según departamento, esto permitirá determinar el acceso a agua potable por departamento.

Figura 3.1: Suministro de agua potable por departamento
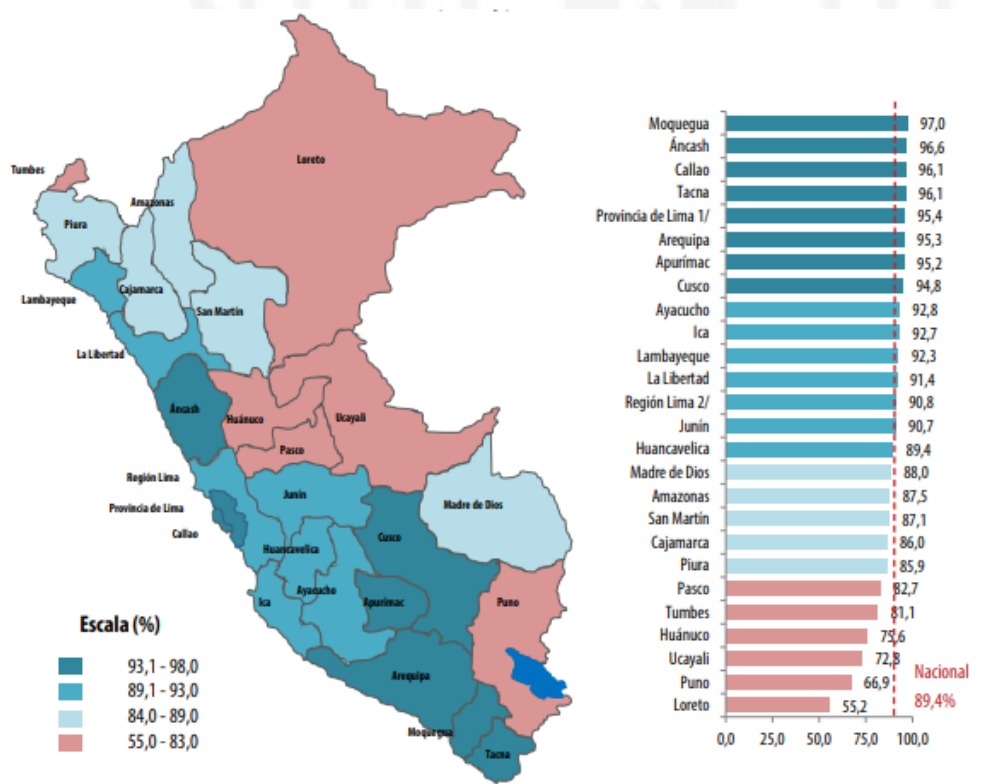

Fuente: Instituto Nacional de Estadística e Informática (2015) 


\section{Suministro de energía eléctrica}

Al igual que el suministro de agua, para controla el ambiente de producción de cacao, se necesita analizar medir constantemente la temperatura, la humedad del ambiente y la humedad de suelo mediante sensores eléctricos. Por ello, la disponibilidad de energía eléctrica será de vital importancia. A continuación, se muestra el porcentaje de viviendas con acceso al servicio de energía eléctrica por departamento según el Instituto Nacional de Estadística e Informática (INEI).

Figura 3.2: Suministro de energía eléctrica por departamento

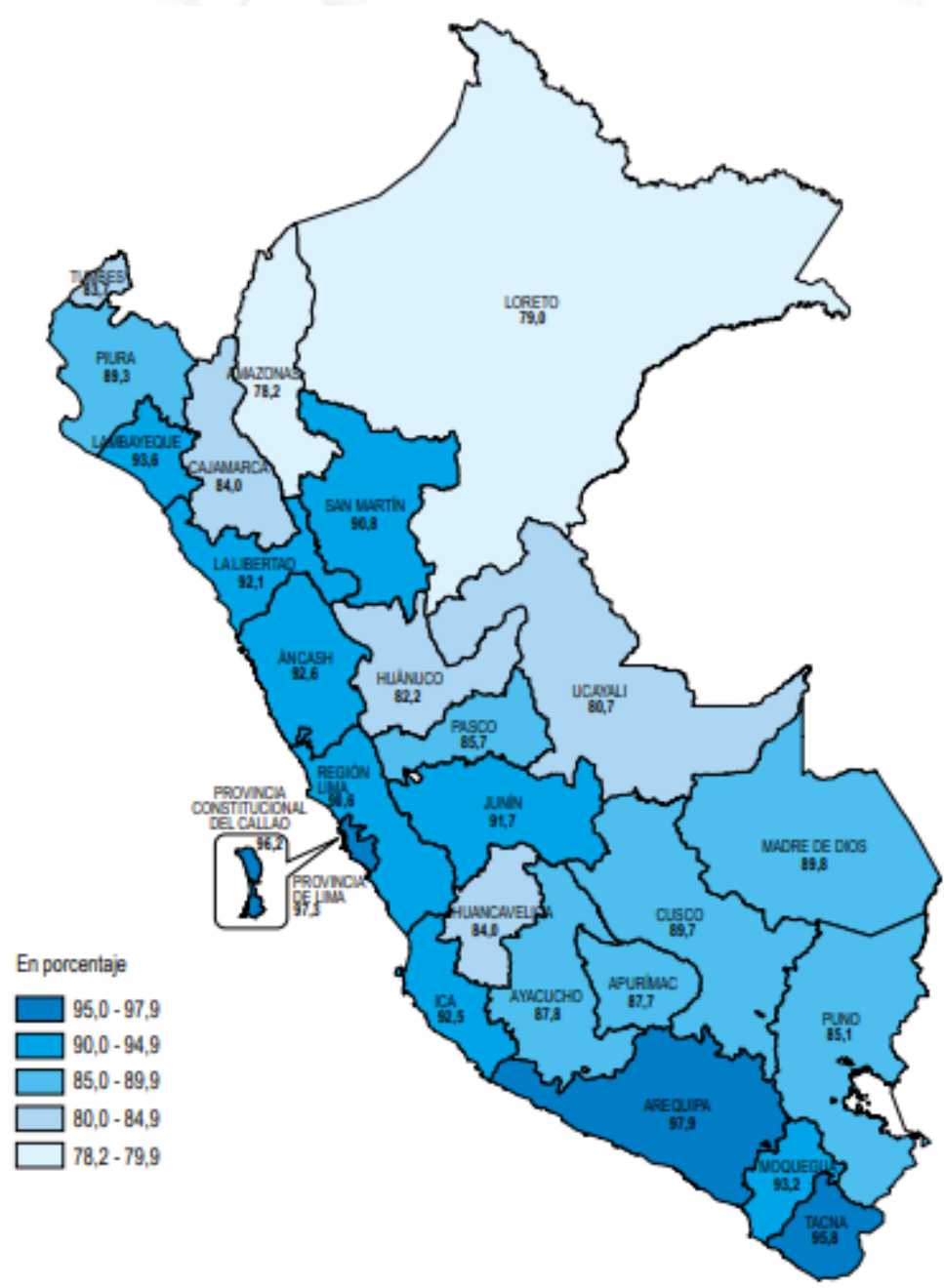

Fuente: Instituto Nacional de Estadística e Informática (2015) 


\section{Temperatura promedio por departamento.}

Las plantaciones de cacao necesitan temperaturas entre $\operatorname{los} 23^{\circ} \mathrm{C} \mathrm{y} 30^{\circ} \mathrm{C}$ para completar adecuadamente su ciclo de vida y producir cacao de alta calidad y en grandes volúmenes por árbol. Específicamente la temperatura de $25^{\circ} \mathrm{C}$ es la temperatura óptima para estas plantaciones (Agricultura, 2016). A continuación se presenta la tabla de temperatura promedio según Departamento proporcionada por el Servicio Nacional de Meteorología e Hidrología (SENAMHI) en el 2016.

Tabla 3.1: Temperatura promedio anual por departamento

\begin{tabular}{|c|c|c|c|c|c|c|c|c|c|c|}
\hline Departamento & 2007 & 2008 & 2009 & 2010 & 2011 & 2012 & 2013 & 2014 & 2015 & 2016 \\
\hline Amazonas & 14.7 & 14.8 & 14.8 & 15.4 & 14.9 & 14.7 & 15.0 & 14.9 & 15.1 & 15.6 \\
\hline Áncash & 12.6 & 12.4 & 12.5 & 12.7 & 12.2 & 12.4 & 12.5 & 12.5 & 12.8 & 13.1 \\
\hline Apurímac & 15.8 & 16.2 & 16.0 & 16.2 & 15.7 & 14.0 & 14.1 & 14.1 & 14.5 & 14.9 \\
\hline Arequipa & 15.9 & 15 & 16.4 & 16.4 & 15.6 & 15.6 & 15.6 & 16.1 & 17.1 & 17.3 \\
\hline Ayacucho & 18.1 & 19.4 & 19.0 & 18.8 & 18.0 & 18.0 & 18.2 & 18.4 & 18.3 & $\ldots$ \\
\hline Cajamarca & 14.4 & 14.4 & 14.7 & 14.9 & 14.4 & 14.6 & 14.9 & 15.0 & 15.4 & 15.6 \\
\hline Cusco & 12.4 & 12.3 & 12.4 & 12.6 & 12.1 & 12.3 & 12.3 & 12.5 & 12.6 & 13.3 \\
\hline Huancavelica & 10.3 & 10 & 10.6 & 10.4 & 9.5 & 9.6 & 10.3 & 10.3 & 10.4 & $\ldots$ \\
\hline Huánuco & 20.5 & 20.4 & 20.5 & 20.9 & 20.2 & 20.3 & 20.7 & 20.6 & 20.8 & 21.4 \\
\hline Ica & 20.6 & 21.6 & 21.8 & 21.4 & 22.2 & 20.7 & 21.5 & 21.0 & 21.6 & 22.9 \\
\hline Junín & 12.4 & 12.1 & 12.4 & 12.7 & 12.1 & 12.1 & 12.4 & 12.4 & 12.6 & 13.0 \\
\hline La Libertad & 18.9 & 20.8 & 20.5 & 19.8 & 19.9 & 21.2 & 19.3 & 21.0 & 22.2 & 21.2 \\
\hline Lambayeque & 19.9 & 21.5 & 21.2 & 20.5 & 20.7 & 22.0 & 20.2 & 21.7 & 22.8 & 22.4 \\
\hline Lima & 18.1 & 19.5 & 19.5 & 18.8 & 19.1 & 19.8 & 18.7 & 19.5 & 20.8 & 20.3 \\
\hline Loreto & 27.4 & 27.3 & 27.4 & 27.6 & 27.5 & 26.8 & 27.4 & 26.9 & 27.3 & 27.5 \\
\hline Madre de Dios & 27.1 & 26.5 & 26.1 & $\ldots$ & 26.6 & 26.9 & 26.6 & 26.5 & 27.1 & 27.0 \\
\hline Moquegua & 19.7 & 18.8 & 19.8 & 19.2 & 19.4 & 19.7 & 19.3 & 19.4 & 19.9 & $\ldots$ \\
\hline Pasco & 5.0 & 5.3 & 5.2 & 5.7 & 5.2 & 5.0 & 5.3 & 5.2 & 5.5 & 6.0 \\
\hline Piura & 24.0 & 24.8 & 24.8 & 24.2 & 24.6 & 25.2 & 23.9 & 25.3 & 26.1 & $\ldots$ \\
\hline Puno & 10.7 & 9.4 & 10.9 & 11.5 & 10.8 & 10.5 & 10.2 & 10.5 & 10.3 & $\ldots$ \\
\hline San Martín & 22.6 & 23.2 & 22.7 & 23.4 & 23.1 & 22.8 & 23.0 & 22.8 & 22.9 & 23.6 \\
\hline Tacna & 16.7 & 18.3 & 18.1 & 17.5 & 17.6 & 18.2 & 17.7 & 18.0 & 18.8 & 18.8 \\
\hline Tumbes & 24.9 & 26.2 & 25.7 & 25.5 & 25.5 & 25.6 & 25.1 & 26.0 & 27.2 & $\ldots$ \\
\hline Ucayali & 26.2 & 26.1 & 25.7 & 26.1 & 25.5 & 25.5 & 25.6 & 25.5 & 26.0 & 26.0 \\
\hline
\end{tabular}

Fuente: Servicio Nacional de Meteorología e Hidrología (2016)

\section{Humedad relativa promedio}

$\mathrm{Al}$ igual que la temperatura las plantaciones de cacao necesitan humedad en el ambiente para poder desarrollarse adecuadamente, por lo tanto encontrar una región que presente humedad relativa promedio anual entre 70\% y 80\% (Agricultura, 2016, pág. 26), es de vital importancia para obtener un grano de cacao con características óptimas. 
Tabla 3.2: Humedad relativa promedio por departamento

\begin{tabular}{|c|c|c|c|c|c|c|c|c|c|c|}
\hline Departamento & 2007 & 2008 & 2009 & 2010 & 2011 & 2012 & 2013 & 2014 & 2015 & 2016 \\
\hline Amazonas & 85 & 88 & 83 & 77 & 77 & 81 & 87 & 83 & 81 & 78 \\
\hline Áncash & 77 & 75 & 78 & 81 & 85 & 80 & 77 & 78 & 76 & 75 \\
\hline Apurímac & 95 & 93 & 91 & 91 & 93 & 87 & 83 & 79 & 82 & 80 \\
\hline Arequipa & 58 & 52 & 57 & 47 & 50 & 54 & 51 & 49 & 48 & 47 \\
\hline Ayacucho & 75 & 70 & 86 & 84 & 78 & 73 & 77 & 77 & 79 & $\ldots$ \\
\hline Cajamarca & 66 & 63 & 69 & 65 & 65 & 65 & 64 & 63 & 63 & 64 \\
\hline Cusco & 72 & 64 & 71 & 74 & 76 & 67 & 74 & 68 & 69 & 64 \\
\hline Huancavelica & 78 & 75 & 77 & 76 & 81 & 84 & 84 & 86 & 85 & $\ldots$ \\
\hline Huánuco & 63 & 67 & 65 & 64 & 67 & 65 & 66 & 65 & 64 & 62 \\
\hline Ica & 80 & 76 & 86 & 84 & 75 & 70 & 68 & 74 & 73 & 67 \\
\hline Junín & 62 & 60 & 67 & 64 & 65 & 63 & 62 & 59 & 59 & 56 \\
\hline La Libertad & 89 & 86 & 89 & 91 & 91 & 87 & 92 & 91 & 85 & 85 \\
\hline Lambayeque & 86 & 82 & 83 & 83 & 82 & 81 & 82 & 80 & 81 & 82 \\
\hline Lima & 87 & 84 & 86 & 85 & 85 & 86 & 86 & 87 & 86 & 85 \\
\hline Loreto & 86 & 83 & 84 & 84 & 83 & 85 & 85 & 84 & 92 & 90 \\
\hline Madre de Dios & 85 & 81 & 86 & $\ldots$ & 83 & 83 & 85 & 90 & 93 & 92 \\
\hline Moquegua & 57 & 55 & 57 & 62 & 63 & 61 & 62 & 63 & 65 & $\ldots$ \\
\hline Pasco & 84 & 79 & 81 & 75 & 82 & 84 & 86 & 85 & 86 & 85 \\
\hline Piura & 74 & 71 & 75 & 76 & 73 & 70 & 75 & 74 & 76 & $\ldots$ \\
\hline Puno & 63 & 56 & 55 & 56 & 63 & 61 & 64 & 65 & 68 & $\ldots$ \\
\hline San Martín & 84 & 74 & 83 & 81 & 82 & 82 & 82 & 83 & 83 & 81 \\
\hline Tacna & 80 & 73 & 75 & 77 & 75 & 75 & 76 & 78 & 80 & 76 \\
\hline Tumbes & 88 & 87 & 91 & 91 & 90 & 85 & 91 & 91 & 78 & $\ldots$ \\
\hline Ucayali & 88 & 84 & 89 & 90 & 90 & 90 & 88 & 90 & 88 & 87 \\
\hline
\end{tabular}

Fuente: Servicio Nacional de Meteorología e Hidrología (2016)

\section{Ley Amazónica:}

El estado fomenta el progreso sostenible en la amazonia, asentando condiciones para la inversión pública y el desarrollo de la inversión privada. Según el artículo 69 de la constitución política del Perú: "El estado promueve el desarrollo sostenible de la amazonia con una legislación adecuada”. Y en honor a ello se difunden diversas normas como la ley $\mathrm{N}^{\circ}$ 27037, que involucra a las regiones de Loreto, Madre de Dios, Ucayali, Amazonas y San Martin, además de algunos distritos y provincias de región de Cusco, Cajamarca, Huánuco, La Libertad, Piura, Puno y Huancavelica para brindarles facilidades tributarias como la exoneración total del impuesto general a las ventas (IGV), implementación de fondos promocionales de financiamiento y compromiso de inversión pública. 


\subsection{Identificación y descripción de las alternativas de localización}

Basados en los factores antes mencionados, se eligió como posibles ubicaciones a los departamentos de San Martin, Junín y Cusco debido a su alta producción nacional de Cacao y a que tiene mayor afinidad con los factores antes mencionados. A continuación se describirá las características más resaltantes de cada departamento seleccionado:

En primer lugar, San Martin es uno delos 24 departamentos que conforman la república del Perú, su capital es Moyobamba y su ciudad más poblada es Tarapoto. Este departamento presenta la mayor producción nacional de Cacao según el ministerio de agricultura (43\% de la producción nacional), a su vez el suministro de agua llega al $87.1 \%$ de la localidad, indicando que hay disponibilidad de este recurso, al igual que la disponibilidad de energía eléctrica que llega al 89,8\% de la población. "Entre el 2010 y 2015, San Martín casi duplicó su número de hectáreas cultivadas del grano, de 25,000 a 46,000" (Exportación de cacao en grano se redujo a US\$ 92 millones entre enero y agosto del 2017, 2017, pág. 2). Por otro lado la temperatura promedio del departamento oscila entre $26.1^{\circ} \mathrm{C}-27.1^{\circ} \mathrm{C}$ con un humedad relativa promedio de $81 \%$ a $84 \%$.

En segundo lugar, Cuzco es un departamento del Perú ubicado entre los 532 y 6372 m.s.n.m. su capital y ciad más poblada es la homónima Cuzco. Según el Ministerio de Agricultura este departamento produce el $9 \%$ del cacao nacional, as su vez en este departamento la disponibilidad de agua para toda la población es del 94,8\% muy por encima del promedio nacional de $89,4 \%$. La temperatura promedio es de $12.1^{\circ} \mathrm{C} \mathrm{y} 12.6^{\circ} \mathrm{C}$ con una humedad relativa anual que se encuentra entre $64 \%$ y $74 \%$.

Finalmente, Junín es el último departamento en análisis, su capital es Huancayo y se encuentra ubicada en el Centro-Oeste del Perú. La temperatura promedio anual de este departamento oscila entre $12.1^{\circ} \mathrm{C}$ y $12.4^{\circ} \mathrm{C}$ y su humedad relativa anual es de $59 \%$ a 67\%. La disponibilidad de energía eléctrica de esta zona llega al 91.7\% de la población y la disponibilidad de agua llega al 90,7 \% de la población. 


\subsection{Evaluación y selección de localización}

\subsubsection{Evaluación y selección de la macro localización}

Para este capítulo se utilizara el método de Ranking de Factores, pero ante de ellos se utilizara la tabla de enfrentamiento de factores para ponderar las variables involucradas, las cuales son:

- DMP: Disponibilidad de Materia prima

- CDT: Costo de Terreno

- IFV: Infraestructura Vial

- SDAP: Suministro de agua Potable

- SDEE: Suministro de Energía Eléctrica

- TP: Temperatura Promedio

- HR: Humedad Relativa

- BT: Beneficios Tributarios (Ley Amazónica)

Tabla 3.3: Enfrentamiento de factores

\begin{tabular}{|c|c|c|c|c|c|c|c|c|c|c|}
\hline Factores & DMP & CDT & IFV & SDAP & SDEE & TP & HR & LA & Conteo & Ponderación \\
\hline DMP & & 1 & 1 & 1 & 1 & 1 & 1 & 1 & 7 & $22.58 \%$ \\
\hline CDT & 0 & & 1 & 1 & 1 & 1 & 1 & 1 & 6 & $19.35 \%$ \\
\hline IFV & 0 & 0 & & 1 & 1 & 1 & 1 & 1 & 5 & $16.13 \%$ \\
\hline SDAP & 0 & 0 & 0 & & 1 & 0 & 0 & 1 & 2 & $6.45 \%$ \\
\hline SDEE & 0 & 0 & 0 & 1 & & 0 & 0 & 1 & 2 & $6.45 \%$ \\
\hline TP & 0 & 0 & 0 & 1 & 1 & & 1 & 1 & 4 & $12.90 \%$ \\
\hline HR & 0 & 0 & 0 & 1 & 1 & 1 & & 1 & 4 & $12.90 \%$ \\
\hline BT & 0 & 1 & 0 & 0 & 0 & 0 & 0 & & 1 & $3.23 \%$ \\
\hline & \multicolumn{8}{|c|}{ TOTAL } & 31 & \\
\hline
\end{tabular}

Elaboración Propia

A continuación se utilizará el Ranking de Factores, para determinar la macro localización de la planta, para ello se le asignará un puntaje representativo a cada departamento por cada factor para poder contrastarlos, los cuales será: 
Tabla 3.4: Escala de factores

\begin{tabular}{|l|l|}
\hline Valor & Significado \\
\hline $\mathbf{1}$ & Muy Malo \\
\hline $\mathbf{2}$ & Malo \\
\hline $\mathbf{3}$ & Regular \\
\hline $\mathbf{4}$ & Bueno \\
\hline $\mathbf{5}$ & Excelente \\
\hline
\end{tabular}

Elaboración Propia

Con los datos anteriormente especificados se procedió a realizar el Rankin de Factores:

Tabla 3.5:Ranking de factores

\begin{tabular}{|c|c|c|c|c|c|c|c|}
\hline \multirow{3}{*}{ 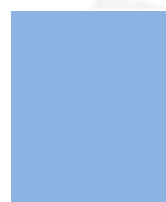 } & \multirow[t]{3}{*}{ Peso } & \multicolumn{6}{|c|}{ Departamentos } \\
\hline & & \multicolumn{2}{|c|}{ San Martin } & \multicolumn{2}{|l|}{ Cuzco } & \multicolumn{2}{|l|}{ Junín } \\
\hline & & Puntaje & Total & Puntaje & Total & Puntaje & Total \\
\hline DMP & $22.58 \%$ & 5 & 1.129 & 4 & 0.903 & 4 & 0.903 \\
\hline CDT & $19.35 \%$ & 4 & 0.774 & 2 & 0.387 & 3 & 0.580 \\
\hline IFV & $16.13 \%$ & 2 & 0.322 & 5 & 0.806 & 3 & 0.483 \\
\hline SDAP & $6.45 \%$ & 3 & 0.193 & 5 & 0.322 & 4 & 0.258 \\
\hline SDEE & $6.45 \%$ & 4 & 0.258 & 3 & 0.193 & 5 & 0.322 \\
\hline TP & $12.90 \%$ & 3 & 0.387 & 2 & 0.258 & 2 & 0.258 \\
\hline HR & $12.90 \%$ & 4 & 0.516 & 3 & 0.387 & 1 & 0.129 \\
\hline BT & $3.23 \%$ & 5 & 0.161 & 3 & 0.096 & 1 & 0.032 \\
\hline TOTAL & & & 3.741 & & 3.354 & & 2.967 \\
\hline
\end{tabular}

Elaboración Propia 


\subsubsection{Evaluación y selección de la micro localización}

Ya definido el departamento, se realizará un análisis más profundo dentro de esta localización para determinar el lugar exacto de la planta, para ello consideramos las localidades de Tocache, Moyobamba y Mariscal Cáceres.

En primer lugar se consideró la localidad de Tocache, porque según el gerente regional de desarrollo Económico de San Martin, Yzia Encomenderos, Tocache es donde se registra la mayor productividad de Cacao en San Martin, cuyo promedio es de 860 Kilos por hectárea. Encomedereos dijo que esto coloca a Tocache sobre indonesio, que ocupa el segundo lugar, con mil kilos por hectárea. (Tocahe es Primer productor de cacao, 2012).

En segundo lugar, se eligió la provincia de Moyobamba, debido a la amplia infraestructura vial que posee la localidad, lo que permite transportar en menor tiempo los lotes de producción hacia los clientes gracias a buen estado de la infraestructura vial.

Tabla 3.6: Infraestructura vial por provincia

\begin{tabular}{|l|l|l|l|}
\hline Provincia & Moyobamba & Tocache & Mariscal Cáceres \\
\hline $\begin{array}{l}\text { Infraestructura } \\
\text { vial }\end{array}$ & $253.2 \mathrm{~km}$ & $176 \mathrm{~km}$ & $26.4 \mathrm{~km}$ \\
\hline
\end{tabular}

Fuente: Instituto Nacional de Estadística e Información (2011)

Y finalmente se escogió la localidad de Mariscal Cáceres por los bajos costos de terreno, factor que será de vital importancia pues, la producción de cacao necesitar una extensa cantidad de terreno para realizar las plantaciones.

A continuación, se presenta los factores cuantitativos más relevantes para el proyecto, en la siguiente tabla: 
Tabla 3.7: Factores cuantitativos por provincia

\begin{tabular}{|c|c|c|c|}
\hline & Moyobamba & Tocache & Mariscal Cáceres \\
\hline $\begin{array}{l}\text { Costo del } \\
\text { terreno }\end{array}$ & $\mathrm{S} / .56 / \mathrm{m}^{2}$ & $\mathrm{~S} / .43 / \mathrm{m}^{2}$ & $\mathrm{~S} / .45 / \mathrm{m}^{2}$ \\
\hline $\begin{array}{l}\text { Costo de } \\
\text { energía }\end{array}$ & S/. 0.30/kwh & S/. 0.25/kwh & S/. 0.41/kwh \\
\hline $\begin{array}{ll}\text { Costo de } & \text { de } \\
\text { agua } & \text { de } \\
\text { regadío } & \end{array}$ & $\mathrm{S} / .1 .13 / \mathrm{m}^{3}$ & $\mathrm{~S} / .0 .95 / \mathrm{m}^{3}$ & $\mathrm{~S} / .1 .03 / \mathrm{m}^{3}$ \\
\hline
\end{tabular}

Fuente: Osinergmin (2015), SUNASS (2014), Urbanía (2018)

Con los datos antes mencionados se procederá a realizar el análisis de microlocalización con el método Brown Gibson. Para lo cual los factores subjetivos a analizar serán:

- Vías de Acceso

- Competidores cercanos

- Disponibilidad de Terreno

- Clima

Tabla 3.8: Valor relativo de los factores objetivos

\begin{tabular}{|c|c|c|c|c|c|c|}
\hline & $\begin{array}{l}\text { Costo del } \\
\text { terreno }\end{array}$ & $\begin{array}{l}\text { Costo de } \\
\text { energía }\end{array}$ & $\begin{array}{l}\text { Costo de } \\
\text { agua de } \\
\text { regadío }\end{array}$ & $\begin{array}{l}\text { TOTAL } \\
\text { (Ci) }\end{array}$ & $\begin{array}{l}\text { Recíproca } \\
\text { (1/Ci) }\end{array}$ & Fo \\
\hline Moyobamba & 56 & 0.3 & 1.13 & 57.43 & 0.017412502 & 0.28280 \\
\hline Tocache & 43 & 0.25 & 0.95 & 44.2 & 0.022624434 & 0.36745 \\
\hline \multirow{2}{*}{$\begin{array}{l}\text { Mariscal } \\
\text { Cáceres }\end{array}$} & 45 & 0.41 & 1.03 & 46.44 & 0.021533161 & 0.34973 \\
\hline & & & & & 0.0615701 & 1 \\
\hline
\end{tabular}

Elaboración Propia 
Tabla 3.9: Enfrentamiento de factores subjetivos

\begin{tabular}{|l|l|l|l|l|l|l|}
\hline Factor & $\begin{array}{l}\text { Vías de } \\
\text { Acceso }\end{array}$ & Competencia & $\begin{array}{l}\text { Disponibilidad } \\
\text { de terreno }\end{array}$ & Clima & Total & Wj \\
\hline Vías de Acceso & $\mathrm{x}$ & $\mathbf{1}$ & $\mathbf{1}$ & $\mathbf{1}$ & $\mathbf{3}$ & $\mathbf{0 . 4 2 8 5 7 1 4 3}$ \\
\hline Competencia & $\mathbf{0}$ & $\mathrm{x}$ & $\mathbf{1}$ & 1 & 2 & $\mathbf{0 . 2 8 5 7 1 4 2 9}$ \\
\hline $\begin{array}{l}\text { Disponibilidad } \\
\text { de terreno }\end{array}$ & $\mathbf{0}$ & $\mathbf{0}$ & $\mathrm{x}$ & $\mathbf{1}$ & $\mathbf{1}$ & $\mathbf{0 . 1 4 2 8 5 7 1 4}$ \\
\hline Clima & $\mathbf{0}$ & $\mathbf{0}$ & $\mathbf{1}$ & $\mathrm{x}$ & $\mathbf{1}$ & $\mathbf{0 . 1 4 2 8 5 7 1 4}$ \\
\hline Total & & & & & 7 & \\
\hline
\end{tabular}

Elaboración Propia

La escala usada para calificar los factores subjetivos es:

Tabla 3.10: Escala de calificación

\begin{tabular}{l|l}
\hline \multicolumn{2}{|c}{ Escala de Calificación } \\
\hline 1 & Malo \\
\hline 2 & Regular \\
\hline 3 & Bueno \\
\hline
\end{tabular}

Fuente: Manual para el diseño de instalaciones manufactureras y de servicios (2018)

Con la escala antes mencionada se procederá a hallar la puntuación de los factores subjetivos:

Tabla 3.11: Puntuación de factores subjetivos

\begin{tabular}{l|l|l|l|l|l|l|l|l}
\hline Localidad & $\begin{array}{l}\text { Vías de } \\
\text { Acceso }\end{array}$ & Rij & Competencia & Rij & $\begin{array}{l}\text { Disponibilida } \\
\text { d de terreno }\end{array}$ & Rij & Clima & Rij \\
\hline Moyobamba & 3 & 0.5 & 2 & 0.4 & 3 & 0.428 & 2 & 0.285 \\
\hline Tocache & 2 & 0.3 & 1 & 0.2 & 2 & 0.285 & 3 & 0.428 \\
\hline $\begin{array}{l}\text { Mariscal } \\
\text { Cáceres }\end{array}$ & 1 & 0.17 & 2 & 0.4 & 2 & 0.285 & 2 & 0.285 \\
\hline & 6 & & 5 & & 7 & & 7 & \\
\hline
\end{tabular}

Elaboración Propia 
Tabla 3.12: Valor relativo de los factores subjetivos

\begin{tabular}{|c|c|}
\hline F. Moyobamba & 0.43061224 \\
\hline F. Tocache & 0.30204082 \\
\hline F. Mariscal Cáceres & 0.26734694 \\
\hline
\end{tabular}

Elaboración Propia

Se considera que los Factores objetivos son 3 veces más importantes que los Subjetivos, por lo que la constate $\mathrm{K}$ será igual a:

$$
\begin{gathered}
k=3(1-k) \\
k=0.75
\end{gathered}
$$

Con el dato K, se hallará las medida de preferencia de la localización

Tabla 3.13: Medida de preferencia de la localización

\begin{tabular}{|c|c|}
\hline MPL Moyobamba & $\mathbf{0 . 3 1 9 7 5 8 8 9}$ \\
\hline MPL Tocache & $\mathbf{0 . 3 5 1 1 0 3 8 2}$ \\
\hline MPL Mariscal Cáceres & $\mathbf{0 . 3 2 9 1 3 7 2 9}$ \\
\hline
\end{tabular}

Elaboración Propia

De acuerdo al Método de Brown Gibson, la alternativa elegida es la provincia de Tocache, por poseer el mayor valor de preferencia. 


\section{CAPÍTULO IV: TAMAÑO DE PLANTA}

Una vez determinada la ubicación de la planta, se deberá realizar un comparativo entre tamaño de planta con el mercado, recurso productivo, tecnología y punto de equilibrio para determinar las correctas dimensiones que debe de tener la planta.

\subsection{Relación tamaño - mercado}

La relación tamaño - mercado nos ofrece información esencial para evaluar cuál es el tamaño máximo que debe tener nuestra planta. Es importante que esté dentro de las especificaciones del tamaño óptimo, ya que de no ser así, se estaría produciendo más de lo que se demanda y esto generaría un exceso de cacao fino que se acumularía como stock no utilizado y la calidad se deterioraría por el tiempo que esté en espera del próximo pedido. Se tomó como referencia la demanda de cacao fino del 2024, el último año proyectado para el proyecto. A continuación se muestran las demandas proyectadas para los próximos cinco años.

Tabla 4.1: Demanda del proyecto

\begin{tabular}{|l|l|}
\hline Año & $\begin{array}{l}\text { Demanda del } \\
\text { proyecto (sacos } \mathbf{6 0} \\
\text { kg) }\end{array}$ \\
\hline $\mathbf{2 0 2 0}$ & 8,837 \\
\hline $\mathbf{2 0 2 1}$ & 9,550 \\
\hline $\mathbf{2 0 2 2}$ & 10,263 \\
\hline $\mathbf{2 0 2 3}$ & 10,977 \\
\hline $\mathbf{2 0 2 4}$ & 11,689 \\
\hline
\end{tabular}

Con las demandas de la proyección de la tabla 4.1, se llega a la conclusión que el tamaño máximo de nuestra planta debe tener una capacidad de producción de 11,689 sacos de cacao fino al año. 


\subsection{Relación tamaño-recurso productivo}

Esta relación busca establecer la disponibilidad de los factores productivos como la mano de obra, agua, energía, materia prima, entre otros. Con ello se busca determinar si alguno de los factores productivos limita el tamaño de planta.

En cuanto al abastecimiento de energía y agua, factores muy importantes para la producción de cacao, no existe limitantes. Se sabe que, Tocache cuanta con SIALTOCACHE empresa abastecedora de Agua potable y ETOSA o ELOR como empresas abastecedoras de energía eléctrica; ambas empresas trabajan de manera continua por lo cual no genera limitación.

En San Martin, existe suficiente PEA sin laborar que puede ser atraída por el trabajo generado en la planta productora de cacao. Razón por la cual la disponibilidad de mano de obra no representa un factor limitante en la producción.

En cuanto a la materia prima se debe tener en cuenta la producción de mazorcas de cacao en el departamento de San Martin. Como se mencionó anteriormente, en el capítulo 2.4.1.5, San Martin produce el $43 \%$ de mazorcas de Cacao a nivel nacional. Al dato anterior, cabe destacar que la tasa de producción del mismo (mazorcas de cacao) desde el año 2000 hasta el 2018, ha tenido una tendencia positiva no menor a 2.3\%. Como puede verse a continuación según datos del INEI y el MINAGRI, la producción de cacao está muy por encima de las exportaciones actuales, por lo que la relación TamañoDemanda, por lo tanto no representa una restricción para el tamaño de planta. 
Figura 4.1: Exportaciones vs producción nacional de cacao

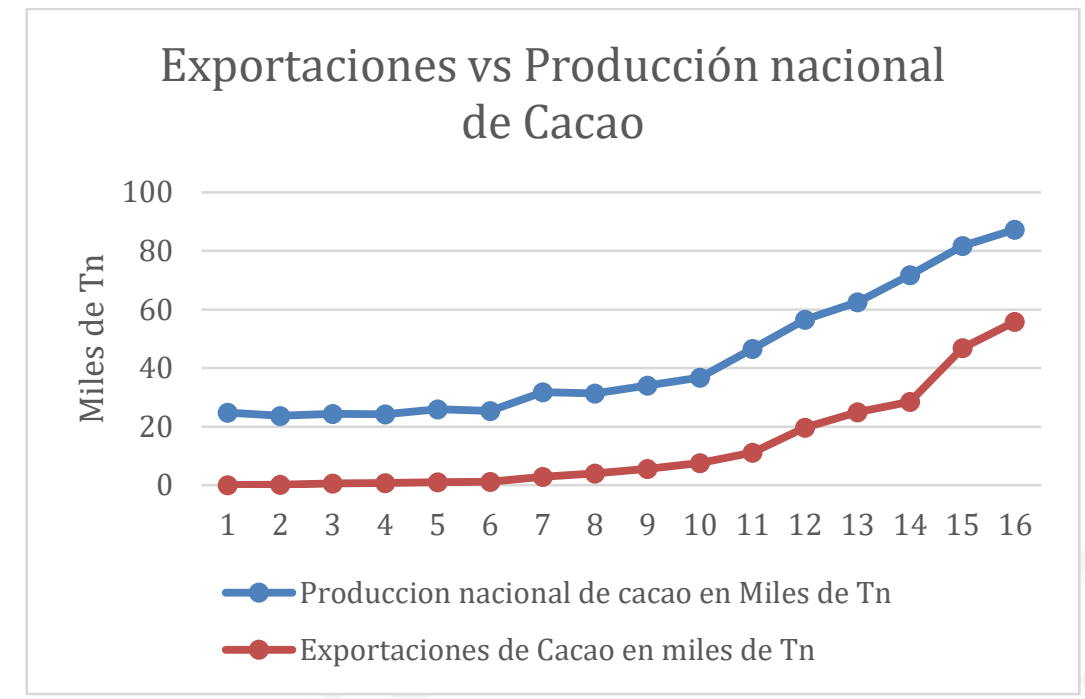

Fuente: INEI (2015), MINAGRI (2016)

\subsection{Relación tamaño-tecnología}

En este punto se analizó la capacidad de producción de cada uno de los procesos que intervienen en la elaboración de cacao fino. La capacidad instalada de la planta será dada por el cuello de botella. Como se determinó en el punto 5.4.2, cálculo de capacidad instalada, la actividad cuello de botella es la fermentación con una capacidad de producto terminado de 11,412 sacos de cacao. Sin embargo al retirarle la utilización y eficiencia el valor real es de 15,431 sacos. Por lo que, esta relación no representa una limitación ya que cubre la demanda del proyecto hasta el año 5.

\subsection{Relación tamaño punto de equilibrio}

En este punto hallaremos la producción mínima que debería generar la planta para ser rentable. Se utilizara la fórmula:

$$
\text { Punto de Equilibrio }=\frac{\text { Costo Fijo }}{\text { Precio Unitario }- \text { Costo Variable Unitario }}
$$

Los costos variables estarán conformados por la materia prima e insumos, el uso de agua y el costo de la electricidad. Por otro lado, los Costos Fijos incluyen los CIF, la MOD y los gastos Operativos. Todos los cálculos y precios utilizados para determinar el punto de equilibrio, se encuentran detallados en el capítulo 7. 
Tabla 4.2: Costos fijos, variable y precio unitario

\begin{tabular}{c|r|l}
\hline Costo Fijo & $1,974,280.70460321$ & soles \\
\hline Costo variable & 1.101443139 & soles $/ \mathrm{kg}$ \\
\hline Precio unitario & 8.16 & soles $/ \mathrm{kg}$ \\
\hline
\end{tabular}

Elaboración Propia

Tabla 4.3: Punto de equilibrio

\begin{tabular}{c|r|l}
\hline Punto de Equilibrio (kg) & $279,700.33$ & $\mathrm{~kg}$ \\
\hline Punto de Equilibrio (sacos) & 4,662 & $\mathrm{sacos}$ \\
\hline
\end{tabular}

Elaboración Propia

\subsection{Selección del tamaño de planta}

Como puede observarse, el tamaño de planta se encuentra limitada por la relación tamaño-mercado con 11,689 sacos de cacao de $60 \mathrm{~kg}$.

Tabla 4.4: Resumen tamaño de planta

\begin{tabular}{c|r}
\hline Relación & \multicolumn{1}{|c|}{$\begin{array}{c}\text { Sacos }(60 \\
\mathrm{kg}) / \mathrm{AN} O\end{array}$} \\
\hline Tamaño-Mercado & 11,689 \\
\hline Tamaño - Recurso Productivo & $1,623,922$ \\
\hline Tamaño - Tecnología & 15,431 \\
\hline Punto de Equilibrio & 4,662 \\
\hline
\end{tabular}

Elaboración Propia 


\section{CAPÍTULO V: INGENIERÍA DEL PROYECTO}

En el presente capítulo, se detallarán las especificaciones del producto, junto a su proceso de producción, para determinar la productividad del proyecto, respetando las normas de calidad solicitadas por los clientes. También, se determinarán las máquinas que formarán parte del proceso productivo, la capacidad instalada de cada estación de trabajo para obtener los operarios necesarios en el proceso y fuera de él, junto a los mantenimientos preventivos respectivos de las máquinas.

Por otro lado, se evaluará la matriz de calidad HACCP, la matriz de seguridad y salud ocupacional y el análisis ambiental mediante la matriz de Leopold. También, se determinará el plan maestro de producción y la disposición de planta para obtener las medidas de la planta y el flujo del proceso productivo.

\subsection{Definición técnica del producto}

\subsubsection{Especificaciones técnicas, composición y diseño del producto}

El grano de cacao es un fruto de color café y aroma agradable y con sabor amargo, con ligeras líneas dulces. Según Machu Picchu Foods S.A.C., empresa comercializadora de productos elaborados de cacao, este producto debe cumplir con las siguientes características físicas, químicas y organolépticas para cumplir con los estándares de calidad mundial. 
Tabla 5.1: Principales características del grano de cacao

\begin{tabular}{|c|c|}
\hline Característica & Requisitos de concentración (\%) \\
\hline Física & $\begin{array}{l}\text { Impurezas: } 2 \% \text { máx. } \\
\text { Mohos: } 5 \% \text { máx. } \\
\text { Fermentados: } 65 \% \text { min. } \\
\text { Violáceas: } 23 \text { máx. } \\
\text { Pizarrosos: } 7 \% \text { máx. } \\
\text { Daños por insectos: Ausencia } \\
\text { Múltiple: } 1 \% \\
\text { Humedad del grano: } 7.5 \% \text { máx. }\end{array}$ \\
\hline Química & $\begin{array}{l}\text { Plomo: < } 1 \mathrm{ppm} \\
\text { Alfatoxinas: } 10 \text { pbb máx. }\end{array}$ \\
\hline Organoléptica & Olor: Libres de olores extraños y desagradables \\
\hline Sensoriales & $\begin{array}{l}\text { Color: Marrón oscuro con variaciones de tonalidad. } \\
\text { Textura: Grano seco } \\
\text { Aroma: Grano amargo }\end{array}$ \\
\hline
\end{tabular}

Fuente: Machu Picchu Foods S.A.C. (2014)

El producto se comercializará en sacos de yute de $60 \mathrm{~kg}$, el cual llevará el logo de la empresa ByT S.R.L., número de lote y la fecha de ensacado. Se eligió este material para el ensacado ya que se adquiere a un costo bajo y brinda la resistencia necesaria para comercializar $60 \mathrm{~kg}$ del producto de forma segura, además de ser reciclables y biodegradables. Una de las ventajas principales de utilizar sacos de yute es que tiene propiedades aislantes, antiestáticas y una moderada retención de la humedad (Los costales de yute, opción ecológica ideal en la industria del empaque, 2013). Actualmente existe un marco regulatorio para el cacao. A continuación, se visualizan las principales Normas Técnicas Peruanas (NTP) relacionadas con la producción de cacao en grano. 
Tabla 5.2: Principales NTPs relacionadas al grano de cacao

\begin{tabular}{|l|l|}
\hline Norma & \multicolumn{2}{l}{ Resumen } \\
\hline NTP-ISO 2451:2016 & $\begin{array}{l}\text { Establece los requisitos, métodos de ensayo, } \\
\text { clasificación, muestreo, envasado y rotulado para los } \\
\text { granos de cacao. También recomienda técnicas de } \\
\text { almacenamiento y desinfección. }\end{array}$ \\
\hline NTP-ISO 1114:2016 & $\begin{array}{l}\text { Describe a detalle la prueba de corte para los granos de } \\
\text { cacao. }\end{array}$ \\
\hline NTP-ISO 2291:2016 & $\begin{array}{l}\text { Especifica el método de rutina para la determinación del } \\
\text { contenido de humedad de los granos de cacao. }\end{array}$ \\
\hline NTP-ISO 2292:2016 & Brinda los estándares óptimos de calidad y especifica el \\
muestreo de granos de cacao envasados en sacos como \\
indica la NTP-ISO 2451:2016. \\
\hline NTP $208.017: 2015 / C O R$ & $\begin{array}{l}\text { Analiza el método gravimétrico para la determinación } \\
\text { de la humedad del grano de cacao. }\end{array}$ \\
\hline
\end{tabular}

Fuente: Centro de Información y Documentación, CID - Instituto Nacional de Calidad, INACAL (2019)

\subsubsection{Marco regulatorio para el producto}

Dentro del marco legal para la producción del cacao fino, se evalúan regulaciones obligatorias, tanto de comercio exterior como peruanas. Entre ellas están:

- La certificación HACCP: Sistema de gestión que asegura un producto higiénico y seguro, requerido por varios países del mundo para importaciones.

- El certificado de origen: Documento que acredita a un país, en este caso Perú, exportar correctamente un producto.

- Licencia de funcionamiento de una planta industrial: Es la autorización que brinda la municipalidad de Tocache para poder operar una planta industrial de cacao fino en grano en aquella zona.

Al cumplir con estas normas legales, se formalizará el proceso de producción y exportación, permitiendo satisfacer a los clientes con un grano de cacao fino de alta calidad, apta para el consumo mundial. 


\subsection{Tecnologías existentes y procesos de producción}

\subsubsection{Naturales de la tecnología requerida}

Existen diversos procesos para elaborar cacao fino de los cuales el grado de automatización del proceso depende del método que se seleccione. Puede ser totalmente manual donde no intervenga en lo absoluto las máquinas y semiautomatizada, donde parte del proceso sea realizado manualmente, como la limpieza inicial de la almendra cuando se separa del mucilago o el corte de las mazorcas para extraer su contenido (cacao envuelto en mucílago) dejando el resto del proceso a máquinas especializadas para el corte, limpieza final de la almendra y el secado de la misma.

A continuación se describirá brevemente los métodos utilizados en la producción de cacao fino.

\subsubsection{Descripción de las tecnologías existentes}

En primer lugar, para el proceso de fermentación del cacao se cuenta con los siguientes métodos:

\section{a. Fermentación en montón:}

Esta actividad aunque muy rustica, es utilizada por algunos agricultores para realizar el proceso de fermentación. Este procedimiento consiste, en colocar una superficie sobre el suelo, generalmente se usan hojas de plátano, para evitar el contacto de la almendra con posibles bacterias presentes en el piso. Posteriormente es dejada por un lapso de 5-6 días, hasta que culmine la fermentación. 
Figura 5.1: Fermentación en montón

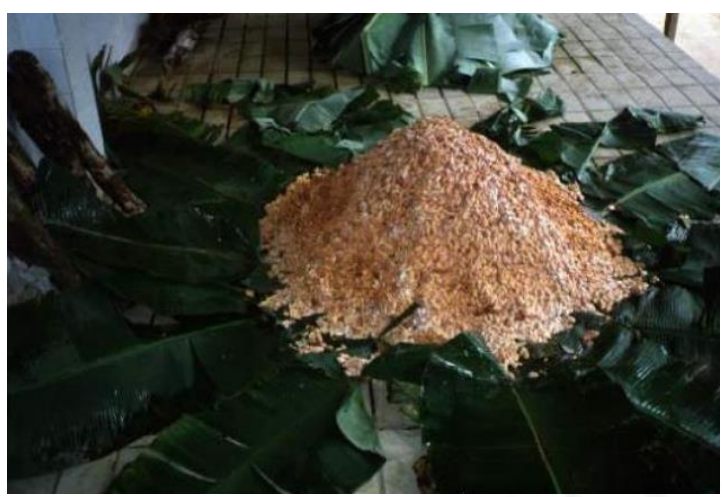

Fuente: Cacao Móvil (2016)

\section{b. Fermentado en canastos:}

Este proceso es muy parecido al anterior; con la diferencia que el cacao con mucilago es depositado en canastos, y posteriormente cubiertas con hojas de plátano, para permitir el ingreso de oxígeno y la fermentación siga su proceso natural.

Figura 5.2: Fermentación en canastos

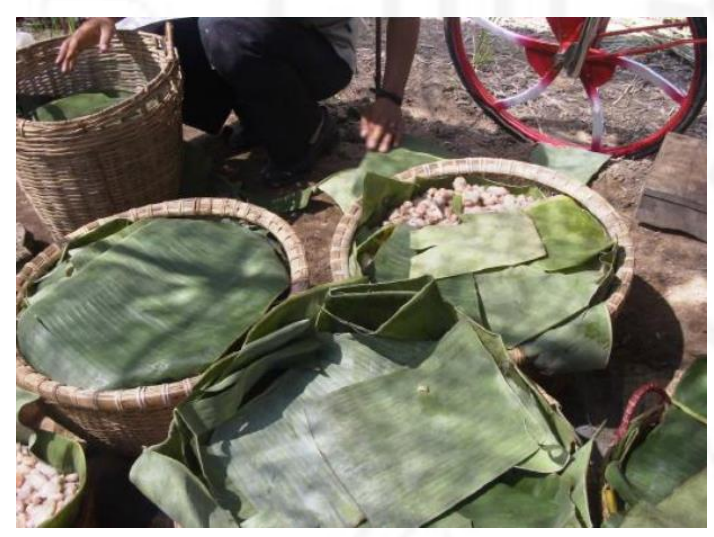

Fuente: Cacao Móvil (2016)

\section{c. Fermentación en cajones de cascada.}

Este procedimiento consiste en depositar el cacao con mucilago en cajones de dimensiones variables de ancho y largo, pero con una altura no mayor a $90 \mathrm{~cm}$. Para así, evitar que las almendras depositadas en la parte inferior se aplasten y rompan durante el proceso de fermentado. Este método permite tener una fermentación más uniforme, ya 
que debido a su distribución, permite pasar las almendras a las siguientes cajas ubicadas delante de ellas moviendo al cacao fermentado de posición, permitiendo que el cacao que se encuentra en la zona central de la caja y cuya fermentación es más avanzada debido al calor proporcionado durante la fermentación por las almendras que se ubicaban a su alrededor, parase ahora a la parte superior y las almendras de la parte superior pasen ahora al centro para continuar así el fermentado.

Figura 5.3: Fermentación en cajones de cascado

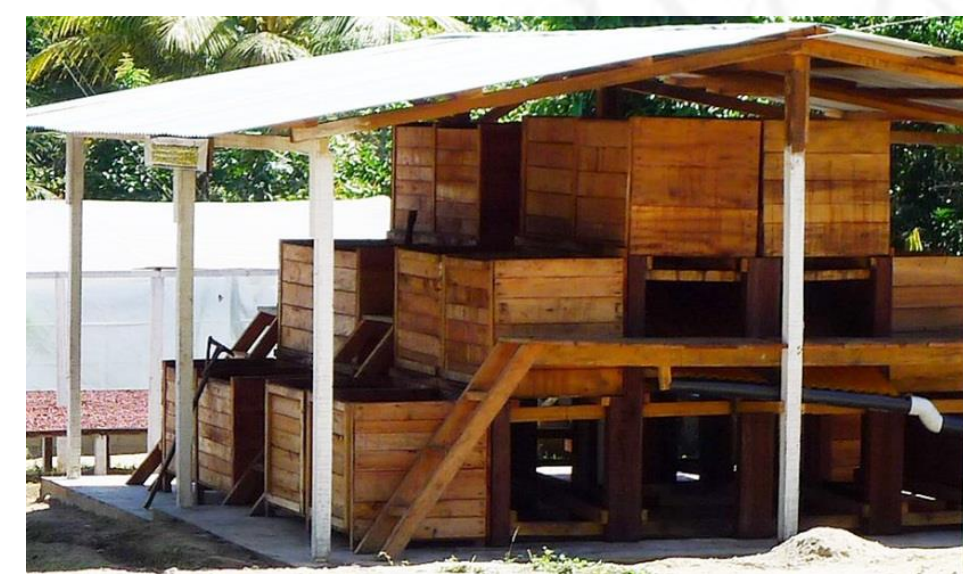

Fuente: Cacao Móvil (2016)

En segundo lugar, para el secado de los granos se cuenta con la siguiente tecnología:

\section{a) Secado con aire contracorriente:}

Este procedimiento consiste en secar un material mediante el uso de un aire caliente, que circula de abajo hacia arriba y suspendiendo el material de arriba hacia abajo. El aire caliente absorbe la humedad del producto a secar, saliendo por un extremo el material seco y por el otro un aire húmedo.

\section{b) Secado solar:}

Este método de secado consta en dejar reposar los granos de cacao fino en un ambiente abierto, el cual recibirá calor solar y viento según el día. 


\subsubsection{Selección tecnológica}

\section{A) Fermentación:}

Si bien es cierto que los métodos utilizados actualmente para la fermentación de cacao en Perú dan muy buenos resultados, la falta de control y estandarización son un problema que deben solucionarse. Por este motivo se plantea la implementación de sensores de temperatura dentro de los fermentadores, para analizar el comportamiento exotérmico en los procesos y estandarizar el comportamiento del mismo durante esta actividad.

A continuación se explicará el método de fermentación seleccionado para el cacao fino.

En primer lugar, se descartó la fermentación en montón ya que, mantener la almendra con el mucilago a la intemperie, ocasiona que muchas bacterias e insectos en el ambiente puedan disminuir la calidad del producto al depositarse sobre la pila de cacao, degradando el producto y en ocasiones infectándolos con mohos o bacterias que dañarían el lote completo.

En segundo lugar, el método de fermentación en canastas, parece una opción viable, sin embargo las dimensiones que posee el contenedor no son muy amplias ni lo suficiente mente resistentes para poder apilar más de 2 canastos ya que, cederían los contenedores ocasionado que las almendra de su interior caigan. A su vez implementar censores en canastas no parece ser muy adecuado, ya que estos elementos son muy sensibles y estar dentro de canasto no permite mantener en buen estado al elemento.

Finalmente, se escogió el método de fermentación por cajones en cascada, gracias a los beneficios que proporciona como la uniformización del fermentado (Lutheran World Relief, 2016), y proporciona un ambiente adecuado para implantar sensores de temperatura para monitorear constantemente el estado de fermentación de cada lote de producción. Esto nos ayudará a uniformizar el proceso determinado las temperaturas adecuadas antes de realizar el movimiento de las almendras y saber en qué momento debe de realizarse, para así mantener la calidad del producto y estandarizar los tiempos de fermentación para el cacao fino proveniente de San Martin. 


\section{B) Secado:}

Finalmente, se optó por utilizar el método de secado con aire en contracorriente ya que permite obtener almendras de cacao con $7 \%$ de humedad, característica idónea para mantener la calidad del producto, y al mismo tiempo, el lapso que demora obtener un producto seco libre de humedad es hasta diez veces menos que si los granos de cacao fino se dejaran reposar en un ambiente abierto esperando calor solar y viento. Otro beneficio del secado con aire en contracorriente es que el producto final mantiene todas las características (humedad, textura, aroma, sabor) que requieren los clientes para cumplir con los estándares de calidad exigidos. También, este proceso es uniforme, ventila y seca al mismo tiempo los granos, con un consumo mínimo de energía eléctrica y una rápida instalación de la máquina.

\subsubsection{Proceso de producción:}

\subsubsection{Descripción del proceso:}

a) Seleccionar: El proceso de producción de granos de cacao fino inicia con la selección manual de semillas.

b) Lavar: Luego, se limpian las semillas, eliminando impurezas a través del enjuague. El agua de lavado será transportada al biodigestor.

c) Plantar: En seguida, se procede a plantar la semilla, colocándola en almácigos con sustrato previamente mezclado y seleccionado para evitar la presencia de cadmio en el suelo.

d) Injertar: Luego de que el cacao tenga tamaño suficiente, se corta el tallo y se injerta sobre un brazo maduro, proveniente de un cacao en etapa adulta. Con esto se reduce el tiempo de crecimiento del cacaotal, brindando características resistentes a enfermedades provenientes de la planta adulta. 
e) Sembrar: Luego del injerto, se debe esperar entre dos a tres meses para plantar el cacao en tierra fértil. Durante los primeros años, se producirán cantidades pequeñas pero con tendencia positiva, hasta llegar a la producción máxima en el quinto año.

f) Deshierbar: Esta actividad debe realizarse mensualmente para retirar las hierbas que crezcan alrededor del cacao que extraen los nutrientes del suelo. La maleza que se retire será transportada al biodigestor.

g) Podar: Esta actividad debe de realizarse cada dos meses con la finalidad de permitir el ingreso del sol a las plantaciones para poder evitar que la humedad del ambiente genere hondos en las plantas, lo cual permitirá un mejor flujo de aire en las plantaciones. Las ramas que se retiren serán transportadas al biodigestor.

h) Abonar: Se colocará abono en el suelo para brindarle más nutrientes al cacaotal, permitiéndole aumentar su desarrollo y productividad y a prevenir la presencia de enfermedades.

i) Controlar: Se controlará la calidad de la plantación antes de iniciar el proceso de cosecha.

j) Cosechar: Se recolectan las mazorcas de cacao del propio cultivo y la demanda restante de agricultores seleccionados. Se seleccionarán las mazorcas cuya maduración sea la óptima, transportando las defectuosas al biodigestor.

k) Cortar: Esta etapa se realiza luego de que haya finalizado la cosecha de las mazorcas en buen estado. Se utilizará una máquina cortadora industrial cuya capacidad es de $1000 \mathrm{~kg} / \mathrm{hr}$. El corte es un proceso por el cual se abre la mazorca, dejando expuesto el fruto interior al ambiente para que el aire que ingresa al cacao con mucílago, logre degradar los azúcares y elimine esta baba. Este proceso debe de realizarse máximo durante los tres días posteriores a la cosecha, puesto que, si se excede este tiempo, se iniciará la degradación del 
fruto dentro de la mazorca, generando un mal olor y pérdida de calidad del producto. La cáscara de la mazorca se transporta al biodigestor.

1) Limpiar: Inmediatamente después del cortado, se procede a limpiar la almendra de cacao con agua para evitar que la fermentación de los azúcares dañe el producto. Se utilizará una máquina de lavado por inmersión con capacidad $1000 \mathrm{~kg} / \mathrm{hr}$. Se retirarán efluentes llenos de mucílago y pedazos de mazorca, los cuales serán transportados al biodigestor.

m) Escurrir: Finalizada la limpieza de las almendras de cacao, estas son ingresadas a sacos de yute, en donde reposarán una noche. Este proceso eliminará hasta el $15 \%$ de peso en agua del excedente de efluentes con mucílago, los cuales serán transportados al biodigestor.

n) Fermentar: En esta etapa, ingresan las almendras a los fermentadores de cajón (madera) ubicados en cascada, iniciando por la parte superior hacia los cajones inferiores cada día. Es de vital importancia monitorear la temperatura de las almendras para determinar cuándo se necesita realizar el movimiento del producto.

Figura 5.4: Cajones en cascada

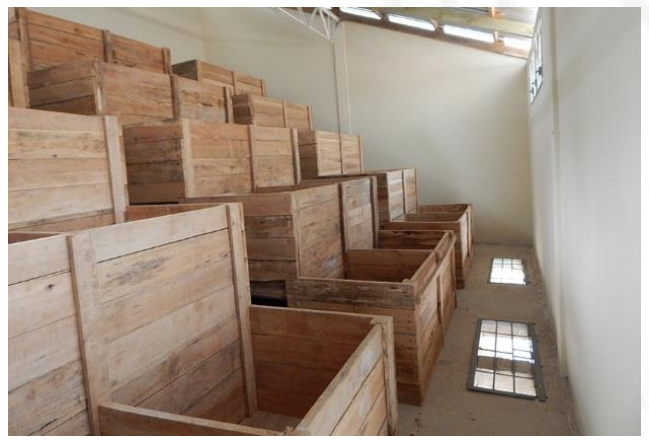

Fuente: Cacao Móvil (2016)

Cabe resaltar que estos cajones deben ubicarse en una área ventilada y mantenerlas dentro de esas instalaciones por un periodo de entre 5-6 días o hasta que la almendra fermente completamente. La fermentación sucede cuando la semilla está bien hinchada y la cáscara se desprende con facilidad; 
el color de la almendra debe ser marrón intenso y desprendiendo un olor agradable.

La temperatura a controlar durante este proceso se especifica a continuación en el cuadro siguiente:

Figura 5.5: Temperaturas de fermentación por día

\begin{tabular}{|c|c|c|c|c|c|}
\hline \multicolumn{1}{|c|}{ Día 1 } & Día 2 & Día 3 & Día 4 & Día 5 & Día 6 \\
\hline $\begin{array}{l}\text { 36 grados } \\
\text { centígrados }\end{array}$ & $\begin{array}{c}40 \text { grados } \\
\text { centígrados }\end{array}$ & $\begin{array}{c}49 \text { grados } \\
\text { centígrados }\end{array}$ & $\begin{array}{c}49.8 \text { grados } \\
\text { centígrados }\end{array}$ & $\begin{array}{c}46 \text { grados } \\
\text { centígrados }\end{array}$ & $\begin{array}{c}45.5 \text { grados } \\
\text { centígrados }\end{array}$ \\
\hline
\end{tabular}

Fuente: Cacao Móvil (2016)

o) Lavar: Luego del fermentado, se inicia el lavado de las almendras de cacao para eliminar por completo las impurezas presentes. Este proceso entrará agua y se realizará en una lavadora industrial con capacidad de $1000 \mathrm{~kg} / \mathrm{hr}$. La merma se transportará al biodigestor.

p) Secar: En el secado, se utilizará $5.94 \mathrm{~kW}$ por día las almendras perderán agua que aún estén presentes por la causa del lavado previo. Esta actividad se realizará utilizando una secadora industrial con capacidad de $150 \mathrm{~kg} / \mathrm{hr}$, reduciendo el peso hasta en un 38\%. Las almendras defectuosas serán transportadas al biodigestor.

q) Seleccionar: Posteriormente, las almendras pasan por un proceso de tamizado para eliminar las defectuosas o con hongos. Para ello, se utilizan mallas colocadas en serie, por donde pasarán las almendras. Las almendras defectuosas serán transportadas al biodigestor.

r) Ensacar: Finalmente, se ensacan los granos de cacao fino, utilizando sacos de yute de $60 \mathrm{~kg}$. Este proceso utilizará una máquina ensacadora de $80 \mathrm{sacos} / \mathrm{hr}$. Luego, el producto terminado será transportado al almacén de producto terminado. 


\subsubsection{Diagrama de operaciones del proceso de producción para cacao}

Figura 5.6: DOP de producción para cacao

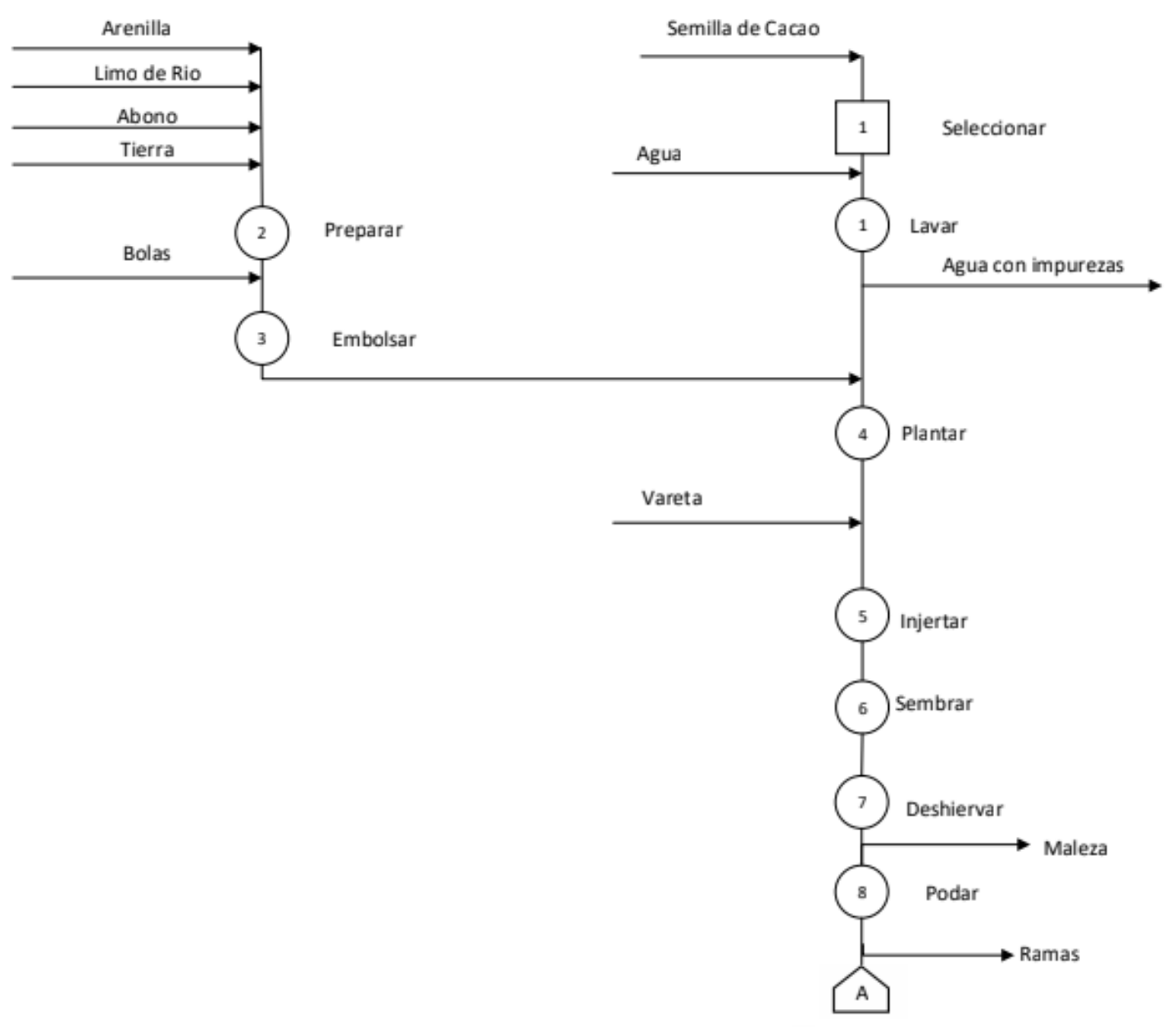


(continuación)

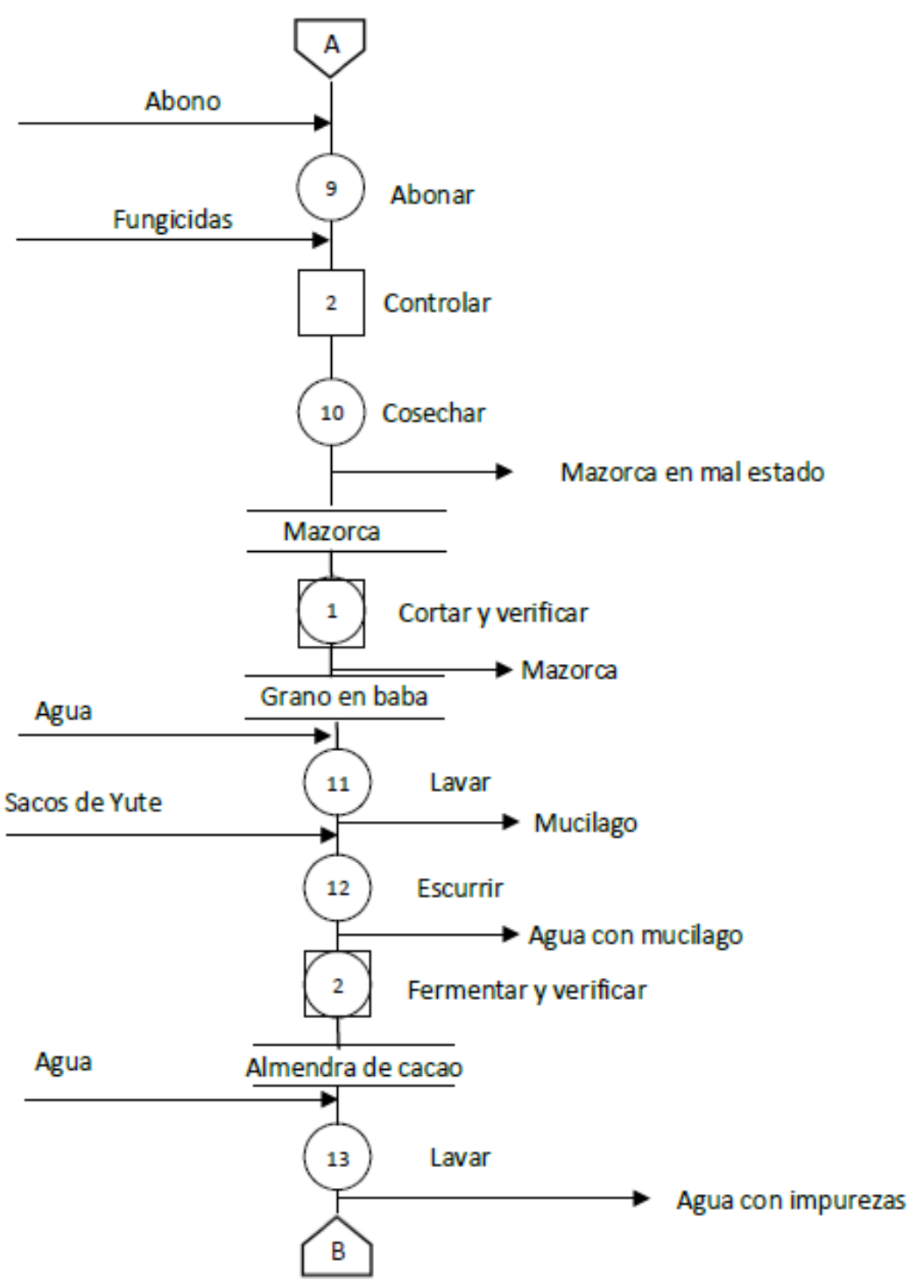

(continúa) 
(continuación)

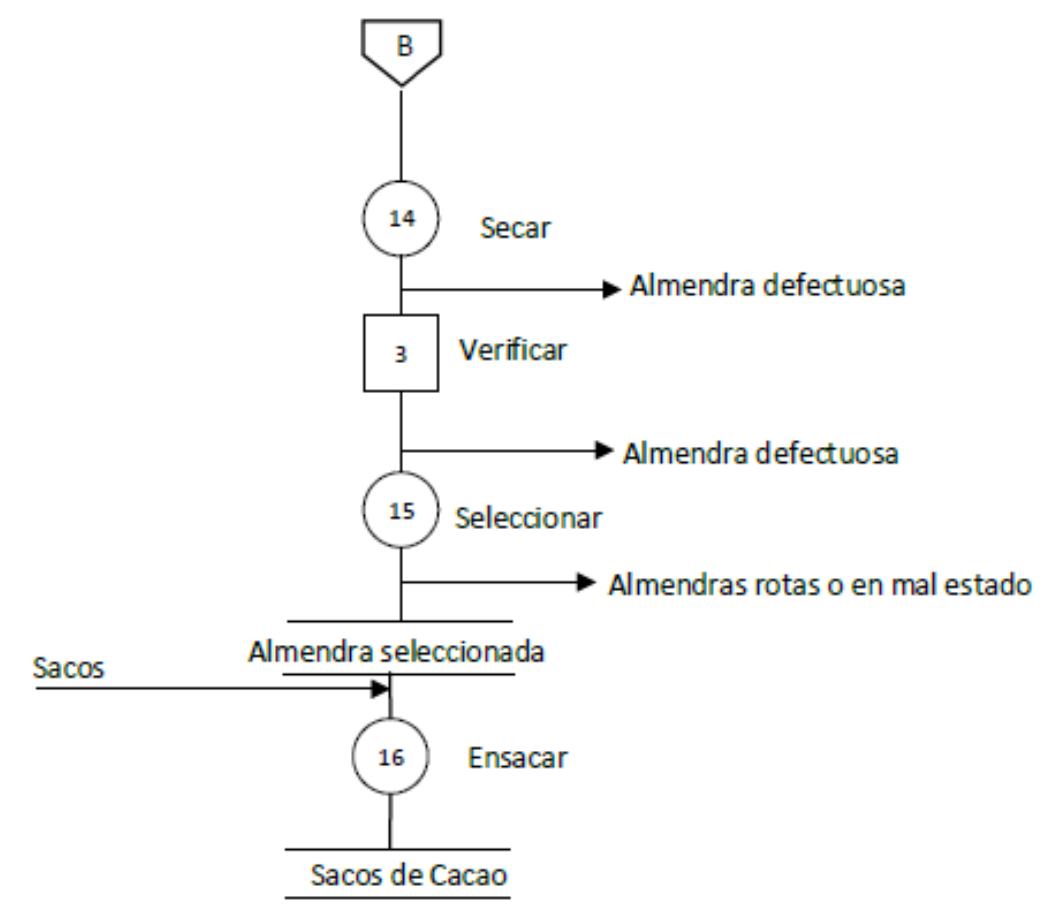

\begin{tabular}{|c|c|}
\hline \multicolumn{2}{|c|}{ Resumen de actividades } \\
\hline Actividad & Cantidad \\
\hline Operación & 16 \\
\hline Inspección & 3 \\
\hline Operación con inspección & 2 \\
\hline Total & 21 \\
\hline
\end{tabular}

Elaboración Propia 


\subsubsection{Balance de materia para el mes de Agosto 2024}

Figura 5.7: Balance de materia

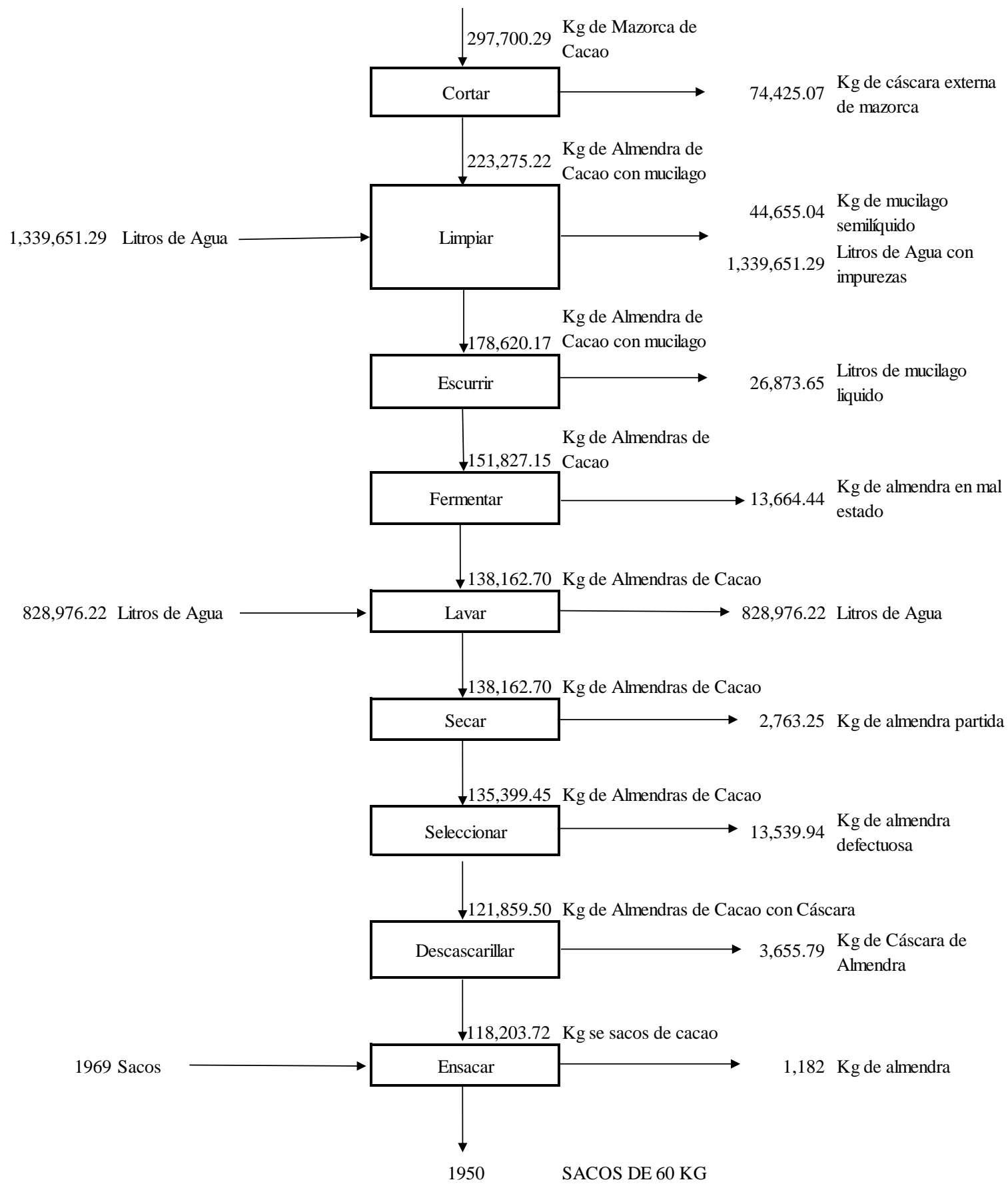

Elaboración Propia 


\subsubsection{Balance de energía}

$$
\Delta H+\Delta \bar{k}_{q}+\Delta E_{0}=Q-\not \underbrace{}_{0}
$$

$$
\Delta H=Q \quad \mathrm{Q}=4,852 \mathrm{kCal} / \mathrm{hr}=5.64 \mathrm{~kW} / \mathrm{hr}
$$

$$
Q=m * C_{e} *\left(T_{2}-T_{1}\right)
$$

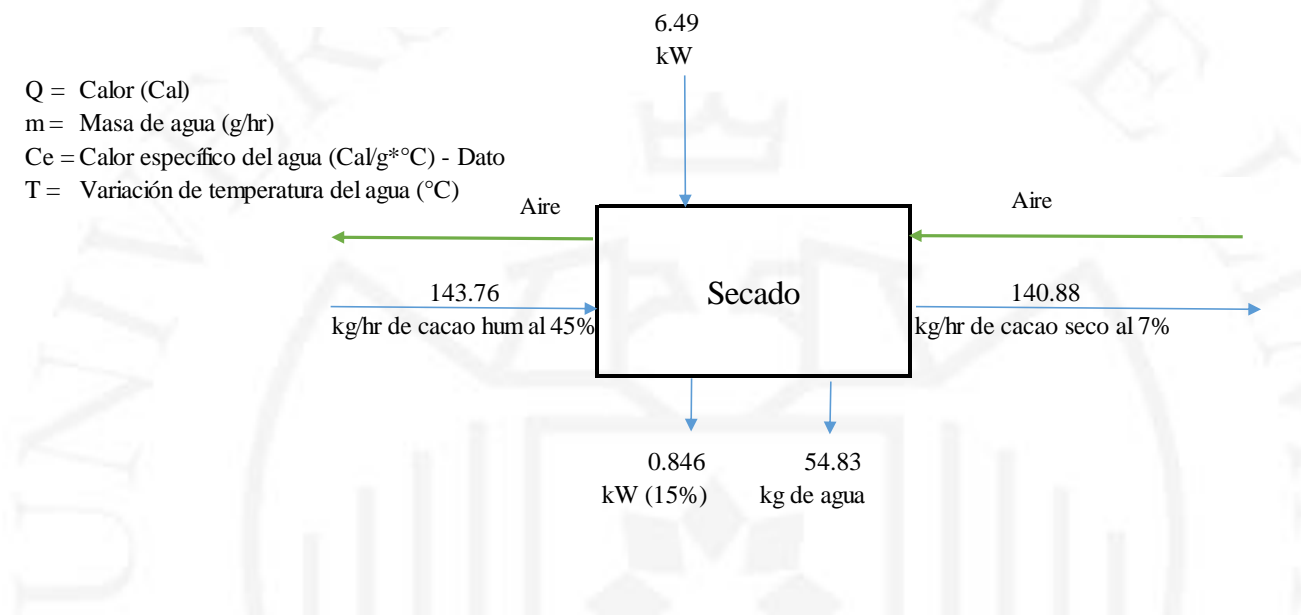

Para hallar la cantidad de $\mathrm{kW}$ necesarios para secar los granos de cacao, primero se eligió la cantidad de kg de cacao en grano que ingresan al secador. Se consideró el balance de materia del quinto año, ya que, sería el mayor flujo que ingresaría al secador en la vida útil del proyecto en análisis. Convirtiendo $828,043.39 \mathrm{~kg} /$ año a kg/hr, considerando 16 hrs laborables al día, se obtuvo $143.76 \mathrm{~kg} / \mathrm{hr}$. Utilizando la fórmula general de balance de energía, se requerirán 5.64 KWh para poder secar los $143.76 \mathrm{~kg}$ de cacao húmedo al 45\%. Al balance, ingresan $64.69 \mathrm{~kg}$ de agua, el cual mediante el proceso de secado se eliminan $54.83 \mathrm{~kg}$, obteniendo la almendra seca al $7 \%$ de humedad. A su vez, cabe mencionar que el agente térmico usado para el proceso será aire en contracorriente. 


\subsection{Características de las instalaciones y equipos}

\subsubsection{Selección de la maquinaria y equipos}

A continuación, se presentan las máquinas requeridas para la producción de cacao fino.

Tabla 5.3: Especificaciones de las actividades semi-automáticas y automáticas

\begin{tabular}{l|l}
\hline Actividad & Maquinaria \\
\hline Cortar & Máquina despulpadora de cacao \\
\hline Limpiar & Máquina lavadora por inmersión \\
\hline Lavado & Máquina lavadora por inmersión \\
\hline Secar & Máquina secadora de granos automática \\
\hline Seleccionar & Máquina de selección de granos por tamaño y condición \\
\hline Descascarillar & Máquina peladora de cacao \\
\hline Ensacar & Máquina ensacadora de cacao \\
\hline
\end{tabular}

Elaboración Propia

Para el sub-proceso de secado, se compararon dos máquinas de Tecnatrop SRL. Por un lado, se analizó la máquina secadora de granos automática y por el otro lado, se consideró la máquina. 


\subsubsection{Especificaciones de la maquinaria}

Tabla 5.4: Especificaciones técnicas de la máquina despulpadora de cacao

\begin{tabular}{l|l|l|}
\hline Máquina & Máquina despulpadora de cacao \\
\hline Marca & PREMIER TECH CHRONOS & \\
\hline Modelo & PTH -850 & \\
\hline $\begin{array}{l}\text { Capacidad } \\
\text { (Kg/Hr) }\end{array}$ & Hasta 1000 & \\
\hline $\begin{array}{l}\text { Alto } \\
\text { (Metros) }\end{array}$ & 1.85 & \\
\hline $\begin{array}{l}\text { Ancho } \\
\text { (Metros) }\end{array}$ & 1.75 & \\
\hline $\begin{array}{l}\text { Largo } \\
\text { (Metros) }\end{array}$ & 2.58 & \\
\hline
\end{tabular}

Fuente: Premier Tech-Chronos (2018)

Tabla 5.5: Especificaciones técnicas de la máquina lavadora por inmersión

\begin{tabular}{l|l|}
\hline Máquina & Máquina lavadora por inmersión \\
\hline Marca & CITALSA \\
\hline Modelo & LIA1 \\
\hline $\begin{array}{l}\text { Capacidad } \\
\text { (Kg/Hr) }\end{array}$ & Hasta 1000 \\
\hline $\begin{array}{l}\text { Alto } \\
\text { (Metros) }\end{array}$ & 1.74 \\
\hline $\begin{array}{l}\text { Ancho } \\
\text { (Metros) }\end{array}$ & 1.03 \\
\hline $\begin{array}{l}\text { Largo } \\
\text { Metros) }\end{array}$ & 2.23
\end{tabular}

Fuente: CI Talsa (2016) 
Tabla 5.6: Especificaciones técnicas de la máquina secadora de granos automática

\begin{tabular}{l|l|l|}
\hline Máquina & $\begin{array}{l}\text { Máquina secadora de granos } \\
\text { automática }\end{array}$ & \\
\hline Marca & TECNATROP SRL & \\
\hline Modelo & AS-45 & \\
\hline $\begin{array}{l}\text { Capacidad } \\
\text { (Kg/Hr) }\end{array}$ & Hasta 150 & \\
\hline $\begin{array}{l}\text { Alto } \\
\text { (Metros) }\end{array}$ & 2.46 & \\
\hline $\begin{array}{l}\text { Ancho } \\
\text { (Metros) }\end{array}$ & 2.32 & \\
\hline $\begin{array}{l}\text { Largo } \\
\text { Metros) }\end{array}$ & 2.65 & \\
\hline
\end{tabular}

Fuente: Tecnatrop (2018)

Tabla 5.7: Especificaciones técnicas de la máquina de selección de granos por tamaño y condición

\begin{tabular}{l|l|}
\hline Máquina & $\begin{array}{l}\text { Máquina de selección de granos } \\
\text { por tamaño y condición }\end{array}$ \\
\hline Marca & TECNATROP SRL \\
\hline Modelo & CM-15 \\
\hline $\begin{array}{l}\text { Capacidad } \\
\text { (Kg/Hr) }\end{array}$ & Hasta 150 \\
\hline $\begin{array}{l}\text { Alto } \\
\text { (Metros) }\end{array}$ & 2.30 \\
\hline $\begin{array}{l}\text { Ancho } \\
\text { (Metros) }\end{array}$ & 2.00 \\
\hline $\begin{array}{l}\text { Largo } \\
\text { (Metros) }\end{array}$ & 3.50 \\
\hline
\end{tabular}

Fuente: Tecnatrop (2018) 
Tabla 5.8: Especificaciones técnicas de la máquina peladora de cacao

\begin{tabular}{l|l|l|}
\hline Máquina & Máquina peladora de cacao & \\
\hline Marca & TECNATROP SRL & \\
\hline Modelo & DESC-100 & \\
\hline $\begin{array}{l}\text { Capacidad } \\
\text { (Kg/Hr) }\end{array}$ & Hasta 150 & \\
\hline $\begin{array}{l}\text { Alto } \\
\text { (Metros) }\end{array}$ & 2.00 & \\
\hline $\begin{array}{l}\text { Ancho } \\
\text { (Metros) }\end{array}$ & 1.76 & \\
\hline $\begin{array}{l}\text { Largo } \\
\text { (Metros) }\end{array}$ & 1.87 & \\
\hline
\end{tabular}

Fuente: Tecnatrop (2018)

Tabla 5.9: Especificaciones técnicas de la máquina ensacadora de cacao

\begin{tabular}{l|l|l}
\hline Máquina & Máquina ensacadora de cacao & \\
\hline Marca & BEGA \\
\hline Modelo & VALHEL-50 & \\
\hline $\begin{array}{l}\text { Capacidad } \\
\text { (Sacos/Hr) }\end{array}$ & Hasta 80 & \\
\hline $\begin{array}{l}\text { Alto } \\
\text { (Metros) }\end{array}$ & 1.70 & \\
\hline $\begin{array}{l}\text { Ancho } \\
\text { (Metros) }\end{array}$ & 0.82 & \\
\hline $\begin{array}{l}\text { Largo } \\
\text { (Metros) }\end{array}$ & 1.75 & \\
\hline
\end{tabular}

Fuente: Bega (2017) 


\subsection{Capacidad instalada}

\subsubsection{Cálculo detallado del número de máquinas y operarios requeridos}

Para el cálculo de máquinas, se tomó como referencia la producción más grande de los 5 años proyectados. Adicionalmente, se utilizó un factor de utilización estándar de 0.92 y un factor de eficiencia estándar de 0.8 .

A continuación, en base a la información antes mencionada se muestran los cálculos efectuados.

Tabla 5.10: Número de máquinas requeridas

\begin{tabular}{|c|c|c|c|c|c|c|c|c|c|c|c|}
\hline Proceso & $\begin{array}{c}\text { Demanda } \\
\text { (kg/año) }\end{array}$ & $\begin{array}{c}\text { Rendimient } \\
\mathbf{0}(\mathbf{k g} / \mathbf{h})\end{array}$ & $\begin{array}{c}\text { Defectuoso } \\
\mathbf{S}\end{array}$ & $\mathbf{T} / \mathbf{D}$ & $\mathbf{H} / \mathbf{T}$ & $\mathbf{D} / \mathbf{S}$ & S/A & $\mathbf{U}$ & $\mathbf{E}$ & $\begin{array}{c}\mathbf{N}^{\circ} \\
\text { Maquinas }\end{array}$ & $\begin{array}{c}\mathbf{N}^{\circ} \text { Maq. } \\
\text { Reales }\end{array}$ \\
\hline Cortar & $1,784,191.75$ & 1000 & $25 \%$ & 2 & 8 & 5 & 52 & 0.92 & 0.80 & 0.57991064 & 1 \\
\hline Limpiar & $1,338,143.81$ & 1000 & $20 \%$ & 2 & 8 & 5 & 52 & 0.92 & 0.80 & 0.43493298 & 1 \\
\hline Fermentar & $909,937.79$ & 5.8333 & $9 \%$ & 1 & 24 & 5 & 52 & 0.92 & 0.80 & 33.8005061 & 33 \\
\hline Lavado & $828,043.39$ & 1000 & 0 & 2 & 8 & 5 & 52 & 0.92 & 0.80 & 0.26913653 & 1 \\
\hline Secar & $828,043.39$ & 150 & $2 \%$ & 2 & 8 & 5 & 52 & 0.92 & 0.80 & 1.79424353 & 2 \\
\hline Seleccionar & $811,482.52$ & 150 & $10 \%$ & 2 & 8 & 5 & 52 & 0.92 & 0.80 & 1.75835866 & 2 \\
\hline Descascarillar & $730,334.27$ & 150 & $3 \%$ & 2 & 8 & 5 & 52 & 0.92 & 0.80 & 1.5825228 & 2 \\
\hline Ensacar & $708,424.24$ & 1200 & $1 \%$ & 2 & 8 & 5 & 52 & 0.92 & 0.80 & 0.19188089 & 1 \\
\hline
\end{tabular}

Elaboración Propia

Para el cálculo de factor hombre se consideró que el horario de trabajo para el área de plantación será de 1 turno diario de 9 horas cada turno con refrigerio de una hora y se trabajará de lunes a viernes las 52 semanas del año, el factor de utilización será de 0.88 y la eficiencia de 0.9 . 
A continuación, se detallan los procesos manuales realizados en la empresa, durante la primera etapa de plantación de terreno, con el que se desea satisfacer la demanda del $5 \%$.

Para lo cual se utilizó la siguiente formula:

$$
N^{\circ} \text { de Operarios }=\frac{\text { Rendimiento } \times \text { Demanda }}{\text { Uilización } \times \text { Eficiencia } \times T /{ }_{H} \times H / T_{T} \times /_{S} \times S / A}
$$

Tabla 5.11: Número de operarios requeridos área de plantación

\begin{tabular}{|l|c|c|c|c|c|c|c|c|c|c|c|}
\hline \multicolumn{1}{|c|}{ Proceso } & Demanda & Rendimiento & $\begin{array}{c}\text { Defectuoso } \\
\text { S }\end{array}$ & T/D & H/T & D/S & S/A & U & E & $\begin{array}{c}\mathbf{N}^{\circ} \\
\text { Operarios }\end{array}$ & $\begin{array}{c}\mathbf{N}^{\circ} \text { Ope. } \\
\text { Reales }\end{array}$ \\
\hline Preparar Sustrato & $2457.74 \mathrm{~kg} /$ año & $276 \mathrm{~kg} / \mathrm{h}$ & $10 \%$ & 1 & 9 & 5 & 1 & 0.89 & 0.9 & 0.3480008 & 1 \\
\hline Embolsar & 2075 bolsas/año & 30 bolsas/h & - & 1 & 9 & 5 & 3 & 0.89 & 0.9 & 0.64032147 & 1 \\
\hline Plantar & 2075 plantas/año & $120 \mathrm{plantas} / \mathrm{h}$ & - & 1 & 9 & 6 & 4 & 0.89 & 0.9 & 0.10005023 & 1 \\
\hline Injertar & 2075 plantas/año & 30 plantas/h & - & 1 & 9 & 5 & 1 & 0.89 & 0.9 & 1.92096442 & 2 \\
\hline Sembrar & 2075 plantas/año & 6 plantas/h & - & 1 & 9 & 6 & 4 & 0.89 & 0.9 & 2.0010046 & 3 \\
\hline Deshierbar & 2075 plantas/año & 60 plantas/h & - & 1 & 9 & 5 & 1 & 0.89 & 0.9 & 0.96048221 & 1 \\
\hline Podar & 2075 plantas/año & 60 plantas/h & - & 1 & 9 & 5 & 1 & 0.89 & 0.9 & 0.96048221 & 1 \\
\hline Abonar & 2075 plantas/año & 80 plantas/h & - & 1 & 9 & 5 & 18 & 0.89 & 0.9 & 0.04002009 & 1 \\
\hline Escurrir & 23,273 sacos/año & 12 sacos/h & $15 \%$ & 1 & 9 & 6 & 20 & 0.89 & 0.9 & 4.48939043 & 5 \\
\hline Cosechar & $2548845 \mathrm{~kg} /$ año & $218.07 \mathrm{~kg} / \mathrm{h}$ & $30 \%$ & 1 & 9 & 6 & 12 & 0.89 & 0.9 & 22.5466784 & 23 \\
\hline
\end{tabular}

Elaboración Propia 
Los procesos se realizarán en serie, pues una vez finalizada las etapas correspondientes desde preparar sustrato hasta sembrar, no volverán a efectuarse después. Todos los trabajadores contratados pasarán a formar parte de las actividades de cosecha y escurrido que serían periódicas y constantes, por lo que, el número total de trabajadores en plantación serán 23.

Para el área de producción se analizaron las actividades que se realizarán en paralelo y aquellas que no para determinar el número de personal requerido, dando los siguientes resultados:

Tabla 5.12: Número de operarios requeridos área de producción

\begin{tabular}{l|c}
\multicolumn{1}{c|}{ Proceso } & $\begin{array}{c}\mathbf{N}^{\circ} \text { Ope. } \\
\text { Reales }\end{array}$ \\
\hline Cortar & 1 \\
\hline Limpiar & 1 \\
\hline Fermentar & \multirow{2}{*}{3} \\
\cline { 1 - 1 } Lavado & \\
\hline Secar & 2 \\
\hline Seleccionar & 2 \\
\hline Descascarillar & 1 \\
\hline Ensacar &
\end{tabular}

Elaboración Propia

En conclusión, se considera que la planta trabajará 2 turnos al día, 5 días a la semana, esto nos da un total de 20 operarios en planta. 


\subsubsection{Cálculo de capacidad instalada:}

Para el cálculo de la capacidad instalada se tomó como referencia al número de máquinas y operarios calculados en el punto 5.4.1. En cuanto a las horas de trabajo, la utilización y eficiencia se mantiene igual que en los capítulos previos. Para el cálculo de capacidad instalada se tomó el cuello de botella encontrado.

En la tabla siguiente se aprecia que la operación de fermentado es el cuello de botella del proceso, por lo que la capacidad instalada será 11,412 sacos al año de producto terminado (sacos de yute de $60 \mathrm{Kg}$ ).

Tabla 5.13: Capacidad instalada

\begin{tabular}{|c|c|c|c|c|c|c|c|c|c|c|c|c|c|}
\hline Operación & QE(KG/AÑN) & Tipo & $\mathbf{P}(\mathrm{kg} / \mathrm{h})$ & M & T/D & $\mathrm{H} / \mathrm{T}$ & $\mathrm{D} / \mathrm{S}$ & S/A & $\mathbf{U}$ & $\mathbf{E}$ & $\mathrm{CO}$ & FC & COPT \\
\hline Cosechar & $2,548,845$ & Manual & 276 & 23 & 1 & 9 & 6 & 12 & 0.89 & 0.90 & $3,290,803$ & 0.00459 & 15,092 \\
\hline Cortar & $1,784,192$ & Automatico & 1,000 & 1 & 2 & 8 & 5 & 52 & 0.92 & 0.80 & $3,076,667$ & 0.00655 & 20,157 \\
\hline Limpiar & $1,338,144$ & Automatico & 1,000 & 1 & 2 & 8 & 5 & 52 & 0.92 & 0.80 & $3,076,667$ & 0.00874 & 26,875 \\
\hline Escurrir & $1,070,515$ & Manual & 552 & 5 & 1 & 9 & 6 & 20 & 0.89 & 0.90 & $2,384,640$ & 0.01092 & 26,038 \\
\hline Fermentar & 909,938 & Semi-Automatico & 6 & 33 & 1 & 24 & 5 & 52 & 0.92 & 0.80 & 888,388 & 0.01285 & 11,412 \\
\hline Lavado & 828,043 & Automatico & 1,000 & 1 & 2 & 8 & 5 & 52 & 0.92 & 0.80 & $3,076,667$ & 0.01412 & 43,431 \\
\hline Secar & 828,043 & Automatico & 150 & 2 & 2 & 8 & 5 & 52 & 0.92 & 0.80 & 923,000 & 0.01412 & 13,029 \\
\hline Descascarillar & 730,334 & Automatico & 150 & 2 & 2 & 8 & 5 & 52 & 0.92 & 0.80 & 923,000 & 0.01601 & 14,773 \\
\hline Ensacar & 708,424 & Automatico & 1,200 & 1 & 2 & 8 & 5 & 52 & 0.92 & 0.80 & $3,692,000$ & 0.01650 & 60,918 \\
\hline Producto terminado & 11,689 & Sacos de $60 \mathrm{~kg}$ & & & & & & & & & & & \\
\hline
\end{tabular}

Elaboración Propia 


\subsection{Resguardo de la calidad y/o inocuidad del producto}

\subsubsection{Calidad de la materia prima, de los insumos, del proceso y del producto materia prima}

A través de este estudio, buscamos ofrecer un producto estandarizado que cumpla con los estándares de calidad internacional para poder expandir en un mediano-largo plazo nuestra cartera de clientes en distintos países productores de chocolate y derivados. También, se debe comprobar que el cacao fino producido sea apropiado para la elaboración de alimentos de consumo humano. Para cumplir con dichos requisitos, se busca certificar una calidad constante de nuestro producto, centralizándonos en la inocuidad del proceso tanto productivo como no productivo

A continuación, se presenta una tabla con algunas de las características exigidas para el cacao:

Tabla 5.14: Requisitos de calidad

\begin{tabular}{|c|c|c|c|c|}
\hline Sub proceso & Etapa & Norma de calidad & Requisitos & Procedimiento \\
\hline Cortado & Salida & $\begin{array}{l}\text { NTP - ISO } \\
1114: 2016\end{array}$ & $\begin{array}{l}\text { Un grano de cacao debe pesar al menos } 1 \text { gr y se deben vender en base a la } \\
\text { clasificación del tamaño. }\end{array}$ & $\begin{array}{l}\text { Este procedimiento lo } \\
\text { realizará el supervisor de } \\
\text { calidad, utilizando una } \\
\text { balanza. Mayor detalle del } \\
\text { procedimiento en anexos. }\end{array}$ \\
\hline Escurrido & Salida & $\begin{array}{l}\text { NTP - ISO } \\
2292: 2016\end{array}$ & $\begin{array}{l}\text { No más del } 12 \% \text { de granos deben de pesar menos del } 33 \% \text { del peso medio. } \\
\text { Evitar contaminación de alérgenos, bacterias, dioxinas, materia extraña, metales } \\
\text { pesados, infestaciones. }\end{array}$ & $\begin{array}{l}\text { Este procedimiento lo } \\
\text { realizará el supervisor de } \\
\text { calidad, utilizando una } \\
\text { balanza. Mayor detalle del } \\
\text { procedimiento en anexos. }\end{array}$ \\
\hline Fermentado & Salida & $\begin{array}{l}\text { NTP - ISO } \\
2292: 2016\end{array}$ & $\begin{array}{l}\text { El fermentado debe de realizarse de manera que el grano de cacao tenga un color } \\
\text { marrón intenso homogéneo, esté hinchado, con olor agradable y que la cáscara se } \\
\text { desprenda facilmente. Las temperaturas en los } 6 \text { dias de fermentado deben de ser: } \\
36^{\circ} \mathrm{C}, 40^{\circ} \mathrm{C}, 49^{\circ} \mathrm{C}, 49.8^{\circ} \mathrm{C}, 46^{\circ} \mathrm{C} \text { y } 45.5^{\circ} \mathrm{C} \text { respectivamente. Se debe evitar un } \\
\text { fermentado corto para evitar un sabor excesivo de amargura y un fermentado } \\
\text { prolongado para evitar el crecimiento de hongos, el olor a humo y el sabor ácido. }\end{array}$ & $\begin{array}{l}\text { Este procedimiento lo } \\
\text { realizará el supervisor de } \\
\text { calidad, utilizando un } \\
\text { termòmetro e inspección } \\
\text { visual. Mayor detalle del } \\
\text { procedimiento en anexos. }\end{array}$ \\
\hline Secado & $\begin{array}{l}\text { Entrada } \\
\text { y salida }\end{array}$ & $\begin{array}{c}\text { NTP - ISO } \\
\text { 2291:2016 y NTP } \\
208.017: 2015 / \text { COR } 1: \\
2016\end{array}$ & $\begin{array}{l}\text { La humedad del grano de cacao que ingresa al secador es variable según la } \\
\text { empresa que lo procese. Sin embargo, en la salida del secador, se debe contar con } \\
\text { un grano con una humedad entre 7-8\% para que se encuentreen el mejor estado y } \\
\text { se evite la infestación de la Ocratoxina A. El límite máximo de HAP } \\
\text { (Hidrocarburos Aromáticos Policíclicos) en granos de cacao deberá ser de } 30 \\
\text { microgramos por kg grasa. Cada grano de cacao descortezado seco deberá } \\
\text { contener 55-58\% de grasa. }\end{array}$ & $\begin{array}{l}\text { Este procedimiento lo } \\
\text { realizará el supervisor de } \\
\text { calidad, utilizando un } \\
\text { medidor de humedad. } \\
\text { Mayor detalle del } \\
\text { procedimiento en anexos. }\end{array}$ \\
\hline
\end{tabular}

Elaboración Propia

A mayor detalle se explicará en Anexos 7, 8 y 9. 


\subsubsection{Estrategia de mejora}

Para asegurar la inocuidad del proceso productivo del cacao fino, se aplicará el análisis de peligros y puntos de control críticos (HACCP). A través de esta matriz, se podrá verificar cada parte de la cadena productiva y determinar todos los posibles riesgos de contaminación para poder tomar decisiones preventivas. Se realizará un programa de capacitación para el personal que se encargue del monitoreo de la implementación del HACCP.

Tabla 5.15: Usos del producto

\begin{tabular}{lll}
\hline $\begin{array}{l}\text { Nombre } \\
\text { Condiciones de manejo y conservación } \\
\text { del cacao fino en grano }\end{array}$ & $\begin{array}{l}\text { Cacao fino en grano } \\
\text { para evitar la absorción de la humedad } \\
\text { extra. }\end{array}$ \\
\hline $\begin{array}{l}\text { Vida útil esperada } \\
\text { Forma de uso de consumidores }\end{array}$ & $\begin{array}{l}\text { Utilizado como materia prima para la } \\
\text { potenciales } \\
\text { Empaque, etiquetado y presentación }\end{array}$ & producción de chocolate y derivados \\
\hline
\end{tabular}

Fuente: CENSALUD (2016) 
Tabla 5.16: Matriz HACCP-Identificación de puntos críticos de control

\begin{tabular}{|c|c|c|c|c|}
\hline Etapa del proceso & Peligro & Medida de Control & $\begin{array}{c}\text { ¿Es un peligro } \\
\text { significativo? }\end{array}$ & ¿Es un PCC? \\
\hline Seleccionar semillas & $\begin{array}{l}\text { Presencia de } \\
\text { bacterias en } \\
\text { semillas. }\end{array}$ & $\begin{array}{l}\text { Control efectivo biológico durante la } \\
\text { etapa de selección. Capacitación } \\
\text { de los operarios sobre Buenas } \\
\text { Prácticas de Manufactura (BPM) y } \\
\text { Procedimientos Operativos } \\
\text { Estandarizados de Saneamiento } \\
\text { (POES) }\end{array}$ & SI & NO \\
\hline Limpiar & $\begin{array}{l}\text { Presencia de } \\
\text { tierra en las } \\
\text { semillas. }\end{array}$ & $\begin{array}{l}\text { Control efectivo de lavado. } \\
\text { Capacitación de los operarios sobre } \\
\text { BPM y POES. }\end{array}$ & NO & NO \\
\hline Injertar & $\begin{array}{l}\text { Presencia de } \\
\text { bacterias en } \\
\text { tallos maduros } \\
\text { luego de la } \\
\text { injertación. }\end{array}$ & $\begin{array}{l}\text { Control efectivo de } \\
\text { injertación.Control efectivo de lavado. } \\
\text { Capacitación de los operarios sobre } \\
\text { BPM y POES. }\end{array}$ & SI & NO \\
\hline Deshierbar & $\begin{array}{l}\text { Falta de } \\
\text { nutrientes en el } \\
\text { suelo por } \\
\text { presencia de } \\
\text { malas hierbas. }\end{array}$ & Control efectivo de deshierbado & SI & NO \\
\hline Podar & $\begin{array}{l}\text { Presencia de } \\
\text { bacterias en } \\
\text { plantación de } \\
\text { cacao fino. }\end{array}$ & $\begin{array}{l}\text { Control efectivo de podado de tallos } \\
\text { cada } 2 \text { meses }\end{array}$ & SI & NO \\
\hline Abonar & $\begin{array}{l}\text { Presencia de } \\
\text { bacterias en } \\
\text { plantación de } \\
\text { cacao fino. }\end{array}$ & $\begin{array}{l}\text { Control efectivo de la cantidad de } \\
\text { nutrientes que recibe cada planta de } \\
\text { cacao fino }\end{array}$ & $\mathrm{NO}$ & NO \\
\hline
\end{tabular}

(continúa) 
(continuación)

\begin{tabular}{|c|c|c|c|c|}
\hline Etapa del proceso & Peligro & Medida de Control & \begin{tabular}{|c|} 
¿Es un peligro \\
significativo?
\end{tabular} & ¿Es un PCC? \\
\hline Cosechar & $\begin{array}{l}\text { Presencia de } \\
\text { bacterias/hong } \\
\text { os en } \\
\text { plantación de } \\
\text { cacao fino. }\end{array}$ & $\begin{array}{l}\text { Control efectivo de cosecha, } \\
\text { observando cuidadosamente las aptas } \\
\text { y no aptas }\end{array}$ & SI & NO \\
\hline Limpiar & $\begin{array}{l}\text { Presencia de } \\
\text { mucilago en el } \\
\text { grano de } \\
\text { cacao fino. }\end{array}$ & $\begin{array}{l}\text { Control efectivo de limpiado en } \\
\text { zaranda.Control efectivo de lavado. } \\
\text { Capacitación de los operarios sobre } \\
\text { BPM y POES. }\end{array}$ & SI & NO \\
\hline Escurrir & $\begin{array}{l}\text { Presencia de } \\
\text { mucilago en } \\
\text { granos de } \\
\text { cacao fino y } \\
\text { bacterias en el } \\
\text { ambiente. }\end{array}$ & $\begin{array}{l}\text { Capacitación de los operarios sobre } \\
\text { BPM y POES. }\end{array}$ & NO & NO \\
\hline Seleccionar & $\begin{array}{l}\text { Presencia de } \\
\text { bacterias e } \\
\text { impurezas en } \\
\text { granos de } \\
\text { cacao fino. } \\
\end{array}$ & $\begin{array}{l}\text { Selección efectiva de granos de cacao } \\
\text { fino. Capacitación de los operarios } \\
\text { sobre BPM y POES. }\end{array}$ & SI & NO \\
\hline Descascarillar & $\begin{array}{l}\text { Presencia de } \\
\text { residuos } \\
\text { sólidos en } \\
\text { granos de } \\
\text { cacao fino. } \\
\end{array}$ & $\begin{array}{l}\text { Control efectivo de la actividad para } \\
\text { evitar cualquier exceso de cáscara. } \\
\text { Capacitación de los operarios sobre } \\
\text { BPM y POES. }\end{array}$ & NO & NO \\
\hline Ensacar & $\begin{array}{l}\text { Presencia de } \\
\text { residuos } \\
\text { sólidos en } \\
\text { sacos del } \\
\text { producto final. }\end{array}$ & $\begin{array}{l}\text { Control efectivo de la actividad para } \\
\text { evitar cualquier exceso de cáscara. } \\
\text { Capacitación de los operarios sobre } \\
\text { BPM y POES. }\end{array}$ & SI & NO \\
\hline
\end{tabular}

Fuente: Manual para el diseño de instalaciones manufactureras y de servicios (2018) 
Tabla 5.17: Matriz HACCP-Puntos críticos de control

\begin{tabular}{|c|c|c|c|c|c|c|c|c|c|c|}
\hline \multirow{2}{*}{$\begin{array}{c}\text { Etapa del } \\
\text { proceso }\end{array}$} & \multirow{2}{*}{ Peligro } & \multirow{2}{*}{ Medida de Control } & \multicolumn{5}{|c|}{ Monitoreo } & \multirow{2}{*}{ Acción correctiva } & \multirow{2}{*}{$\begin{array}{c}\text { Verificación } \\
\text { Cuándo y Quién }\end{array}$} & \multirow{2}{*}{ Registros } \\
\hline & & & ¿Qué? & ¿Cómo? & ¿Cuándo? & ¿Donde? & Quién? & & & \\
\hline Plantar & \begin{tabular}{|l} 
Presencia de \\
residuos \\
solidos y \\
baterias en la \\
tierra.
\end{tabular} & $\begin{array}{l}\text { Control efectivo en la preparación de la } \\
\text { tierra fértil.Control efectivo de lavado. } \\
\text { Capacitación de los operarios sobre } \\
\text { BPM y POES. }\end{array}$ & $\begin{array}{l}\text { Eliminación de } \\
\text { plantas } \\
\text { infectadas. }\end{array}$ & $\begin{array}{l}\text { Realizando un correcto } \\
\text { procedimiento de } \\
\text { plantado bajo } \\
\text { parámetros } \\
\text { controlados. }\end{array}$ & \begin{tabular}{|l|} 
Cada vez que \\
inicie la etapa \\
de \\
deshierbado.
\end{tabular} & $\begin{array}{l}\text { Hectáreas de } \\
\text { plantación. }\end{array}$ & Biólogo. & $\begin{array}{l}\text { Descartar } \\
\text { inmediatamente } \\
\text { defectuosos. }\end{array}$ & \begin{tabular}{|l} 
Cuándo: \\
Verificación de \\
conformidad cada \\
inicio de la \\
deshierbado. \\
Quién: Supervisor \\
de planta. \\
\end{tabular} & R-HACCP-05 \\
\hline Cortar & $\begin{array}{l}\text { Exceso de aire } \\
\text { del ambiente } \\
\text { en los granos } \\
\text { de cacao fino. }\end{array}$ & $\begin{array}{l}\text { Control efectivo de los tiempos de } \\
\text { exposición de la mazorca abierta al } \\
\text { ambiente. Control efectivo de lavado. } \\
\text { Capacitación de los operarios sobre } \\
\text { BPM y POES. }\end{array}$ & $\begin{array}{l}\text { Degradación del } \\
\text { cacao fino } \\
\text { dentro de la } \\
\text { mazorca. }\end{array}$ & $\begin{array}{l}\text { Realizando un control } \\
\text { estricto de la cantidad } \\
\text { de horas que el cacao } \\
\text { es expuesto al } \\
\text { ambiente. }\end{array}$ & $\begin{array}{l}\text { Cada vez que } \\
\text { se abra una } \\
\text { mazorca. }\end{array}$ & $\begin{array}{l}\text { Área de } \\
\text { cortado. }\end{array}$ & Operario. & $\begin{array}{l}\text { Luego de los tres días, } \\
\text { descartar mazorca } \\
\text { conteniendo cacao fino } \\
\text { envuelto de mucilago. }\end{array}$ & \begin{tabular}{|l|} 
Cuándo: \\
Verificación de \\
conformidad cada 3 \\
días. \\
Quién: Supervisor \\
de planta. \\
\end{tabular} & R-HACCP-10 \\
\hline Fermentar & $\begin{array}{l}\text { Presencia de } \\
\text { bacterias en } \\
\text { plantación de } \\
\text { cacao fino. }\end{array}$ & $\begin{array}{l}\text { Control efectivo de las } 6 \text { diferentes } \\
\text { temperaturas a la cual debe llegar el } \\
\text { grano de cacao fino }\end{array}$ & $\begin{array}{l}\text { La eliminación } \\
\text { de } \\
\text { bacterias/hongos } \\
\text { en los granos de } \\
\text { cacao fino. }\end{array}$ & $\begin{array}{l}\text { Realizando un control } \\
\text { estricto de las } 6 \\
\text { distintas temperaturas } \\
\text { por día de fermentado } \\
\text { y humedad }\end{array}$ & \begin{tabular}{|l|} 
Todo el día, \\
durante los 6 \\
días de \\
fermentación \\
de determinado \\
lote de cacao \\
fino.
\end{tabular} & $\begin{array}{l}\text { Área de } \\
\text { fermentado } \\
\text { (ventilado). }\end{array}$ & Operario. & $\begin{array}{l}\text { Descartar lote si se } \\
\text { presentan variaciones } \\
\text { en la temperatura en } \\
\text { alguno de los días, ya } \\
\text { que no se realizará un } \\
\text { fermentado óptimo. }\end{array}$ & $\begin{array}{l}\text { Cuándo: } \\
\text { Verificación diaria de } \\
\text { conformidad. } \\
\text { Quién: Supervisor } \\
\text { de planta. }\end{array}$ & R-HACCP-13 \\
\hline Lavar & $\begin{array}{l}\text { Presencia de } \\
\text { tierra en las } \\
\text { semillas. }\end{array}$ & $\begin{array}{l}\text { Control efectivo de lavado. } \\
\text { Capacitación de los operarios sobre } \\
\text { BPM y POES. }\end{array}$ & \multirow{2}{*}{\begin{tabular}{|l} 
Eliminación de \\
impurezas. \\
Capacitación de \\
los operarios \\
sobre BPM y \\
POES. \\
Eliminación de \\
residuos sólidos. \\
Capacitación de \\
los operarios \\
sobre BPM y \\
POES.
\end{tabular}} & $\begin{array}{l}\text { Realizando un control } \\
\text { estricto de limpurezas } \\
\text { presentes luego del } \\
\text { lavado. }\end{array}$ & $\begin{array}{l}\text { Cada vez que } \\
\text { culmine la } \\
\text { etapa de } \\
\text { lavado. }\end{array}$ & $\begin{array}{l}\text { Área de } \\
\text { lavado. }\end{array}$ & Operario. & Reprocesar lote. & $\begin{array}{l}\text { Cuándo: } \\
\text { Verificación diaria de } \\
\text { conformidad. } \\
\text { Quién: Supervisor } \\
\text { de planta. }\end{array}$ & R-HACCP-13 \\
\hline Secar & $\begin{array}{l}\text { Presencia de } \\
\text { residuos } \\
\text { solidos en } \\
\text { granos de } \\
\text { cacao fino. }\end{array}$ & $\begin{array}{l}\text { Control efectivo de secado. } \\
\text { Capacitación de los operarios sobre } \\
\text { BPM y POES. }\end{array}$ & & $\begin{array}{l}\text { Realizando un control } \\
\text { estricto de limpurezas } \\
\text { presentes luego del } \\
\text { secado. }\end{array}$ & $\begin{array}{l}\text { Cada vez que } \\
\text { culmine la } \\
\text { etapa de } \\
\text { secado. }\end{array}$ & $\begin{array}{l}\text { Área de } \\
\text { secado. }\end{array}$ & Operario. & Reprocesar lote. & \begin{tabular}{|l} 
Cuándo: \\
Verificación diaria de \\
conformidad. \\
Quién: Supervisor \\
de planta. \\
\end{tabular} & R-HACCP-13 \\
\hline
\end{tabular}

Fuente: Manual para el diseño de instalaciones manufactureras y de servicios (2018) 
Para un correcto funcionamiento del proyecto, se deben analizar variables medibles y que puedan ser cuantificadas. Se deberá evaluar la eficiencia y eficacia del proceso productivo de cacao fino y el mantenimiento estricto de los puntos críticos de control. Por otro lado, es indispensable documentar todas las actividades del sistema y las acciones correctivas realizadas ya que, con esta información se podrán analizar los tiempos y proponer alternativas de mejora. Entre los documentos a almacenar están los principales: la evaluación de los peligros en el sistema y la identificación y posterior análisis de los límites y puntos críticos de control.

\subsection{Estudio de impacto ambiental}

Para el presente estudio analizaremos la zona de plantación de la empresa y la fábrica productora de cacao fino. Para realizar esto, se evaluarán los procesos que intervienen en la producción del cacao fino en la matriz de aspectos e impactos ambientales que se presenta a continuación:

Tabla 5.18: Nivel de significancia

\begin{tabular}{l|c}
\hline \multicolumn{2}{c}{ Niveles de significancia } \\
\hline \multicolumn{1}{c}{ Significancia } & Valoración \\
\hline Muy poco significativo & $0.10-<0.39$ \\
\hline Poco significativo & $0.40-<0.49$ \\
\hline Moderamente significativo & $0.50-<0.59$ \\
\hline Muy significativo & $0.60-<0.69$ \\
\hline Altamente significativo & $0.70-<1.0$ \\
\hline
\end{tabular}

Elaboración Propia

Tabla 5.19: Evaluación de impactos

\begin{tabular}{|c|c|c|c|c|c|}
\hline \multicolumn{6}{|c|}{ Evaluación de impactos } \\
\hline Rangos & Magnitud (m) & Duración (d) & Extensión (e) & \multicolumn{2}{|c|}{ Sensibilidad } \\
\hline \multirow[b]{2}{*}{1} & Muy pequeña & Días & Puntual & \multirow[b]{2}{*}{0.80} & \multirow[b]{2}{*}{ Nula } \\
\hline & Casi Imperceptible & 1-7 días & En un punto del proyecto & & \\
\hline \multirow[b]{2}{*}{2} & Pequeña & Días & Puntual & \multirow[b]{2}{*}{0.85} & \multirow[b]{2}{*}{ Baja } \\
\hline & Leve alteración & 1-4 semanas & En un punto del proyecto & & \\
\hline \multirow[b]{2}{*}{3} & Mediana & Meses & Área del proyecto & \multirow[b]{2}{*}{0.90} & \multirow[b]{2}{*}{ Media } \\
\hline & Moderada alteración & $1-12$ meses & En en área del proyecto & & \\
\hline \multirow[b]{2}{*}{4} & Alta & Años & Más allá del proyecto & \multirow[b]{2}{*}{0.95} & \multirow[b]{2}{*}{ Alta } \\
\hline & Se produce modificación & 1-10 años & Dentro del área de influencia & & \\
\hline \multirow[b]{2}{*}{5} & Muy alta & Permanente & Distrital & \multirow[b]{2}{*}{1.00} & \multirow[b]{2}{*}{ Extrema } \\
\hline & Modificación sustancial & Más de 10 años & Fuera del área de influencia & & \\
\hline
\end{tabular}

Fuente: Manual para el diseño de instalaciones manufactureras y de servicios (2018) 
Tabla 5.20: Matriz Leopold

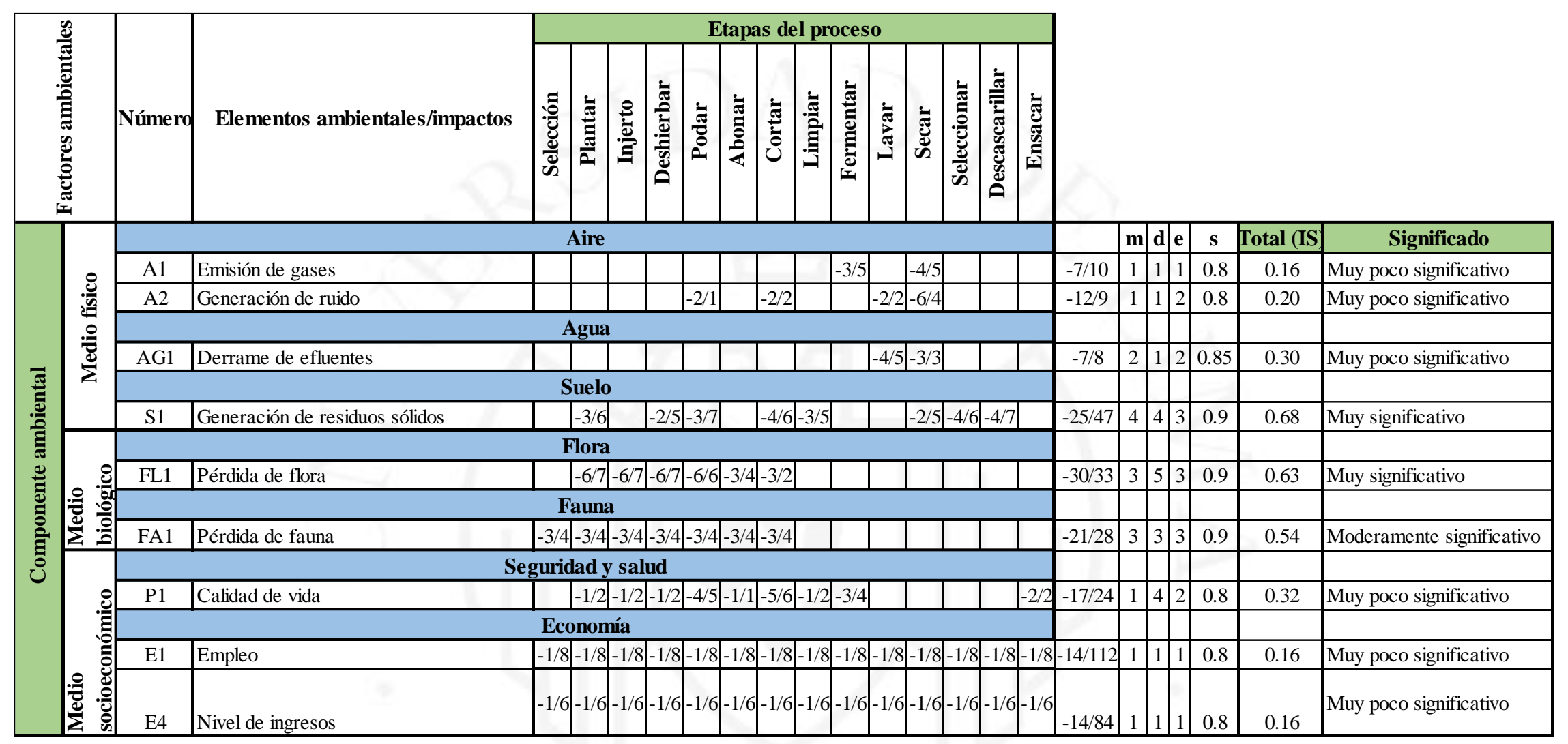

Fuente: Manual para el diseño de instalaciones manufactureras y de servicios (2018) 
La matriz de Leopold identifica los impactos ambientales que generaría la implementación del presente proyecto. Como se observa en la matriz, el componente ambiental que se ve afectado significativamente es el medio biológico (pérdida de flora, ya que para poder sembrar 5 hectáreas de cacao, se deberá de eliminar la flora presente en el terreno comprado.

Por otro lado, la contaminación del suelo a causa de generación de efluentes podría afectar la plantación de cacao. Entre las medidas correctivas destacan dos programas; en primer lugar, destaca el programa de uso eficiente de agua. Este programa plantea capacitaciones del personal de cosecha y siembra para inspeccionar semanalmente, el grado de humedad presente en el terreno, para así poder realizar un estudio detallado por estación del tiempo necesario para poder realizar riego en los sembríos, de esta manera se logrará determinar el momento óptimo para el riego en cada área, así se evitará el desperdicio del agua y se mejorara la eficiencia de uso de este recurso no renovable.

En segundo lugar destaca el programa de gestión de residuos sólidos, cuya finalidad es utilizar las merma del proceso de deshierbe, poda, selección, lavado, escurrido y limpieza para utilizarlo en la preparación de composta. Formándose así un entorno autosustentable con la actividad de abonado de la plantación, de esta manera se utilizan recursos naturales evitando dañar el suelo.

\subsection{Seguridad y salud ocupacional}

El presente estudio cumplirá con la Ley 29783, ley de la Seguridad y Salud en el Trabajo y el Decreto Supremo Nº 005-2012 TR, de manera que se buscará promover la prevención de riesgos mediante un sistema eficiente de Gestión de Seguridad y Salud en el Trabajo (SGSST). Para lograr la correcta implementación de esta gestión, se realizarán capacitaciones a todo el personal tanto administrativo como de producción acerca de los

procesos y normas a cumplir para tener un ambiente de trabajo seguro. Asimismo, se brindarán Equipos de Protección Personal (EPP's). A continuación, se presentan los principales peligros y riesgos en cada etapa del proceso productivo de cacao fino. 
Tabla 5.21: Mapa de peligros y riesgos

\begin{tabular}{|c|c|c|c|}
\hline Etapa del proceso & Peligro & Riesgo & Acción preventiva \\
\hline Seleccionar semillas & Toxinas & Probabilidad de irritación a la mucosa & $\begin{array}{l}\text { Uso de guantes, mascarillas y capacitación sobre riesgos al } \\
\text { personal }\end{array}$ \\
\hline Plantar & Movimiento repetitivo & Probabilidad de desarrollar lesiones lumbares & $\begin{array}{l}\text { Ofrecer capacitación acerca del método correcto de realizar el } \\
\text { plantado, así como fajas para la salud del trabajador }\end{array}$ \\
\hline Injerto & Movimiento repetitivo & Probabilidad de desarrollar lesiones lumbares & $\begin{array}{l}\text { Capacitación acerca del método correcto de realizar el injerto, } \\
\text { así como fajas para la salud del trabajador }\end{array}$ \\
\hline Deshierbar & Movimiento repetitivo & Probabilidad de desarrollar lesiones lumbares & $\begin{array}{l}\text { Capacitación acerca del método correcto de realizar el } \\
\text { deshierbado, así como fajas para la salud del trabajador }\end{array}$ \\
\hline \multirow[b]{2}{*}{ Podar } & Cuchillo & Probabilidad de corte & \multirow{2}{*}{$\begin{array}{l}\text { Capacitación acerca del método correcto de realizar el corte, } \\
\text { así como fajas para la salud del trabajador }\end{array}$} \\
\hline & Movimiento repetitivo & Probabilidad de desarrollar lesiones lumbares & \\
\hline Abonar & Movimiento repetitivo & Probabilidad de desarrollar lesiones lumbares & $\begin{array}{l}\text { Capacitación acerca del método correcto de realizar el } \\
\text { abonado, asi como fajas para la salud del trabajador }\end{array}$ \\
\hline \multirow[b]{2}{*}{ Cortar } & Cuchillas y partes en movimiento & Probabilidad de corte y atrapamiento & \multirow{2}{*}{$\begin{array}{l}\text { Capacitación acerca del método correcto de realizar el } \\
\text { cortado, asi como fajas para la salud del trabajador }\end{array}$} \\
\hline & Manejo incorrecto de maquinaria & Probabilidad de corte & \\
\hline \multirow{2}{*}{ Limpiar } & \begin{tabular}{|l|} 
Manejo incorrecto de maquinaria \\
Corto circuito
\end{tabular} & $\begin{array}{l}\text { Probabilidad de corto circuito } \\
\text { Probabilidad de incendio }\end{array}$ & Mantener aislados todos los circuitos eléctricos \\
\hline & Partes en movimiento & $\begin{array}{l}\text { Probabilidad de que la máquina golpee } o \text { aplaste } \\
\text { alguna extremidad }\end{array}$ & $\begin{array}{l}\text { Instalar guardas de seguridad que ayuden a prevenir el } \\
\text { contacto del cuerpo con las partes en movimiento }\end{array}$ \\
\hline Fermentar & Cajas mal apiladas & $\begin{array}{l}\text { Probabilidad de que las cajas golpeen a algún } \\
\text { operario }\end{array}$ & $\begin{array}{l}\text { Marcar la zona de fermentado con líneas amarillas } \\
\text { fosforescentes para restringir la zona. Capacitación de } \\
\text { operarios acerca de los riesgos presentes en el fermentado }\end{array}$ \\
\hline \multirow{3}{*}{ Lavar } & Manejo incorrecto de maquinaria & Probabilidad de corto circuito & \multirow{2}{*}{ Mantener aislados todos los circuitos eléctricos } \\
\hline & Corto circuito & Probabilidad de incendio & \\
\hline & Partes en movimiento & $\begin{array}{l}\text { Probabilidad de que la máquina golpee } o \text { aplaste } \\
\text { alguna extremidad }\end{array}$ & $\begin{array}{l}\text { Instalar guardas de seguridad que ayuden a prevenir el } \\
\text { contacto del cuerpo con las partes en movimiento }\end{array}$ \\
\hline \multirow{2}{*}{ Secar } & Ruido en altos decibeles & Probabilidad de daño auditivo & \multirow{2}{*}{$\begin{array}{l}\text { Capacitación acerca de la exposición a los riesgos, el método } \\
\text { correcto de realizar el secado y la utilización de los EPP's } \\
\text { (tapones de oído) }\end{array}$} \\
\hline & Partes en movimiento & Probabilidad de atrapamiento & \\
\hline Seleccionar & Manejo incorrecto de maquinaria & Probabilidad de atrapamiento & $\begin{array}{l}\text { Capacitación acerca del método correcto de realizar la } \\
\text { selección }\end{array}$ \\
\hline \multirow{2}{*}{ Descascarillar } & Cuchillas y partes en movimiento & Probabilidad de corte $y$ atrapamiento & \multirow{2}{*}{$\begin{array}{l}\text { Capacitación acerca del método correcto de realizar el } \\
\text { descascarillado, asi como guardas para evitar el atrapamiento }\end{array}$} \\
\hline & Manejo incorrecto de maquinaria & Probabilidad de corte & \\
\hline \multirow[b]{2}{*}{ Ensacar } & Manejo incorrecto de maquinaria & Probabilidad de atrapamiento & \multirow{2}{*}{$\begin{array}{l}\text { Capacitación acerca del método óptimo de manejar objetos } \\
\text { pesados(Ej: sacos de } 60 \mathrm{~kg} \text {, así como fajas para el trabajador }\end{array}$} \\
\hline & Movimiento repetitivo & Probabilidad de desarrollar lesiones lumbares & \\
\hline
\end{tabular}

Fuente: Manual para el diseño de instalaciones manufactureras y de servicios (2018) 
Tabla 5.22: Puntajes para el análisis de la matriz IPERC

\begin{tabular}{|c|c|c|c|c|c|c|c|}
\hline \multirow[b]{2}{*}{ Índice } & \multicolumn{4}{|c|}{ Probabilidad } & \multirow[b]{2}{*}{ Severidad } & \multicolumn{2}{|c|}{ Estimación del Riesgo } \\
\hline & $\begin{array}{c}\text { Número de } \\
\text { personas } \\
\text { expuestas }\end{array}$ & $\begin{array}{l}\text { Procedimientos } \\
\text { existentes }\end{array}$ & Capacitaciones & Exposición al Riesgo & & $\begin{array}{l}\text { Grado } \\
\text { Riesgo }\end{array}$ & Puntaje \\
\hline \multirow{2}{*}{1} & \multirow{2}{*}{ De 1 a 3} & \multirow{2}{*}{$\begin{array}{l}\text { Existen, son } \\
\text { satisfactorios y } \\
\text { suficientes }\end{array}$} & \multirow{2}{*}{$\begin{array}{c}\text { Personal entrenado, } \\
\text { conoce el peligro y } \\
\text { lo previene }\end{array}$} & \multirow{2}{*}{$\begin{array}{c}\text { Al menos una vez al } \\
\text { año } \\
\text { ESPORÁDICAMENTE }\end{array}$} & \multirow{2}{*}{$\begin{array}{l}\text { DISCONFORMIDAD } \\
\text { / INCOMODIDAD }\end{array}$} & Trivial $(\mathrm{T})$ & 4 \\
\hline & & & & & & $\begin{array}{l}\text { Tolerable } \\
\text { (To) }\end{array}$ & de 5 a 8 \\
\hline \multirow{2}{*}{2} & \multirow{2}{*}{ De 4 a 12} & \multirow{2}{*}{$\begin{array}{l}\quad \text { Existen } \\
\text { parcialmente y no } \\
\text { son satisfactorios } \\
\text { o suficientes }\end{array}$} & \multirow{2}{*}{$\begin{array}{c}\text { Personal } \\
\text { parcialmente } \\
\text { entrenado, conoce } \\
\text { el peligro pero no } \\
\text { toma acción de } \\
\text { control }\end{array}$} & \multirow{2}{*}{$\begin{array}{c}\text { Al menos una vez al } \\
\text { mes } \\
\text { EVENTUALMENTE }\end{array}$} & \multirow{2}{*}{$\begin{array}{c}\text { DAÑO A LA SALUD } \\
\text { REVERSIBLE }\end{array}$} & $\begin{array}{l}\text { Moderado } \\
\text { (Mo) }\end{array}$ & de 9 a 16 \\
\hline & & & & & & $\begin{array}{l}\text { Importante } \\
\text { (Im) }\end{array}$ & de 17 a 24 \\
\hline 3 & Más de 12 & No existen & $\begin{array}{c}\text { Personal no } \\
\text { entrenado, no } \\
\text { conoce el peligro, no } \\
\text { toma acciones de } \\
\text { control }\end{array}$ & $\begin{array}{c}\text { Almenos una vez al } \\
\text { día } \\
\text { PERMANENTE }\end{array}$ & $\begin{array}{l}\text { DAÑO A LA SALUD } \\
\text { IRREVERSIBLE }\end{array}$ & $\begin{array}{l}\text { Intolerable } \\
\text { (IT) }\end{array}$ & de 25 a 36 \\
\hline
\end{tabular}

Fuente: Manual para el diseño de instalaciones manufactureras y de servicios (2018) 
Tabla 5.23: Matriz IPERC

\begin{tabular}{|c|c|c|c|c|c|c|c|c|c|c|c|c|}
\hline & & & \multicolumn{4}{|c|}{ Sub índices de probabilidad } & \multirow[b]{2}{*}{ 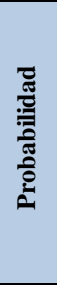 } & \multirow{2}{*}{ 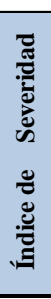 } & \multirow{2}{*}{ 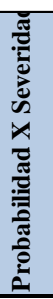 } & \multirow[b]{2}{*}{ 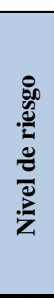 } & \multirow[b]{2}{*}{ 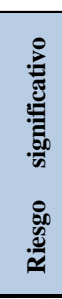 } & \multirow[b]{2}{*}{ Medida de control } \\
\hline 20 & $e^{30}$ & هั & 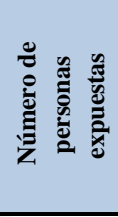 & 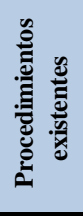 & 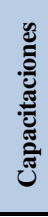 & 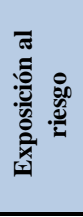 & & & & & & \\
\hline Seleccionar semillas & Toxinas & $\begin{array}{c}\text { Probabilidad de irritación a } \\
\text { la mucosa }\end{array}$ & 2 & 1 & 1 & 1 & 5 & 1 & 5 & To & $\mathrm{NO}$ & Uso de EPP's: Guantes y mascarillas \\
\hline Plantar & $\begin{array}{l}\text { Movimiento } \\
\text { repetitivo }\end{array}$ & $\begin{array}{c}\text { Probabilidad de desarrollar } \\
\text { lesiones lumbares }\end{array}$ & 2 & 1 & 1 & 1 & 5 & 2 & 10 & Mo & NO & $\begin{array}{l}\text { Capacitar al personal acerca de los riesgos ergonómicos. } \\
\text { Uso de fajas. Implementar pausa activa para reducir riesgo. } \\
\text { Realizar examen médico mensualmente. }\end{array}$ \\
\hline Injertar & $\begin{array}{l}\text { Movimiento } \\
\text { repetitivo }\end{array}$ & $\begin{array}{c}\text { Probabilidad de desarrollar } \\
\text { lesiones lumbares }\end{array}$ & 3 & 1 & 1 & 1 & 6 & 2 & 12 & Mo & NO & $\begin{array}{l}\text { Capacitar al personal acerca de los riesgos ergonómicos. } \\
\text { Uso de fajas. Implementar pausa activa para reducir riesgo. } \\
\text { Realizar examen médico mensualmente }\end{array}$ \\
\hline Deshierbar & $\begin{array}{l}\text { Movimiento } \\
\text { repetitivo }\end{array}$ & $\begin{array}{c}\text { Probabilidad de desarrollar } \\
\text { lesiones lumbares }\end{array}$ & 2 & 1 & 1 & 1 & 5 & 2 & 10 & Mo & NO & $\begin{array}{l}\text { Capacitar al personal acerca de los riesgos ergonómicos. } \\
\text { Uso de fajas. Implementar pausa activa para reducir riesgo. } \\
\text { Realizar examen médico mensualmente }\end{array}$ \\
\hline \multirow[b]{2}{*}{ Podar } & Cuchillo & Probabilidad de corte & \multirow[b]{2}{*}{2} & \multirow[b]{2}{*}{1} & \multirow[b]{2}{*}{1} & \multirow[b]{2}{*}{2} & \multirow[b]{2}{*}{6} & \multirow[b]{2}{*}{2} & \multirow[b]{2}{*}{12} & \multirow[b]{2}{*}{ Mo } & \multirow[b]{2}{*}{ NO } & \multirow{2}{*}{$\begin{array}{l}\text { Capacitar al personal acerca de los riesgos ergonómicos. } \\
\text { Uso de fajas y guantes. Implementar pausa activa para } \\
\text { reducir riesgo. Realizar examen médico mensualmente. }\end{array}$} \\
\hline & $\begin{array}{l}\text { Movimiento } \\
\text { repetitivo }\end{array}$ & $\begin{array}{l}\text { Probabilidad de desarrollar } \\
\text { lesiones lumbares }\end{array}$ & & & & & & & & & & \\
\hline Abonar & $\begin{array}{l}\text { Movimiento } \\
\text { repetitivo }\end{array}$ & $\begin{array}{l}\text { Probabilidad de desarrollar } \\
\text { lesiones lumbares }\end{array}$ & 1 & 1 & 1 & 1 & 4 & 2 & 8 & To & NO & $\begin{array}{l}\text { Capacitar al personal acerca de los riesgos ergonómicos. } \\
\text { Uso de fajas. Implementar pausa activa para reducir riesgo. } \\
\text { Realizar examen médico mensualmente. }\end{array}$ \\
\hline \multirow{2}{*}{ Cortar } & $\begin{array}{l}\text { Cuchillas y partes } \\
\text { en movimiento }\end{array}$ & $\begin{array}{l}\text { Probabilidad de corte y } \\
\text { atrapamiento }\end{array}$ & \multirow{2}{*}{1} & \multirow{2}{*}{1} & \multirow{2}{*}{1} & \multirow{2}{*}{2} & \multirow{2}{*}{5} & \multirow{2}{*}{2} & \multirow{2}{*}{10} & \multirow{2}{*}{ Mo } & \multirow{2}{*}{ NO } & \multirow{2}{*}{$\begin{array}{l}\text { Capacitar personal acerca de riesgos del sub-proceso y del } \\
\text { uso correcto de la maquinaria. Marcar zonas restringidas e } \\
\text { instalar guardas de seguridad. }\end{array}$} \\
\hline & $\begin{array}{l}\text { Manejo incorrecto } \\
\text { de maquinaria }\end{array}$ & Probabilidad de corte & & & & & & & & & & \\
\hline
\end{tabular}

(continúa) 


\section{(continuación)}

\begin{tabular}{|c|c|c|c|c|c|c|c|c|c|c|c|c|}
\hline & & & \multicolumn{4}{|c|}{ Sub índices de probabilidad } & \multirow[b]{2}{*}{ 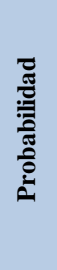 } & \multirow{2}{*}{ 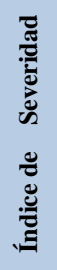 } & \multirow[b]{2}{*}{ 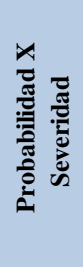 } & \multirow[b]{2}{*}{ 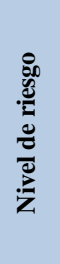 } & \multirow{2}{*}{ 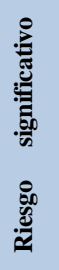 } & \multirow[b]{2}{*}{ Medida de control } \\
\hline$x^{2}$ & Se & كْتمن & 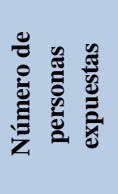 & 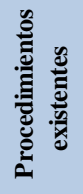 & 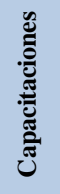 & 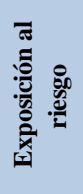 & & & & & & \\
\hline \multirow{3}{*}{ Limpiar } & $\begin{array}{l}\text { Manejo incorrecto } \\
\text { de maquinaria }\end{array}$ & $\begin{array}{l}\begin{array}{l}\text { Probabilidad de corto } \\
\text { circuito }\end{array} \\
\end{array}$ & \multirow{3}{*}{1} & \multirow{3}{*}{1} & \multirow{3}{*}{1} & \multirow{3}{*}{1} & \multirow{3}{*}{4} & \multirow{3}{*}{2} & \multirow{3}{*}{8} & \multirow{3}{*}{ To } & \multirow{3}{*}{ NO } & \multirow{3}{*}{$\begin{array}{c}\text { Capacitación al personal acerca del uso correcto de la } \\
\text { maquinaria. Instalar guardas de seguridad y alarma contra } \\
\text { incendio. }\end{array}$} \\
\hline & Corto circuito & Probabilidad de incendio & & & & & & & & & & \\
\hline & $\begin{array}{l}\text { Partes en } \\
\text { movimiento }\end{array}$ & $\begin{array}{l}\text { Probabilidad de que la } \\
\text { máquina golpee o aplaste } \\
\text { alguna extremidad }\end{array}$ & & & & & & & & & & \\
\hline Fermentar & Cajas mal apiladas & $\begin{array}{l}\text { Probabilidad de que las } \\
\text { cajas golpeen a algún } \\
\text { operario }\end{array}$ & 1 & 1 & 1 & 1 & 4 & 2 & 8 & To & NO & $\begin{array}{l}\text { Capacitación al personal sobre los riesgos del puesto. } \\
\text { Instalar guarda protectora. }\end{array}$ \\
\hline \multirow{3}{*}{ Lavar } & $\begin{array}{l}\text { Manejo incorrecto } \\
\text { de maquinaria }\end{array}$ & $\begin{array}{l}\text { Probabilidad de corto } \\
\text { circuito }\end{array}$ & \multirow{3}{*}{1} & \multirow{3}{*}{1} & \multirow{3}{*}{1} & \multirow{3}{*}{1} & \multirow{3}{*}{4} & \multirow{3}{*}{2} & \multirow{3}{*}{8} & \multirow{3}{*}{ To } & \multirow{3}{*}{ NO } & \multirow{3}{*}{$\begin{array}{l}\text { Capacitación al personal acerca del uso correcto de la } \\
\text { maquinaria. Instalar guardas de seguridad y alarma contra } \\
\text { incendio. }\end{array}$} \\
\hline & Corto circuito & Probabilidad de incendio & & & & & & & & & & \\
\hline & $\begin{array}{l}\text { Partes en } \\
\text { movimiento }\end{array}$ & $\begin{array}{l}\text { Probabilidad de que la } \\
\text { máquina golpee o aplaste } \\
\text { alguna extremidad }\end{array}$ & & & & & & & & & & \\
\hline \multirow{2}{*}{ Secar } & $\begin{array}{l}\text { Ruido en altos } \\
\text { decibeles }\end{array}$ & $\begin{array}{l}\text { Probabilidad de daño } \\
\text { auditivo }\end{array}$ & \multirow{2}{*}{1} & \multirow{2}{*}{1} & \multirow{2}{*}{1} & \multirow{2}{*}{1} & \multirow{2}{*}{4} & \multirow{2}{*}{3} & \multirow{2}{*}{12} & Mo & NO & Uso de EPP’s: Tapones de oido. Capacitación al personal \\
\hline & $\begin{array}{l}\text { Partes en } \\
\text { movimiento }\end{array}$ & $\begin{array}{l}\text { Probabilidad de } \\
\text { atrapamiento }\end{array}$ & & & & & & & & 1010 & No & acerca de los riesgos del sub-proceso. \\
\hline
\end{tabular}

(continúa) 


\section{(continuación)}

\begin{tabular}{|c|c|c|c|c|c|c|c|c|c|c|c|c|}
\hline & \multirow[b]{2}{*}{$e^{00}$} & \multirow[b]{2}{*}{ 80 } & \multicolumn{4}{|c|}{ Sub índices de probabilidad } & \multirow[b]{2}{*}{ 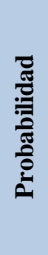 } & \multirow{2}{*}{ 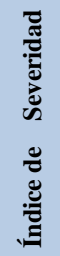 } & \multirow[b]{2}{*}{ 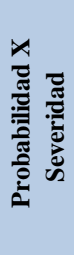 } & \multirow[b]{2}{*}{ 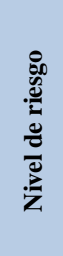 } & \multirow{2}{*}{ 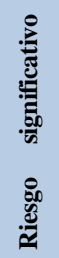 } & \multirow[b]{2}{*}{ Medida de control } \\
\hline $20^{0^{2}}$ & & & 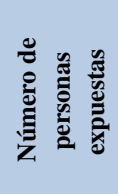 & 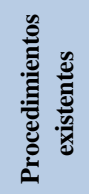 & 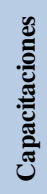 & 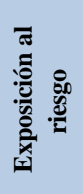 & & & & & & \\
\hline Seleccionar & $\begin{array}{l}\text { Manejo incorrecto } \\
\text { de maquinaria }\end{array}$ & $\begin{array}{l}\text { Probabilidad de } \\
\text { atrapamiento }\end{array}$ & 1 & 1 & 1 & 1 & 4 & 1 & 4 & $\mathrm{~T}$ & NO & $\begin{array}{l}\text { Capacitación al personal sobre los riesgos del puesto. } \\
\text { Instalar guarda protectora. }\end{array}$ \\
\hline \multirow[b]{2}{*}{ Tostar } & $\begin{array}{l}\text { Ruido en altos } \\
\text { decibeles }\end{array}$ & $\begin{array}{l}\text { Probabilidad de daño } \\
\text { auditivo }\end{array}$ & \multirow[b]{2}{*}{1} & \multirow[b]{2}{*}{1} & \multirow[b]{2}{*}{1} & \multirow[b]{2}{*}{1} & \multirow[b]{2}{*}{4} & \multirow[b]{2}{*}{3} & \multirow[b]{2}{*}{12} & \multirow[b]{2}{*}{ Mo } & \multirow[b]{2}{*}{ NO } & \multirow{2}{*}{$\begin{array}{l}\text { Uso de EPP's: Tapones de oido y guantes especiales. } \\
\text { Capacitación al personal acerca de los riesgos del sub- } \\
\text { proceso. }\end{array}$} \\
\hline & $\begin{array}{l}\text { Manejo incorrecto } \\
\text { de maquinaria }\end{array}$ & $\begin{array}{l}\text { Probabilidad de } \\
\text { quemaduras }\end{array}$ & & & & & & & & & & \\
\hline \multirow{2}{*}{ Descascarillar } & $\begin{array}{l}\text { Cuchillas y partes } \\
\text { en movimiento }\end{array}$ & $\begin{array}{l}\text { Probabilidad de corte y } \\
\text { atrapamiento }\end{array}$ & \multirow{2}{*}{1} & \multirow{2}{*}{1} & \multirow{2}{*}{1} & \multirow{2}{*}{1} & \multirow{2}{*}{4} & \multirow{2}{*}{2} & \multirow{2}{*}{8} & \multirow{2}{*}{ To } & \multirow{2}{*}{ NO } & \multirow{2}{*}{$\begin{array}{c}\text { Capacitar personal acerca de riesgos del sub-proceso y del } \\
\text { uso correcto de la maquinaria. Marcar zonas restringidas e } \\
\text { instalar guardas de seguridad. }\end{array}$} \\
\hline & $\begin{array}{l}\text { Manejo incorrecto } \\
\text { de maquinaria }\end{array}$ & Probabilidad de corte & & & & & & & & & & \\
\hline \multirow{2}{*}{ Ensacar } & $\begin{array}{l}\text { Manejo incorrecto } \\
\text { de maquinaria }\end{array}$ & $\begin{array}{l}\text { Probabilidad de } \\
\text { atrapamiento }\end{array}$ & \multirow[b]{2}{*}{1} & \multirow[b]{2}{*}{1} & \multirow[b]{2}{*}{1} & \multirow{2}{*}{1} & \multirow{2}{*}{4} & \multirow{2}{*}{2} & & & & Capacitar al personal acerca de los riesgos ergonómicos. \\
\hline & $\begin{array}{l}\text { Movimiento } \\
\text { repetitivo }\end{array}$ & $\begin{array}{l}\text { Probabilidad de desarrollar } \\
\text { lesiones lumbares }\end{array}$ & & & & & & & 8 & To & NO & $\begin{array}{l}\text { Uso de fajas. Implementar pausa activa para reducir riesgo. } \\
\text { Realizar examen médico mensualmente. }\end{array}$ \\
\hline
\end{tabular}

Fuente: Manual para el diseño de instalaciones manufactureras y de servicios (2018) 
Capacitar al personal es fundamental para poder optimizar procesos. Si bien genera un costo adicional, en el mediano-largo plazo ser reflejará el óptimo funcionamiento del sistema con un porcentaje de error mínimo. Con estas capacitaciones se busca que los operarios cumplan con lo siguiente:

1. Correcto uso de los EPP's y entender el rol tan importante que cumple dentro de sus funciones a diario.

2. Entender perfectamente el funcionamiento de las máquinas y procedimientos de cada sub-proceso.

3. Conocimiento absoluto del plan de emergencia y evacuación (Incluyendo el correcto uso de los botiquines de primeros auxilios y extintores

4. Entender las consecuencias de los riesgos existentes en el centro de trabajo y cómo puede perjudicar a su salud y familia

\subsection{Sistema de mantenimiento}

Es importante mantener constante la producción de cacao a lo largo del año para asegurar la calidad del producto. A continuación, se detalla un programa de mantenimiento que busca la continuidad del proceso. Para ello, se ha previsto realizar mantenimiento preventivo a los equipos y sensores instalados, con la finalidad de mantener la disponibilidad de la máquina.

Se contará con un jefe de mantenimiento, con el apoyo de 2 operarios. Este tendrá la función de capacitar a los operarios en el uso adecuado de las máquinas y realizar pruebas en marcha del equipo, para que los ayudantes sean capaces de detectar imperfecciones en el adecuado funcionamiento del activo y diagnosticar adecuadamente la causa raíz del problema.

De igual manera para mantener la garantía de los activos se realizarán los mantenimientos sugeridos por el fabricante en el plazo determinado durante los días sábado y domingo que será cuando la planta no opere. A continuación, se presenta el cuadro de mantenimiento propuesto para cada equipo, dado que los todos equipos son críticos en el proceso en serie. 
Tabla 5.24: Número de mantenimientos por trimestre

\begin{tabular}{c|c|c|c|c|c}
\hline Actividad & Maquina & Proceso & $\begin{array}{c}\text { Veces por } \\
\text { Trimestre }\end{array}$ & $\begin{array}{c}\text { Tipo de } \\
\text { MTTO }\end{array}$ & Duración \\
\hline $\begin{array}{c}\text { Separar la mazorca de } \\
\text { la pulpa }\end{array}$ & Despulpadora de cacao & Cortar & 6 & Preventivo & 2 horas \\
\hline $\begin{array}{c}\text { Eliminar el exceso de } \\
\text { mucilago }\end{array}$ & Lavadora por Inmersión & Limpiar & 3 & Preventivo & 1 hora \\
\hline $\begin{array}{c}\text { Limpiar el cacao } \\
\text { fermentado de agentes } \\
\text { contaminantes }\end{array}$ & Lavadora por inmersión & Lavar & 3 & Preventivo & 1 hora \\
\hline $\begin{array}{c}\text { Secado de Cacao } \\
\text { Seleccionado de Cacao }\end{array}$ & $\begin{array}{c}\text { Secadora de Granos } \\
\text { Automática } \\
\text { por tamaño y condición }\end{array}$ & Secar & 3 & Preventivo & 1 hora \\
\hline $\begin{array}{c}\text { Descascarillado de } \\
\text { cacao }\end{array}$ & Peladora de cacao & Descascarillar & 6 & Preventivo & 2 horas \\
\hline $\begin{array}{c}\text { Ensacado de almendra } \\
\text { tostada }\end{array}$ & Ensacadora de cacao & Ensacar & 6 & Preventivo & 2 horas \\
\hline
\end{tabular}

Elaboración Propia

Seguidamente, se presenta el cronograma de mantenimiento a lo largo del año:

Tabla 5.25: Cronograma de implementación de los mantenimientos

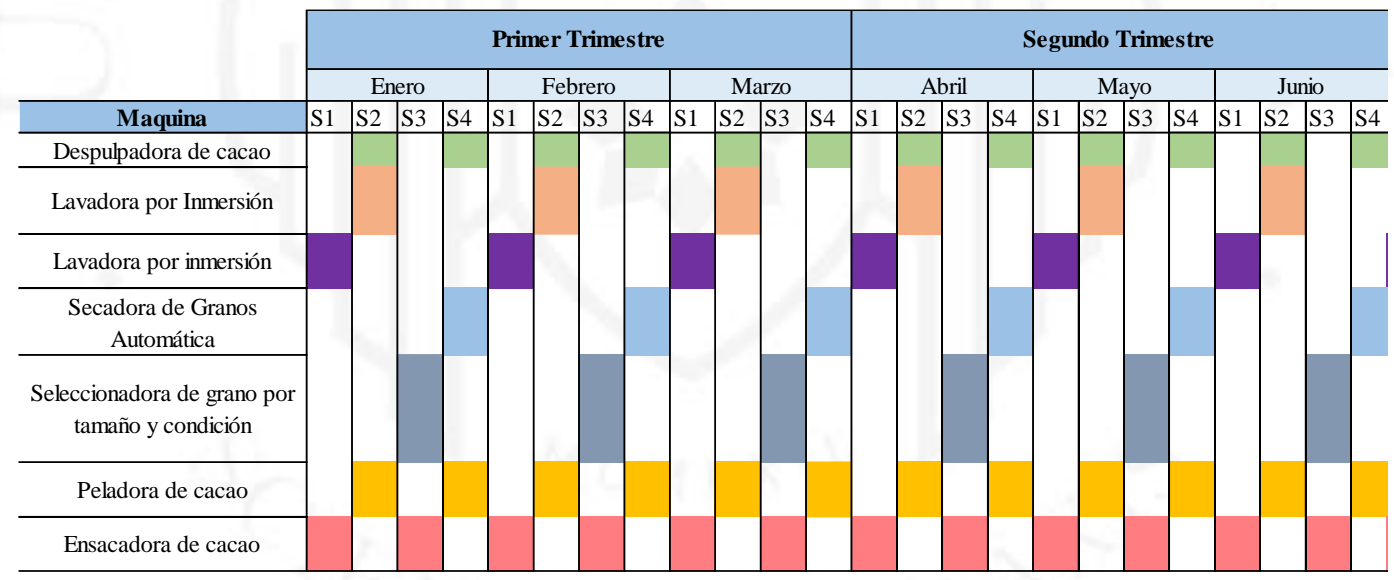

(continúa) 
(continuación)

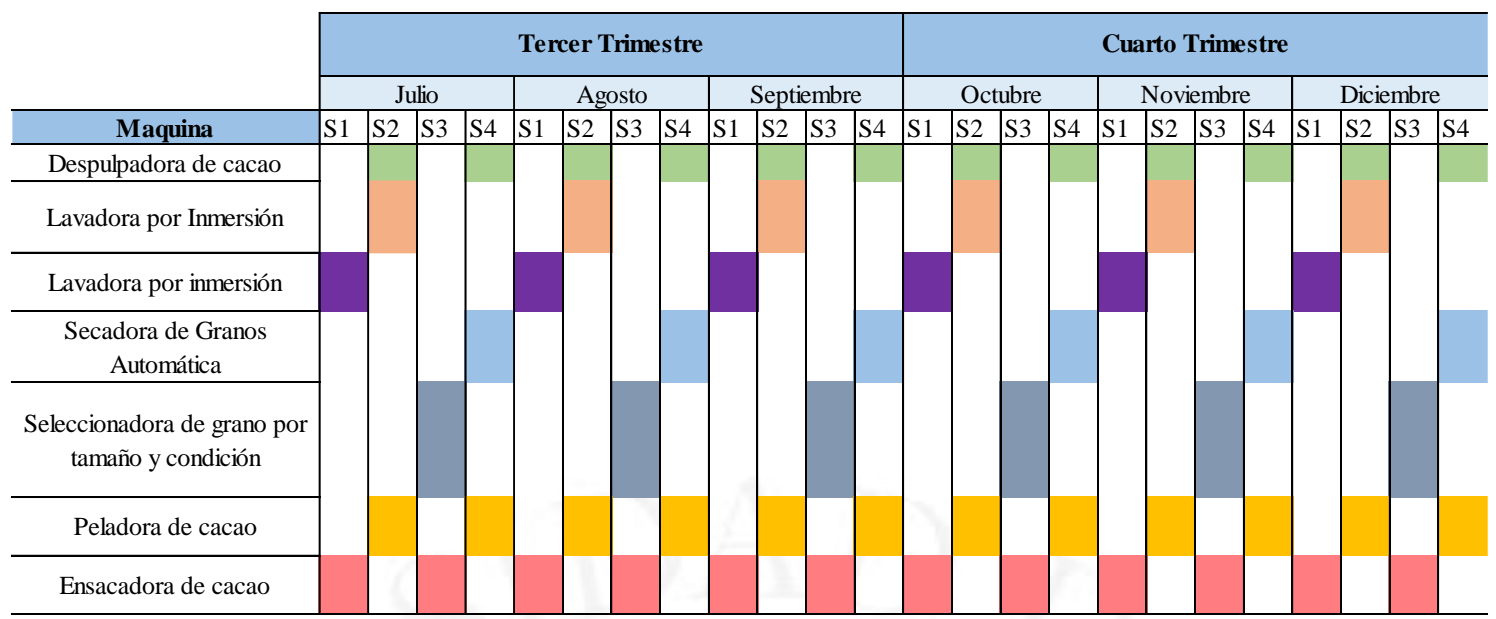

Elaboración propia

\subsection{Diseño de la cadena de suministro}

Para poder comprender la cadena de suministro, se usará la matriz SIPOC (Supplier input-process-outputs-customer) en la cual se especificará las entradas y salidas del proceso de producción de cacao fino, principalmente en el sub proceso de fermentado, siendo el corazón del proceso.

Tabla 5.26: Matriz SIPOC

\begin{tabular}{|c|c|c|c|c|}
\hline Proveedor & Entradas & Proceso & Salidas & Clientes \\
\hline Área de escurrido & Almendras de cacao & Colocar almendras en cajas & \multirow{2}{*}{$\begin{array}{c}\text { Cacao fermentado } \\
\text { húmedo }\end{array}$} & Área de secado \\
\hline Proveedor de luz & Energía eléctrica & $\begin{array}{l}\text { Revisar humedad de almendra a } \\
\text { la entrada de la actividad }\end{array}$ & & Almacén de PT \\
\hline Proveedor de sensores de humedad & Sensores de humedad & $\begin{array}{l}\text { Mover el lote de producción } \\
\text { diariamente }\end{array}$ & \multirow{2}{*}{$\begin{array}{l}\text { Certificado de } \\
\text { calidad del lote }\end{array}$} & $\begin{array}{l}\text { Distribuidores } \\
\text { mayoristas }\end{array}$ \\
\hline Proveedor de termómetros & Termómetros & Medir la temperatura diariamente & & Área de ensacado \\
\hline
\end{tabular}

Elaboración propia

\subsection{Programa de producción}

En el presente capítulo, se analizará la producción de cacao en sacos de $60 \mathrm{~kg}$ hasta el año 2024, vida útil del proyecto y tendrá como objetivo cubrir la demanda del mercado. Adicionalmente se tienen las siguientes condiciones: 
- Se elaborará un plan de producción detallado anualmente, un plan agregado de producción el cual estará detallado mensualmente, así como un plan de requerimientos de producción

- La demanda se obtendrá del punto 2.4.1.5.

- Se trabajará con una producción de tipo Make to Order ya que, se trata de un producto perecible, se trabajará con la política "first in first out" (FIFO), para poder contar siempre con productos frescos de alta calidad.

- El horizonte a tomar será de 5 años

Con los datos previamente mencionados se procederá a elaborar el plan estratégico de producción, teniendo en cuenta lo siguiente:

a) Para el mantenimiento reactivo o correctivo se perderá en promedio 2 días

b) El lead time para producción es de 2 días

c) Se desea un stock de seguridad de 4 días para poder satisfacer el pedido de nuestros clientes.

A continuación, se presenta el plan maestro de producción anual de la planta:

Tabla 5.27: Programa de producción anual

\begin{tabular}{c|c|r|c|c}
\hline Año & $\begin{array}{c}\text { Stock Inicial } \\
(\mathbf{s a c o s} 60 \mathbf{~ k g})\end{array}$ & $\begin{array}{c}\text { Demanda (Sacos } \\
\mathbf{6 0} \mathbf{~ k g})\end{array}$ & $\begin{array}{c}\text { Producción } \\
(\text { Sacos 60 kg) }\end{array}$ & $\begin{array}{c}\text { Stock Final } \\
(\text { Sacos 60 kg) }\end{array}$ \\
\hline 2020 & 0 & 8123 & 8257 & 134 \\
\hline 2021 & 134 & 8837 & 8848 & 145 \\
\hline 2022 & 145 & 9550 & 9562 & 157 \\
\hline 2023 & 157 & 10263 & 10275 & 169 \\
\hline 2024 & 169 & 11689 & 11713 & 192 \\
\hline
\end{tabular}

Elaboración Propia

Asimismo, y como se mencionó previamente, se procederá a elaborar el plan maestro de producción, detallado de forma mensual para el año 2024. 
Tabla 5.28: Programa de producción mensual

\begin{tabular}{c|c|c|c|c|c|c|c|c|c|c|c|c}
\hline Mes & Ene & Feb & Mar & Abr & May & Jun & Jul & Ago & Set & Oct & Nov & Dic \\
\hline $\begin{array}{c}\text { Stock Inicial } \\
(\text { sacos 60 kg) }\end{array}$ & 169 & 137 & 125 & 130 & 121 & 220 & 287 & 446 & 504 & 423 & 312 & 219 \\
\hline $\begin{array}{c}\text { Demanda } \\
(\text { Sacos 60 kg) }\end{array}$ & 515 & 470 & 488 & 453 & 826 & 1077 & 1671 & 1892 & 1585 & 1169 & 823 & 722 \\
\hline $\begin{array}{c}\text { Producción } \\
(\text { Sacos 60 kg) }\end{array}$ & 484 & 458 & 493 & 444 & 925 & 1144 & 1830 & 1950 & 1503 & 1058 & 730 & 695 \\
\hline $\begin{array}{c}\text { Stock Final } \\
(\text { Sacos 60 kg) }\end{array}$ & 137 & 125 & 130 & 121 & 220 & 287 & 446 & 504 & 423 & 312 & 219 & 192 \\
\hline
\end{tabular}

Elaboración Propia

\subsection{Requerimiento de insumos, servicios y personal indirecto}

\subsubsection{Materia prima, insumos y otros materiales}

En este capítulo se procederá a determinar los requerimientos en cuanto a insumos necesarios para poder obtener la producción total de sacos de $60 \mathrm{~kg}$ de almendra de cacao, para ello se tiene que:

Figura 5.8: Diagrama de Gozinto

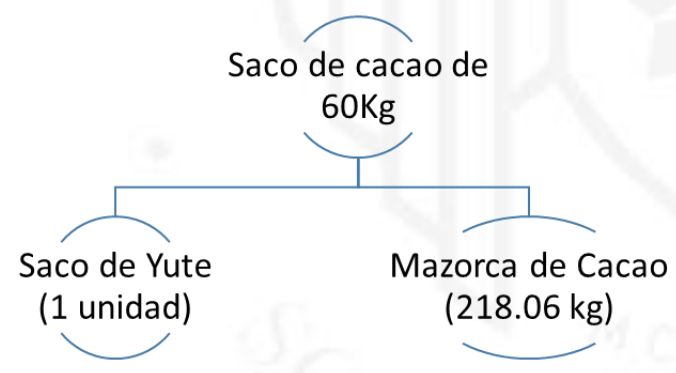

Fuente: Manual para el diseño de instalaciones manufactureras y de servicios (2018)

Con estos datos se procederá a realizar el MRP del saco de Yute de $60 \mathrm{Kg}$, teniendo como datos lo siguiente:

- Se requiere de un nivel de servicio de $95 \%$

- El plazo de entrega del proveedor es de 10 días

- La desviación en el tiempo de entrega del producto es de 1 día

- El pedido de los sacos solo se realiza por cientos 
Con estos datos se determinó un el requerimiento y pedidos de sacos de yute para cacao:

Tabla 5.29: Cuadro de requerimientos para sacos

\begin{tabular}{c|r|r|r|r}
\hline Año & $\begin{array}{r}\text { Stock Inicial } \\
\text { (sacos 60 kg) }\end{array}$ & $\begin{array}{c}\text { Requerimiento } \\
\text { (Sacos 60 kg) }\end{array}$ & $\begin{array}{c}\text { Pedido } \\
\text { (Sacos 60 kg) }\end{array}$ & $\begin{array}{c}\text { Stock Final } \\
\text { (Sacos 60 kg) }\end{array}$ \\
\hline 2020 & - & 8,257 & 8,400 & 143 \\
\hline 2021 & 143 & 8,848 & 8,900 & 195 \\
\hline 2022 & 195 & 9,562 & 9,500 & 133 \\
\hline 2023 & 133 & 10,275 & 10,300 & 158 \\
\hline 2024 & 158 & 11,713 & 11,700 & 145 \\
\hline
\end{tabular}

Elaboración Propia

De igual manera se procederá a realizar el requerimiento y la cantidad de pedidos de mazorcas de cacao teniendo en cuenta lo siguiente:

- No se mantendrá stock de las mazorcas de cacao, ya que una vez cortada, empieza a biodegradarse, por lo cual la materia prima ingresará directamente a ser cortada, limpiada y enviada a la zona de escurrido donde se la mantendrá por aproximadamente 18-24 horas.

Con este dato, se determinó que el requerimiento mazorcas de cacao es de:

Tabla 5.30: Cuadro de requerimientos para mazorcas

\begin{tabular}{c|r}
\hline Año & $\begin{array}{c}\text { Requerimiento } \\
\text { (mazorcas de } \\
\text { cacao kg) }\end{array}$ \\
\hline 2020 & $1,800,505$ \\
\hline 2021 & $1,929,423$ \\
\hline 2022 & $2,084,944$ \\
\hline 2023 & $2,240,465$ \\
\hline 2024 & $2,554,068$ \\
\hline
\end{tabular}

Elaboración Propia

En el área de plantación se necesitarán los siguientes insumos: 
Tabla 5.31: Cuadro de insumos para plantación

\begin{tabular}{c|c|c|c|c|c|c}
\hline Material & UM & $\mathbf{2 0 2 0}$ & $\mathbf{2 0 2 1}$ & $\mathbf{2 0 2 2}$ & $\mathbf{2 0 2 3}$ & $\mathbf{2 0 2 4}$ \\
\hline Abono & Onzas & 324.40 & 528.54 & 952.57 & $1,023.71$ & $1,165.95$ \\
\hline $\begin{array}{c}\text { Bolsas para } \\
\text { injerto }\end{array}$ & Unidad & $2,074.00$ & & & & \\
\hline Sustrato & $\mathbf{K g}$ & $3,457.74$ & & & & \\
\hline
\end{tabular}

Elaboración Propia

\subsubsection{Servicio: energía eléctrica, agua, vapor, combustible, etc.}

\section{Energía Eléctrica:}

Los procesos presentes en la cadena de producción de cacao fino utilizan maquinaria que depende de energía eléctrica para su funcionamiento. Es por este motivo que se presenta a continuación el cálculo requerido para determinar el consumo de energía para el horizonte del proyecto. Para determinar el costo de energía eléctrica se utilizará la tarifa BT3.

Tabla 5.32: Cálculo de H-Máquina al año

\begin{tabular}{c|c|r|r|r|r|r}
\cline { 3 - 7 } \multicolumn{2}{c}{} & \multicolumn{7}{c}{ Años } & \multicolumn{1}{c}{$\mathbf{2 0 2 2}$} & $\mathbf{2 0 2 3}$ & $\mathbf{2 0 2 4}$ \\
\cline { 3 - 8 } Equipo & $\begin{array}{c}\text { Rendimient } \\
\text { o (kg/hora) }\end{array}$ & \multicolumn{5}{c}{ Horas de producción anual } \\
\hline \multirow{2}{*}{ Despulpadora de Cacao } & 1000 & $1,239.9$ & $1,348.8$ & $1,457.7$ & $1,566.5$ & $1,784.2$ \\
\hline Lavado por Inmersión & 1000 & 930.0 & $1,011.6$ & $1,093.3$ & $1,174.9$ & $1,338.1$ \\
\hline Secadora de granos & 150 & $3,836.4$ & $4,173.2$ & $4,510.0$ & $4,846.9$ & $5,520.3$ \\
\hline Seleccionadora de granos & 150 & $3,759.6$ & $4,089.7$ & $4,419.8$ & $4,749.9$ & $5,409.9$ \\
\hline Peladora de Granos & 150 & $3,383.7$ & $3,680.8$ & $3,977.8$ & $4,274.9$ & $4,868.9$ \\
\hline Ensacadora & 1200 & 410.3 & 446.3 & 482.3 & 518.3 & 590.4 \\
\hline
\end{tabular}

Elaboración Propia 
Tabla 5.33: Cálculo de Kw-h/año

\begin{tabular}{|c|c|c|c|c|c|c|c|}
\hline & & & \multirow{2}{*}{\multicolumn{5}{|c|}{ Años }} \\
\hline & & & & & & & \\
\hline & & & 2020 & 2021 & 2022 & 2023 & 2024 \\
\hline Equipo & KW/H & Cantidad & \multicolumn{5}{|c|}{ Kw consumidos al año } \\
\hline Despulpadora de Cacao & 3.5 & 1 & $4,339.79$ & $4,720.81$ & $5,101.84$ & $5,482.87$ & $6,244.67$ \\
\hline Lavado por Inmersion & 2.02 & 2 & $3,757.02$ & $4,086.88$ & $4,416.74$ & $4,746.60$ & $5,406.10$ \\
\hline Secadora de granos & 0.5 & 2 & $3,836.37$ & $4,173.20$ & $4,510.03$ & $4,846.85$ & $5,520.29$ \\
\hline Seleccionadora de granos & 7.5 & 2 & $56,394.68$ & $61,346.04$ & $66,297.40$ & $71,248.76$ & $81,148.25$ \\
\hline Peladora de Granos & 2.13 & 2 & $14,414.48$ & $15,680.05$ & $16,945.62$ & $18,211.18$ & $20,741.49$ \\
\hline Ensacadora & 2 & 1 & 820.54 & 892.58 & 964.63 & $1,036.67$ & $1,180.71$ \\
\hline Sensores de Temperatura & 0.004 & 82.5 & $20,235.60$ & $20,235.60$ & $20,235.60$ & $20,235.60$ & $20,235.60$ \\
\hline Sensor de Humedad & 0.0065 & 33 & $13,153.14$ & $13,153.14$ & $13,153.14$ & $13,153.14$ & $13,153.14$ \\
\hline Total (kw/año) & & & $116,951.6$ & $124,288.3$ & $131,625.0$ & $138,961.7$ & $153,630.3$ \\
\hline
\end{tabular}

Elaboración Propia

Agua:

El consumo de agua estará dado por el proceso de limpieza del cacao cuando aún posee mucílago y posteriormente cuando la almendra ya haya fermentado. A continuación, se presenta el cálculo efectuado para determinar el consumo de agua donde, adicionalmente como dato técnico, se conoce que la máquina tiene una capacidad de $500 \mathrm{~kg}$ de producto para los cuales utiliza $3 \mathrm{~m}^{3}$ de agua.

Tabla 5.34: Consumo de agua anual

\begin{tabular}{c|r|r|r|r|r}
\cline { 2 - 6 } & \multicolumn{1}{c|}{$\mathbf{2 0 2 0}$} & \multicolumn{1}{c}{ Años } & \multicolumn{1}{c}{$\mathbf{2 0 2 2}$} & \multicolumn{1}{c}{$\mathbf{2 0 2 3}$} & \multicolumn{1}{c}{$\mathbf{2 0 2 4}$} \\
\hline Cantidad a lavar $(\mathrm{kg})$ & $1,505,410.42$ & $1,587,058.94$ & $1,668,707.46$ & $1,750,355.98$ & $1,913,599.69$ \\
\hline Proporción $\left(3 \mathrm{~m}^{3} / 500 \mathrm{~kg}\right)$ & 0.006 & 0.006 & 0.006 & 0.006 & 0.006 \\
\hline $\begin{array}{c}\text { Consumo de Agua } \mathbf{m}^{\mathbf{3}} \\
\text { Anual }\end{array}$ & $\mathbf{9 , 0 3 2 . 4 6}$ & $\mathbf{9 , 5 2 2 . 3 5}$ & $\mathbf{1 0 , 0 1 2 . 2 4}$ & $\mathbf{1 0 , 5 0 2 . 1 4}$ & $\mathbf{1 1 , 4 8 1 . 6 0}$ \\
\hline
\end{tabular}

Elaboración Propia

\subsubsection{Determinación del número de trabajadores indirectos}

Los trabajadores indirectos para este estudio son aquellos que no forman parte del proceso productivo del cacao fino, sino que cumplen una función administrativa en diversos niveles de jerarquía. En esta oportunidad se tomaron en cuenta los siguientes puestos indirectos: 
Tabla 5.35: Principales puestos y funciones de trabajo indirectos

\begin{tabular}{|c|c|c|}
\hline Puesto & Funciones & Cantidad \\
\hline Gerente General & $\begin{array}{l}\text { Encargado del área administrativa financiera y } \\
\text { comercial de la empresa }\end{array}$ & 1 \\
\hline Gerente de Operaciones & $\begin{array}{l}\text { Encargado de implementar las mejoras contínuas en el } \\
\text { proceso, buscando maquinaria más eficiente que } \\
\text { reduzcan los costos y coordinar la logistica del producto } \\
\text { terminado }\end{array}$ & 1 \\
\hline Jefe de producción & \begin{tabular}{|l|} 
Supervisar constantemente las actividades de los \\
operarios \\
Realizar una evaluación de desempeño mensual de los \\
operarios \\
Proponer mejoras contínuas al gerente de operaciones
\end{tabular} & 1 \\
\hline Jefe de plantación & $\begin{array}{l}\text { Supervisar proceso de plantación desde la selección de } \\
\text { la semilla hasta la cosecha } \\
\text { Proponer mejoras contínuas }\end{array}$ & 1 \\
\hline Supervisor de almacén & $\begin{array}{l}\text { Verificar toda recepción y almacenamiento de las } \\
\text { semillas e insumos } \\
\text { Mantener un registro ordenado de lo que entra y sale } \\
\text { del almacén, como también mantener el Stock de } \\
\text { Seguridad } \\
\text { Capacitar a los operarios acerca de la técnica de } \\
\text { almacenamiento PEPS asi como el uso de los } \\
\text { programas para registro de unidades }\end{array}$ & 1 \\
\hline Supervisor de seguridad & \begin{tabular}{|l|} 
Asegurar la seguridad de los obreros y la maquinaria \\
mediante capacitaciones \\
Encargarse que se cumpla la Ley 29783 \\
Determinar soluciones a los Peligros y Riesgos \\
existentes en planta
\end{tabular} & 1 \\
\hline $\begin{array}{l}\text { Supervisor de Control de } \\
\text { Calidad }\end{array}$ & $\begin{array}{l}\text { Realizar pruebas químicas y biológicas al producto } \\
\text { terminado para asegurar inocuidad } \\
\text { Liderar proyectos de mejora contínua para los } \\
\text { procesos productivosy no productivos } \\
\text { Presentar mensualmente reporte de calidad del } \\
\text { producto (Conformes/Disconformes) }\end{array}$ & 1 \\
\hline
\end{tabular}

Elaboración Propia

\subsubsection{Servicios de terceros}

Se considerarán distintos servicios de terceros (outsourcing) para el correcto funcionamiento del proyecto. El principal motivo por el que se consideraron servicios ajenos fue porque estos no le dan un valor agregado a la estrategia genérica del proyecto y el costo es más económico. 


\section{Servicios de mantenimiento:}

Se tercerizará este servicio ya que se requiere de un mantenimiento continuo para las máquinas puesto que, es indispensable contar con un control óptimo de los parámetros a utilizar. Al contar con un servicio tercerizado, se estaría ahorrando dinero y espacio al no almacenar los repuestos de las máquinas.

\section{Servicios de limpieza/higiene:}

Es fundamental contar con un equipo de limpieza en todo momento, ya que la salud y la buena calidad del producto son metas fundamentales en este proyecto. Este personal debe ser capacitado para que realice correctamente el limpiado de las máquinas. Por temas de reducción de costos administrativos, se optará contratar una empresa de limpieza y ellos proveerán los materiales y personal suficiente para realizar el trabajo en el tiempo pactado.

\section{Servicios de seguridad:}

Se tercerizará este servicio para evitar la constante preocupación al contratar personal de confianza y que esté capacitado para proteger la instalación y a los trabajadores en todo momento. Estas empresas de seguridad suelen capacitar a su personal para cualquier tipo de situación en cualquier tipo de empresa, enseñándole los valores que deben respetar en todo momento, así como incentivos para que lo hagan motivados.

\section{$\underline{\text { Servicios de transporte: }}$}

Es importante tercerizar este servicio ya que, es considerado un costo adicional fuerte transportar el producto final al puerto. También, estas empresas de transporte aseguran la total confianza de su personal y vehículos de transporte. 


\subsection{Disposición de planta}

\subsubsection{Características físicas del proyecto}

\section{Factor Edificio:}

La planta se ubicará en el distrito de Tocache, San Martín y de manera independiente contará con todas las herramientas necesarias para su óptimo funcionamiento. Esta construcción tendrá un solo nivel de acero y cemento con una estructura antisísmica, con señalizaciones claras tanto en los pasillos como en las estaciones de trabajo.

Por otro lado, se debe tener presente la alta calidad que se dará al producto para su posterior venta al exterior. Para esto, se procede a elaborar un diseño higiénico para evitar que el proceso productivo se contamine en algún momento. Mediante esta implementación del diseño, se logrará facilitar la desinfección del ambiente dentro de la planta, manteniendo al personal libre de cualquier riesgo para su salud y evitando la disminución de la calidad del producto terminado.

De manera más detallada, un diseño higiénico se basa principalmente en implementar ciertas acciones en un ambiente para medir su facilidad de limpiado tanto de los equipos como de las áreas de trabajo. Se recomienda evitar el uso de materiales que generen merma en procesos como el transporte de materiales o producto terminado de un lugar a otro en la planta.

En cuanto a la maquinaria, estas deben contar con un canal de drenaje para que el lavado de aquellas sea lo más simple posible y se logre eliminar por completo la suciedad que se genera en el día a día en cada estación. Estas tendrán una plataforma con ruedas con seguro y solo se moverán de su sitio para la limpieza de la zona de trabajo.

La ventilación es esencial para evitar un ambiente congestionado y de poca visibilidad para los trabajadores. Si no se mantiene un ambiente ventilado, se condensarán los vapores y aumentará la temperatura. Para esto, no solo se requiere de extractores de aire y ventiladores, sino también tener un techo con altura mínima de 5 metros. También, 
la planta de producción deberá tener una luminosidad aproximadamente entre 215-230 lux para la óptima realización de las actividades diarias.

\section{$\underline{\text { Factor Servicio: }}$}

Es importante tener los servicios básicos dentro de la planta para poder contar con un ambiente de trabajo agradable para el personal ya que, si ellos se sienten satisfechos en su trabajo, la productividad aumentará de manera notoria gracias a la motivación que se genera en cada uno.

Los servicios necesarios para el área de producción y administrativa son:

\section{Producción:}

- Camerino: Guardarán sus cosas personales como mochila, ropa, EPP's, entre otros.

- Servicios Higiénicos (S.S.H.H.).

- Almacén de materia prima y productos terminados ubicados en zonas estratégicas para lograr el menor recorrido posible y optimizar tiempos.

- Área de calidad: Se tomarán muestras del lote para realizar las pruebas de calidad y determinar si son aptas para la comercialización.

\section{Administración:}

- Oficinas con equipos instalados para el óptimo funcionamiento de sus labores diarias.

- Servicios Higiénicos (S.S.H.H.).

La planta contará con una enfermería y todo el personal tendrá seguro médico y pasarán por exámenes regulares cada año para asegurarse que todos tengan buena salud. También, se tendrá un comedor con mesas, microondas, sillas y sillones para satisfacer las necesidades alimenticias de los trabajadores. 


\subsubsection{Determinación de las zonas físicas requeridas}

Luego de conocer el factor servicio y edificio y la cantidad de trabajadores tanto directos como indirectos requeridos, se procedió a evaluar qué zonas físicas son necesarias en la planta. Estas son:
a) Área de escurrido
b) Almacén de producto terminado
c) Área de producción
d) Patio de maniobras
e) Área administrativa
f) Laboratorio de calidad
g) Comedor
h) S.S.H.H.
i) Enfermería
j) Almacén de fertilizante
k) Biodigestor
1) Otros

\subsubsection{Cálculo de áreas para cada zona}

A) Área de Escurrido y almacén de Insumos

Para el escurrido, las almendras deben colocarse en sacos de yute de $60 \mathrm{Kg}$ para poder dejarlas reposar durante 24-36 horas en promedio según dato obtenido por Verlinda Verónica Sotelo Egusquiza en su tesis: "EFECTO DEL TIEMPO DE ESCURRIMIENTO DEL MUCILAGO EN LA FERMENTACION, CALIDAD FISICA Y ORGANOLÉPTICA” . De este dato antes mencionado se determina que la zona de escurrido debe tener la capacidad de albergar 142 sacos.

Se sabe que una parihuela tiene la capacidad de $2500 \mathrm{Kg}$ y sus dimensiones son de $1.00 \times 1.20$ x 0.115 metros (largo x ancho x altura). Además, según el Decreto Supremo $\mathrm{N}^{\circ}$ 005-2009-TR, el apilamiento no debe exceder los 2 metros de altura, por lo que se obtuvieron los siguientes resultados: 
a.1) Debido a las restricciones de dimensión se tiene que, en una parihuela por nivel solo ingresan 2 sacos.

Figura 5.9: Disposición de sacos en parihuela

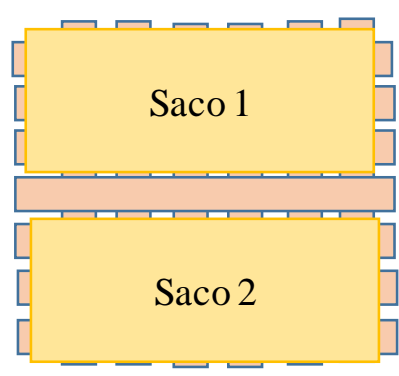

Elaboración Propia

a.2) Debido a las restricciones de altura, solo puede apilarse hasta 4 niveles.

a.3) En una parihuela ingresan 8 sacos de $60 \mathrm{Kg}$, debido a esto, y para una demanda diaria de $8,505.72 \mathrm{Kg}$ de grano con mucílago, se necesitarán 142 sacos equivalentes a 18 parihuelas llenas que ocuparán un total de $21.26 \mathrm{~m} 2$.

Adicionalmente se dejará espacio entre parihuelas de $10 \mathrm{~cm}$ para permitir el ingreso de aire. Además, para que pueda ingresar el montacargas eléctrico el ancho de pasillo principal será de 3 metros y para los pasillos secundarios 2.2 metros.

De igual manera se analizó el espacio requerido para almacenar los paquetes de sacos de cacao teniendo en cuenta que para el año 2024 se tendrá la necesidad más alta de 1900 sacos para producción, con este dato y además sabiendo que cada paquete de 100 sacos tiene 0.9 metros de largo, 0.6 metros de ancho y una altura de 1.25 metros, realizando las operaciones antes mencionadas, se determinó que en una parihuela ingresarán 4 paquetes, 2 en el primer nivel y los 2 subsecuentes en un segundo nivel. De esta manera, se determinó que se necesitarán 5 parihuelas que ocuparán un espacio de $5.70 \mathrm{~m}^{2}$.

Adicionalmente, se dejará cuatro parihuelas extras para almacenar insumos u otros aditivos necesarios no previstos. 
A continuación, se detalla una vista preliminar de la zona de escurrido más el almacén de insumos con un área total de $103.68 \mathrm{~m}^{2}$.

Figura 5.10: Plano del área de escurrido

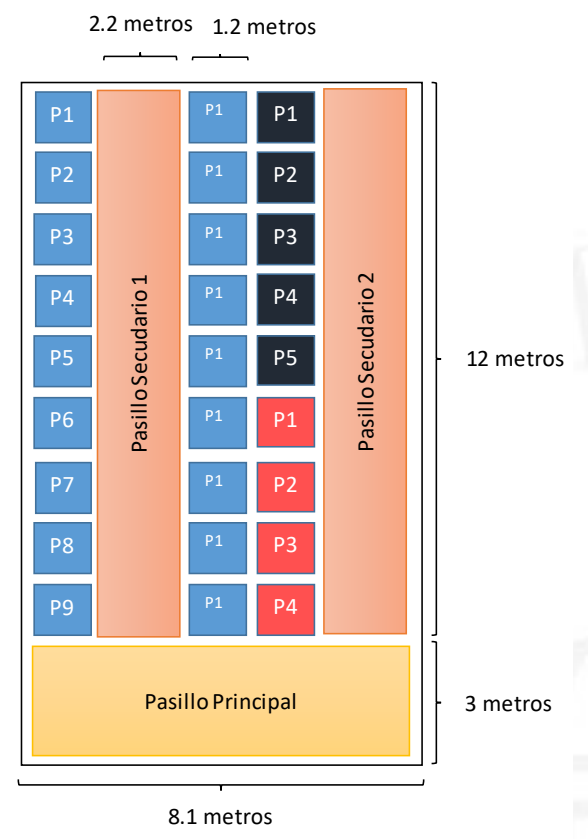

Elaboración Propia

B) Almacén de producto terminado

Para poder determinar el almacén de producto terminado de trabaja con el inventario promedio del año de mayor demanda que para este caso será de 248 sacos de $60 \mathrm{~kg}$. Adicionalmente, se conoce que en una parihuela de 1.00 x 1.20 x 0.115 metros (largo $\mathrm{x}$ ancho x altura) ingresan 8 sacos. Por lo que en total serán 22 parihuelas. De igual manera que la zona de escurrido, habrá la misma separación entre parihuelas y el mismo ancho en los pasadizos principales y secundarios. A continuación se presenta una vista preliminar del almacén de productos terminados con un área total de $107.92 \mathrm{~m}^{2}$. 
Figura 5.11: Plano de almacén de producto terminado

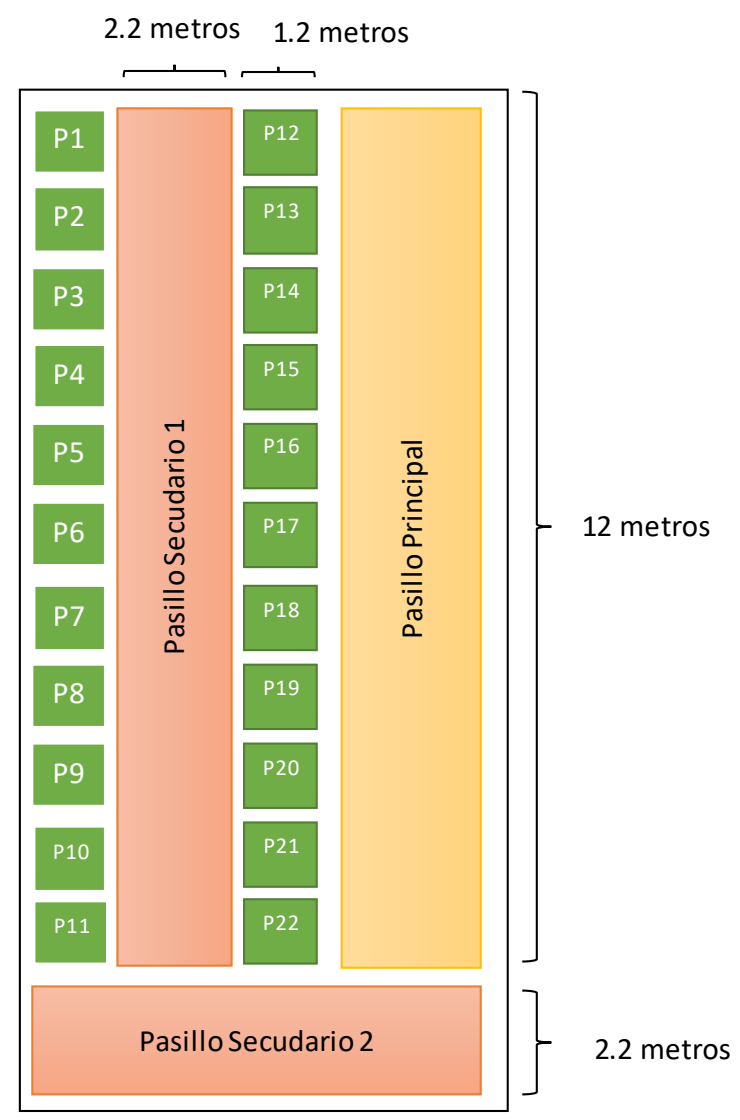

Elaboración Propia

C) Área de producción

El cálculo del área correspondiente a producción se efectuará a detalle en el capítulo 5.12.5 denominado "Disposición de detalle de la zona productiva".

D) Patio de maniobras

El patio de maniobras debe permitir el flujo tanto de despacho como de ingreso de productos a la planta. Por esta razón, debe tener acceso inmediato a la zona de cortado donde inicia el proceso de producción de cacao y al almacén de producto terminado. Además, debe ser suficientemente amplio para permitir maniobrar de forma segura a los camiones. Por este motivo se considera que el ancho del patio sea de mínimo 5 metros de ancho. El largo se calculará más adelante cuando se determine la disposición de planta. 
E) Área administrativa

A continuación, se detalla el tamaño de oficinas asignadas para cada puesto de trabajo, teniendo en cuenta que la oficina del gerente general se contará con un ambiente mayor para realizar reuniones semanales con los gerentes de las diversas áreas mostradas.

Tabla 5.36: Tamaño de oficinas

\begin{tabular}{llll}
\hline Puesto & \multicolumn{1}{c}{ Oficinas } & \\
& Clasificación & $\begin{array}{l}\text { Tamaño de oficina } \\
(\mathbf{m} 2)\end{array}$ \\
\hline $\begin{array}{l}\text { Gerente general } \\
\text { Supervisor de Control de } \\
\text { Calidad }\end{array}$ & $\begin{array}{l}\text { Ejecutivo Principal } \\
\text { Mando Medio }\end{array}$ & 20 \\
Gerente Comercial & Ejecutivo & 15 \\
\hline $\begin{array}{l}\text { Supervisor } \\
\text { Almacenes }\end{array}$ & Mando Medio & 9.5 \\
\hline $\begin{array}{l}\text { Vendedor (x2) } \\
\text { Gerente de Finanzas }\end{array}$ & $\begin{array}{l}\text { Oficinista } \\
\text { Mando Medio }\end{array}$ & 7 \\
\hline Secretaria & Trabajo Mínimo & 6 \\
\hline
\end{tabular}

Fuente: Ministerio de vivienda, construcción y saneamiento (2015)

F) Laboratorio de calidad

El tamaño del laboratorio de calidad fue determinado en el anterior punto, siendo éste de 15 metros cuadrados. El presente laboratorio estará equipado con las herramientas y máquinas necesarias para verificar adecuadamente el producto y realizar un seguimiento de calidad a lo largo del proceso.

\section{G) Comedor}

Debido a que se trabajará 2 turnos al día, la planta contará con un comedor totalmente equipado de mesas, microondas y sillas. Para determinar el cálculo del comedor se considerar que cada persona ocupará $1.43 \mathrm{~m} 2$. Así mismo, del análisis anterior se puede determinar que del área administrativa se cuenta con 8 personas y del área de producción 
20 personas, dando así un total de $40.4 \mathrm{~m} 2$. Sin embargo, este comedor tendrá dos pisos por lo que el área se reduce a $20.2 \mathrm{~m} 2$. Teniendo en cuenta el tamaño de pasillo y mesas el área total calculada asciende a 72.93 metros cuadrados.

H) Servicios higiénicos

h.1) Área de producción

Para el área de producción, teniendo en cuenta la Norma A. 060 propuesta por el Ministerio de vivienda, construcción y saneamiento, se tendrá para los hombres: 3 lavatorios, 3 urinarios y 3 inodoros. Para las mujeres a su vez, se contará con: 2 lavatorios y 2 inodoros, dando un total de $18 \mathrm{~m} 2$.

El área de producción tendrá 5 duchas y un vestuario a razón de $1.5 \mathrm{~m} 2$ por trabajador por turno de trabajo, el cual contará con bancas y espacio designado para guardar sus pertenencias si así lo desean. Resultando así un total de $30 \mathrm{~m} 2$.

h.2) Área administrativa

Para el Área administrativa, teniendo en cuenta la norma A.080, se tendrá para los hombres: 2 lavatorios, 2 urinarios y 2 inodoros. Para las mujeres se contará con 2 lavatorios y 2 inodoros. Lo que da como resultado un total de $12 \mathrm{~m} 2$.

\section{I) Enfermería}

En la enfermería se tendrá una camilla y medicina necesaria para atender al personal en caso de emergencias con la finalidad de estabilizarlo hasta que llegue personal capacitado. Debido a esto, se ha considerado que el tópico debe tener $14 \mathrm{~m} 2$. Además, debe estar cerca del área de producción ya que hay mayor probabilidad de accidente en esta zona. 
J) Almacén de fertilizante

Este almacén será creado para poder almacenar fertilizante orgánico que será creado con la merma de los subproductos de cada proceso, de esta manera se pretende preservar el medio ambiente y a su vez generar un vínculo más fuerte con los proveedores, que exigen subsidios, ya sea monetariamente o que se financie parte de los insumos necesarios para mantener su terreno. Además, la capacidad de fertilizante que dan los biodigestores es de 6,618 kg cada 3 semanas, lo que conlleva a un total de 110 sacos de $60 \mathrm{~kg}$. Con estos datos y de igual manera que la zona de escurrido se procederá a dimensionar el almacén de fertilizante. A continuación se presenta una vista preliminar del almacén de productos terminados con un área total de $49.22 \mathrm{~m}^{2}$.

Figura 5.12: Almacén de fertilizante

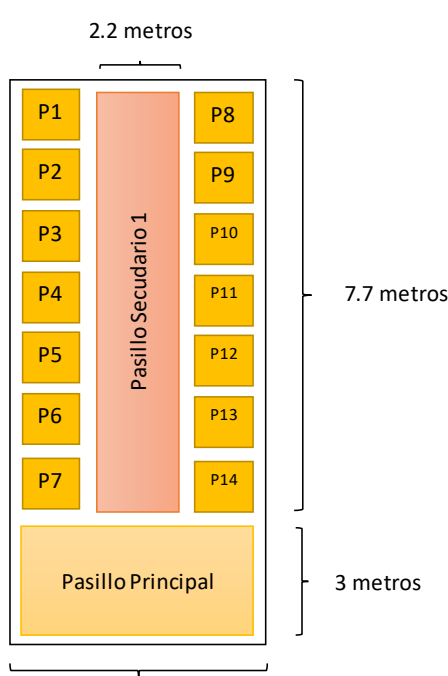

4.6 metros

Elaboración Propia

K) Biodigestor

Esta área será creada para dar un mejor uso a los subproductos de cada proceso necesario para obtener almendras de caca para exportación, el Área de la zona del biodigestor estará dada por las dimensiones de los 3 biodisgestores a comprar de $38.49 \mathrm{~m} 3$, los cuales ocuparán un total de $29 \mathrm{~m} 2$ más pasillos y un área donde se pueda cargar el fertilizante a sacos resulta un total de $34.5 \mathrm{~m} 2$. 


\section{L) Otros}

El área consignada para los estacionamientos será de $80 \mathrm{~m} 2$ con capacidad para 5 vehículos y dispondrá de un estacionamiento para discapacitados como lo indica la ley 28084. Para el área de estacionamiento se considera el artículo 65 del reglamento nacional de edificación, el cual considera un largo de 5 metros x 2.70 metros de ancho para cada vehículo.

Finalmente, respecto al tema de seguridad, se ubicara una caseta para el guardián de $5 \mathrm{~m} 2$, cuya finalidad será llevar control del ingreso y salida tanto del personal como de cualquier vehículo de la planta.

Tabla 5.37: Resumen metraje de las áreas

\begin{tabular}{|l|l|}
\hline Área & Tamaño ( m2 ) \\
\hline Zona de Escurrido y almacén de Insumos & 103.68 \\
\hline Almacén de Productos Terminados & 107.92 \\
\hline Zona Administrativa & 77 \\
\hline Comedor & 72.93 \\
\hline Servicios higiénicos & 42 \\
\hline Enfermería & 13.97 \\
\hline Otros & 85 \\
\hline Almacén de Fertilizante & 49.2 \\
\hline Biodigestor & 34.5 \\
\hline TOTAL & 586.20 \\
\hline
\end{tabular}

Elaboración Propia

\subsubsection{Dispositivos de seguridad industrial y señalización}

La implementación de los dispositivos y las señalizaciones de seguridad y emergencia, significarán la disminución de accidentes y riesgos en la empresa. Cada dispositivo y señalización debe respetar la Norma Técnica Peruana 339.010 1 "Señales de Seguridad" y el mismo supervisor de planta será el encargado de elaborar un mapa de riesgos y el plan de evacuación. A continuación se observan algunos dispositivos de seguridad 
activos y pasivos, como también EPP's y otras señales esenciales que deben utilizarse en caso de un incendio, sismo o emisión de algún gas tóxico.

\section{Dispositivos de Seguridad Activos:}

- Alarma contra incendio y sismos

- Detector de humos y gases

- Extintores de polvo químico seco (PQS)

- Rociadores de agua

\section{Dispositivos de Seguridad Pasivos:}

- Señales de salidas de emergencia

- Señales de zonas seguras

- Señales de ubicación de EPP's

- Paredes y puertas contra incendio y antisísmica

Figura 5.13: Señales para equipos contra incendios

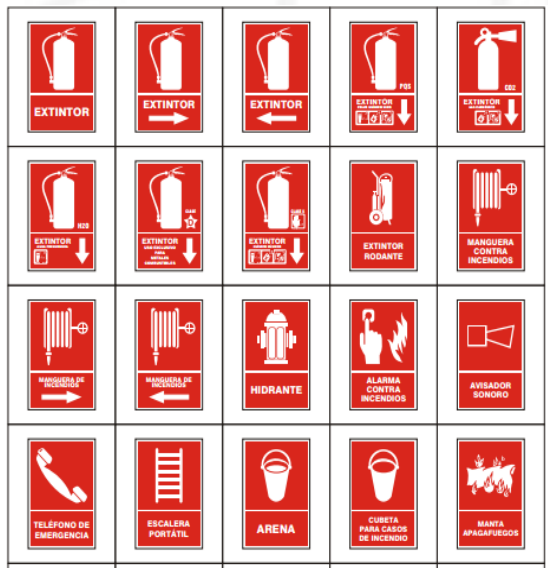

Fuente: NTP 399.010-1 “SEÑALES DE SEGURIDAD” (2016)

\section{Señalizaciones en la planta de producción:}

- Señales de advertencia:

- Cuidado piso húmedo/mojado, Cuidado con las manos, Atención riesgo de atrapamiento y corte. 
Figura 5.14: Señales de advertencia

\begin{tabular}{|c|c|c|c|c|}
\hline$\frac{44}{20}$ & 会 & A & 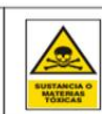 & 金 \\
\hline$=$ & A & $\$$ & 쇼 & $=$ \\
\hline $\begin{array}{l}\text { 金 } \\
=0\end{array}$ & $\begin{array}{ll}\mathrm{A} \\
\mathrm{O}\end{array}$ & $\begin{array}{l}0.0 \\
=0 \\
=0\end{array}$ & 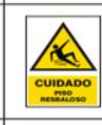 & wive \\
\hline 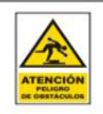 & 坥 & 事 & A & 4 \\
\hline
\end{tabular}

Fuente: NTP 399.010-1 “SEÑALES DE SEGURIDAD” (2016)

- Señales de prohibición:

- Prohibido fumar, prohibido ingreso no autorizado, prohibido ingerir bebidas y/o alimentos, prohibido ingreso sin EPP's.

Figura 5.15: Señales de prohibición

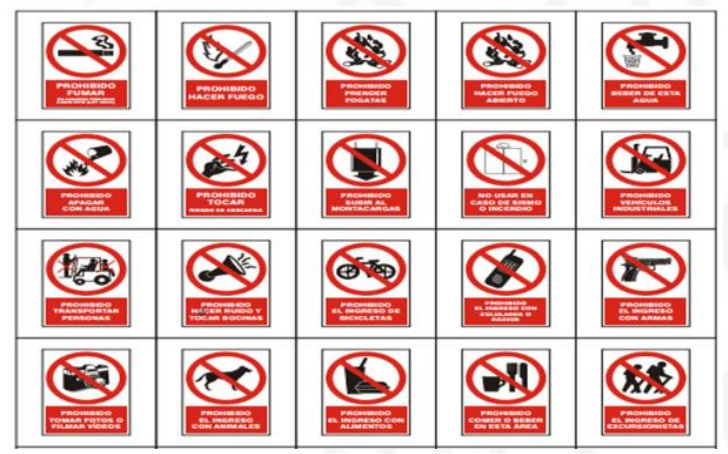

Fuente: NTP 399.010-1 “SEÑALES DE SEGURIDAD (2016)

- Señales de emergencia:

- Salida de emergencia, Zona segura

Figura 5.16: Señales de emergencia

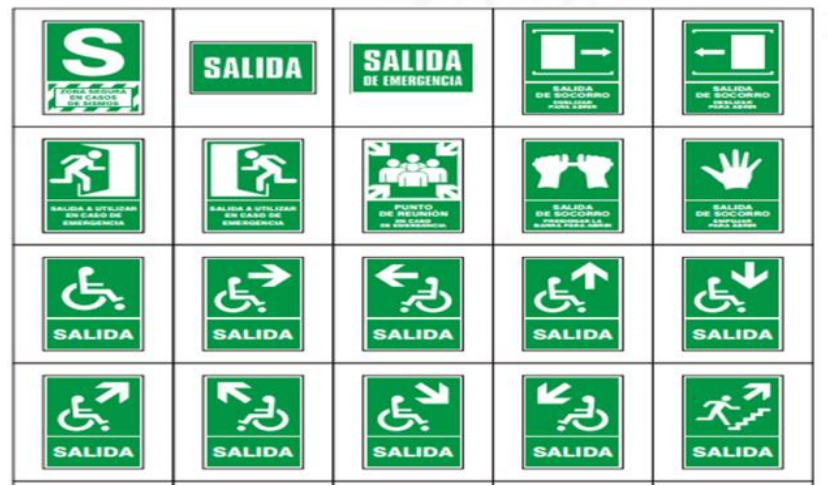

Fuente: NTP 399.010-1 “SEÑALES DE SEGURIDAD (2016) 
- Señales de protección y obligación:

- Uso obligatorio de lentes de seguridad, guantes, botas, ropa, mascarillas, protección auditiva.

Figura 5.17: Señales de protección y obligación

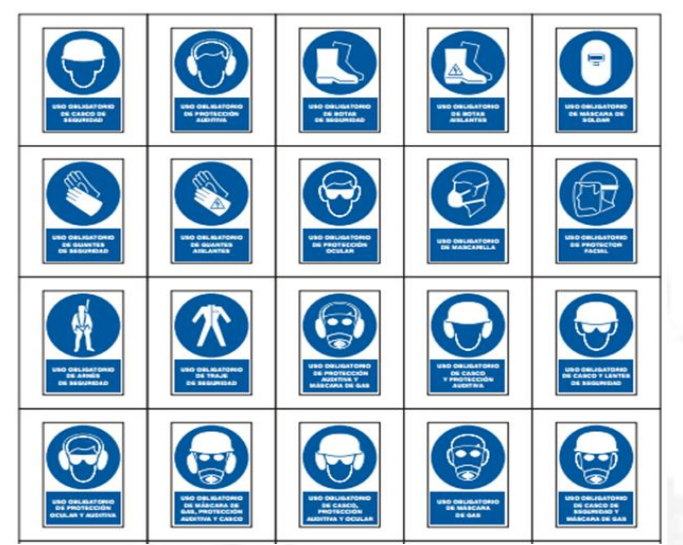

Fuente: NTP 399.010-1 “SEÑALES DE SEGURIDAD (2016)

\section{Equipos de Protección Personal (EPP's):}

Son aquellos equipos necesarios para la protección del personal directo e indirecto de los posibles peligros a los que pueden estar expuestos en el día a día dentro de la planta.

Tipos de EPP's:

- Lentes de seguridad

- Botas de seguridad

- Tapones para la protección auditiva

- Guantes de seguridad

- Mascarillas

- Vestimenta apropiada (uniforme) 


\subsubsection{Disposición de detalle de la zona productiva}

A continuación, se muestra el análisis Guerchet, el cual establece el tamaño mínimo del área productiva.

Tabla 5.38: Análisis de Guerchet- elemento estático

\begin{tabular}{|c|c|c|c|c|c|c|c|c|c|c|c|c|}
\hline \multicolumn{4}{|c|}{ Elementos estáticos } & \multicolumn{3}{|c|}{ Dimensiones } & \multicolumn{4}{|c|}{ Superficie } & \multicolumn{2}{|c|}{ Cálculos de K } \\
\hline Zona & Maquina & \begin{tabular}{|c|}
$\mathrm{N}^{\circ} \mathrm{de}$ \\
elementos \\
\end{tabular} & \begin{tabular}{|c|}
$\begin{array}{c}\text { Alto } \\
\text { (metros) }\end{array}$ \\
\end{tabular} & $\begin{array}{l}\text { Ancho } \\
\text { (metros) }\end{array}$ & $\begin{array}{c}\text { Largo } \\
\text { (metros) }\end{array}$ & $\begin{array}{l}\text { Lados } \\
(\mathrm{N})\end{array}$ & Ss & $\mathrm{Sg}$ & $\mathrm{Se}$ & ST & Ss $\times \mathrm{n} \times \mathrm{h}$ & Ss $\times \mathrm{n}$ \\
\hline \multirow{3}{*}{ Cortado } & $\begin{array}{c}\text { Pto Espera Parihuela con } \\
\text { MP en jabas } \\
\end{array}$ & 1 & 0.95 & 1.2 & 1 & - & - & - & - & - & - & - \\
\hline & \begin{tabular}{|l|} 
Despulpadora de Cacao \\
\end{tabular} & 1 & 1.85 & 1.746 & 3.35 & 1 & 5.8491 & 5.8491 & 7.0485 & 18.7467 & 10.820835 & 5.8491 \\
\hline & $\begin{array}{l}\text { Parihuela con Almendra } \\
\text { despulpada en jabas }\end{array}$ & 1 & 0.115 & 1.2 & 1 & - & $\begin{array}{ll}- \\
\end{array}$ & - & - & - & - & \\
\hline \multirow{3}{*}{$\begin{array}{r}\text { Limpieza pre } \\
\text { operacional }\end{array}$} & $\begin{array}{l}\text { Parihuela con Almendra } \\
\text { despulpada en jabas }\end{array}$ & 1 & 0.115 & 1.2 & 1 & - & 1.2 & - & 0.7230 & 1.9230 & 0.138 & 1.2 \\
\hline & Lavadora por inmersión & 1 & 1.738 & 1.028 & 2.233 & 1 & 2.295524 & 2.30 & 2.7662 & 7.3573 & 3.98962071 & 2.295524 \\
\hline & $\begin{array}{c}\text { Parihuela con almendra } \\
\text { limpia en sacos }\end{array}$ & 1 & 0.115 & 1.2 & 1 & - & 1.2 & - & 0.7230 & 1.9230 & 0.138 & 1.2 \\
\hline \multirow{3}{*}{ Fermentado } & $\begin{array}{c}\text { Parihuela con almendra } \\
\text { limpia en sacos }\end{array}$ & 1 & 0.95 & 1.2 & 1 & - & 1.2 & - & 0.7230 & 1.9230 & 1.14 & 1.2 \\
\hline & Fermentadora & 33 & 1 & 1 & 1 & 1 & 1 & 1.00 & 1.2051 & 105.7670 & 33 & 33 \\
\hline & \begin{tabular}{|c|} 
Pto Espera Parihuela con \\
almendra fermentada \\
dispuesta en jabas
\end{tabular} & 1 & 0.95 & 1.2 & 1 & - & 1.2 & - & 0.7230 & 1.9230 & 1.14 & 1.2 \\
\hline \multirow{9}{*}{$\begin{array}{c}\text { Limpieza } \\
\text { Operacional }\end{array}$} & $\begin{array}{c}\text { Pto Espera Parihuela con } \\
\text { almendra fermentada } \\
\text { dispuesta en jabas } \\
\end{array}$ & 1 & 0.95 & 1.2 & 1 & - & 1.2 & - & 0.7230 & 1.9230 & 1.14 & 1.2 \\
\hline & Lavadora por inmersión & 1 & 1.738 & 1.028 & 2.233 & 1 & 2.295524 & 2.30 & 2.7662 & 7.3573 & 3.98962071 & 2.295524 \\
\hline & \begin{tabular}{|c|} 
Pto Espera Parihuela con \\
almendra limpia dispuesta \\
en jabas
\end{tabular} & 1 & 0.95 & 1.2 & 1 & - & 1.2 & - & 0.7230 & 1.9230 & 1.14 & 1.2 \\
\hline & \begin{tabular}{|c|} 
Pto Espera Parihuela con \\
almendra limpia dispuesta \\
en jabas
\end{tabular} & 1 & 0.95 & 1.2 & 1 & & & - & - & - & & \\
\hline & $\begin{array}{c}\text { Secadora de granos } \\
\text { automática }\end{array}$ & 2 & 2.455 & 2.32 & 2.65 & 1 & 6.148 & 6.15 & 7.4087 & 39.4094 & 30.18668 & 12.296 \\
\hline & $\begin{array}{c}\begin{array}{c}\text { Pto Espera Parihuela con } \\
\text { almendra seca dispuesta } \\
\text { en jabas }\end{array} \\
\end{array}$ & 1 & 0.95 & 1.2 & 1 & & & - & - & - & & \\
\hline & $\begin{array}{c}\text { Pto Espera Parihuela con } \\
\text { almendra seca dispuesta } \\
\text { en jabas }\end{array}$ & 1 & 0.95 & 1.2 & 1 & & - & - & - & - & & \\
\hline & \begin{tabular}{|c|} 
Seleccionadora de cacao \\
por tamaño y condición
\end{tabular} & 2 & 2.3 & 2 & 3.5 & 1 & 7 & 7.00 & 8.4354 & 44.8709 & 32.2 & 14 \\
\hline & $\begin{array}{l}\text { Pto Espera java con } \\
\text { almendra seleccionada }\end{array}$ & 1 & 0.315 & 0.362 & 0.522 & - & - & - & - & - & - & \\
\hline \multirow{3}{*}{$\begin{array}{c}\text { Descascarilla } \\
\text { do }\end{array}$} & \begin{tabular}{|l} 
Pto Espera Parihuela con \\
almendra de cacao limpia \\
\end{tabular} & 1 & 0.95 & 1.2 & 1 & - & 1.2 & - & 0.7230 & 1.9230 & 1.14 & 1.2 \\
\hline & Peladora de Cacao & 2 & 2 & 1.756 & 1.87 & 1 & 3.28372 & 3.28 & 3.9571 & 21.0491 & 13.13488 & 6.56744 \\
\hline & $\begin{array}{c}\text { Pto Espera 1 Parihuelas } \\
\text { con almendra de cacao } \\
\text { descascarillada } \\
\end{array}$ & 1 & 0.95 & 1.2 & 1 & & 1.2 & - & 0.7230 & 1.9230 & 1.14 & 1.2 \\
\hline \multirow{3}{*}{ Ensacado } & $\begin{array}{c}\text { Pto Espera } 5 \text { Parihuelas } \\
\text { con almendra de cacao } \\
\text { descascarillada } \\
\end{array}$ & 5 & 0.95 & 6 & 5 & - & 30 & - & 18.0759 & 48.0759 & 142.5 & 150 \\
\hline & Ensacadora de cacao & 1 & 1.7 & 0.82 & 1.75 & 1 & 1.435 & 1.44 & 1.7293 & 4.5993 & 2.4395 & 1.435 \\
\hline & $\begin{array}{c}\text { Pto Espera 1 Parihuelas } \\
\text { con almendra de cacao } \\
\text { ensacada }\end{array}$ & 1 & 0.95 & 1.2 & 1 & - & 1.2 & - & 0.7230 & 1.9230 & 1.14 & 1.2 \\
\hline & & & & & & & & & & 314.5402 & 280.52 & 238.54 \\
\hline
\end{tabular}

Elaboración Propia 
Tabla 5.39: Análisis de Guerchet- elementos móviles

\begin{tabular}{|c|c|c|c|c|c|c|c|}
\hline & \multicolumn{5}{|c|}{ Dimensiones } & \multicolumn{2}{|c|}{ Cálculo de K } \\
\hline Elementos & $\begin{array}{c}\mathrm{N}^{\circ} \mathrm{de} \\
\text { elementos } \\
(\mathrm{n})\end{array}$ & $\begin{array}{c}\text { Alto } \\
\text { (metros) }\end{array}$ & $\begin{array}{c}\text { Ancho } \\
\text { (metros) }\end{array}$ & $\begin{array}{c}\text { Largo } \\
\text { (metros) }\end{array}$ & Ss & Ss $\times \mathrm{n} \times \mathrm{h}$ & Ss $\mathrm{x} \mathrm{n}$ \\
\hline Operarios & 20 & 0.95 & & & 0.50 & 9.50 & 10.00 \\
\hline Montacargas eléctrico & 2 & 2.24 & \multicolumn{2}{|c|}{1.41} & 6.25 & 27.98 & 12.49 \\
\hline Carretilla Hidráulica & 6 & 0.81 & 0.7 & 1.5 & 1.54 & 7.48 & 9.24 \\
\hline & & & & & & 44.96 & 31.73 \\
\hline
\end{tabular}

Elaboración Propia

Se analizaron los puntos de espera y aquellos que representaban menos del $30 \%$ del área gravitatoria no fueron consideradas. En el cuadro siguiente se muestra el análisis de los puntos de espera. Aquellos con fondo verde son los que no cumplieron la condición, esto también puede observarse en el diagrama Guerchet presentado previamente en la tabla 42.

Tabla 5.40: Análisis puntos de espera

\begin{tabular}{|c|c|c|}
\hline Puntos de Espera & Estación & $\begin{array}{c}\text { Relación SS } \\
\text { Pto. Esp./Sg } \\
\text { Maquina } \\
\end{array}$ \\
\hline Pto Espera Parihuela con MP en jabas & Zona de cortado & $20.52 \%$ \\
\hline Parihuela con Almendra despulpada en jabas & Zona de cortado & $20.52 \%$ \\
\hline Parihuela con Almendra despulpada en jabas & Zona de Limpieza Pre-Operacional & $52.28 \%$ \\
\hline Parihuela con almendra limpia en sacos & Zona de Limpieza Pre-Operacional & $52.28 \%$ \\
\hline Parihuela con almendra limpia en sacos & \begin{tabular}{|l|} 
Zona de Fermentado \\
\end{tabular} & $120.00 \%$ \\
\hline $\begin{array}{c}\text { Pto Espera Parihuela con almendra fermentada } \\
\text { dispuesta en jabas }\end{array}$ & Zona de Fermentado & $120.00 \%$ \\
\hline $\begin{array}{l}\text { Pto Espera Parihuela con almendra fermentada } \\
\text { dispuesta en jabas }\end{array}$ & Zona de Limpieza Operacional & $52.28 \%$ \\
\hline $\begin{array}{l}\text { Pto Espera Parihuela con almendra limpia } \\
\text { dispuesta en jabas }\end{array}$ & Zona de Limpieza Operacional & $52.28 \%$ \\
\hline $\begin{array}{l}\text { Pto Espera Parihuela con almendra limpia } \\
\text { dispuesta en jabas }\end{array}$ & Zona de Limpieza Operacional & $19.52 \%$ \\
\hline $\begin{array}{l}\text { Pto Espera Parihuela con almendra seca } \\
\text { dispuesta en jabas } \\
\end{array}$ & Zona de Limpieza Operacional & $19.52 \%$ \\
\hline $\begin{array}{l}\text { Pto Espera Parihuela con almendra seca } \\
\text { dispuesta en jabas } \\
\end{array}$ & Zona de Limpieza Operacional & $17.14 \%$ \\
\hline Pto Espera java con almendra seleccionada & Zona de Limpieza Operacional & $2.70 \%$ \\
\hline $\begin{array}{l}\text { Pto Espera Parihuela con almendra de cacao } \\
\text { limpia }\end{array}$ & Zona de Descascarillado & $36.54 \%$ \\
\hline $\begin{array}{c}\text { Pto Espera } 1 \text { Parihuelas con almendra de cacao } \\
\text { descascarillada }\end{array}$ & Zona de Descascarillado & $36.54 \%$ \\
\hline $\begin{array}{c}\text { Pto Espera } 5 \text { Parihuelas con almendra de cacao } \\
\text { descascarillada }\end{array}$ & Zona de Ensacado & $2090.59 \%$ \\
\hline $\begin{array}{c}\text { Pto Espera } 1 \text { Parihuelas con almendra de cacao } \\
\text { ensacada }\end{array}$ & Zona de Ensacado & $83.62 \%$ \\
\hline
\end{tabular}

Elaboración Propia 
Seguidamente, se presenta el cálculo de K para determinar la superficie estática y así finalmente determinar el área productiva, siendo esta de $314.54 \mathrm{~m} 2$.

Tabla 5.41: Cálculo de K

\begin{tabular}{c|c}
\hline \multicolumn{2}{c}{ Cálculo de K } \\
\hline hem & 1.41713124 \\
\hline hee & 1.17598221 \\
\hline K & 0.6025309 \\
\hline
\end{tabular}

Elaboración Propia

Tabla 5.42: Dimensiones de la zona de producción

\begin{tabular}{c|c|c}
\hline Dimensión & $\begin{array}{c}\text { Tamaño Real } \\
(\mathbf{m})\end{array}$ & $\begin{array}{c}\text { Tamaño } \\
\text { Ajustado } \\
(\mathbf{m})\end{array}$ \\
\hline $\mathrm{L}$ & 25.08 & 25 \\
\hline $\mathrm{L} / 2$ & 12.54 & 13 \\
\hline
\end{tabular}

Elaboración Propia

\subsubsection{Disposición general}

Se procedió a elaborar un diagrama relacional para evaluar la afinidad y cercanía de cada zona y así contar con una disposición óptima de planta.

El proceso inicia con la recepción de las mazorcas cultivadas que llegan en un camión al área de producción. Estas pasan por el proceso de limpiado y escurrido, por lo que es absolutamente necesario que el área de producción, el área de escurrido y el patio de maniobras estén cerca ya que así se disminuirán los tiempos de llegada y salida del almacén y mantendrán el flujo del proceso. En el sub proceso de escurrido, las mazorcas cortadas son expuestas al medio ambiente, por lo que la planta no contará con techo en una parte de su instalación.

Luego, los sacos de cacao fino pasan a un laboratorio de calidad para su inspección; aquellos defectuosos son rechazados. Para esta estación, es altamente no recomendable que los S.S.H.H. estén cerca así como también al almacén de productos terminados para lograr la inocuidad del producto. 
Posteriormente a la inspección, los sacos de cacao fino son almacenados en el almacén de productos terminados. Es especialmente necesario que el área de producción y patio de maniobras estén cerca de este almacén para tener un flujo del proceso óptimo. Para tener un control absoluto de la seguridad del personal directo, es importante que la enfermería esté cerca al área de producción.

Por otro lado, el área administrativa cuenta con las oficinas de las gerencias, vendedores, secretaria y otras. Debido al nivel de concentración requerida, no es recomendable que esta se encuentre cerca al área de producción ni de escurrido por la exposición al ruido que puedan tener los mismos trabajadores de la empresa como también los clientes que se reúnan con ellos en las oficinas y los gases que puedan emitirse en el proceso.

También, se cuenta con un comedor tanto para el personal directo como indirecto. No es recomendable que el comedor esté cerca al almacén de productos terminados ni al área de producción y área de escurrido para así poder reducir la probabilidad de contaminar el producto con materiales externos al proceso productivo. Por otra parte, es importante que los S.S.H.H. se encuentren cerca del área administrativa, área de producción y el comedor.

Finalmente, es normal que la zona de estacionamientos esté cerca de la salida de la planta ya que ahí podrán dejar estacionados los carros tanto el personal de la empresa como los clientes.

Para la elaboración de la tabla y diagrama relacional, se muestra una lista de criterios y motivos que se tomaron en cuenta para analizar la criticidad de la ubicación de cada zona física de la planta. 
Tabla 5.43: Lista de motivos

\begin{tabular}{c|c}
\hline Código & Lista de Motivos \\
\hline 1 & Flujo de proceso \\
\hline 2 & Inocuidad del Producto \\
\hline 3 & Control y Seguridad \\
\hline 4 & $\begin{array}{c}\text { Ruido o exposición a partículas } \\
\text { emitidas }\end{array}$ \\
\hline 5 & Atención de clientes \\
\hline
\end{tabular}

Elaboración propia

Tabla 5.44: Lista de criterios

\begin{tabular}{c|c}
\hline Código & Lista de Criterios \\
\hline $\mathrm{A}$ & Absolutamente Necesario \\
\hline $\mathrm{E}$ & Especialmente Necesario \\
\hline $\mathrm{I}$ & Importante \\
\hline $\mathrm{O}$ & Normal u Ordinario \\
\hline $\mathrm{U}$ & Sin Importancia \\
\hline $\mathrm{X}$ & No Recomendable \\
\hline $\mathrm{XX}$ & Altamente no Recomendable \\
\hline
\end{tabular}

Elaboración propia

A través del análisis de los criterios y motivos de cada zona de la planta, se ha preparado la tabla relacional de actividades.

Figura 5.18: Tabla relacional

\begin{tabular}{|l|l|l}
\hline 1 & Área de Escurrido \\
\hline 2 & Almacén de Productos Terminados \\
\hline 3 & Área de Producción \\
\hline 4 & Patio de Maniobras \\
\hline 5 & Área Administrativa & Laboratorio de Calidad \\
\hline 8 & Comedor & Baños Planta (S.S.H.H) \\
\hline 9 & Enfermería & Otros (Caseta Vigilancia, Estacionamiento) \\
\hline 10 &
\end{tabular}

Elaboración Propia 
Figura 5.19: Diagrama relacional

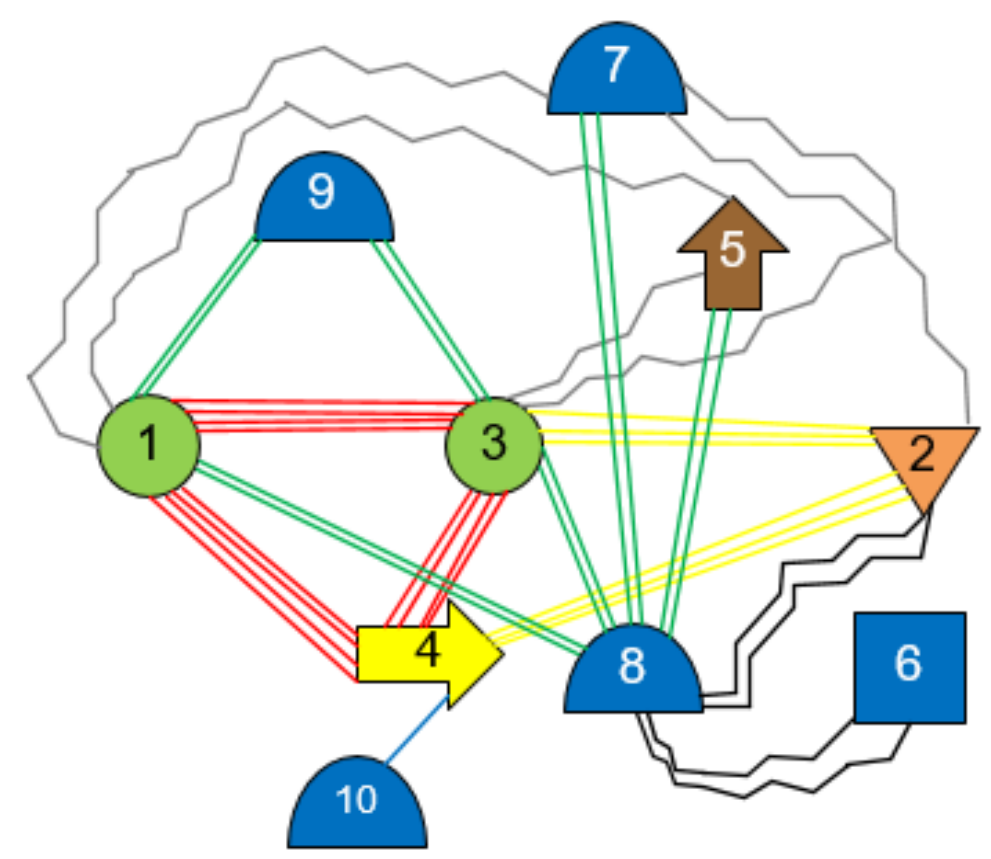

Elaboración Propia 


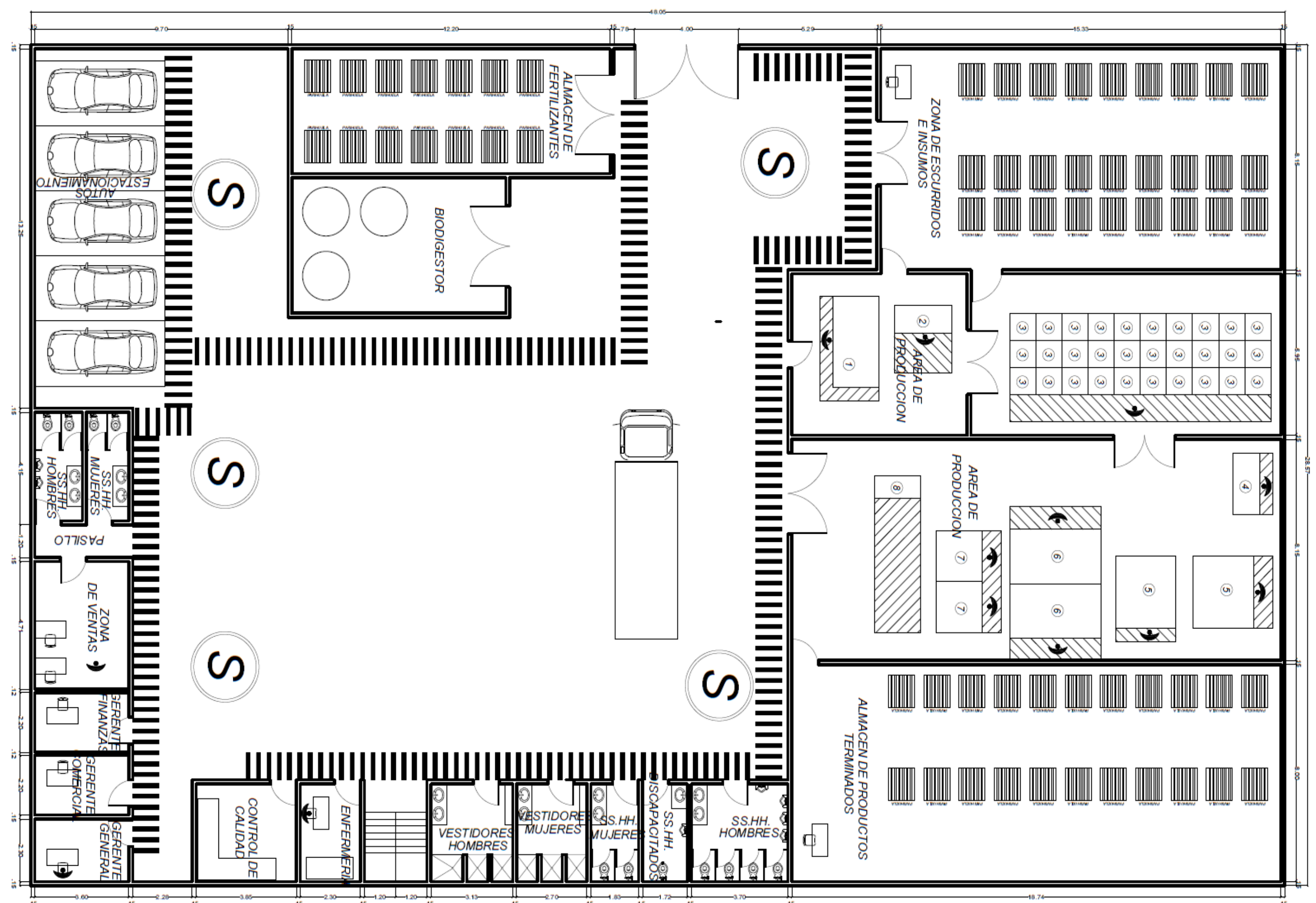

PRIMER PISO

PRODUCTORADE CACAO FIN 
Figura 5.21: Plano de la planta segundo piso

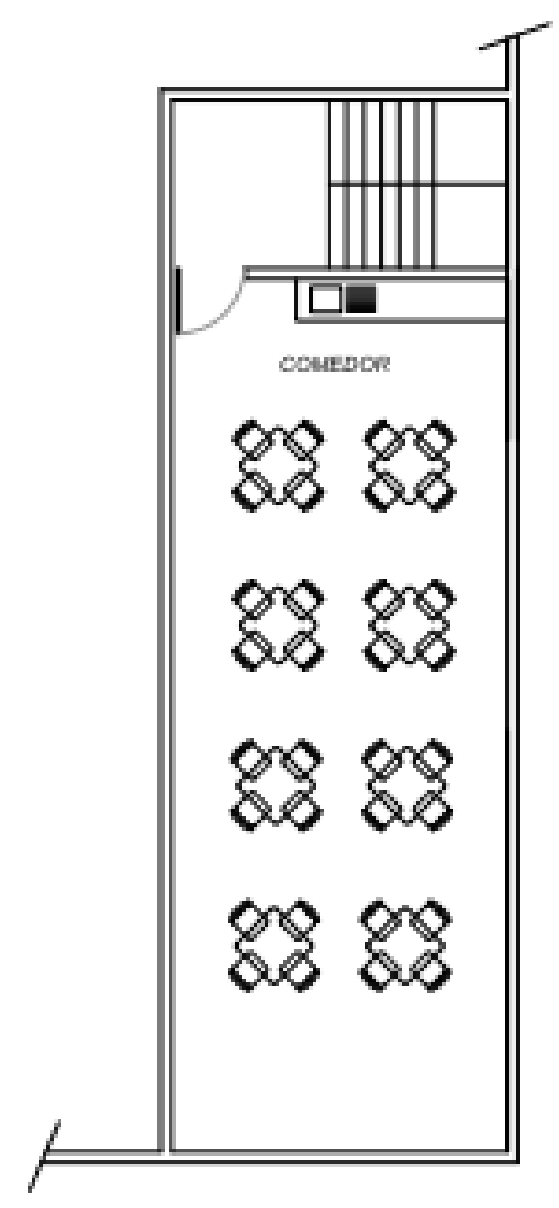

\section{SEGUNDO PISO}

\begin{tabular}{|c|c|c|c|c|}
\hline 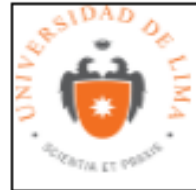 & $\begin{array}{r}\text { Universic } \\
\text { Escuela Un } \\
\text { Ingeniería } \\
\text { Facultad de In }\end{array}$ & trial & $\begin{array}{l}\text { Plano } \\
\text { produ }\end{array}$ & $\begin{array}{l}\text { distribución de una planta } \\
\text { a de Cacao Fino Tostado }\end{array}$ \\
\hline $\mathrm{F}$ & ala Gráfica (m) & $\begin{array}{r}\text { Bria } \\
\text { José }\end{array}$ & $\begin{array}{l}\text { ntes: } \\
\text { QGUILA } \\
\text { PASTOR }\end{array}$ & \\
\hline
\end{tabular}

Elaboración Propia 


\subsection{Cronograma de implementación del proyecto}

Figura 5.22: Cronograma de implementación

\begin{tabular}{|c|c|c|c|c|c|c|c|c|c|c|c|c|c|}
\hline Nombre de Tarea & Duración & Comienzo & Fin & oct & nov & ene & feb & mar & abr & may & jun & jul & agc \\
\hline Conseguir Financiamiento & 30 días & $\operatorname{lun} 22 / 10 / 20$ & vie $30 / 11 / 18$ & & 1 & & & & & & & & \\
\hline Obtener RUC y Formar Empresa & 20 días & lun $3 / 12 / 18$ & vie $28 / 12 / 18$ & & & & & & & & & & \\
\hline Presentación anual del plan de Proyecto & 2 días & $\operatorname{lun} 31 / 12 / 18$ & $\operatorname{mar} 1 / 01 / 19$ & & & & & & & & & & \\
\hline Aprobación de la Construcción & 25 días & mie 2/01/19 & $\operatorname{mar} 5 / 02 / 19$ & & & & & & & & & & \\
\hline $\begin{array}{l}\text { Construcción e Instalación del Área de Producción y } \\
\text { Administración }\end{array}$ & 90 días & mie $6 / 02 / 19$ & $\operatorname{mar} 11 / 06 / 19$ & & & & & & & & & & \\
\hline Instalación Eléctrica & 25 días & mie $12 / 06 / 19$ & $\operatorname{mar} 16 / 07 / 19$ & & & & & & & & & 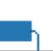 & \\
\hline Nivelación de Suelos & 30 días & mie $6 / 02 / 19$ & $\operatorname{mar} 19 / 03 / 19$ & & & & & 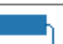 & & & & & \\
\hline Construcción de Almácigos & 7 días & mie $6 / 02 / 19$ & jue $14 / 02 / 19$ & & & & & & & & & & \\
\hline Plantación de Cacao & 30 días & mie 20/03/19 & $\operatorname{mar} 30 / 04 / 19$ & & & & & & & & & & \\
\hline Adquisición de Maquinaria & 25 días & mie $12 / 06 / 19$ & $\operatorname{mar} 16 / 07 / 19$ & & & & & & & & & & \\
\hline Instalación de Maquinaria & 3 días & mie $17 / 07 / 19$ & vie $19 / 07 / 19$ & & & & & & & & & 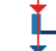 & \\
\hline Instalación del Área Administrativa & 7 días & mie $17 / 07 / 19$ & jue $25 / 07 / 19$ & & & & & & & & & & \\
\hline Compra de Insumos & 7 días & mie $12 / 06 / 19$ & jue $20 / 06 / 19$ & & & & & & & & & & \\
\hline Reclutamiento y Capacitación del Personal & 35 días & mie $17 / 07 / 19$ & $\operatorname{mar} 3 / 09 / 19$ & & & & & & & & & $\downarrow$ & \\
\hline Pruebas en Marcha & 7 días & mie 4/09/19 & jue 12/09/19 & & & & & & & & & & \\
\hline Puesta en Marcha & 0 días & vie $13 / 09 / 19$ & vie $13 / 09 / 19$ & & & & & & & & & & \\
\hline
\end{tabular}

Elaboración Propia 


\section{CAPÍTULO VI: ORGANIZACIÓN Y ADMINISTRACIÓN}

\subsection{Formación de la organización empresarial}

En el Perú existen varios tipos de empresas que tienen diferentes tipos de regímenes tributarios. Esta empresa será una Sociedad de Responsabilidad Limitada (S.R.L.) ya que solo contará con dos accionistas y el capital se dividirá de manera equivalente, sin embargo no podrán ser consideradas como acciones. Este capital deberá ser depositado en alguna institución financiera bajo nombre de la empresa, ya que si aquella presenta alguna obligación financiera, los accionistas no tendrán que cubrirla con su patrimonio (Diferencias entre Sociedad Anónima Cerrada y Sociedad Comercial de Responsabilidad Limitada, 2017). La empresa contará con una gerencia que estará encargada de la administración general y dirección y será el representante legal de aquella.

\section{Misión:}

Ofrecer cacao fino en grano de alta calidad, que cumpla con los estándares a nivel mundial, con la tecnología más eficiente y con un personal altamente capacitado, capaz de realizar sus labores de la mejor manera en cada etapa del proceso para satisfacer las necesidades de los productores de chocolate y derivados en el extranjero.

\section{Visión:}

Ser la empresa lider de abastecimiento de cacao fino en grano para los acopiadores y exportadores de este en el extranjero, satisfaciendo las necesidades de los productores de chocolates y derivados. 
Valores:

- Pasión por elaborar un producto terminado de alta calidad.

- Confianza y respeto tanto al personal de la empresa como al cliente.

- Responsabilidad social, implementando acciones que ayuden a los demás y al medio ambiente.

- Trabajo en equipo para lograr eficiencia en los procesos y motivación laboral para satisfacer a nuestros clientes.

- Mantener la honestidad e integridad con el personal, nuestros proveedores y clientes para generar confianza y buena relación con ellos.

\section{Principales objetivos de la empresa:}

- Mantener constante el crecimiento económico-financiero de la empresa en el mediano-largo plazo

- Brindar confianza y exclusividad a nuestros clientes, sobre todo a los clientes clave del mercado de cacao fino en grano para lograr una fuerte penetración de mercado y aumentar nuestra participación.

- Fomentar el reciclaje y crear conciencia e iniciar proyectos de responsabilidad social para ayudar a la población de Tocache y reducir la contaminación del medio ambiente.

- Implementar Kaizen (Mejora continua) en los procesos de producción y no producción para lograr una mejor productividad.

- Tener un ambiente laboral cómodo para los trabajadores, respetando la ergonomía de todos los procesos de la empresa.

- Contar con trabajadores de diversas culturas para evaluar los distintos puntos de vista y tomar las mejores decisiones. 
6.2. Requerimiento de personal directivo, administrativa y de servicios; y funciones generales de los principales puestos

Tabla 6.1: Perfil de puestos administrativos

\begin{tabular}{|c|c|}
\hline Puesto & Perfil Requerido \\
\hline Gerente General & $\begin{array}{l}\text { - } \text { Conocimiento en planificación de objetivos } \\
\text { encargado de organizar la producción de cacao) } \\
\text { - Liderazgo de equipo } \\
\text { - Experiencia en el control de personal } \\
\text { - Conocimiento avanzado en el manejo de herramientas } \\
\text { - contables } \\
\text { Capacidad de Comunicación destacada }\end{array}$ \\
\hline $\begin{array}{l}\text { Gerente } \\
\text { Comercial }\end{array}$ & $\begin{array}{l}\text { - Conocimiento en logística de Salida } \\
\text { - Experiencia mínima de } 3 \text { años en el puesto, de } \\
\text { preferencia en rubro similar } \\
\text { - Capacidad de Liderazgo } \\
\text { - Conocimiento avanzado de Ingles }\end{array}$ \\
\hline Vendedor & $\begin{array}{l}\text { - Bachiller de administración de empresas } \\
\text { - Experiencia en el rubro de alimentos } \\
\text { - Conocimiento avanzado de ingles } \\
\text { - Conocimiento de Logística de entrada }\end{array}$ \\
\hline Secretaria & $\begin{array}{l}\text { - Egresada de la carrera técnica de secretaria } \\
\text { - Experiencia en el puesto }\end{array}$ \\
\hline
\end{tabular}

Elaboración Propia 
Tabla 6.2: F unciones de puesto administrativos

\begin{tabular}{|c|c|c|}
\hline Puesto & Funciones & Cantidad \\
\hline Gerente General & $\begin{array}{l}\text { - Planificar los objetivos a corto y largo plazo de } \\
\text { la empresa } \\
\text { - Encargado del área de producción } \\
\text { - Decidir sobre las contrataciones y despidos } \\
\text { - Encargado de determinar los KPIs de } \\
\text { Producción relevantes para la empresa } \\
\text { - Llevar un registro adecuado de los gastos y } \\
\text { costos incurridos } \\
\text { - Responsable de la elaboración, ejecución y } \\
\text { coordinación presupuestaria, con el resto de las } \\
\text { unidades de la empresa } \\
\text { - Responsable de preparar los estados financieros } \\
\text { y entregar soporte a todas las unidades, } \\
\text { supervisando y manteniendo la normativa } \\
\text { contable de la empresa. }\end{array}$ & 1 \\
\hline $\begin{array}{l}\text { Gerente } \\
\text { Comercial }\end{array}$ & $\begin{array}{l}\text { o Concretar canales comerciales } \\
\text { - Reclutar y seleccionar al personal de ventas } \\
\text { - Encargado de trazar las estrategias comerciales } \\
\text { - Tener conocimiento de marketing y saber } \\
\text { responderá problemas }\end{array}$ & 1 \\
\hline Vendedor & $\begin{array}{l}\text { - Encargado de encontrar nuevos clientes, } \\
\text { mantener a los actuales } \\
\text { - Realizar visitar periódicas a los clientes de } \\
\text { mayores ventas } \\
\text { - Recibir y despachas pedidos de compra } \\
\text { - Prepara los Pronósticos de ventas }\end{array}$ & 2 \\
\hline Secretaria & $\begin{array}{l}\text { - } \text { Encargada de agendar reuniones } \\
\text { - } \quad \text { Recepcionar a los clientes y proveedores }\end{array}$ & 1 \\
\hline
\end{tabular}

Elaboración Propia 
6.3. Esquema de la estructura organizacional

Figura 6.1: Organigrama

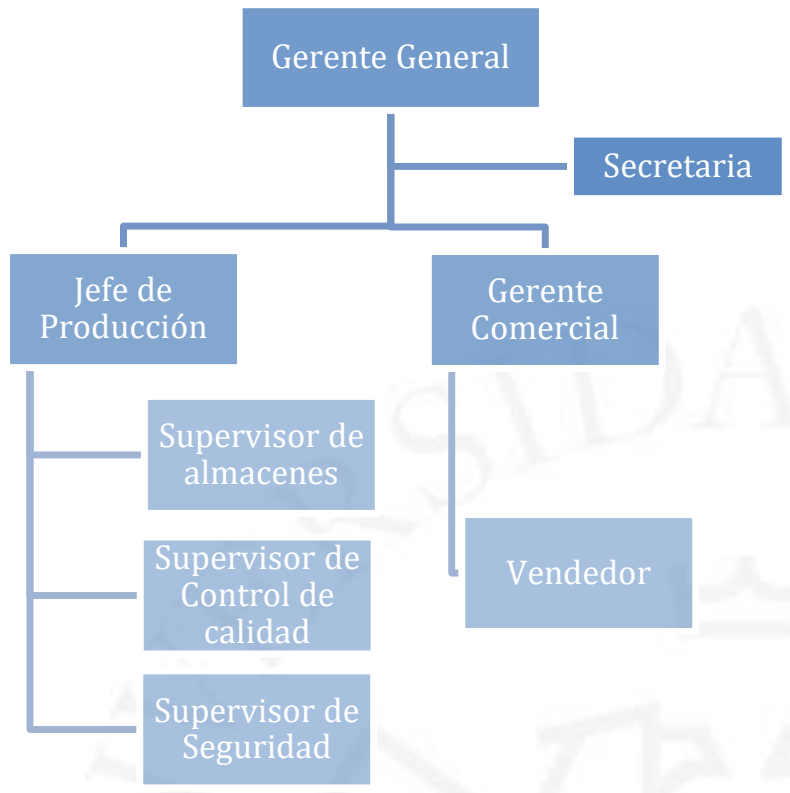

Elaboración Propia 


\section{CAPÍTULO VII: PRESUPUESTO Y EVALUACIONES DEL PROYECTO}

\subsection{Inversiones}

\subsubsection{Estimación de las inversiones de largo plazo (tangibles e intangibles)}

En este capítulo se estimará la inversión a largo plazo, las cuales están conformadas por los activos tangibles e intangibles. A su vez, se tomará como referencia el tipo de cambio actual 3.40 soles el dólar.

La inversión tangible estará conformado por la construcción de las instalaciones, maquinaria, equipos y el terreno. A continuación se enumeran los costos:

\section{a) Costo de terreno:}

Se obtuvo del producto del costo del metro cuadrado en el distrito de Tocache por los metros cuadrados necesarios, tanto para la plantación, como para la planta productora de cacao fino. Los cuales a su vez son:

Tabla 7.1: Áreas de la planta

\begin{tabular}{c|r|r}
\cline { 2 - 3 } & Area en m2 & \multicolumn{1}{c}{ Precio } \\
\hline Area de terreno & $35,000.00$ & $1,505,000$ \\
\hline Area de planta & $1,372.80$ & 59,030 \\
\hline TOTAL & $36,372.80$ & $1,564,030$ \\
\hline
\end{tabular}

Elaboración Propia 
Tabla 7.2: Costo de terreno

\begin{tabular}{c|c|c|c}
\hline \multicolumn{4}{c}{ Costo de Terreno } \\
\hline Activo Intangible & Área (m2) & $\begin{array}{c}\text { Precio (S/. / } \\
\mathbf{m 2})\end{array}$ & Costo Total (S/.) \\
\hline $\begin{array}{c}\text { Terreno (Zona de planta } \\
+ \text { Zona de plantación) }\end{array}$ & $36,372.80$ & 43.00 & $1,564,030.40$ \\
\hline
\end{tabular}

Elaboración Propia

\section{b) Costo de construcción de instalación:}

Para realizar los cálculos referentes a los costos de construcción, se utilizó el cuadro de Valores Unitarios Oficiales de Edificación para la Selva, multiplicando el costo por metro cuadrado por el área del proyecto (Octubre 2015). El área total para la construcción de todas las instalaciones será de S/. 468,545.93.

Tabla 7.3: Costos de construcción

\begin{tabular}{|c|c|c|c|c|c|c|c|c|c|c|c|c|c|c|}
\hline & \multicolumn{2}{|c|}{ Almacenes } & \multicolumn{2}{|c|}{ Comedor } & \multicolumn{2}{|c|}{ Enfermería } & \multicolumn{2}{|c|}{ Vestuario } & \multicolumn{2}{|c|}{ Zona de Producción } & \multicolumn{2}{|c|}{ Oficinas } & \multicolumn{2}{|c|}{ Biodigestor } \\
\hline & Tipo & Costo & Tipo & Costo & Tipo & Costo & Tipo & Costo & Tipo & Costo & Tipo & Costo & Tipo & Costo \\
\hline Techos & $\mathrm{D}$ & 100.85 & $\mathrm{D}$ & 100.81 & $\mathrm{~F}$ & 20.68 & $\mathrm{~F}$ & 20.68 & C & 158.88 & $\mathrm{C}$ & 158.88 & $\mathrm{H}$ & 0 \\
\hline Ventanas y Puertas & $\mathrm{F}$ & 50.49 & $\mathrm{~F}$ & 50.49 & $\mathrm{~F}$ & 50.59 & $\mathrm{~F}$ & 50.59 & $\mathrm{~F}$ & 50.49 & $\mathrm{E}$ & 37.6 & I & \\
\hline Baños & $\mathrm{H}$ & 0 & $\mathrm{H}$ & 0 & $\mathrm{E}$ & 15.85 & $\mathrm{~F}$ & 11.81 & $\mathrm{H}$ & 0 & E & 15.85 & $\mathrm{H}$ & 0 \\
\hline Revestimiento & $\mathrm{F}$ & 59.37 & $\mathrm{E}$ & 84.23 & $\mathrm{~F}$ & 59.37 & $\mathrm{~F}$ & 59.37 & $\mathrm{~F}$ & 59.37 & $\mathrm{~F}$ & 59.37 & I & 0 \\
\hline Pisos & G & 36.58 & $\mathrm{E}$ & 60.69 & $\mathrm{E}$ & 60.69 & G & 36.58 & $\mathrm{H}$ & 22.89 & $\mathrm{~F}$ & 41.45 & $\mathrm{H}$ & 22.89 \\
\hline Muros y Columnas & $\mathrm{D}$ & 208.29 & $\mathrm{D}$ & 208.29 & $\mathrm{D}$ & 208.29 & D & 208.29 & $\mathrm{C}$ & 215.39 & $\mathrm{C}$ & 215.39 & I & 7 \\
\hline $\begin{array}{c}\text { Instalaciones eléctricas } \\
\text { y sanitarias }\end{array}$ & D & 81.92 & $\mathrm{C}$ & 129.68 & A & 281.54 & $\mathrm{E}$ & 59.5 & $\mathrm{C}$ & 129.68 & $\mathrm{E}$ & 59.5 & $\mathrm{H}$ & 17.5 \\
\hline Coto total $(\mathrm{s} / . / \mathrm{m} 2)$ & \multicolumn{2}{|c|}{537.5} & \multicolumn{2}{|c|}{634.19} & \multicolumn{2}{|c|}{697.01} & \multicolumn{2}{|c|}{446.82} & \multicolumn{2}{|r|}{636.7} & \multicolumn{2}{|c|}{588.04} & \multicolumn{2}{|c|}{$\frac{1}{40.39}$} \\
\hline Área (m2) & \multicolumn{2}{|c|}{260.82} & \multirow{2}{*}{\multicolumn{2}{|c|}{$\frac{72.93}{46251.4767}$}} & \multicolumn{2}{|c|}{\begin{tabular}{r|}
13.97 \\
\end{tabular}} & \multicolumn{2}{|c|}{\begin{tabular}{l|l|}
42 & \\
\end{tabular}} & \multirow{2}{*}{\multicolumn{2}{|c|}{\begin{tabular}{l|l}
325 & \\
2060275
\end{tabular}}} & \multicolumn{2}{|c|}{77} & \\
\hline Costo Total por Área & \multicolumn{2}{|c|}{140190.75} & & & \multirow{2}{*}{\multicolumn{2}{|c|}{9737.2297}} & \multirow{2}{*}{\multicolumn{2}{|c|}{18766.44}} & & & \multirow{2}{*}{\multicolumn{2}{|c|}{45279.08}} & & \\
\hline & & & & $\cos 1$ & & & & & \multicolumn{2}{|c|}{206927.5} & & & \multicolumn{2}{|c|}{$\begin{array}{c}1393.455 \\
468.545 .93\end{array}$} \\
\hline
\end{tabular}

Fuente: Colegio de Arquitectura del Perú (2018)

\section{c) Costo de la maquinaria:}

La siguiente tabla muestra los costos de la maquinaria necesaria para la zona de producción de la planta. Dado que no todas las máquinas se encuentran en Perú, se le ha incluido el costo tanto del seguro naviero, como el costo del flete e impuestos y desaduanaje. 
Tabla 7.4: Costo de maquinaria

\begin{tabular}{|c|c|c|c|}
\hline \multicolumn{4}{|c|}{ Costo de Maquinaria } \\
\hline Maquinaria & Cantidad & \begin{tabular}{|c|} 
Unitario $(\mathrm{S} / . /$ \\
unid)
\end{tabular} & Costo Total (S/.) \\
\hline $\begin{array}{l}\text { Máquina despulpadora } \\
\text { de cacao }\end{array}$ & 1 & $49,500.00$ & $49,500.00$ \\
\hline $\begin{array}{l}\text { Máquina lavadora por } \\
\text { inmersión }\end{array}$ & 2 & $22,243.00$ & $44,486.00$ \\
\hline $\begin{array}{l}\text { Máquina secadora de } \\
\text { granos automática }\end{array}$ & 2 & $18,900.00$ & $37,800.00$ \\
\hline $\begin{array}{l}\text { Máquina de selección de } \\
\text { granos por tamaño y } \\
\text { condición }\end{array}$ & 2 & $29,348.00$ & $58,696.00$ \\
\hline $\begin{array}{l}\text { Máquina peladora de } \\
\text { cacao }\end{array}$ & 2 & $9,198.00$ & $18,396.00$ \\
\hline $\begin{array}{l}\text { Máquina ensacadora de } \\
\text { cacao }\end{array}$ & 1 & $59,394.00$ & $59,394.00$ \\
\hline Cajones Fermentadores & 33 & 250.00 & $8,250.00$ \\
\hline Biodigestor & 3 & $10,200.00$ & $30,600.00$ \\
\hline Generador de energia & 1 & $23,800.00$ & $23,800.00$ \\
\hline \multicolumn{3}{|c|}{ Costo Total de Maquinaria } & $330,922.00$ \\
\hline
\end{tabular}

Elaboración Propia

\section{d) Costo de equipos:}

Los equipos se adquirirán en Perú y los precios se han obtenido de las empresas Promart y Sodimac. 
Tabla 7.5: Costo de equipos

\begin{tabular}{|c|c|c|c|c|}
\hline Zona & Equipo & $\begin{array}{c}\text { Cantidad } \\
\text { Requerida }\end{array}$ & $\begin{array}{c}\text { Costo } \\
\text { Unitario }(\mathrm{S} / .)\end{array}$ & $\begin{array}{c}\text { Costo Total } \\
\text { (S/.) }\end{array}$ \\
\hline \multirow{3}{*}{ Tópico } & Camilla & 1 & 200.0 & 200.0 \\
\hline & Botiquín & 1 & 41.9 & 41.9 \\
\hline & Escritorio Recto simple & 1 & 210.0 & 210.0 \\
\hline Vigilancia & Escritorio Recto simple & 1 & 199.0 & 199.0 \\
\hline \multirow{4}{*}{ Comedor } & Microondas 20L & 1 & 212.0 & 212.0 \\
\hline & Basurero 140L & 2 & 69.9 & 139.8 \\
\hline & Refrigeradora $177 \mathrm{~L}$ & 1 & 679.0 & 679.0 \\
\hline & Juego Mesa Melanina con 5 sillas & 4 & 240.0 & 960.0 \\
\hline \multirow{2}{*}{ Almacén } & Parihuelas & 22 & 15.0 & 330.0 \\
\hline & Estantes comunes & 6 & 199.9 & $1,199.4$ \\
\hline \multirow{10}{*}{$\begin{array}{c}\text { Zona } \\
\text { Administrativa }\end{array}$} & Sillas & 10 & 101.9 & $1,019.2$ \\
\hline & Sillas ejecutivas & 7 & 276.0 & $1,931.7$ \\
\hline & Impresora & 1 & 167.0 & 167.0 \\
\hline & Mesa Reunión & 1 & 641.7 & 641.7 \\
\hline & Ventiladores de Pared & 4 & 75.0 & 300.0 \\
\hline & Teléfono de Escritorio & 10 & 59.9 & 599.0 \\
\hline & Escritorio recto con Cajones & 7 & 280.0 & $1,960.0$ \\
\hline & Escritorio en "L" con estantes y cajones & 6 & 450.0 & $2,700.0$ \\
\hline & Computadora ACER CORE I3 & 10 & $1,299.0$ & $12,990.0$ \\
\hline & Archivadores 4 Cajones & 9 & 105.9 & 953.1 \\
\hline \multirow{2}{*}{ Básica } & Señalética & 50 & 4.9 & 245.0 \\
\hline & Extintores & 8 & 99.9 & 799.2 \\
\hline \multirow{9}{*}{ S.S.H.H. } & Dispensador de Jabón $450 \mathrm{ml}$ & 9 & 12.9 & 116.1 \\
\hline & Secadores Eléctricos & 4 & 339.4 & $1,357.6$ \\
\hline & Urinario & 5 & 98.9 & 494.5 \\
\hline & Inodoros One Piece & 9 & 201.0 & $1,809.0$ \\
\hline & Espejos $60 \times 60 \mathrm{~cm}$ & 4 & 65.0 & 260.0 \\
\hline & Calzado suela antideslizante & 16 & 55.0 & 880.0 \\
\hline & Banca 2 metros de madera & 2 & 175.0 & 350.0 \\
\hline & Lavatorio con Pedestal & 9 & 72.3 & 650.7 \\
\hline & Llave mezcladora de lavatorio & 9 & 65.9 & 593.1 \\
\hline \multirow{3}{*}{$\begin{array}{l}\text { Laboratorio de } \\
\text { Calidad }\end{array}$} & Medidor de Humedad & 1 & 299.0 & 299.0 \\
\hline & Balanza & 1 & 399.0 & 399.0 \\
\hline & Meza de aluminio inoxidable & 1 & 630.0 & 630.0 \\
\hline \multirow{4}{*}{ Producción } & Meza de aluminio inoxidable & 1 & 630.0 & 630.0 \\
\hline & Montacargas manual & 4 & $1,499.0$ & $5,996.0$ \\
\hline & Parihuelas & 37 & 15.0 & 555.0 \\
\hline & Jabas & 120 & 13.5 & $1,620.0$ \\
\hline \multicolumn{4}{|c|}{ Costo Total Equipos } & $45,116.95$ \\
\hline
\end{tabular}

Elaboración Propia

En cuanto a la inversión a largo plazo intangible, se tienen los costos de constitución, los cuales constan de lo siguiente: 
Tabla 7.6: Inversión intangibles

\begin{tabular}{|c|c|}
\hline Intangible & Costo \\
\hline Estudios Pre factibilidad & S/ 10,000.00 \\
\hline Diseño y Planos & S/ 4,000.00 \\
\hline Capacitación Operarios & S/ 20,000.00 \\
\hline Licencia Construcción & S/ 4,685.46 \\
\hline $\begin{array}{c}\text { Licencia } \\
\text { Funcionamiento }\end{array}$ & $\mathrm{S} / 180.00$ \\
\hline $\begin{array}{c}\text { Registro de Marca } \\
\text { Total Intangibles }\end{array}$ & S/ $394,400.45$ \\
\hline
\end{tabular}

Elaboración Propia

\subsubsection{Estimación de las inversiones de corto plazo (Capital de Trabajo)}

El capital de trabajo es el monto necesario para poder realizar operaciones en la planta durante un periodo determinado de tiempo, el cual está determinado por el periodo promedio de cobro y pago. Al ser una empresa nueva, se considera el periodo promedio de pago al contado en un $50 \%$ y el resto en un periodo posterior no mayor a 30 días. A su vez, el periodo promedio de cobranza se efectuará en un plazo no mayor a 30 días calendarios. El capital de trabajo estará compuesto por los salarios, servicios tercerizados, energía y agua.

Tabla 7.7: Capital de trabajo

\begin{tabular}{l|c}
\hline Egresos Anuales & Monto \\
\hline Costo De Ventas & $2,488,257$ \\
\hline Gastos & 634,057 \\
Administrativos & 161,001 \\
\hline Gastos de Ventas & 220,700 \\
\hline Egresos financieros & $\mathbf{3 , 5 0 4 , 0 1 5}$ \\
\hline \multicolumn{1}{c|}{ Total Egresos } & $\mathbf{3 3 5 , 0 8 5}$ \\
\hline Capital Trabajo &
\end{tabular}

Elaboración Propia 
Finalmente, se estimó que la inversión total para el proyecto será de S/. 2, 783,101.

Tabla 7.8: Inversión total

\begin{tabular}{c|c|}
\hline Concepto & Monto \\
\hline Costos Tangibles & $2,408,615$ \\
\hline Costos Intangibles & 39,400 \\
\hline Total Inv. Largo Plazo & $2,448,016$ \\
\hline Capital de Trabajo & 335,085 \\
\hline Total Inversion & $\mathbf{2 , 7 8 3 , 1 0 1}$ \\
\hline
\end{tabular}

Elaboración Propia

\subsection{Costos de producción}

\subsubsection{Costos de materia prima}

Para poder determinar el costo de materia prima se utilizó la demanda de los insumos con ayuda del balance de materia para el año 5. De esta manera, se obtuvo que para elaborar un saco de $60 \mathrm{~kg}$ de cacao fino se utilizó $114.48 \mathrm{~kg}$ de almendra de cacao más un saco de yute. Según, AGRODATA PERÚ, el precio de la tonelada de cacao en el puerto del callao es de $\$ 2.30 / \mathrm{kg}$. En cuanto al precio del saco, se cotizaron algunas empresas del mercado. De esta manera, obtuvo que el costo de la materia prima para el año 2020 será de S/. $458,026.84$.

Tabla 7.9: Demanda anual de materia prima

\begin{tabular}{l|r|r|r|r|r}
\hline Año & \multicolumn{1}{|c|}{2020} & 2021 & 2022 & \multicolumn{1}{|c|}{2023} & \multicolumn{1}{c}{2024} \\
\hline Producción anual (sacos) & 8,257 & 8,848 & 9,562 & 10,275 & 10,275 \\
\hline Mazorca de Cacao $(\mathrm{kg})$ & $1,771,342$ & $1,926,863$ & $2,082,384$ & $2,237,905$ & $2,548,845$ \\
\hline Sacos de yute de 60 kg & 8,257 & 8,848 & 9,562 & 10,275 & 11,689 \\
\hline Abono (KG) & 467 & 699 & 1,166 & 1,166 & 1,166 \\
\hline
\end{tabular}

Elaboración Propia

Tabla 7.10: Precio de Mp e insumos

\begin{tabular}{l|r|c}
\hline Materia Prima e Insumo & Costo & Unidad \\
\hline Mazorca de Cacao & 251 & S/. / ton \\
\hline Saco de Yute & 850 & S/. / 1000 bolsas \\
\hline Abono & 800 & s/. / saco \\
\hline
\end{tabular}

Elaboración Propia 
Tabla 7.11: Costo de MP e insumos

\begin{tabular}{l|r|r|r|r|r}
\hline Materia Prima & \multicolumn{1}{|c|}{2020} & \multicolumn{1}{|c|}{2021} & 2022 & \multicolumn{1}{c|}{2023} & \multicolumn{1}{c}{2024} \\
\hline Mazorca de cacao & 444,607 & 483,643 & 522,678 & 561,714 & 639,760 \\
\hline Sacos de Yute de 60 kg & 7,019 & 7,521 & 8,127 & 8,734 & 9,936 \\
\hline Abono & 6,400 & 8,800 & 14,400 & 14,400 & 14,400 \\
\hline Total & 458,026 & 499,964 & 545,205 & 584,848 & 664,096 \\
\hline
\end{tabular}

Elaboración Propia

\subsubsection{Costo de la mano de obra directa:}

El costo de mano de obra directa está compuesta por los salarios de los 27 operarios de la zona de producción, incluyéndose las gratificaciones, Essalud y CTS. Se obtuvo un costo total anual de S/. 658,530.00.

Tabla 7.12: Costo de la mano de obra directa

\begin{tabular}{|c|c|c|c|c|c|c|c|c|c|}
\hline Posición & $\begin{array}{c}\begin{array}{c}\text { Operarios por } \\
\text { turno }\end{array} \\
\end{array}$ & Turnos & \begin{tabular}{|c|}
$\begin{array}{c}\text { Operarios } \\
\text { Totales }\end{array}$ \\
\end{tabular} & $\begin{array}{c}\text { Salario } \\
\text { Mensual } \\
\end{array}$ & \#Sueldos & Salario Annual & ESSALUD 9\% & $\begin{array}{c}2 \text { CTS } \\
\text { Anuales } \\
\end{array}$ & Costo Total \\
\hline Operario de Recepción & 1 & 2 & 2 & 1,500 & 14 & 21,000 & 1,890 & 1,500 & 48,780 \\
\hline Operario de Despulpado & 1 & 2 & 2 & 1,500 & 14 & 21,000 & 1,890 & 1,500 & 48,780 \\
\hline Operario de Limpieza primaria & 1 & 2 & 2 & 1,500 & 14 & 21,000 & 1,890 & 1,500 & 48,780 \\
\hline Operario de Fermentado & \multirow{3}{*}{3} & \multirow{3}{*}{2} & \multirow{3}{*}{6} & \multirow{3}{*}{1,500} & \multirow{3}{*}{14} & \multirow{3}{*}{21,000} & \multirow{3}{*}{1,890} & \multirow{3}{*}{1,500} & \multirow{3}{*}{146,340} \\
\hline Operario de Lavado & & & & & & & & & \\
\hline Operario de Secado & & & & & & & & & \\
\hline Operario de Seleccionado & 2 & 2 & 4 & 1,500 & 14 & 21,000 & 1,890 & 1,500 & 97,560 \\
\hline Operario de Descascarillado & 2 & 2 & 4 & 1,500 & 14 & 21,000 & 1,890 & 1,500 & 97,560 \\
\hline Operario de Ensacado & 1 & 2 & 2 & 1,500 & 14 & 21,000 & 1,890 & 1,500 & 48,780 \\
\hline Operario de Escurrido & 5 & 1 & 5 & 1,500 & 14 & 21,000 & 1,890 & 1,500 & 121,950 \\
\hline & & & & & & \multicolumn{3}{|c|}{ Costo Mano de Obra Directa Total } & 658,530 \\
\hline
\end{tabular}

Elaboración Propia

\subsubsection{Costo indirecto de fabricación (materiales indirectos, mano de obra indirecta y costos generales de planta).}

\section{Mano de obra indirecta}

De igual manera que la mano de obra directa, la mano de obra indirecta incluye los sueldos, Essalud, CTs y gratificaciones. La MOI está conformada por el jefe de producción, supervisor de seguridad, el supervisor de almacenes y el supervisor de calidad. 
Tabla 7.13: Costo de la mano de obra indirecta

\begin{tabular}{l|c|c|c|c|c|c|c|c|c}
\hline \multicolumn{1}{c|}{ Posición } & Cantidad & Turnos & $\begin{array}{c}\text { Operarios } \\
\text { Totales }\end{array}$ & $\begin{array}{c}\text { Salario } \\
\text { Mensual }\end{array}$ & \#Sueldos & Salario Anual & ESSALUD 9\% & $\begin{array}{c}\text { 2 CTS } \\
\text { Anuales }\end{array}$ & Costo Total \\
\hline Jefe de Producción & 1 & 2 & 2 & 10,000 & 14 & 140,000 & 12,600 & 10,000 & 325,200 \\
\hline Supervisor Calidad & 1 & 1 & 1 & 5,000 & 14 & 70,000 & 6,300 & 5,000 & 81,300 \\
\hline Supervisor Almacenes & 1 & 2 & 2 & 7,000 & 14 & 98,000 & 8,820 & 7,000 & 227,640 \\
\hline Supervisor Seguridad & 1 & 1 & 1 & 4,000 & 14 & 56,000 & 5,040 & 4,000 & 65,040 \\
\hline Vigilante & 3 & 3 & 9 & 1,500 & 14 & 21,000 & 1,890 & 1,500 & 219,510 \\
\hline
\end{tabular}

Elaboración Propia

\section{Depreciación de activos tangibles:}

Según SUNAT, los equipos se depreciarán a un ritmo constante de $25 \%$ anual y la maquinaria a un ritmo de $10 \%$ anual.

Tabla 7.14: Depreciación de maquinaria

\begin{tabular}{|c|c|c|c|}
\hline Costo total Maquinaria & S/ 330,922 & $\begin{array}{c}\text { Ritmo de } \\
\text { Depreciación }\end{array}$ & $10 \%$ \\
\hline Depreciación Acumulada & S/ 165,461 & Valor Residual & S/ 165,461 \\
\hline \hline Año & Valor Inicial & Depreciación & Valor Final \\
\hline 2020 & 330,922 & 33,092 & 297,830 \\
\hline 2021 & 297,830 & 33,092 & 264,738 \\
\hline 2022 & 264,738 & 33,092 & 231,645 \\
\hline 2023 & 231,645 & 33,092 & 198,553 \\
\hline 2024 & 198,553 & 33,092 & 165,461 \\
\hline
\end{tabular}

Elaboración Propia

Tabla 7.15: Depreciación de equipos productivos

\begin{tabular}{c|c|c|c}
\hline $\begin{array}{c}\text { Costo total } \\
\text { Equipos } \\
\text { Productivos }\end{array}$ & S/ 45,116.95 & $\begin{array}{c}\text { Ritmo de } \\
\text { Depreciación }\end{array}$ & $25 \%$ \\
\hline $\begin{array}{c}\text { Depreciació } \\
\mathbf{n} \\
\text { Acumulada }\end{array}$ & S/ 45,116.95 & Valor Residual & S/ 0.00 \\
\hline \hline Año & Valor Inicial & Depreciación & Valor Final \\
\hline 2020 & $45,116.95$ & $11,279.24$ & $33,837.71$ \\
\hline 2021 & $33,837.71$ & $11,279.24$ & $22,558.48$ \\
\hline 2022 & $22,558.48$ & $11,279.24$ & $11,279.24$ \\
\hline 2023 & $11,279.24$ & $11,279.24$ & 0.00 \\
\hline
\end{tabular}

Elaboración Propia 


\section{Servicios tercerizados}

Los servicios de mantenimiento y limpieza tienen una participación importante en la parte productiva ya que, mantener un ambiente inocuo es determinante para la calidad final del producto y el mantenimiento adecuado mejora la productividad en la empresa. Es por este motivo que, ambos se consideran parte del costo indirecto de fabricación. El costo de limpieza está relacionado al área de producción, teniendo en cuenta que se considerarán tres personas para esta función, con un sueldo mensual de S/. 1,500.00. También es importante considerar el costo de capacitación a los operarios acerca de las Buenas Prácticas de Manejo (BPM) de máquinas y de procedimientos de plantación. Este valor se obtuvo multiplicando el costo por persona capacitada tanto en el proceso productivo como en la plantación, por dos veces al año. A su vez, el costo de mantenimiento representará el $7.37 \%$ del costo total de la maquinaria.

Tabla 7.16: Costo de servicios tercerizados de limpieza y mtto

\begin{tabular}{c|c|c|c|c}
\hline Servcio & $\begin{array}{c}\text { Costo total } \\
\text { Mensual }\end{array}$ & $\begin{array}{c}\text { Relación } \\
\text { Destinada a } \\
\text { Producción }\end{array}$ & CIF Mensual & CIF Anual \\
\hline Limpieza & $\mathrm{S} / 4,500.00$ & $37.39 \%$ & $\mathrm{~S} / 1,682.73$ & $\mathrm{~S} / 20,192.79$ \\
\hline Mantenimiento reactivo & $\mathrm{S} / 3,753.16$ & $100.00 \%$ & $\mathrm{~S} / 3,753.16$ & $\mathrm{~S} / 45,037.92$ \\
\hline Mantenimiento preventivo & $\mathrm{S} / 18,765.80$ & $100.00 \%$ & $\mathrm{~S} / 18,765.80$ & $\mathrm{~S} / 225,189.60$ \\
\hline Mantenimiento correctivo & $\mathrm{S} / 1,876.58$ & & & $\mathrm{~S} / 22,518.96$ \\
\hline $\begin{array}{l}\text { Capacitacion a operarios produccion + plantacion } \\
\text { (mantenimiento, uso de maq + gestion ambiental) }\end{array}$ & & & & $\mathrm{S} / 11,520.00$ \\
\hline \multicolumn{2}{r}{ Total CIF Terciarizado } & & S/ 324,459.27 \\
\hline
\end{tabular}

Elaboración Propia

A su vez, también se tercerizarán las actividades relacionados con la zona de plantación, ya que de este cálculo se obtendrá la parte de la materia prima que se utilizará para satisfacer parte de la demanda, dando así un total anual de S/. 28,230.00. 
Tabla 7.17: Costo de servicios tercerizados para la plantación

\begin{tabular}{l|c|c|c|c}
\hline \multicolumn{1}{c|}{ Posición } & Ope rarios por Jornal & Jornales & $\begin{array}{c}\text { Salario por } \\
\text { Jornal }\end{array}$ & Costo Anual \\
\hline Personal para preparar Sustrato & 1 & 5 & 15.00 & 75.00 \\
\hline Trabajador de Embolsado & 1 & 15 & 15.00 & 225.00 \\
\hline Trabajador para plantación & 1 & 24 & 15.00 & 360.00 \\
\hline Trabajador de Injerción & 2 & 5 & 15.00 & 150.00 \\
\hline Trabajador de Siembra & 3 & 24 & 15.00 & $1,080.00$ \\
\hline Trabajador de Deshierve & 1 & 5 & 15.00 & 75.00 \\
\hline Trabajdor de Podado & 1 & 5 & 15.00 & 75.00 \\
\hline Trabajdorn de Abonado & 1 & 90 & 15.00 & $1,350.00$ \\
\hline Tabajador de cosecha & 23 & 72 & 15.00 & $24,840.00$ \\
\hline \multicolumn{2}{r|}{ Costo Mano de Obra Directa Tercerizada Total } & $\mathbf{2 8 , 2 3 0 . 0 0}$ \\
\hline
\end{tabular}

Elaboración Propia

\subsection{Presupuesto operativos}

\subsubsection{Presupuesto de ingreso por ventas}

El precio de venta determinado para el proyecto será de S/. 469 por saco de $60 \mathrm{~kg} \mathrm{de}$ cacao fino en grano. Según Agrodata Perú, a agosto 2019, el precio promedio del kilogramo de cacao fino en grano es de USD 2.30 y considerando un tipo de cambio de S/. 3.40 cada dólar, se convirtió aquel valor a soles, multiplicándolo por $60 \mathrm{~kg}$ para hallar el precio por saco. Para la elaboración del presupuesto de ventas al 2024, se consideró un 18\% de Impuesto General a las Ventas, obteniendo así un valor de venta de S/. 398 por saco.

Tabla 7.18: Presupuesto de ingreso por ventas anuales

\begin{tabular}{|c|c|c|c|c|c|}
\hline Concepto & 2020 & 2021 & 2022 & 2023 & 2024 \\
\hline Precio de Venta (S/. Por saco) & 490 & 490 & 490 & 490 & 490 \\
\hline Valor de Venta (S/. Por saco) & 415 & 415 & 415 & 415 & 415 \\
\hline Unidades vendidas (Sacos) & 8,123 & 8,837 & 9,550 & 10,263 & 11,689 \\
\hline Ventas Totales (S/.) & $3,977,202$ & $4,326,394$ & $4,675,586$ & $5,024,778$ & $5,722,934$ \\
\hline
\end{tabular}

Elaboración Propia 


\subsubsection{Presupuesto operativo de costos}

Para la elaboración del costo de producción, se consideran los costos de materia prima, la mano de obra directa y los costos indirectos de fabricación. A continuación se observa el costo total anual de producción.

Tabla 7.19: Presupuesto operativo de costos anuales

\begin{tabular}{|l|r|r|r|r|r|}
\hline Componente & \multicolumn{1}{|c|}{2020} & \multicolumn{1}{c|}{2021} & \multicolumn{1}{c|}{2022} & \multicolumn{1}{c|}{2023} & \multicolumn{1}{c|}{2024} \\
\hline Costo Material Directo & 458,026 & 499,964 & 545,205 & 584,848 & 664,096 \\
\hline Costo Mano de Obra Directa & 686,760 & 686,760 & 686,760 & 686,760 & 686,760 \\
\hline Costo CIF & $1,384,438$ & $1,389,509$ & $1,394,580$ & $1,399,652$ & $1,409,791$ \\
\hline Costo de Producción Total (S) & $\mathbf{2 , 5 2 9 , 2 2 3}$ & $\mathbf{2 , 5 7 6 , 2 3 3}$ & $\mathbf{2 , 6 2 6 , 5 4 6}$ & $\mathbf{2 , 6 7 1 , 2 6 0}$ & $\mathbf{2 , 7 6 0 , 6 4 8}$ \\
\hline
\end{tabular}

Elaboración Propia

\subsubsection{Presupuesto operativo de gastos}

Para la elaboración del presupuesto operativo de gastos, se consideraron los gastos administrativos y los gastos de ventas. Por un lado, los gastos administrativos están compuestos por los salarios del personal administrativo, el servicio de agua y luz, la depreciación de los equipos de oficinas y los servicios tercerizados. Por otro lado, los gastos de ventas están compuestos por el gasto de distribución y de publicidad.

\section{a. Gastos administrativos}

\section{Sueldo del personal administrativo}

Para el cálculo del salario, se consideraron las gratificaciones, pago de CTS y Essalud (9\%).

Tabla 7.20: Sueldo del personal administrativo

\begin{tabular}{|c|c|c|c|c|c|c|c|}
\hline Puesto & $\begin{array}{l}\text { Número de } \\
\text { Personas }\end{array}$ & $\begin{array}{c}\text { Salario } \\
\text { Mensual }\end{array}$ & $\begin{array}{l}\text { Número de } \\
\text { Sueldos }\end{array}$ & $\begin{array}{l}\text { Salario } \\
\text { Annual }\end{array}$ & $\begin{array}{c}\text { ESSALUD } \\
(9 \%)\end{array}$ & CTS Anuales (2) & Costo Total \\
\hline Gerente General & 1 & $8,000.00$ & 14 & $112,000.00$ & $10,080.00$ & $8,000.00$ & $130,080.00$ \\
\hline Gerente Administrativo Financier & 1 & $7,000.00$ & 14 & $98,000.00$ & $8,820.00$ & $7,000.00$ & $113,820.00$ \\
\hline Gerente Comercial & 1 & $5,000.00$ & 14 & $70,000.00$ & $6,300.00$ & $5,000.00$ & $81,300.00$ \\
\hline Vendedor & 1 & $4,000.00$ & 14 & $56,000.00$ & $5,040.00$ & $4,000.00$ & $65,040.00$ \\
\hline Secretaria & 1 & $2,000.00$ & 14 & $28,000.00$ & $2,520.00$ & $2,000.00$ & $32,520.00$ \\
\hline Total & 5 & $26,000.00$ & 70 & $364,000.00$ & $32,760.00$ & $26,000.00$ & $422,760.00$ \\
\hline
\end{tabular}

Elaboración Propia 


\section{Depreciación de los equipos administrativos}

Según SUNAT, para el cálculo de la depreciación de los equipos administrativos, se consideran ritmos de depreciación específicos, siendo en este caso un ritmo del $20 \%$ anual del valor del equipo, con lo cual se obtiene un valor residual de S/. 0.00 al final de la vida útil del estudio. El costo total de los equipos requeridos asciende a S/. 45,116.95.

Tabla 7.21: Depreciación de equipos administrativos

\begin{tabular}{c|c|c|c}
\hline Costo total Equipos & S/ 45,116.95 & $\begin{array}{c}\text { Ritmo de } \\
\text { Depreciación }\end{array}$ & $20 \%$ \\
\hline Depreciación Acumulada & S/ 45,116.95 & Valor Residual & S/ 0.00 \\
\hline \hline Año & Valor Inicial & Depreciación & Valor Final \\
\hline 2020 & $45,116.95$ & $9,023.39$ & $36,093.56$ \\
\hline 2021 & $36,093.56$ & $9,023.39$ & $27,070.17$ \\
\hline 2022 & $27,070.17$ & $9,023.39$ & $18,046.78$ \\
\hline 2023 & $18,046.78$ & $9,023.39$ & $9,023.39$ \\
\hline 2024 & $9,023.39$ & $9,023.39$ & 0.00 \\
\hline
\end{tabular}

Elaboración Propia

\section{Depreciación de intangibles}

Según SUNAT, para el cálculo de la depreciación de los intangibles, se considera un ritmo del 10\% anual del valor anual. Los intangibles están compuestos por: Estudios de pre-factibilidad, Diseño y Planos, Capacitación al personal, Licencia de Construcción, Licencia de Funcionamiento y Registro de Marca y estos costos ascienden a un total de S/. 39,400.45.

Tabla 7.22: Depreciación de intangibles

\begin{tabular}{|c|c|c|c|}
\hline $\begin{array}{c}\text { Costo total } \\
\text { Intangibles }\end{array}$ & $\mathrm{S} / 39,400.45$ & $\begin{array}{c}\text { Ritmo de } \\
\text { Depreciación }\end{array}$ & $10 \%$ \\
\hline $\begin{array}{c}\text { Amortización } \\
\text { Acumulada }\end{array}$ & $\mathrm{S} / 19,700.22$ & Valor Residual & $\mathrm{S} / 19,700.22$ \\
\hline \hline Año & Valor Inicial & Amortización & Valor Final \\
\hline 2020 & $39,400.45$ & $3,940.04$ & $35,460.40$ \\
\hline 2021 & $35,460.40$ & $3,940.04$ & $31,520.36$ \\
\hline 2022 & $31,520.36$ & $3,940.04$ & $27,580.31$ \\
\hline 2023 & $27,580.31$ & $3,940.04$ & $23,640.27$ \\
\hline 2024 & $23,640.27$ & $3,940.04$ & $19,700.22$ \\
\hline
\end{tabular}

Elaboración Propia 


\section{Depreciación de obras civiles}

Según SUNAT, para el cálculo de la depreciación de las obras civiles, se considera un ritmo del 5\% anual del valor anual. El costo total de las obras civiles asciende a S/. $468,54593$.

Tabla 7.23: Depreciación de obras civiles

\begin{tabular}{|c|c|c|c|}
\hline Costo total Obras Civiles & S/ 468,545.93 & $\begin{array}{c}\text { Ritmo de } \\
\text { Depreciación }\end{array}$ & $5 \%$ \\
\hline Depreciación Acumulada & S/ 117,136.48 & Valor Residual & S/ 351,409.45 \\
\hline \hline Año & Valor Inicial & Depreciación & Valor Final \\
\hline 2020 & $468,545.93$ & $23,427.30$ & $445,118.63$ \\
\hline 2021 & $445,118.63$ & $23,427.30$ & $421,691.34$ \\
\hline 2022 & $421,691.34$ & $23,427.30$ & $398,264.04$ \\
\hline 2023 & $398,264.04$ & $23,427.30$ & $374,836.75$ \\
\hline 2024 & $374,836.75$ & $23,427.30$ & $351,409.45$ \\
\hline
\end{tabular}

Elaboración Propia

\section{Servicio de agua y luz}

Se tomó como referencia el Reglamento Nacional de Edificaciones para la elaboración del consumo energético de agua y luz. Este reglamento detalla que el suministro de agua para la zona útil de las oficinas administrativas se evaluará a razón de $6 \mathrm{~L} / \mathrm{d}$ por metro cuadrado y el consumo humano para cualquier industria será de aproximadamente 80 litros por persona en un turno de 8 horas. En este estudio se utilizó la tarifa de consumo de agua de Tocache, San Martín. 
Tabla 7.24: Consumo de agua (No destinada a la producción)

\begin{tabular}{|c|c|c|c|c|c|c|c|c|c|c|c|}
\hline Área & Reglamento & Unidad & Cantidad & Unidad & $\begin{array}{c}\text { Consumo por } \\
\text { Turno }\end{array}$ & Turnos/Día & Consumo Diario & Días/Sem & Sem/Año & $\mid \begin{array}{c}\text { Consumo } \\
\text { Anual }\left(\mathrm{m}^{3}\right)\end{array}$ & $\begin{array}{c}\text { Consumo } \\
\text { Anual (Soles) }\end{array}$ \\
\hline Zona Adm. Piso 1 & 6 & L/d por $\mathrm{m}^{2}$ & 50 & $\mathrm{~m}^{2}$ & 297 & 1 & 297 & 5 & 52 & 77.22 & S/ 464.77 \\
\hline Zona Adm. Piso 2 & 6 & $\mathrm{~L} / \mathrm{d}$ por $\mathrm{m}^{2}$ & 28 & $\mathrm{~m}^{2}$ & 165 & 1 & 165 & 5 & 52 & 42.90 & S/ 259.40 \\
\hline Enfermería & 6 & Ld por $\mathrm{m}^{2}$ & 14 & $\mathrm{~m}^{2}$ & 83.82 & 2 & 168 & 5 & 52 & 43.59 & S/ 263.51 \\
\hline Comedor & 6 & L/d por $m^{2}$ & 73 & $\mathrm{~m}^{2}$ & 437.58 & 2 & 875 & 5 & 52 & 227.54 & S/ $1,364.30$ \\
\hline Vigilancia & 6 & Ld por $\mathrm{m}^{2}$ & 18 & $\mathrm{~m}^{2}$ & 107.58 & 3 & 323 & 5 & 52 & 83.91 & S/ 504.82 \\
\hline \multicolumn{10}{|c|}{ Consumo Anual de Agua (No destinada a producción) } & 475.16 & S/ 2,856.81 \\
\hline
\end{tabular}

Elaboración Propia

Por otro lado, para el cálculo del consumo de energía eléctrica en las áreas no destinadas a la producción se consideró el valor aproximado de $52.50 \mathrm{Kwh} / \mathrm{m}^{2}$ que indica el artículo "Energía en edificios de oficinas” (Enectiva, 2017).

Tabla 7.25: Consumo de energía en zona adm. y otras zonas no destinadas a la producción

\begin{tabular}{c|c|c|c|c|c|c|c}
\hline Área & Reglamento & Unidad & Metraje & $\begin{array}{c}\text { Consumo } \\
\text { Anual (KW- } \\
\text { hr/turno) }\end{array}$ & $\begin{array}{c}\text { Horas fuera de } \\
\text { hora punta }\end{array}$ & $\begin{array}{c}\text { Horas de } \\
\text { hora punta }\end{array}$ & $\begin{array}{c}\text { Costo Anual } \\
\text { (Soles) }\end{array}$ \\
\hline Zona Adm. Piso 1 & 52.5 & $\mathrm{Kwh} / \mathrm{m} 2$ año & 50 & 2,599 & 8 & 0 & $\mathrm{~S} / 4,355.51$ \\
\hline Zona Adm. Piso 2 & 52.5 & $\mathrm{Kwh} / \mathrm{m} 2$ año & 28 & 1,444 & 8 & 0 & $\mathrm{~S} / 2,419.73$ \\
\hline Comedor & 52.5 & $\mathrm{Kwh} / \mathrm{m} 2$ año & 73 & 3,829 & 3 & 0 & $\mathrm{~S} / 2,406.42$ \\
\hline Servicios Higiénicos (Vestidores) & 52.5 & $\mathrm{Kwh} / \mathrm{m} 2$ año & 28 & 1,444 & 4 & 0 & $\mathrm{~S} / 1,209.86$ \\
\hline Servicios Higiénicos (Administrativo) & 52.5 & $\mathrm{Kwh} / \mathrm{m} 2$ año & 14 & 733 & 2 & 0 & $\mathrm{~S} / 307.31$ \\
\hline Enfermería & 52.5 & $\mathrm{Kwh} / \mathrm{m} 2$ año & 14 & 733 & 12 & 4 & $\mathrm{~S} / 2,578.72$ \\
\hline Vigilancia & 52.5 & $\mathrm{Kwh} / \mathrm{m} 2$ año & 18 & 941 & 18 & 6 & $\mathrm{~S} / 4,964.55$ \\
\hline Consumo Total Electricidad (No destinada a producción) & $\mathbf{1 1 , 7 2 3}$ & & Costo Total & $\mathrm{S} / \mathbf{1 8 , 2 4 2 . 0 8}$ \\
\hline \multicolumn{7}{|l|}{ Tarifa Hora } \\
\hline
\end{tabular}

Elaboración Propia 


\section{Costo de Servicio de Terceros}

Para el cálculo de los costos de terceros, pertenecientes a los gastos administrativos generales se tomaron en cuenta los siguientes: Costo de Seguridad, Costo de Limpieza y Servicio de Enfermería.

Tabla 7.26: Costo de servicios de terceros

\begin{tabular}{c|r|r}
\hline Servicio & Costo Mensual & \multicolumn{1}{c}{ Costo Anual } \\
\hline Seguridad & $6,000.00$ & $72,000.00$ \\
\hline Limpieza & $2,817.27$ & $33,807.21$ \\
\hline Enfermería & $4,000.00$ & $48,000.00$ \\
\hline Total & $\mathbf{1 2 , 8 1 7 . 2 7}$ & $\mathbf{1 5 3 , 8 0 7 . 2 1}$ \\
\hline
\end{tabular}

Elaboración Propia

Tabla 7.27: Pronóstico de gastos adm. totales

\begin{tabular}{c|c|c|c|c|c}
\hline Componente & $\mathbf{2 0 2 0}$ & $\mathbf{2 0 2 1}$ & $\mathbf{2 0 2 2}$ & $\mathbf{2 0 2 3}$ & $\mathbf{2 0 2 4}$ \\
\hline Sueldos Administrativos & $\mathrm{S} / 422,760.00$ & $\mathrm{~S} / 422,760.00$ & $\mathrm{~S} / 422,760.00$ & $\mathrm{~S} / 422,760.00$ & $\mathrm{~S} / 422,760.00$ \\
\hline Depreciación Equipos y Edificio & $\mathrm{S} / 36,390.73$ & $\mathrm{~S} / 36,390.73$ & $\mathrm{~S} / 36,390.73$ & $\mathrm{~S} / 36,390.73$ & $\mathrm{~S} / 36,390.73$ \\
\hline Agua (Zona Adm.) & $\mathrm{S} / 2,856.81$ & $\mathrm{~S} / 2,856.81$ & $\mathrm{~S} / 2,856.81$ & $\mathrm{~S} / 2,856.81$ & $\mathrm{~S} / 2,856.81$ \\
\hline Energía (Zona Adm.) & $\mathrm{S} / 18,242.08$ & $\mathrm{~S} / 18,242.08$ & $\mathrm{~S} / 18,242.08$ & $\mathrm{~S} / 18,242.08$ & $\mathrm{~S} / 18,242.08$ \\
\hline Servicios Terciarizados & $\mathrm{S} / 153,807.21$ & $\mathrm{~S} / 153,807.21$ & $\mathrm{~S} / 153,807.21$ & $\mathrm{~S} / 153,807.21$ & $\mathrm{~S} / 153,807.21$ \\
\hline Total Gastos Administrativos & $\mathrm{S} / \mathbf{6 3 4 , 0 5 6 . 8 4}$ & $\mathrm{S} / \mathbf{6 3 4 , 0 5 6 . 8 4}$ & $\mathrm{S} / \mathbf{6 3 4 , 0 5 6 . 8 4}$ & $\mathrm{S} / \mathbf{6 3 4 , 0 5 6 . 8 4}$ & $\mathrm{S} / \mathbf{6 3 4 , 0 5 6 . 8 4}$ \\
\hline
\end{tabular}

Elaboración Propia

\section{b. Gastos de ventas}

Para determinar los gastos de ventas se consideraron los gastos de distribución y de publicidad. Se consideró un presupuesto de gasto en publicidad de S/. 48,000.00 anuales y se tomó como referencia el gasto de distribución por kilogramo de cacao del Ministerio de Agricultura-Coopain, lo cual asciende a S/. 0.15. A este gasto se le sumaron los gastos del chofer, siendo este de S/. 150 por semana, lo cual lleva a un gasto de distribución de S/. 113,001.00. Por último, se determinaron los gastos de ventas totales de S/. 161,000.00.

Tabla 7.28: Presupuesto operativo de gastos totales

\begin{tabular}{l|c|c|c|c|c}
\hline Gastos & 2020 & 2021 & 2022 & 2023 & 2024 \\
\hline Distribución & $\mathrm{S} / 113,001.00$ & $\mathrm{~S} / 113,001.00$ & $\mathrm{~S} / 113,001.00$ & $\mathrm{~S} / 113,001.00$ & $\mathrm{~S} / 113,001.00$ \\
\hline Publicidad & $\mathrm{S} / 48,000.00$ & $\mathrm{~S} / 48,000.00$ & $\mathrm{~S} / 48,000.00$ & $\mathrm{~S} / 48,000.00$ & $\mathrm{~S} / 48,000.00$ \\
\hline Gastos de Ventas & $\mathrm{S} / \mathbf{1 6 1 , 0 0 1 . 0 0}$ & $\mathrm{S} / \mathbf{1 6 1 , 0 0 1 . 0 0}$ & $\mathrm{S} / \mathbf{1 6 1 , 0 0 1 . 0 0}$ & $\mathrm{S} / \mathbf{1 6 1 , 0 0 1 . 0 0}$ & $\mathrm{S} / \mathbf{1 6 1 , 0 0 1 . 0 0}$ \\
\hline Gastos Administrativos & $\mathrm{S} / \mathbf{6 3 4 , 0 5 6 . 8 4}$ & $\mathrm{S} / \mathbf{6 3 4 , 0 5 6 . 8 4}$ & $\mathrm{S} / \mathbf{6 3 4 , 0 5 6 . 8 4}$ & $\mathrm{S} / \mathbf{6 3 4 , 0 5 6 . 8 4}$ & $\mathrm{S} / \mathbf{6 3 4 , 0 5 6 . 8 4}$ \\
\hline \hline Presupuesto de Gastos & S/ 795,057.84 & $\mathrm{S} / \mathbf{7 9 5 , 0 5 7 . 8 4}$ & $\mathrm{S} / \mathbf{7 9 5 , 0 5 7 . 8 4}$ & $\mathrm{S} / \mathbf{7 9 5 , 0 5 7 . 8 4}$ & S/ 795,057.84 \\
\hline
\end{tabular}

Elaboración Propia 


\subsection{Presupuestos financieros}

\subsubsection{Presupuesto de servicio a la deuda}

Este proyecto financiará el $52 \%$ de la inversión total mediante un préstamo realizado por el Banco de Crédito del Perú (BCP) a una TEA de $15.25 \%$ por 5 años según la Superintendencia de Banca y Seguros (SBS). En un supuesto caso conservador, se solicitará un préstamo bancario menor al valor total del inmueble tasado por un Perito aprobado por el BCP, otorgando en garantía al banco el mismo terreno. La deuda asciende a S/. 1, 447,213.

Tabla 7.29: Detalles del endeudamiento

\begin{tabular}{c|r}
\hline \multicolumn{2}{|c}{ Endeudamiento a Largo Plazo (S/.) } \\
\hline Inversión Total & $2,783,101$ \\
\hline \% Endeudamineto & $52 \%$ \\
\hline Capital Propio & $1,335,888$ \\
\hline Deuda Total & $1,447,213$ \\
\hline Banco & Banco de Crédito del Perú \\
\hline TEA & $15.25 \%$ \\
\hline Tipo de Cuotas & Crecientes \\
\hline Plazo & 5 años \\
\hline
\end{tabular}

Elaboración Propia

Tabla 7.30: Cronograma de servicio a la deuda (Cuotas Crecientes)

\begin{tabular}{c|r|r|r|r|r}
\hline Año & \multicolumn{1}{|c|}{ Saldo Inicial } & Amortización & \multicolumn{1}{c|}{ Intereses } & \multicolumn{1}{c|}{ Cuota } & \multicolumn{1}{c}{ Saldo Final } \\
\hline $\mathbf{2 0 2 0}$ & $1,447,213$ & 96,481 & 220,700 & 317,181 & $1,350,732$ \\
\hline $\mathbf{2 0 2 1}$ & $1,350,732$ & 192,962 & 205,987 & 398,948 & $1,157,770$ \\
\hline $\mathbf{2 0 2 2}$ & $1,157,770$ & 289,443 & 176,560 & 466,002 & 868,328 \\
\hline $\mathbf{2 0 2 3}$ & 868,328 & 385,923 & 132,420 & 518,343 & 482,404 \\
\hline $\mathbf{2 0 2 4}$ & 482,404 & 482,404 & 73,567 & 555,971 & - \\
\hline
\end{tabular}

Elaboración Propia

\subsubsection{Presupuesto de estado de resultados}

A continuación se observa el Estado de Resultados proyectado anualmente a los próximos cinco años, considerando un Impuesto a la Renta del $29.50 \%$ y una participación del $10 \%$ según SUNAT. 
Tabla 7.31: Presupuesto de estado de resultados al 2024

\begin{tabular}{|c|c|c|c|c|c|}
\hline & 2020 & 2021 & 2022 & 2023 & 2024 \\
\hline Ventas & $3,977,202$ & $4,326,394$ & $4,675,586$ & $5,024,778$ & $5,722,934$ \\
\hline Costo de Ventas & $2,488,257$ & $2,572,814$ & $2,623,320$ & $2,668,207$ & $2,755,112$ \\
\hline Utilidad Bruta & $1,488,946$ & $1,753,581$ & $2,052,266$ & $2,356,571$ & $2,967,822$ \\
\hline Gastos Administrativos & 634,057 & 634,057 & 634,057 & 634,057 & 634,057 \\
\hline Gastos de Ventas & 161,001 & 161,001 & 161,001 & 161,001 & 161,001 \\
\hline Utilidad Operativa & 693,888 & $\mathbf{9 5 8 , 5 2 3}$ & $1,257,208$ & $1,561,513$ & $2,172,764$ \\
\hline Egresos Financieros & 220,700 & 205,987 & 176,560 & 132,420 & 73,567 \\
\hline Ingresos Financieros & - & - & - & - & - \\
\hline Otros Egresos & - & - & - & - & - \\
\hline Otros Ingresos & - & - & - & - & - \\
\hline $\begin{array}{l}\text { Utilidad Antes de Impuestos y } \\
\text { Participaciones }\end{array}$ & 473,188 & 752,536 & $1,080,649$ & $1,429,094$ & $2,099,198$ \\
\hline Participación Laboral (10\%) & 47,319 & 75,254 & 108,065 & 142,909 & 209,920 \\
\hline Utilidad Antes de Impuestos & 425,869 & 677,283 & $\mathbf{9 7 2 , 5 8 4}$ & $1,286,184$ & $1,889,278$ \\
\hline Impuesto a la Renta $(29.5 \%)$ & 125,631 & 199,798 & 286,912 & 379,424 & 557,337 \\
\hline Utilidad Neta & 300,238 & 477,484 & 685,671 & 906,760 & $1,331,941$ \\
\hline
\end{tabular}

Elaboración Propia

\subsubsection{Presupuesto de estado de situación financiera}

Para la elaboración del Estado de Situación Financiera, se muestran los siguientes cálculos de cada cuenta perteneciente a este. Para este proyecto, se consideró que el cliente pagará el 100\% de la venta en un periodo de un mes (30 días). Es importante tomar en cuenta que la venta de diciembre del primer año se recibe en Enero del segundo año. 
Tabla 7.32: Cuentas por cobrar comerciales

\begin{tabular}{|c|c|c|c|c|c|c|c|}
\hline Cobranzas 2020 & Enero & Febrero & Marzo & Abril & Mayo & Junio & \\
\hline Ventas & S/ $175,276.16$ & $\mathrm{~S} / 159,863.22$ & S/ $166,051.25$ & S/ $154,154.87$ & $\mathrm{~S} / 280,892.76$ & S/ 366,530.86 & \\
\hline A los 30 días $(100 \%)$ & & S/ $175,276.16$ & S/ $159,863.22$ & S/ $166,051.25$ & S/ $154,154.87$ & S/ $280,892.76$ & \\
\hline \multirow[t]{2}{*}{ Ingreso Total } & $\mathrm{S} / 0.00$ & S/ $175,276.16$ & $\mathrm{~S} / 159,863.22$ & S/ $166,051.25$ & S/ $154,154.87$ & S/ 280,892.76 & \\
\hline & Julio & Agosto & Septiembre & Octubre & Noviembre & Diciembre & ENERO \\
\hline Ventas & $\mathrm{S} / 568,621.42$ & $\mathrm{~S} / 643,594.55$ & $\mathrm{~S} / 539,130.50$ & S/ 397,637.44 & S/ 279,897.17 & S/ 245,552.27 & \\
\hline A los 30 días $(100 \%)$ & S/ 366,530.86 & $\mathrm{S} / 568,621.42$ & $\mathrm{~S} / 643,594.55$ & $\mathrm{~S} / 539,130.50$ & S/ 397,637.44 & S/ 279,897.17 & S/ 245,552.27 \\
\hline Ingreso Total & S/ 366,530.86 & $\mathrm{S} / 568,621.42$ & $\mathrm{~S} / 643,594.55$ & $\mathrm{~S} / 539,130.50$ & S/ 397,637.44 & S/ 279,897.17 & \\
\hline Ingresos por Cobranzas 2020 & $\mathrm{~S} / \mathbf{3 , 7 3 1}$ & & & & & & \\
\hline
\end{tabular}

Elaboración Propia

Tabla 7.33: Impuesto a las ventas

\begin{tabular}{|c|c|c|c|c|c|c|}
\hline Impuestos 2020 & Enero & Febrero & Marzo & Abril & Mayo & Junio \\
\hline Impuesto de Ventas & S/ 26,737.04 & $\mathrm{S} / 24,385.91$ & $\mathrm{~S} / 25,329.85$ & $\mathrm{~S} / 23,515.15$ & S/ 42,848.05 & S/ 55,911.49 \\
\hline \multirow[t]{2}{*}{ Egreso Total } & S/ 26,737.04 & $\mathrm{S} / 24,385.91$ & $\mathrm{~S} / 25,329.85$ & $\mathrm{~S} / 23,515.15$ & S/ 42,848.05 & S/ 55,911.49 \\
\hline & Julio & Agosto & Septiembre & Octubre & Noviembre & Diciembre \\
\hline Ventas & S/ 55,911.49 & S/ 55,911.49 & S/ 55,911.49 & S/ 55,911.49 & S/ 55,911.49 & S/ 55,911.49 \\
\hline Egreso Total & S/ 55,911.49 & S/ 55,911.49 & S/ 55,911.49 & S/ 55,911.49 & S/ 55,911.49 & S/ 55,911.49 \\
\hline
\end{tabular}

Elaboración Propia 
En cuando al pago a proveedores, se les pagará con una política del 50\% al contado y el resto a un mes (30 días).

Tabla 7.34: Cuentas por pagar comerciales

\begin{tabular}{l|c|c|c|c|c|c|c}
\hline \multicolumn{1}{|c|}{ Compras 2020 } & Enero & Febrero & Marzo & \multicolumn{1}{c|}{ Abril } & \multicolumn{1}{c|}{ Mayo } & \multicolumn{1}{c}{ Junio } \\
\hline Compras & $\mathrm{S} / 26,327.12$ & $\mathrm{~S} / 17,666.46$ & $\mathrm{~S} / 19,087.14$ & $\mathrm{~S} / 18,131.32$ & $\mathrm{~S} / 35,688.78$ & $\mathrm{~S} / 44,206.96$ \\
\hline Al contado (50\%) & $\mathrm{S} / 13,163.56$ & $\mathrm{~S} / 8,833.23$ & $\mathrm{~S} / 9,543.57$ & $\mathrm{~S} / 9,065.66$ & $\mathrm{~S} / 17,844.39$ & $\mathrm{~S} / 22,103.48$ \\
\hline A los 30 días (50\%) & & $\mathrm{S} / 8,833.23$ & $\mathrm{~S} / 9,543.57$ & $\mathrm{~S} / 9,065.66$ & $\mathrm{~S} / 17,844.39$ & $\mathrm{~S} / 22,103.48$ \\
\hline Ingreso Total & $\mathrm{S} / 13,163.56$ & $\mathrm{~S} / 17,666.46$ & $\mathrm{~S} / 19,087.14$ & $\mathrm{~S} / 18,131.32$ & $\mathrm{~S} / 35,688.78$ & $\mathrm{~S} / 44,206.96$ \\
\hline Compras & Julio & Agosto & Septiembre & Octubre & Noviembre & Diciembre & Enero \\
\hline Al contado (50\%) & $\mathrm{S} / 71,693.08$ & $\mathrm{~S} / 75,371.66$ & $\mathrm{~S} / 58,004.66$ & $\mathrm{~S} / 41,826.63$ & $\mathrm{~S} / 28,289.50$ & $\mathrm{~S} / 26,766.17$ & \\
\hline A los 30 días (50\%) & $\mathrm{S} / 35,846.54$ & $\mathrm{~S} / 37,685.83$ & $\mathrm{~S} / 29,002.33$ & $\mathrm{~S} / 20,913.32$ & $\mathrm{~S} / 14,144.75$ & $\mathrm{~S} / 13,383.08$ & \\
\hline Ingreso Total & $\mathrm{S} / 35,846.54$ & $\mathrm{~S} / 37,685.83$ & $\mathrm{~S} / 29,002.33$ & $\mathrm{~S} / 20,913.32$ & $\mathrm{~S} / 14,144.75$ & $\mathrm{~S} / 13,383.08$ & $\mathrm{~S} / 13,383.08$ \\
\hline Total Egreso Compras 2020 & $\mathrm{S} / 71,693.08$ & $\mathrm{~S} / 75,371.66$ & $\mathrm{~S} / 58,004.66$ & $\mathrm{~S} / 41,826.63$ & $\mathrm{~S} / 28,289.50$ & $\mathrm{~S} / 26,766.17$ & \\
\hline
\end{tabular}

Elaboración Propia

Tabla 7.35: Tributos por pagar

\begin{tabular}{l|r}
\hline Tributos por Pagar & Monto \\
\hline Débito Fiscal de las Ventas & $\mathrm{S} / 82,648.53$ \\
\hline Escudo Fiscal de las Compras & $\mathrm{S} / 17,643.64$ \\
\hline Flujo de IGV & $\mathrm{S} / 12,012.33$ \\
\hline Impuestos Gtos. Adm. & $\mathrm{S} / 114,130.23$ \\
\hline Impuestos Gtos. Ventas & $\mathrm{S} / 28,980.18$ \\
\hline Flujo de Caja de IGV & $-\mathrm{S} / 131,098.08$ \\
\hline
\end{tabular}

Elaboración Propia 
Tabla 7.36: Flujo de caja por concepto de materia prima

\begin{tabular}{l|r}
\hline Flujo de Caja por Conceptos de MP & Monto \\
\hline Total Valor Compras 2020 & $\mathrm{S} / 98,020.21$ \\
\hline IGV de las Compras & $\mathrm{S} / 17,643.64$ \\
\hline Total Precio Compras 2020 & $\mathrm{S} / 115,663.84$ \\
\hline Total por Pagar 2020 (Con IGV) & S/ 13,383.08 \\
\hline Flujo de Caja por compra de MP & S/ 102,280.76 \\
\hline
\end{tabular}

Elaboración Propia

Tabla 7.37: Flujo de caja 2020

\begin{tabular}{l|r}
\hline \multicolumn{2}{c}{ Flujo de Caja 2020 (S/.) } \\
\hline Ingresos & $3,862,748$ \\
\hline Ingresos por Cobranza & $1,447,213$ \\
\hline Financiamiento & $\mathbf{5 , 3 0 9 , 9 6 1}$ \\
\hline Total Ingresos & \\
\hline & \\
\hline Egresos & $(711,796)$ \\
\hline Gastos Administrativos & $(189,981)$ \\
\hline Gastos Ventas & $(2,448,016)$ \\
\hline Inversión Largo Plazo & $(520,313)$ \\
\hline Materia Prima & $(686,760)$ \\
\hline Sueldos MOD & $(1,340,066)$ \\
\hline CIF & $(220,700)$ \\
\hline Pago de Intereses & $(96,481)$ \\
\hline Amortización Deuda & $(\mathbf{6 , 2 1 4 , 1 1 3 )}$ \\
\hline Total Egresos & $\mathbf{1 , 3 3 5 , 8 8 8}$ \\
\hline & $(904,152)$ \\
\hline Saldo Inicial & $\mathbf{4 3 1 , 7 3 7}$ \\
\hline Variación &
\end{tabular}

Elaboración Propia 
Tabla 7.38: Estado de situación financiera 2020

\begin{tabular}{|c|c|c|c|}
\hline \multicolumn{2}{|l|}{ Activo Corriente } & \multicolumn{2}{|l|}{ Pasivo Corriente } \\
\hline Caja y Bancos & 431,737 & Imp. A la Renta & 125,631 \\
\hline Cuentas por Cobrar Comerciales & 328,201 & Remunerac. Y participaciones & 47,319 \\
\hline Inventario Producto Terminado & 46,000 & Cuentas por Pagar & 13,383 \\
\hline \multirow[t]{2}{*}{ Total Activo Corriente } & 805,938 & Deuda a Corto Plazo & 96,481 \\
\hline & & Total Pasivo corriente & 282,814 \\
\hline \multicolumn{2}{|l|}{\begin{tabular}{|l} 
Activo No Corriente \\
\end{tabular}} & \multicolumn{2}{|l|}{ Pasivo No Corriente } \\
\hline Maquinaria y Equipos & 339,723 & Deuda Largo Plazo & $1,254,251$ \\
\hline Depreciación Fabril & $(44,371)$ & Total Pasivo No Corriente & $1,254,251$ \\
\hline Activos No fabriles (Inm, Equip, etc.) & $2,108,293$ & & \\
\hline Depreciación No Fabril & $(36,391)$ & \multicolumn{2}{|l|}{ Patrimonio } \\
\hline \multirow[t]{3}{*}{\begin{tabular}{|l} 
Total Activo No Corriente \\
\end{tabular}} & $2,367,254$ & Capital Social & $1,335,888$ \\
\hline & & Resultados del Ejercicio & $\mathbf{3 0 0 , 2 3 8}$ \\
\hline & & Total Patrimonio & $1,636,126$ \\
\hline Total Activos & $3,173,191$ & Total Patrimonio y Pasivos & $3,173,191$ \\
\hline
\end{tabular}

Elaboración Propia

\subsubsection{Flujo de fondos netos (Económico y Financiero)}

Para el presente proyecto, no se considerará la inflación, la empresa recuperará su capital de trabajo y se liquidará en el último año (5). 


\subsubsection{Flujo de fondos económico}

Tabla 7.39: Flujo de fondos económico

\begin{tabular}{|c|c|c|c|c|c|c|}
\hline Flujo de Caja Económico & Año 0 & 2020 & 2021 & 2022 & 2023 & 2024 \\
\hline Utilidad Neta & & 300,238 & 477,484 & 685,671 & 906,760 & $1,331,941$ \\
\hline \multicolumn{7}{|l|}{ Ajustes } \\
\hline Depreciación Fabril & & 44,371 & 44,371 & 44,371 & 44,371 & 33,092 \\
\hline Depreciación No Fabril & & 36,391 & 36,391 & 36,391 & 36,391 & 36,391 \\
\hline Intereses & & 220,700 & 205,987 & 176,560 & 132,420 & 73,567 \\
\hline Capital de Trabajo & & & 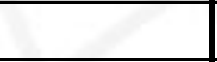 & & & 346,534 \\
\hline Valor en libros & & & & & & 371,110 \\
\hline Inversion & $(2,783,101)$ & & & & & \\
\hline Flujo de Caja Económico & $(2,783,101)$ & 601,700 & 764,233 & 942,994 & $1,119,942$ & $2,192,634$ \\
\hline Flujo de Caja Económico Descontado & $(2,783,101)$ & 515,469 & 560,881 & 592,894 & 603,234 & $1,011,765$ \\
\hline Flujo de Caja Económico Acumulado & $(2,783,101)$ & $(2,267,632)$ & $(1,706,751)$ & $(1,113,857)$ & $(510,623)$ & 501,142 \\
\hline
\end{tabular}

Elaboración Propia 


\subsubsection{Flujo de fondos financiero}

Tabla 7.40: Flujo de fondos financiero

\begin{tabular}{|c|c|c|c|c|c|c|}
\hline Flujo de Caja Financiero & Año 0 & 2019 & 2020 & 2021 & 2022 & 2023 \\
\hline Flujo de Caja Económico & $(2,783,101)$ & 601,700 & 764,233 & 942,994 & $1,119,942$ & $2,192,634$ \\
\hline \multicolumn{7}{|l|}{ Ajustes } \\
\hline Intereses & & $(220,700)$ & $(205,987)$ & $(176,560)$ & $(132,420)$ & $(73,567)$ \\
\hline Amortización Deuda & & $(96,481)$ & $(192,962)$ & $(289,443)$ & $(385,923)$ & $(482,404)$ \\
\hline Escudo Fiscal Intereses & & 65,106 & 60,766 & 52,085 & 39,064 & 21,702 \\
\hline Deuda & $1,447,213$ & & & & & \\
\hline Flujo de Caja Económico & $(1,335,888)$ & 349,626 & 426,051 & 529,076 & 640,663 & $1,658,366$ \\
\hline Flujo de Caja Económico Descontado & $(1,335,888)$ & 299,520 & 312,685 & 332,649 & 345,080 & 765,233 \\
\hline Flujo de Caja EconómicoAcumulado & $(1,335,888)$ & $(1,036,369)$ & $(723,684)$ & $(391,035)$ & $(45,955)$ & 719,278 \\
\hline
\end{tabular}

Elaboración Propia 


\subsection{Evaluación económica-financiera}

Para la evaluación económica-financiera del proyecto se utilizó el BETA de la industria alimentaria de Estados Unidos para luego hallar el BETA de nuestra empresa mediante la ecuación:

\section{BETA de la empresa $=$ BETA desempalancada $\times\{1+\{1-$ Impuesto a la renta $\}$ $\times$ deuda}

Para calcular el COK de la empresa, se tomó en cuenta la ecuación $\quad \mathrm{COK}=$ $\mathrm{Rf}+\mathrm{B} *(\mathrm{Rm}-\mathrm{Rf})+\mathrm{Rp}$. A continuación se detalla el significado de cada componente de la ecuación.

Tabla 7.41: Cálculo del COK

\begin{tabular}{l|r}
\hline \multicolumn{2}{c}{ Cálculo del COK } \\
\hline Tasa libre de Riesgo ( rf) & $3,06 \%$ \\
\hline Rendimiento de S\&PP 500 (Rm) & $12,32 \%$ \\
\hline Indicadores de Riesgo (Rp) & $1,10 \%$ \\
\hline Beta de desapalancamiento & 0,7696 \\
\hline Beta de la Empresa & 1,36 \\
\hline COK & $\mathbf{1 6 , 7 3 \%}$ \\
\hline
\end{tabular}

Elaboración Propia

\subsubsection{Evaluación económica: VAN, TIR, RBC, PR.}

Luego de elaborar el flujo de fondos económico, se calcularon los siguientes indicadores. Dado que el VAN es positivo, se puede concluir que desde una visión económica, el proyecto es rentable. Además, se recomienda invertir en un proyecto cuando el TIR es mayor al COK, siendo este $22,81 \%$. Se obtuvo una relación beneficio/costo de 1.18 por lo que la empresa tiene la capacidad de generar ingresos por cada sol que se invirtió en el proyecto. Se espera recuperar la inversión en 4 años, 2 meses y 24 días. 
Tabla 7.42: Evaluación económica

\begin{tabular}{c|c}
\hline \multicolumn{2}{|c}{ Evaluación Económica } \\
\hline VAN & S/ 501,142.07 \\
\hline TIR & $22,81 \%$ \\
\hline B/C & 1.18 \\
\hline PR & $\begin{array}{c}\text { años 2 meses 24 } \\
\text { dias }\end{array}$ \\
\hline
\end{tabular}

Elaboración Propia

\subsubsection{Evaluación financiera: VAN, TIR, RBC, PR}

Luego de elaborar el flujo de fondos financiero, se calcularon los siguientes indicadores. Dado que el VAN es positivo, se puede concluir que desde una visión financiera, el proyecto sí es rentable, en donde el TIR es mayor al COK, siendo este $32.87 \%$. Se obtuvo una relación beneficio/costo de 1.54 por lo que la empresa tiene la capacidad de generar 1.54 veces más ingreso por cada sol que se invirtió en el proyecto. Se espera recuperar la inversión en 4 años y 10 días.

Tabla 7.43: Evaluación financiera

\begin{tabular}{c|c}
\hline \multicolumn{2}{c}{ Evaluación Financiera } \\
\hline VAN & S/ 719,278.25 \\
\hline TIR & $32,87 \%$ \\
\hline B/C & 1.54 \\
\hline PR & $\begin{array}{c}4 \text { años y } 10 \\
\text { dias }\end{array}$ \\
\hline
\end{tabular}

Elaboración Propia 


\subsubsection{Análisis de ratios (liquidez, endeudamiento, rentabilidad, cobertura)}

A continuación, se presentará el análisis de ratios para el proyecto

Tabla 7.44: Análisis de ratios

\begin{tabular}{|c|c|c|c|}
\hline Categoría & Ratio & Valor & Análisis del Ratio \\
\hline \multirow{6}{*}{ Liquidez } & $\begin{array}{l}\text { Capital de } \\
\text { Trabajo }\end{array}$ & 335,085 & $\begin{array}{l}\text { Es la cantidad de dinero que tiene la empresa para seguir operando, } \\
\text { luego de haber cubierto sus obligaciones de corto plazo. La empresa } \\
\text { cuenta con S/. } 335,085 \text { para operar en el } 2020 \text {. }\end{array}$ \\
\hline & Razón Corriente & 2.85 & $\begin{array}{l}\text { Permite analizar la capacidad de la empresa para cubrir sus } \\
\text { obligaciones financieras de corto plazo. En este caso, la empresa es } \\
\text { capaz de cubrir hasta } 2.85 \text { veces mas sus obligaciones financieras. }\end{array}$ \\
\hline & $\begin{array}{l}\text { Periodo } \\
\text { Promedio de } \\
\text { Cobro (días) }\end{array}$ & 29.71 & $\begin{array}{l}\text { Es el periodo de tiempo que se demora la empresa en cobrarle a sus } \\
\text { clientes, en este caso es de } 29.71 \text { días. }\end{array}$ \\
\hline & $\begin{array}{l}\text { Rotación de } \\
\text { Inventarios }\end{array}$ & 6.66 & $\begin{array}{l}\text { Permite identificar cuántas veces el inventario se convierte en dinero, } \\
\text { ya sea al contado o al crédito. En este caso, la empresa se demorará } \\
6.66 \text { días. }\end{array}$ \\
\hline & $\begin{array}{l}\text { Periodo } \\
\text { promedio de } \\
\text { Pagos (días) } \\
\end{array}$ & 1.94 & $\begin{array}{l}\text { Es el periodo de tiempo que se demora la empresa en pagarle a sus } \\
\text { proveedores en este caso es de } 1.94 \text { días. }\end{array}$ \\
\hline & $\begin{array}{l}\text { Duración Ciclo } \\
\text { de Liquidez } \\
\text { (días) }\end{array}$ & 34.43 & $\begin{array}{l}\text { Es el periodo desde que la empresa compra la MP hasta que se } \\
\text { realice la cobranza por el producto terminado. Nuestra empresa } \\
\text { pretende demorarse aproximadamente } 34 \text { días en lograr una venta } \\
\text { desde que se compro la MP. }\end{array}$ \\
\hline Ende udamiento & Apalancamiento & 0.939 & $\begin{array}{l}\text { Es la capacidad de una empresa para endeudarse con alguna } \\
\text { institución financiera. La empresa está endeudada por debajo del valor } \\
\text { de su patrimonio. }\end{array}$ \\
\hline \multirow{7}{*}{ Rentabilidad } & ROE (\%) & $18.35 \%$ & $\begin{array}{l}\text { Es el indicador más preciso para medir la rentabilidad del capital } \\
\text { invertido de un proyecto. La utilidad neta para el } 2020 \text { corresponderán } \\
\text { al } 18.35 \% \text { del patrimonio invertido por los socios. }\end{array}$ \\
\hline & $\begin{array}{l}\text { Margen Bruto } \\
(\%)\end{array}$ & $37.44 \%$ & $\begin{array}{l}\text { Es el margen de ganancia luego de la resta del costo de ventas con } \\
\text { respecto a los ingresos. }\end{array}$ \\
\hline & \begin{tabular}{|l} 
Margen \\
Operativo (\%)
\end{tabular} & $17.45 \%$ & $\begin{array}{l}\text { Es el margen de ganancia luego de la resta de los gastos } \\
\text { administrativos y de ventas con respecto a los ingresos. }\end{array}$ \\
\hline & $\begin{array}{l}\text { Margen Neto } \\
(\%)\end{array}$ & $7.55 \%$ & $\begin{array}{l}\text { Es el margen de ganancia luego de la resta del impuesto a la renta con } \\
\text { respecto a los ingresos. }\end{array}$ \\
\hline & EBITDA (S/.) & 774,650 & \multirow{2}{*}{$\begin{array}{l}\text { Es la suma de la utilidad operativa + la depreciación y permite } \\
\text { visualizar la generación de la empresa descontando los gastos por }\end{array}$} \\
\hline & EBITDA (\%) & $19.48 \%$ & \\
\hline & ROA $(\%)$ & $9.46 \%$ & $\begin{array}{l}\text { Este indicador muestra el porcentaje de las utilidades que genera la } \\
\text { empresa con respecto a los activos totales que tiene. }\end{array}$ \\
\hline Cobertura & $\begin{array}{l}\text { Cobertura de } \\
\text { Intereses }\end{array}$ & 3.51 & $\begin{array}{l}\text { Indica cuántas veces en un periodo de tiempo determinado el flujo de } \\
\text { caja es superior que las deudas financieras a pagar. La empresa podrá } \\
\text { cubrir hasta } 3.51 \text { veces sus obligaciones financieras del año en el } \\
\text { corto plazo. }\end{array}$ \\
\hline
\end{tabular}

Elaboración Propia 


\subsubsection{Análisis de sensibilidad del proyecto}

El cacao fino en grano, como los demás productos alimenticios y no alimenticios, están expuestos a cambios en los precios. Estos cambios pueden darse por un aumento del costo de la materia prima por algún desastre natural, por la demanda en un periodo determinado o algún otro factor. Las utilidades de las empresas comercializadoras de estos productos estarán siempre sensibles a aquellas variaciones conforme pase el tiempo, por lo que se realizó un análisis de sensibilidad de precios por kg de cacao fino en grano para poder evaluar la rentabilidad de la empresa ante cualquier cambio en el mercado. A su vez, debido a que gran parte de la inversión está vinculada con la adquisición de terreno de cultivo se analizará que cantidad de terreno adquirir para obtener un financiero positivo.

Tabla 7.45: Análisis de sensibilidad de precios de cacao fino en el Perú

\begin{tabular}{|c|c|c|c|c|c|c|c|c|c|c|}
\hline & \multicolumn{9}{|c|}{ Variación Precio de Venta $(\$ / \mathrm{Kg})$} \\
\hline & & 2.4 & 2.33 & 2.26 & 2.19 & 2.12 & 2.05 & 1.98 & 1.91 & 1.84 \\
\hline \multirow{15}{*}{ 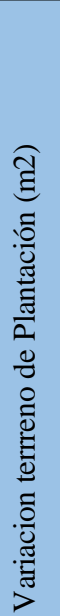 } & 35000 & 719,278 & 444,101 & 168,924 & $-106,253$ & $-381,430$ & $-656,607$ & $-931,784$ & $-1,206,961$ & $-1,482,137$ \\
\hline & 32500 & 810,370 & 535,193 & 260,016 & $-15,161$ & $-290,338$ & $-565,515$ & $-840,692$ & $-1,115,869$ & $-1,391,046$ \\
\hline & 30000 & 901,462 & 626,285 & 351,108 & 75,931 & $-199,246$ & $-474,423$ & $-749,600$ & $-1,024,777$ & $-1,299,954$ \\
\hline & 27500 & 992,554 & 717,377 & 442,200 & 167,023 & $-108,154$ & $-383,331$ & $-658,508$ & $-933,685$ & $-1,208,862$ \\
\hline & 25000 & $1,083,646$ & 808,469 & 533,292 & 258,115 & $-17,062$ & $-292,239$ & $-567,416$ & $-842,593$ & $-1,117,770$ \\
\hline & 22500 & $1,174,738$ & 899,561 & 624,384 & 349,207 & 74,030 & $-201,147$ & $-476,324$ & $-751,501$ & $-1,026,678$ \\
\hline & 20000 & $1,265,830$ & 990,653 & 715,476 & 440,299 & 165,122 & $-110,055$ & $-385,232$ & $-660,409$ & $-935,586$ \\
\hline & 17500 & $1,356,922$ & $1,081,745$ & 806,568 & 531,391 & 256,214 & $-18,963$ & $-294,140$ & $-569,317$ & $-844,494$ \\
\hline & 15000 & $1,448,014$ & $1,172,837$ & 897,660 & 622,483 & 347,306 & 72,129 & $-203,048$ & $-478,225$ & $-753,402$ \\
\hline & 12500 & $1,539,106$ & $1,263,929$ & 988,752 & 713,575 & 438,398 & 163,221 & $-111,956$ & $-387,133$ & $-662,310$ \\
\hline & 10000 & $1,630,198$ & $1,355,021$ & $1,079,844$ & 804,667 & 529,490 & 254,313 & $-20,864$ & $-296,041$ & $-571,218$ \\
\hline & 7500 & $1,721,289$ & $1,446,112$ & $1,170,936$ & 895,759 & 620,582 & 345,405 & 70,228 & $-204,949$ & $-480,126$ \\
\hline & 5000 & $1,812,381$ & $1,537,204$ & $1,262,027$ & 986,850 & 711,674 & 436,497 & 161,320 & $-113,857$ & $-389,034$ \\
\hline & 2500 & $1,903,473$ & $1,628,296$ & $1,353,119$ & $1,077,942$ & 802,765 & 527,588 & 252,412 & $-22,765$ & $-297,942$ \\
\hline & 0 & $1,994,565$ & $1,719,388$ & $1,444,211$ & $1,169,034$ & 893,857 & 618,680 & 343,503 & 68,326 & $-206,850$ \\
\hline
\end{tabular}

Elaboración Propia 


\section{CAPÍTULO VIII: EVALUACIÓN SOCIAL DEL PROYECTO}

El presente proyecto está diseñado para que cumpla con la rentabilidad sostenida, impactando de manera positiva al medio ambiente y a la sociedad que la rodea. A continuación, se identifica el impacto social del proyecto, desde la viabilidad económicafinanciera, hasta el valor agregado que genera a la sociedad.

\subsection{Identificación de las zonas y comunidades de influencia del proyecto}

La planta se instalará en Tocache, provincia ubicada en la Cordillera de los Andes, la cual cuenta con una importante economía comercial. Esta se divide en dos morfo estructuras importantes: por el este, la Cordillera Sub andina y por el oeste, la Cordillera Oriental. En esta zona, se han generado diversos procesos que explican la diversidad de la vegetación y los hábitats.

La zona industrial es considerada una fuente de altos recursos ambientales y permitirá contratar a los agricultores de la zona, permitiéndoles ahorrar tiempo y dinero en movilidad.

7.2. Análisis de indicadores sociales (valor agregado, densidad de capital, intensidad de capital, relación producto - capital y productividad de mano de obra)

\section{Valor agregado}

Este indicador muestra el valor añadido de todo el proceso productivo, en donde se comparan los ingresos por ventas de sacos de cacao en grano con los costos de los materiales directos de fabricación. Primero se calculó el valor agregado anual y luego el valor agregado neto, utilizando la Tasa Social de Descuento (TSD) es de $7.97 \%$ 
(ACTUALIZACIÓN DE LA TASA SOCIAL DE DESCUENTO 2012, 2012, p. 34). El resultado de este indicador nos refleja que el proyecto es beneficioso para la sociedad, dado que genera un valor agregado positivo de S/. 16, 538,193.

Tabla 8.1: Valor agregado

\begin{tabular}{l|rrrrr}
\cline { 2 - 6 } & \multicolumn{1}{c|}{$\mathbf{2 0 2 0}$} & $\mathbf{2 0 2 1}$ & $\mathbf{2 0 2 2}$ & \multicolumn{1}{c}{$\mathbf{2 0 2 3}$} & \multicolumn{1}{c}{$\mathbf{2 0 2 4}$} \\
\hline Ingresos por ventas (S/.) & $3,977,202$ & $4,326,394$ & $4,675,586$ & $5,024,778$ & $5,722,934$ \\
(-) Costo de materiales (S/.) & $-458,026$ & $-499,964$ & $-545,205$ & $-584,848$ & $-664,096$ \\
\hline Valor Agregado (S/.) & $\mathbf{3 , 5 1 9 , 1 7 7}$ & $\mathbf{3 , 8 2 6 , 4 3 1}$ & $\mathbf{4 , 1 3 0 , 3 8 1}$ & $\mathbf{4 , 4 3 9 , 9 3 0}$ & $\mathbf{5 , 0 5 8 , 8 3 8}$ \\
\hline
\end{tabular}

\begin{tabular}{l|l}
\hline Valor Agregado Ne to $(\mathrm{S} /)$. & $16,538,193$ \\
\hline
\end{tabular}

Elaboración Propia

\section{Densidad de capital}

La densidad de capital muestra el grado de inversión del proyecto por cada colaborador de la empresa. Se obtiene dividiendo la inversión total del proyecto entre el número total de colaboradores. Según la tabla a continuación, se obtiene que por cada puesto de trabajo requerido, se requiere de una inversión de S/. 33,940.

Tabla 8.2: Densidad de capital

\begin{tabular}{l|r}
\hline Inversión del proyecto (S/.) & $2,783,101$ \\
\hline Número de trabajadores & 82 \\
\hline \multicolumn{2}{|c|}{} \\
\hline Densidad de capital (S/. / Trab) & 33,940 \\
\hline
\end{tabular}

Elaboración Propia

\section{Intensidad de capital}

La intensidad de capital y la relación Producto - Capital se relacionan, dado que ambos evalúan la relación entre la inversión total del proyecto y el valor agregado.

Según el resultado de la intensidad de capital, por cada $\mathrm{S} /$. 1 de valor agregado, se requiere S/. 0.17 de inversión, generando una alta rentabilidad social. 
Tabla 8.3: Intensidad de capital

\begin{tabular}{l|r}
\hline Inversión del proyecto (S/.) & $2,864,043$ \\
\hline Valor Agregado Ne to $(\mathbf{S} /)$. & $16,538,193$ \\
\hline
\end{tabular}

\begin{tabular}{l|r}
\hline Intensidad de capital & 0.17 \\
\hline
\end{tabular}

Elaboración Propia

\section{Relación producto - capital}

Según el resultado de la tabla líneas abajo, se obtiene S/. 5.94 de valor agregado por cada sol invertido, lo cual proyecta un elevado nivel de efectividad social.

Tabla 8.4: Relación producto-capital

\begin{tabular}{l|r}
\hline Valor Agregado Ne to $(\mathrm{S} /)$. & $16,538,193$ \\
\hline Inversión del proyecto $(\mathbf{S} /)$. & $2,783,101$ \\
\hline
\end{tabular}

\begin{tabular}{l|r}
\hline Relación Producto - Capital & 5.94 \\
\hline
\end{tabular}

Elaboración Propia

\section{Productividad de mano de obra}

Finalmente, este indicador relaciona el valor promedio de producción por año con el número de colaboradores de la empresa. Según el resultado, por cada puesto de trabajo por año generado en la empresa, se puede producir S/. 33,940 de cacao en grano. Analizando este importe, se observa que el valor representa una producción anual de más de 11,689 sacos de cacao fino en grano, superando de esta manera el punto de equilibrio (4,713 sacos de cacao fino en grano), es decir, más de 2 veces el volumen requerido para alcanzar una utilidad cero.

Tabla 8.5: Productividad MO

\begin{tabular}{|l|r}
\hline Inversión del proyecto $(\mathrm{S} /)$. & $2,783,101$ \\
\hline Número de trabajadores & 82 \\
\hline
\end{tabular}

\begin{tabular}{|l|r}
\hline Productividad MO (S/. / Trab) & 33,940 \\
\hline
\end{tabular}

Elaboración Propia 


\section{CONCLUSIONES}

- Se confirma la factibilidad de instalar una planta productora de cacao fino en el Perú, pues existe un mercado que necesita el producto y además, es tecnológica, económica y financieramente viable.

- Se determinó que el lugar óptimo para ubicar la planta será la ciudad de Tocache en el departamento de San Martin; debido a que, cuenta con un clima favorable para el crecimiento del cacao. Además, cuenta con una adecuada red vial y el costo de terreno es considerablemente más bajo que el de su competencia más cercana.

- Se concluyó, según el análisis de Porter que, la implementación de una fábrica productora de cacao, será viable en parte debido a la demanda insatisfecha de este sector. Sin embargo, se debe tener cuidando siempre con el poder de negociación de los proveedores, en especial de aquellos que proveen materia prima, debido a la fragmentación del mercado y a la predisposición de estos para subsidiar parte de la producción.

- Gracias, a las preguntas número 25 y 26 de la encuesta realizada, se determinó una intención del 64\% del mercado a comprar cacao fino procedente de la fábrica; así como también, una intensidad del $73 \%$ del mercado a comprar inmediatamente el producto final ofrecido. Con estos datos anteriores, de logró determinar la demanda del proyecto teniendo en cuenta otros factores, como porcentaje de cacao fino en Perú, frecuencia de compra, capacidad máxima de producción según la región San Martin y la participación de mercado de los actuales competidores. Cuyos resultados se encuentran plasmados en el capítulo 2.4.

- Se determinó la producción real del proyecto, teniendo en cuenta la estacionalidad del cacao en Perú, así como también, el stock de seguridad tanto para el producto terminado, con ayuda de las políticas de inventario descritas en el capítulo 5.10, y a su vez el stock de seguridad para insumos, teniendo en cuenta la desviación en el tiempo de entrega del proveedor, el nivel de servicio y el plazo de entrega previsto por el comerciante. 
- Se logró definir, el tamaño óptimo de la planta teniendo en cuenta que, como factor limitante se tiene a la relación tamaño-mercado, ya que al analizarla junto al tamaño recurso productivo, tecnológico y teniendo en cuenta el punto de equilibrio analizado en el capítulo 4, esta relación será la que determinará el tamaño para el cual la planta será diseñada. La cual, tendrá la capacidad suficiente para producir sin ningún inconveniente 11,689 Sacos de $60 \mathrm{~kg}$. de cacao fino.

- Se determinó, como se puede ver en el plano presente en la figura 5.20, específicamente en el área de producción, que la mejor distribución de la maquinaria y estaciones de trabajo será la disposición en célula de trabajo, ya que permite alcanzar flexibilidad y eficiencia en la elaboración del producto. A su vez, brida una reducción amplia en el tiempo de maduración de la curva de aprendizaje de los colaboradores, permitiendo ser atendida por números variables de operarios en turnos distintos, para finalmente disminuir los costos y el tiempo de preparación de las maquinas.

- Se obtuvo un análisis económico financiero positivo, con un VAN económico de S/. 501,142.07, una TIR de 22,81\%, mayor al COK lo cual significa que económicamente se recupera la inversión en el periodo de cinco años. El periodo de recupero es de 4 años, 2 meses y 24 días. Por otro lado, el proyecto es también financieramente viable, obteniendo un VAN Financiero de S/. 719,278.25, una TIR de $32,87 \%$, siendo este mayor al COK, lo cual significa que el proyecto es financieramente rentable y sí se recupera la inversión en un periodo de 4 años y 10 días.

- Los ratios financieros demuestran que tenemos una excelente liquidez, pudiendo cubrir deudas a corto plazo. A su vez, el capital de trabajo es de S/. 335,085, el cual al ser positivo y relativamente alto en comparación con los activos corrientes, permite a la empresa seguir operando.

- Finalmente, este proyecto genera un valor agregado neto de S/. 16, 538,193, considerando la Tasa Social de Descuento de 7,97\%. 


\section{RECOMENDACIONES}

- Se recomienda realizar el plan de mantenimiento descrito en el capítulo 5.8, para así poder mantener a la planta operativa el mayor tiempo posible; ya que, la disponibilidad del equipo juega un rol crucial en la operación.

- Se recomienda implementar el programa de gestión de residuos sólidos descritos en el capítulo 5.6, para que de esta manera se realice una simbiosis en el área de plantación para re-utilizar las ramas de la operación de poda y así realizar fertilizante orgánico y mantener la denominación de producto orgánico.

- Se sugiere mantener una relación sólida con los clientes, ya que son pocos los que se encuentran en este rubro, pero tiene una alta demanda del producto final ofrecido. Entre ellos se encuentra Las Palma a los cuales se ofrecerán precios según la estrategia de penetración, para así obtener fidelización de los clientes.

- Se recomienda buscar clientes nuevos para incluirlos en la cartera de potenciales interesados, por medio de participación en exposiciones y ferias alimentarias de este rubro.

- Se recomienda valuar la viabilidad del proyecto, en un periodo posterior a los 5 años analizados, debido a que la capacidad de tecnología está muy próxima a la demanda de mercado, lo que indica que un crecimiento de la demanda posterior al año 5 necesitara de mayor inversión en maquinaria para satisfacer su crecimiento.

- Se recomienda solicitar al banco una línea de Descuento de Facturas Negociables para poder adelantar las cobranzas al día 0 y así aumentar la liquidez en el corto plazo.

- Dado que los valores de liquidez muestran resultados positivos como por ejemplo: el capital de trabajo elevado, es recomendable para un futuro cercano, invertir en un análisis de optimización de excedente de dinero, para así poder aumentar la rentabilidad de la empresa. 
- El proceso debe tener estándares altos en cuanto a la higiene, para así poder asegurar la inocuidad del producto final; debido a que, éste es un insumo comestible. Por lo que, es fundamental controlar la limpieza en cada fase del proceso. Así mismo, se recomienda obtener una certificación HACCP para mejorar la imagen del producto con el cliente.

- Se recomienda, el método de fermentado a cajones en cascada ya que es el más adecuado; debido a que, permite mantener la inocuidad del producto mientras los azucares van degradándose y a su vez, permite producir lotes grandes; a comparación de, los otros métodos tradicionales que no mantienen un ambiente libre de gérmenes y su capacidad de producción es más reducida.

- Se recomienda, implementar un subproceso de reutilización de mermas procedentes del área de producción, como el descrito en el proyecto con la zona de biodigestores, ya que cerca del $75 \%$ de la materia prima que ingresa es eliminada durante el proceso de fabricación de cacao. 


\section{REFERENCIAS}

Agroinsur. (2007). Procesamiento de harina de lúcuma liofilizada. Tacna.

Alata, R. E. (2010). Obtención de lúcuma (pouteria obovata) en polvo por atomización. Lima: Universidad Nacional de Ingeniería.

Alvarez, Z., Bravo, L., y Tagami , R. (2006). Plan de negocios para la industrialización y exportación de lúcuma de seda. Lima: ESAN.

Archive, J. (14 de Enero de 2010). Huaral.pe. Recuperado el 11 de 11 de 2017, de Huaral.pe: http://www.huaral.pe/2010/01/14/actividad-economica/

Barnalab. (2015). Barnalab. Recuperado el 15 de Abril de 2018, de ¿Qué es la liofilización?: https://www.barnalab.com/que-es-la-liofilizacion/

Bazarte, H. (2008). Manual de prácticas en el manejo intensivo de cacao. Maracaibo, 124-128.

BBC Mundo. (21 de Febrero de 2018). 5 razones por las que el chocolate está en peligro en todo el mundo. $B B C$ News.

Bega. (2017). Bega. Recuperado el 15 de Abril de 2018, de Envasadora para saco valvulado:

https://docs.wixstatic.com/ugd/c68b19_f4ca5b28d1e340b6aa2513962ac8d4e2.p df

Betelgeux. (25 de Marzo de 2015). Diseño higiénico en la industria alimentaria. Recuperado el 30 de Mayo de 2018, de Betelgeux: http://www.betelgeux.es/blog/2015/03/25/diseno-higienico-en-la-industriaalimentaria/

Carranza, J., y Sánchez, M. (2002). Cinética de secado de musa paradisiaca "plátano" y manihot esculenta grantz "yuca". Revista Amazónica de Investigación, 16-25. Recuperado el 21 de abril de 2017, de http://www.gob.gob.edu.unu.cnm.edu.edu.unapiquitos.edu.pe/pregrado/facultad es/alimentarias/descargas/vol2/2.pdf

Chávez y Juscamaita (2013). Estudio de Pre-factibilidad para la exportación de cacao en grano tostado al mercado Estadounidense (Tesis para obtener el título de Ingeniero Industrial) Pontificia Universidad Católica del Perú, Perú

CI Talsa. (2016). CI Talsa. Recuperado el 15 de Abril de 2018, de Lavadora de frutas por inmersión citalsa lia1: https://citalsa.com/agroindustria/postcosecha/lavadora-defrutas-por-inmersion-citalsa-lia1

Colegio de Arquitectos del Perú. (2018). Cuadro de Valores Unitarios Oficiales de Edificaciones para la Costa. Lima: CAPLIMA.

Colliers International. (2016). Reporte de Mercado Industrial-Primer semestre del 2016. Lima: Colliers International.

Commerce, F. o. (2016). Cacao en Grano: Requisitos de Calidad de la Industria del Chocolate y del Cacao. FCC.

Concha, C. y. (2000). Evaluación de las concentraciones de metales pesados para determinar la calidad de frutas de consumo masivo en la ciudad de Piura. Universidad Nacional de Piura.

Contreras, L. Y. (2013). Aislamiento de microorganismos para control biológico de Moniliophthora roreri . Palmira.

El Peruano. (2006). Reglamento Nacional de Edificaciones. Lima: El Peruano. 
Enectiva. (17 de 6 de 2017). Energía en edificios de Oficinas. Recuperado el 29 de 6 de 2018, de Enectiva: https://www.enectiva.cz/es/blog/2015/06/ideas-energiaedificio-de-oficinas/

Espinoza, L. C. (2018). Plan de negocio de exportación de cacao en grano seco al mercado de Estados Unidos - Juanjuí, San Martín. San Martin: 1.

Felipa, P. B. (20 de Agosto de 2015). La Cadena de Valor del Cacao en Perú y su oportunidad en el Mercado mundial. Semestre Económico, 18, 129-156.

Freire, Casanova, Plaza, Rodríguez, Sotomayor, Tarqui y Zambrano (2017). Selección de genotipos de cacao (Theobroma cacao L.) con resistencia a escoba de bruja (Moniliophthora perniciosa) en Los Ríos, Ecuador. Revista de Ciencias Agrarias. 10(1), 17-26. Resumen Recuperado de file:///D:/Descargas/DialnetSeleccionDeGenotiposDeCacaoTheobromaCacaoLConResis-6261803.pdf

Fundación Hondureña de Investigación Agrícola (2003). Identificación y Control de la Moniliasis del cacao. Recuperado de http://repositorio.bibliotecaorton.catie.ac.cr/bitstream/handle/11554/2324/Identif icacion_y_control_de_la_Moniliasis.pdf? sequence $=1 \&$ isAllowed $=\mathrm{y}$

Garcia, D. (2016). Caracterización de algunos metabolitos primarios y secundarios en dos variedades comerciales de lúcuma. Universidad Nacional Agraria La Molina.

Gonzalez, A. (02 de Enero de 2018). Equipos de Protección Personal. Recuperado el 30 de Mayo de 2018, de https://prezi.com/nnz4uzbmshxv/equipos-de-proteccionpersonal-epp/

Huanachín, W. (19 de 07 de 2011). Empiezan a escasear terrenos industriales al sur de Lima . Gestión, pág. 1.

INDECOPI. (2004). Señales de seguridad. Colores, símbolos, formas y dimensiones de señales de seguridad. Lima, Perú.

Indexmundi. (3 de Octubre de 2019). indexmundi. recuperado el 3 de octubre de 2019, de indexmundi: https://www.indexmundi.com/es/precios-demercado/?mercancia $=$ granos-de-cacao

INEI. (2009). Consumo de Alimentos y Bebidas. INEI.

INEI. (2014). Una mirada a Lima Metropolitana. Lima. Recuperado el 22 de junio de 2017

INEI. (2016). Registro Nacional de Municipalidades 2016 . Lima: INEI.

INEI. (Octubre de 2017). Anuario Estadístico de la Criminalidad y de Seguridad Ciudadana 2011- 2016. Lima: INEI.

INEI. (2017). Estructura Empresarial. Lima: INEI.

Ipsos. (2011). Ipsos. Recuperado el 03 de mayo de 2017, de http://www.ipsos.pe/estudio_tendencias_salud_alimentacion

Janesick, V. J. (1998). "Stretching" exercises for qualitative researchers. Sage Publications.

Jiménez, E. (2012). Elaboración de harina de 3 variedades de plátano verde (Musa SSP) y su uso como materia prima para la panificación. Tesis, México. Recuperado el 22 de abril de 2017, de http://www.biblio.colpos.mx:8080/xmlui/bitstream/10521/1729/1/Jimenez_Mar quez_E_MC_Produccion_Agroalimentaria_Tropico_2012.pdf

José Antonio López Ucariegue, Cesar Eduardo Martin Flores Grandez, Nilton Guerrero Pérez. (2015). Caracterización del contenido de npk en la cáscara de cinco clones de cacao (theobroma cacao 1) del jardín interclonal de la universidad nacional de ucayali. investigación universitaria vol. 8 , 14-19.

Lavado, A., Yenque, J., y Roberto Robles. (4 de 10 de 2012). Estudio de rendimiento de harina de lúcuma a partir del fruto fresco. pág. 4. 
Leandro, Germon, Maximova, Mora, y Rakotobe (2017). Effects of microclimatic variables on the symptoms and signs onset of Moniliophthora roreri, causal agent of Moniliophthora pod rot in cacao.PLOS ONE. 12(10), 15-33. Resumen Recuperado de

https://journals.plos.org/plosone/article/file?id=10.1371/journal.pone. $0184638 \&$ type $=$ printable

Llerena, W. F. (2016). Mejoramiento del Proceso de Fermetación del Cacao. Universidad Internacional de Andalucia.

Loor, A. V. (2018). Microorganismos endófitos asociados a Theobroma cacao como agentes de control biológico de Moniliophthora roreri. Ecuador.

Lozada, Escobar, Herrera, Perea y Stashenko (2012). Efecto in vitro de aceites esenciales de tres especies de Lippia sobre Moniliophthora roreri (Cif. y Par.) Evans et al., agente causante de la moniliasis del cacao (Theobroma cacao L.). Acta Agronómica. 61(2), 102-110. Resumen Recuperado de http://www.scielo.org.co/scielo.php?pid=S0120$28122012000200002 \&$ script $=$ sci_abstract\&tlng=es

Luz Marina Hernandez, P. V. (2009). El plátano. Mérida. Recuperado el 17 de abril de 2017, de http://www.saber.ula.ve/handle/123456789/30260

Maggi Savin-Baden, C. H. (2013). Qualitative Research. Routledge.

Martínez, g. 1. (2003). Biodigestión Anaerobia de residuos sólidos urbanos. Bogota: Universidad Distrital Francisco Jose de Caldas.

MINAGRI. (2016). Estudio del cacao en el Perú y el Mundo. Lima: MINAGRI.

MINAGRI. (2016). Producción Agrícola y Ganadera 2016. Ministerio de Argícultura y Riego.

Ministerio de Agricultura y Riego. (2016). Estudio del Cacao en el Perú y en el Mundo. "Alimentos de los dioses", 77-78.

Mosquera, L. H., Moraga, G., Martínez, J. J., y Martínez, N. (2013). Protocolo de actuación para contribuir a la mejora del estado nutricional de poblaciones infantiles en vías de desarrollo, a partir de materias primas de uso tradicional. Choco. Recuperado el 17 de abril de 2017, de http://www.sextocongresocud.es/wpcontent/uploads/2013/03/vicongresocud2013_submission_95.pdf

Pesamatic. (2013). Pesamatic SAC. Recuperado el 15 de Abril de 2018, de Unicelda Rex: http://pesamaticindustrial.com/uniceldas-rex/

Romero, C. A. (2016). Estudio del cacao en el Perú y en el Mundo. Minagri. Lima: MINAGRI-DPGA-DEEIA.

Salazar, R. P., y Bustamante, D. R. (2017). Estudio de pre-factibilidad para la instalación de una planta dedicada a la producción de chocolate con cacao orgánico peruano. Universidad de Lima, Lima. Lima: 1.

Sampieri, R. H. (2014). Metodología de la Investigación. Mc Graw Hill.

Sanchez, L. A. (1989). Beneficio del Cacao. Costa Rica: FHIA.

Sierra Exportadora. (2014). Desarrollemos el mejor cacao del Mundo con Valor Agregado.

Sunat. (2017). Aduanet. Recuperado el 20 de junio de 2017, de http://www.aduanet.gob.pe/servlet/AIScrollini?partida=803102000

Tirado, Lopera y Ríos (2016). Strategies for Control of Moniliophthora roreri and Moniliophthora perniciosa in Theobroma cacao L. Ciencia y Tecnología Agropecuaria. 17(3), 417-430.Resumen Recuperado de http://www.scielo.org.co/scielo.php?script=sci_abstract\&pid=S012287062016000300009 
Tocahe es Primer productor de cacao. (06 de Julio de 2012). Perú21.

Veritrade. (mayo de 2017). Veritrade. Recuperado el 04 de mayo de 2017, de http://business.veritrade.info/Veritrade/MisBusquedas.aspx

Veritrade. (2018). Exportacines. Recuperado de http://www.business.veritrade.info/Veritrade/MisBusquedas.aspx

Veritrade. (2018). Importaciones. Recuperado de http://www.business.veritrade.info/Veritrade/MisBusquedas.aspx 


\section{BIBLIOGRAFÍA}

Acha, R. (2012). Tostando el Futuro. Semana Económica (º1337). Pág 4-6

Choncen Gordillo, F. J. (1992). Estudio de factibilidad para la instalación de una planta de calzado. (Tesis para optar el título de Ingeniero Industrial). Universidad de Lima, Lima, Perú.

Morales, O. (2015). La Alianza Cacao Perú y la cadena productiva del cacao fino de aroma. Lima: ESAN.

Paredes Arce, M. (2000). Rehabilitación - renovación en cacao. Lima: Winrock International. 
ANEXOS 
Anexo 1: Demanda interna aparente de cacao

\begin{tabular}{|l|l|l|l|l|}
\hline Año & $\begin{array}{l}\text { Producción } \\
(\mathbf{T N})\end{array}$ & $\begin{array}{l}\text { Exportaciones } \\
(\mathbf{T N})\end{array}$ & $\begin{array}{l}\text { Importación } \\
(\mathbf{T N})\end{array}$ & DIA (TN) \\
\hline $\mathbf{2 0 0 0}$ & 24786 & 40 & 773 & 25519 \\
\hline $\mathbf{2 0 0 1}$ & 23671 & 216 & 281 & 23455 \\
\hline $\mathbf{2 0 0 2}$ & 24353 & 634 & 150 & 24000 \\
\hline $\mathbf{2 0 0 3}$ & 24214 & 784 & 61 & 23580 \\
\hline $\mathbf{2 0 0 4}$ & 25921 & 1009 & & 24973 \\
\hline $\mathbf{2 0 0 5}$ & 25257 & 1141 & & 24116 \\
\hline $\mathbf{2 0 0 6}$ & 31676 & 2892 & 937 & 28784 \\
\hline $\mathbf{2 0 0 7}$ & 31387 & 4004 & 232 & 28320 \\
\hline $\mathbf{2 0 0 8}$ & 34003 & 5514 & 100 & 28721 \\
\hline $\mathbf{2 0 0 9}$ & 36803 & 7533 & 225 & 29370 \\
\hline $\mathbf{2 0 1 0}$ & 46613 & 11084 & 75 & 35754 \\
\hline $\mathbf{2 0 1 1}$ & 56499 & 19727 & 25 & 36847 \\
\hline $\mathbf{2 0 1 2}$ & 62492 & 24939 & 624 & 37578 \\
\hline $\mathbf{2 0 1 3}$ & 71838 & 28494.791 & 448 & 43967.209 \\
\hline $\mathbf{2 0 1 4}$ & 81651 & 46892.794 & 271 & 35206.206 \\
\hline $\mathbf{2 0 1 5}$ & 87317 & 55828.182 & & 31759.818 \\
\hline
\end{tabular}

Fuente: Sunat, Minagri y Agrodata (2016) 
Anexo 2: Gráfica de Ecuación Exponencial

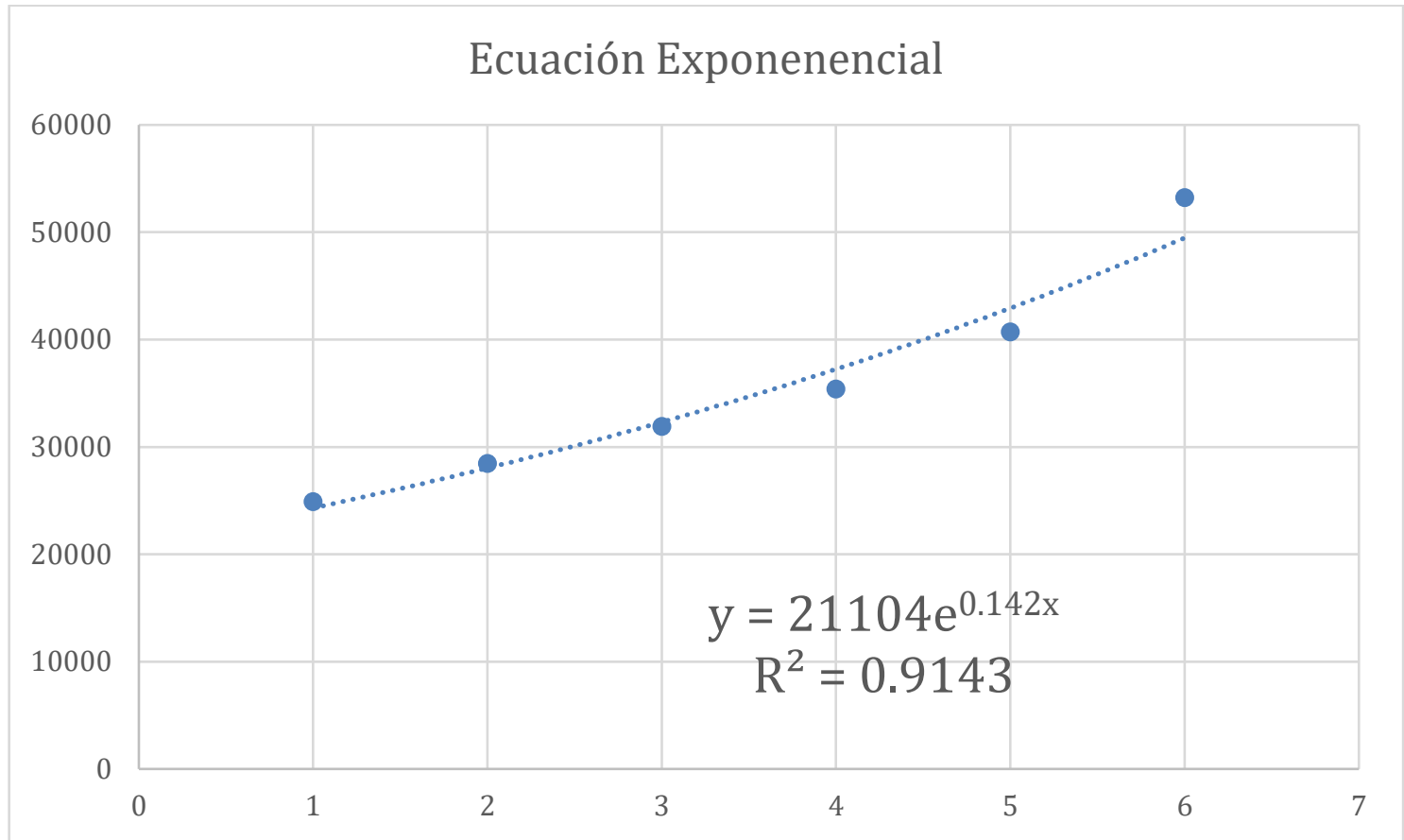

Elaboración Propia

\section{Anexo 3: Gráfica de Ecuación Lineal}

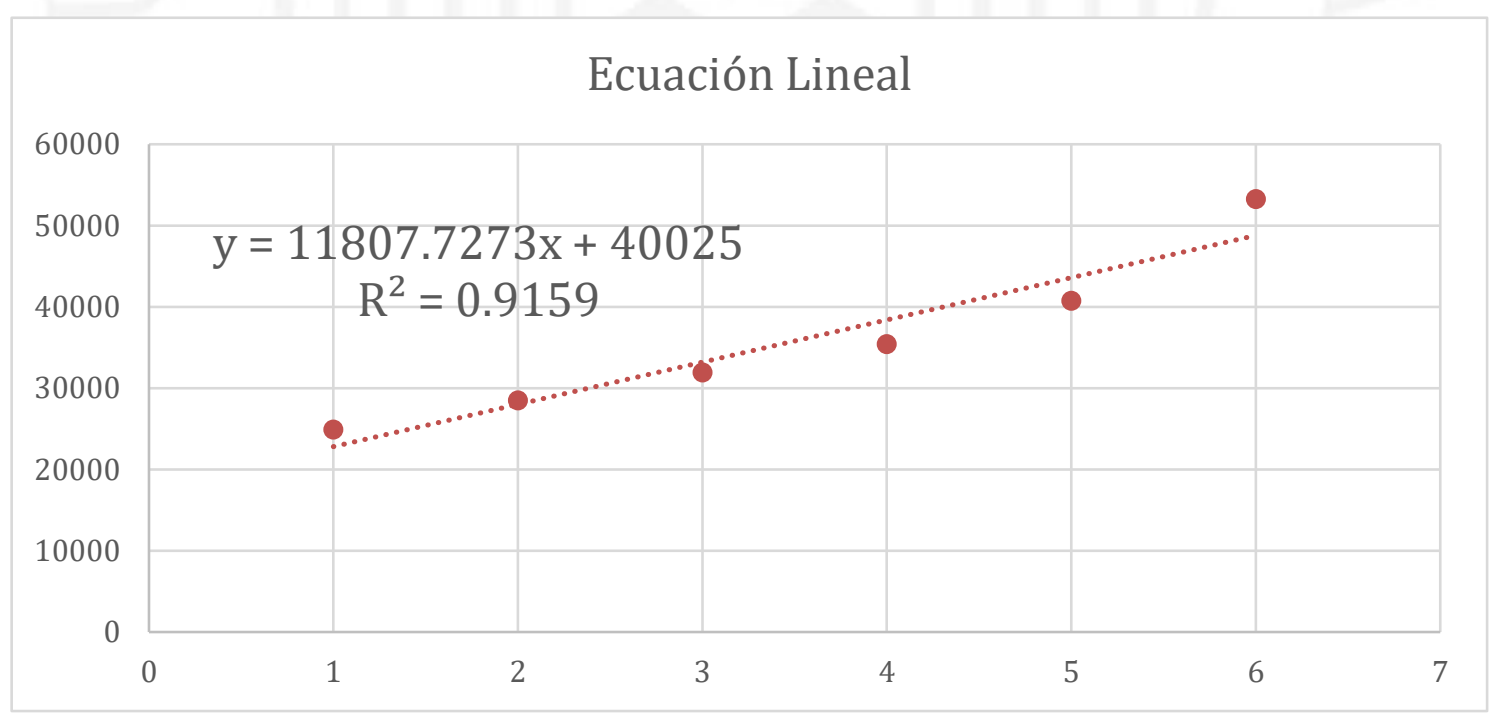

Elaboración Propia 
Anexo 4: Gráfica de Ecuación Logarítmica

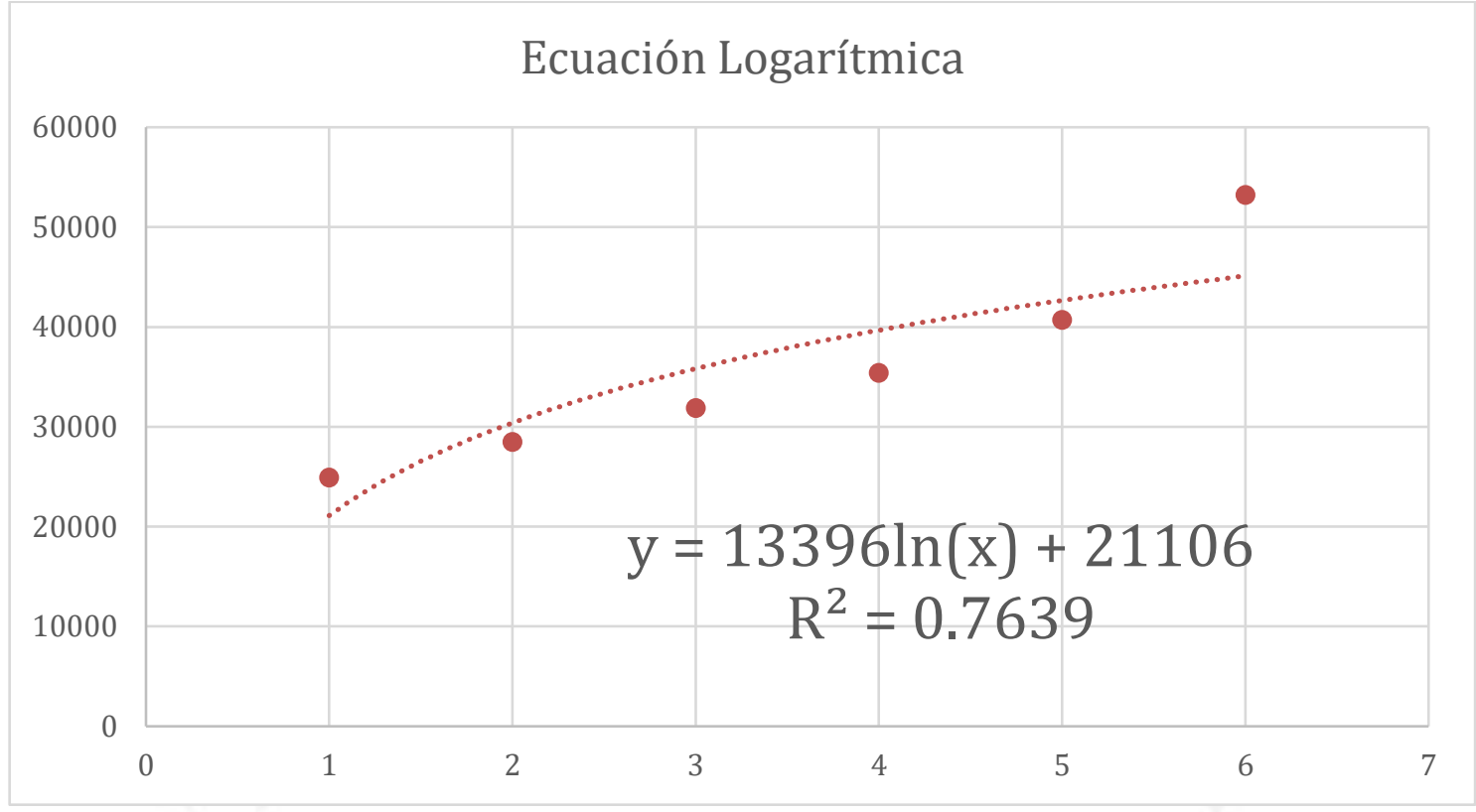

Elaboración Propia

Anexo 5: Gráfica de Ecuación Potencial

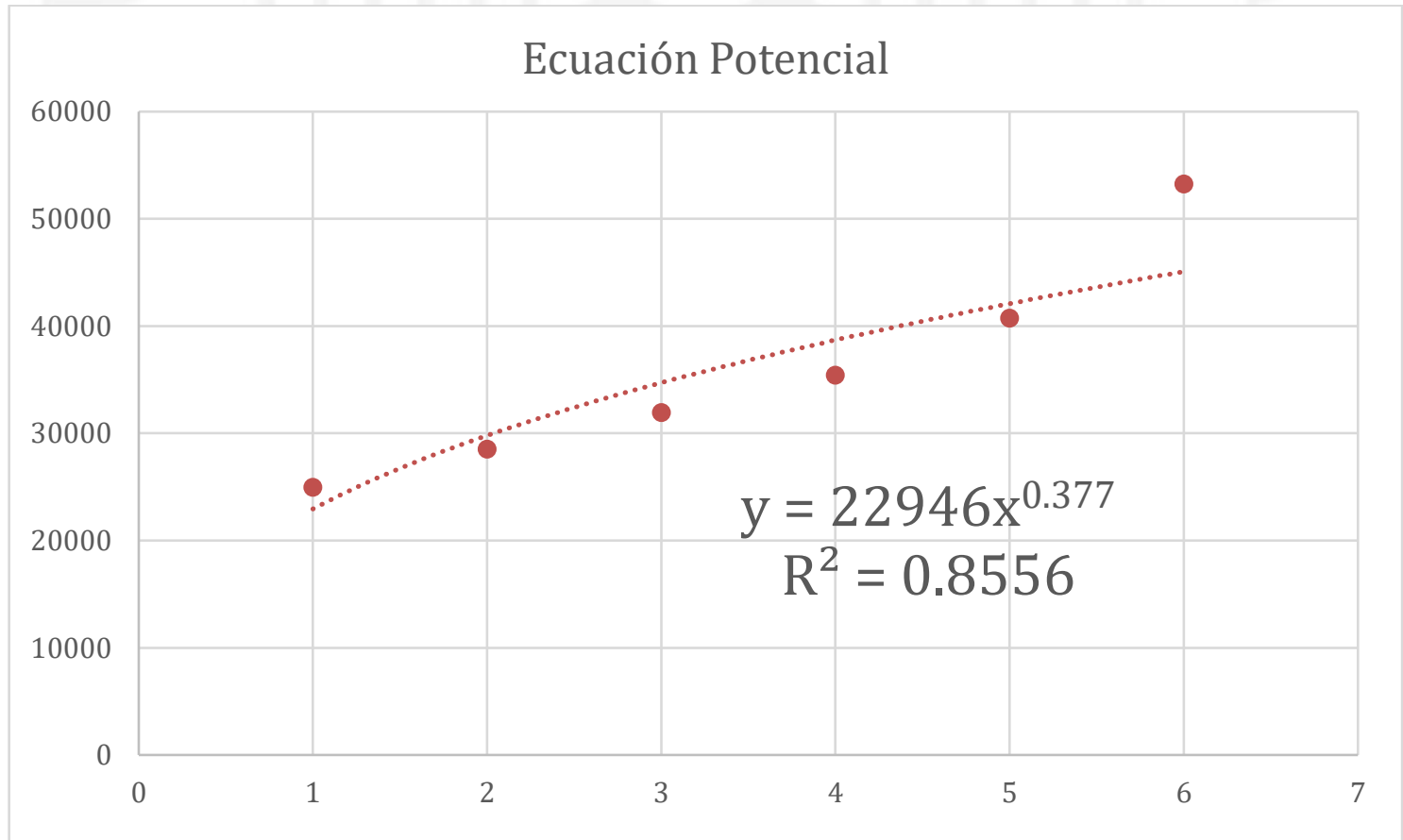

Elaboración Propia 
Anexo 6: Entrevista

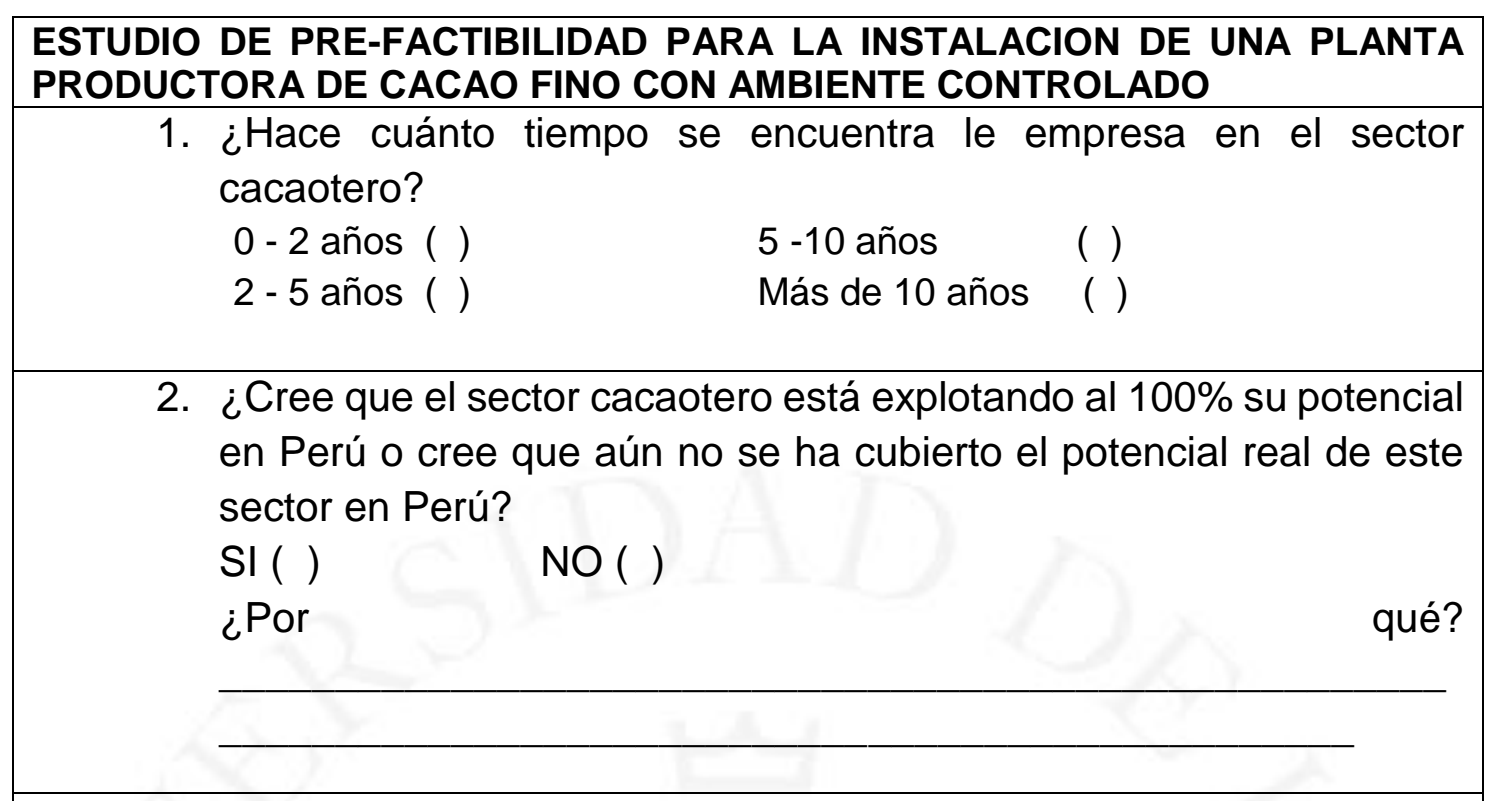

3. ¿Cree que el estado genera incentivos para los agricultores de cacao?
$\mathrm{SI}(\mathbf{)}$
NO ( )

De responder afirmativamente, ¿Qué clase de incentivos brinda?

4. ¿Qué especie de cacao genera mayor ganancia a la empresa?

\begin{tabular}{lll} 
Criollo ( ) & CCN-51 ( ) \\
Nativo ( ) & Forastero ( ) \\
Trinitario ( ) & Otro: \\
\hline
\end{tabular}

Mencione a qué se debe esta rentabilidad asociada:

5. ¿Qué especie de cacao es la más demandada por el mercado?
Criollo ( )
Nativo ( )
Trinitario ( )
CCN-51
Forastero
Otro:

Mencione qué uso se le da a este tipo de cacao en el mercado:

6. Enumerar en orden de importancia, del 1 al 6 , qué factores considera determinantes para una adecuada producción de cacao. Siendo 1 el nivel más alto de importancia y 6 el más bajo. 


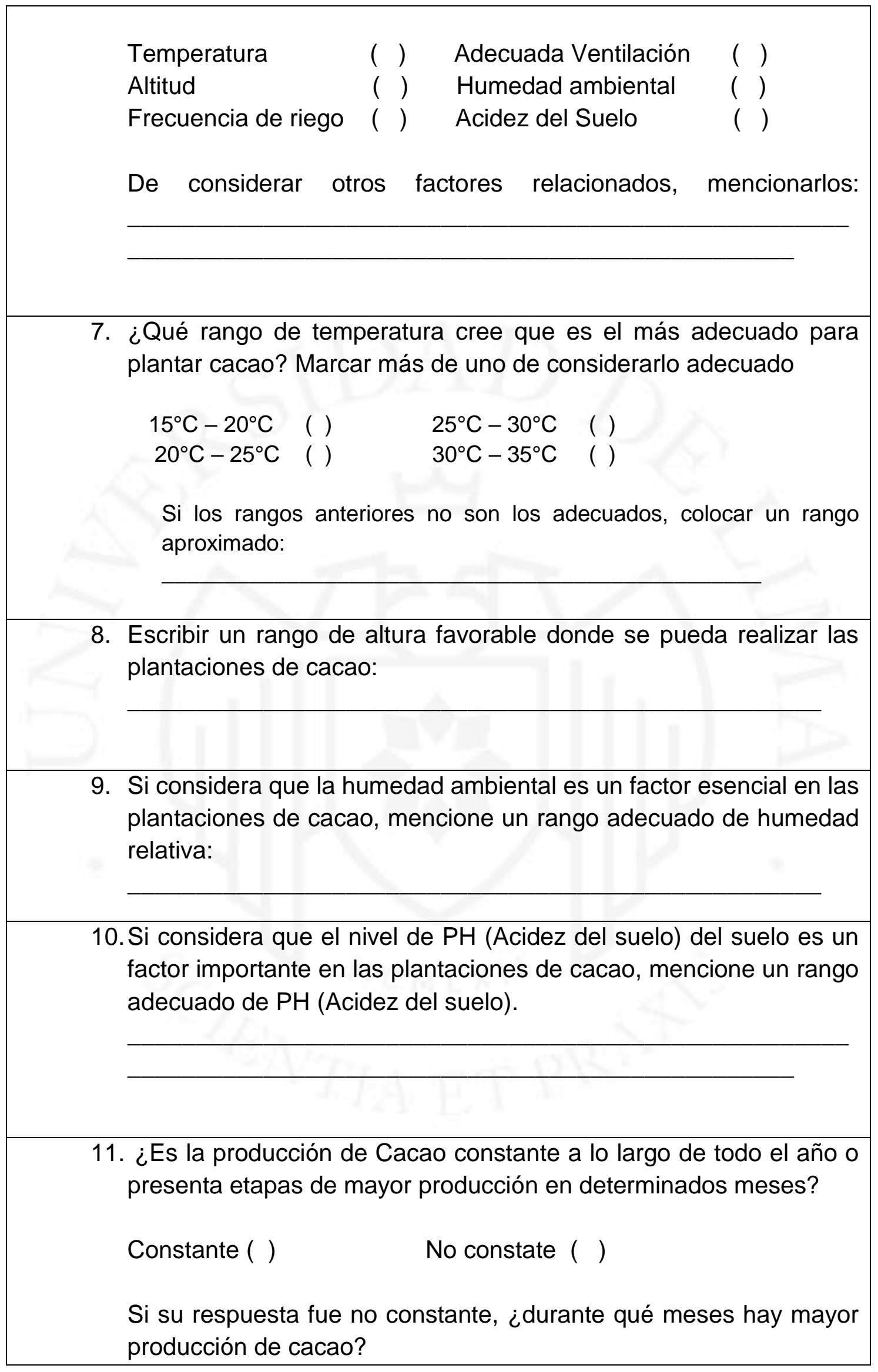




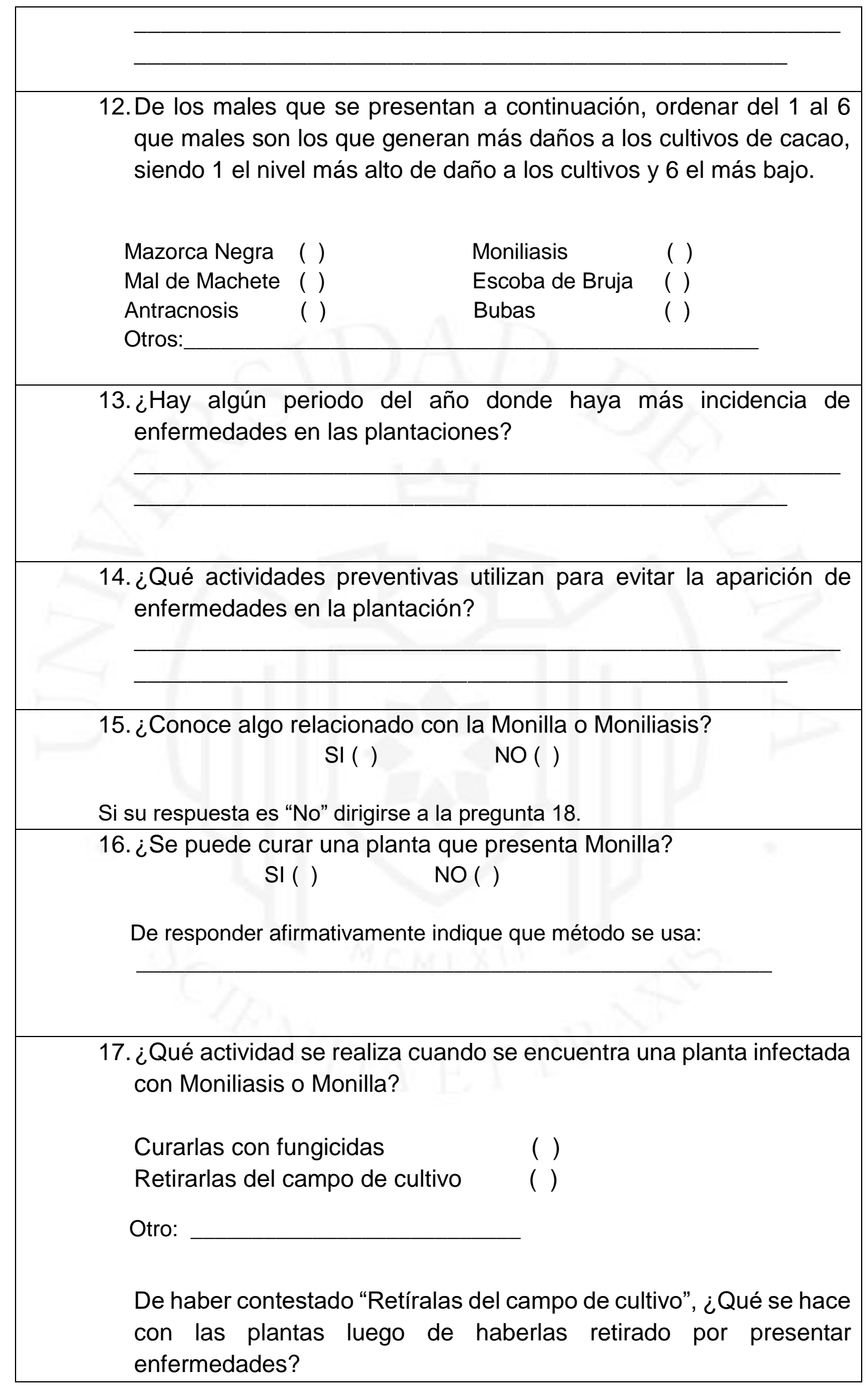




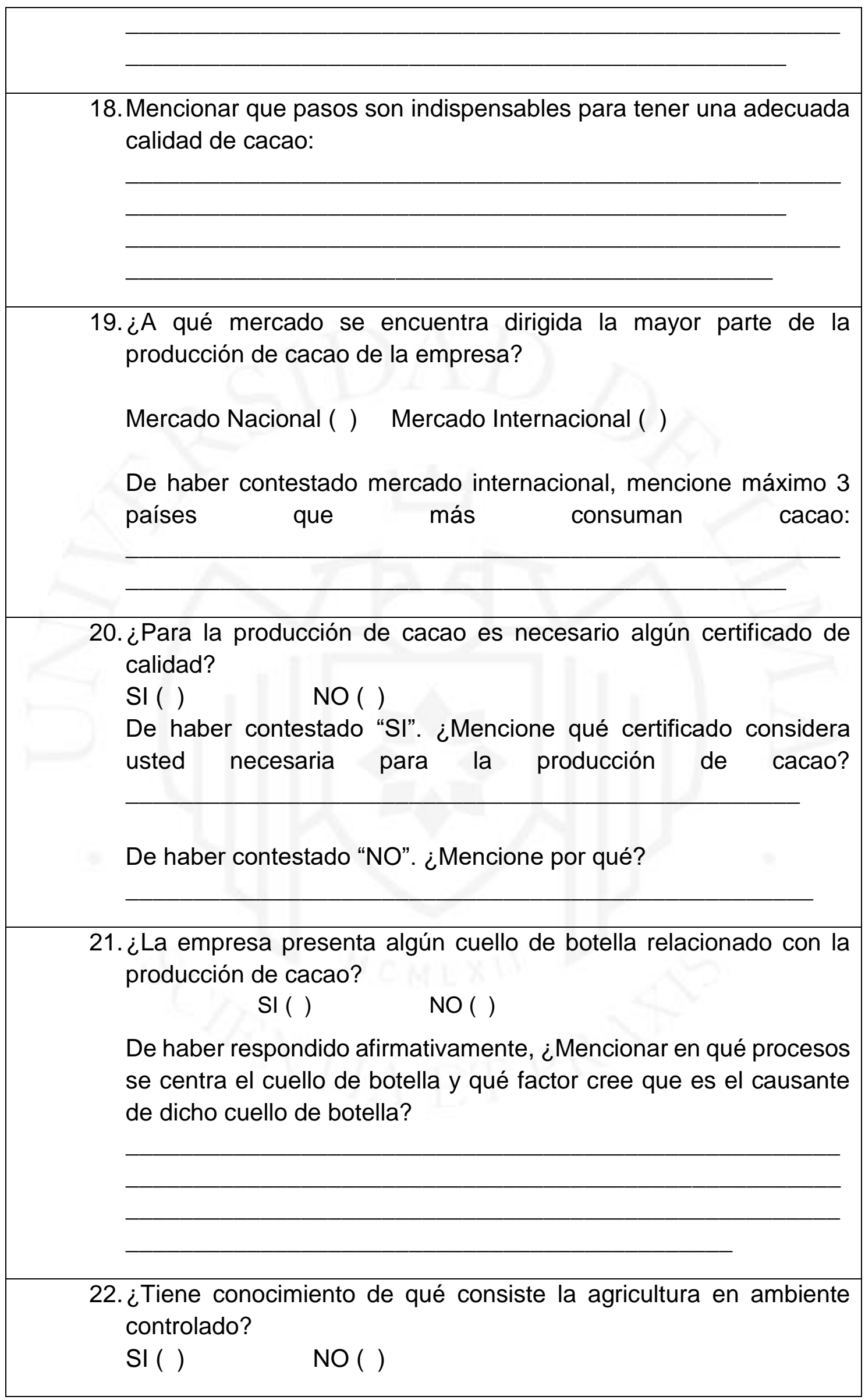




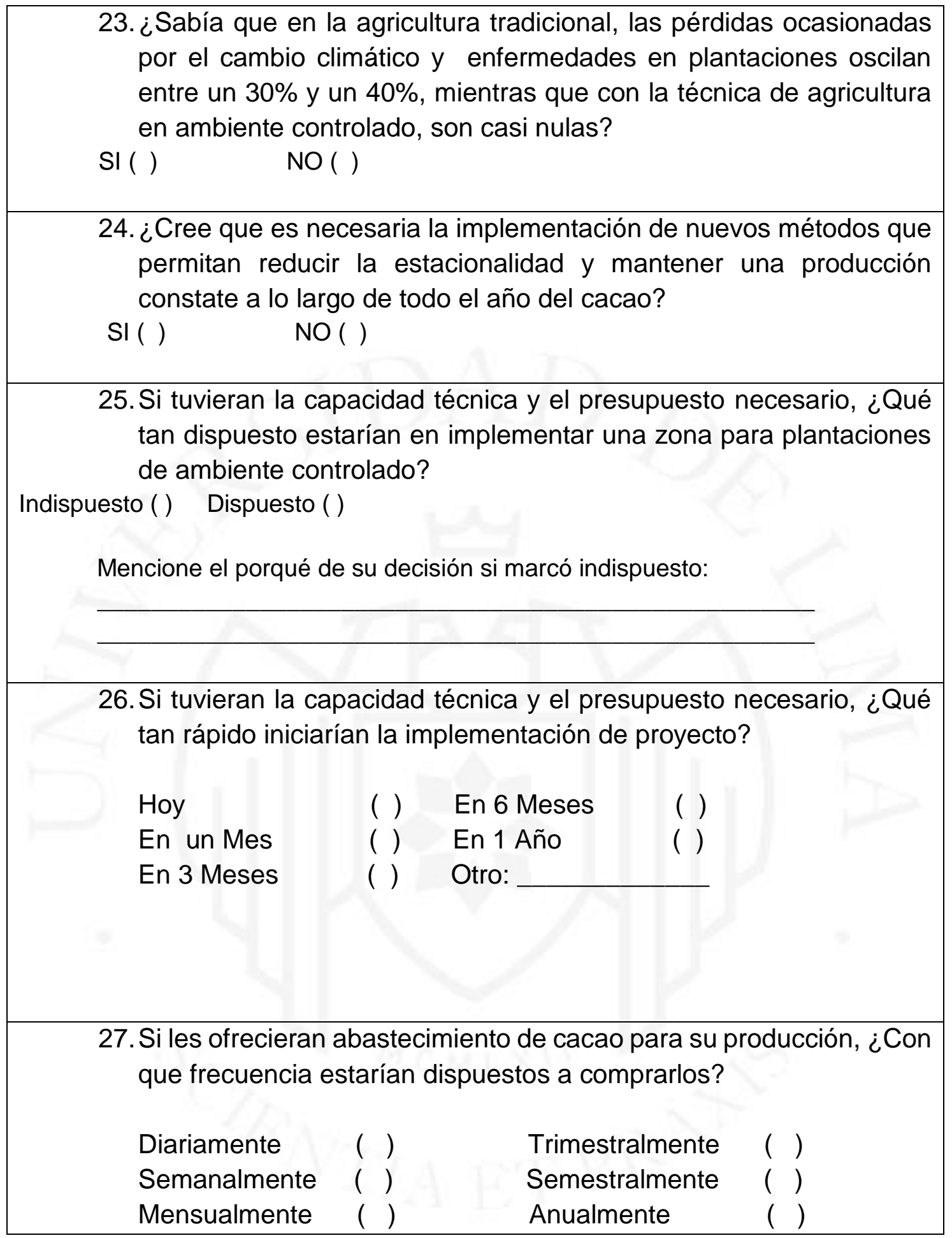




\section{Anexo 7: Revisión de calidad del cacao}

Cortado:

Esta actividad lo realizará el operario del área de cortado, el cual tendrá guantes quirúrgicos para evitar cualquier tipo de contaminación. Esta persona colocará la mazorca en la máquina cortadora verificando previamente de manera visual si la mazorca está libre de cualquier agente fúngico, olor peculiar o manchas extrañas, como se puede observar a continuación.

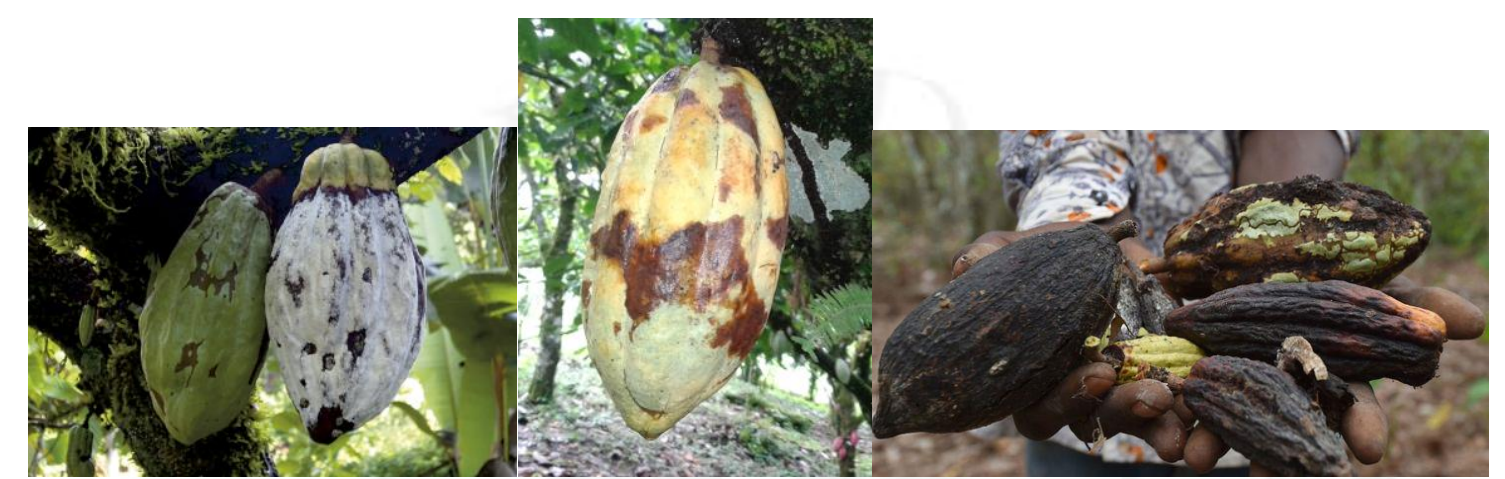

Fuente: Agrodata (2019)

Escurrido:

En esta etapa las almendras de cacao previamente limpias pasarán a ser ensacadas para posteriormente dejarlas reposar durante 18-24 horas con la finalidad de eliminar la mayor cantidad de mucilago y agua. Durante este proceso el supervisor de control de calidad, calculará el tamaño de muestra del lote a escurrir, con la finalidad de hacerle pruebas en el laboratorio de calidad y determinar que no más del $12 \%$ de granos deben de pesar menos del $33 \%$ del peso medio. Al mismo tiempo el encargado debe observar y determinar que estas almendras estén libres de bacterias dioxina y materias extrañas, para esto el laboratorio de calidad contara con las herramientas necesarias para analizar la presencia de estos agentes en las almendras.

Fermentado:

El proceso de fermentado se realizará durante un periodo no menor a 6 días en los cuales, se controlará la temperatura interna dentro de cada caja fermentadora, con ayuda de un sensor de temperatura, el cual enviara la información a una computadora, para determinar las siguientes temperaturas durante los 6 días: 


\begin{tabular}{|c|c|c|c|c|c|}
\hline \multicolumn{1}{|c|}{ Día 1 } & Día 2 & Día 3 & Día 4 & Día 5 & Día 6 \\
\hline $\begin{array}{l}\text { 36 grados } \\
\text { centígrados }\end{array}$ & $\begin{array}{c}40 \text { grados } \\
\text { centígrados }\end{array}$ & $\begin{array}{c}49 \text { grados } \\
\text { centígrados }\end{array}$ & $\begin{array}{c}49.8 \text { grados } \\
\text { centígrados }\end{array}$ & $\begin{array}{c}46 \text { grados } \\
\text { centígrados }\end{array}$ & $\begin{array}{l}45.5 \text { grados } \\
\text { centígrados }\end{array}$ \\
\hline
\end{tabular}

Fuente: Cacao Móvil (2016)

Al final del sexto día, cuando se transportan los productos al siguiente proceso, nuevamente el supervisor de calidad tomará una muestra representativa para verificar si el lote tiene las características organolépticas adecuadas. De esta manera él tiene que verificar una buena fermentación Para lo cual el grano debe tener el siguiente color y formas:

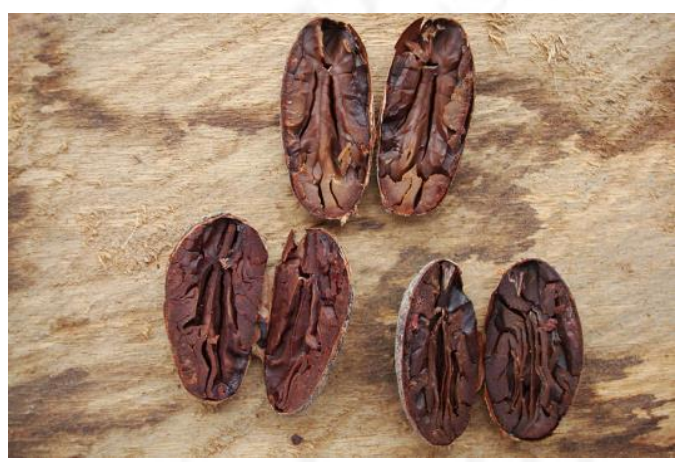

Fuente: Agrodata (2019)

A su vez este tiene que estar libre de moho como se puede ver a continuación:

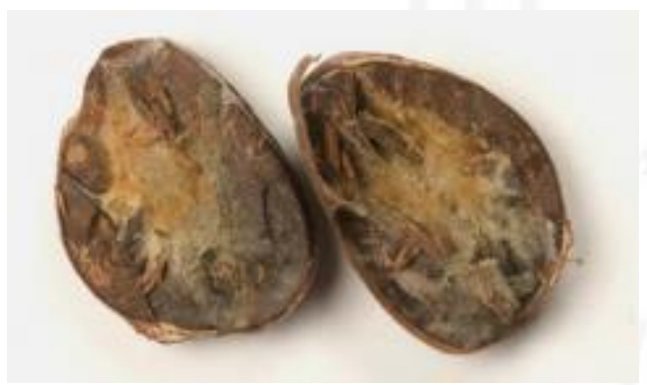

Fuente: Agrodata (2019)

Y evitar tener una apariencia como la siguiente, pues denota una mala fermentación, muy característica de un fermentado corto. 


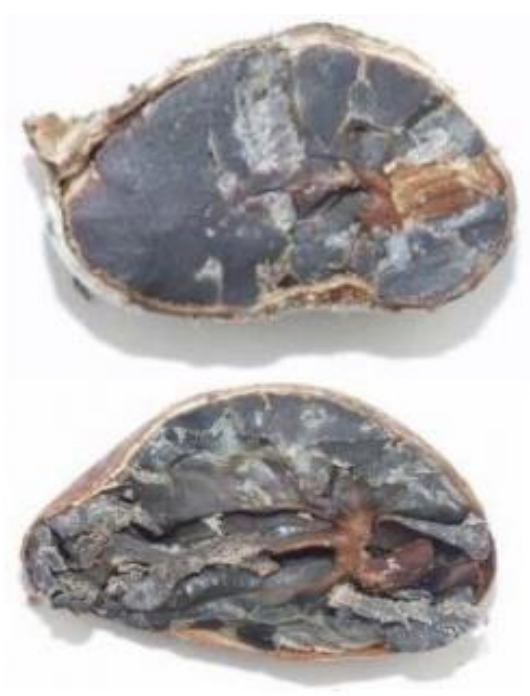

Fuente: Agrodata (2019)

Secado:

A la Salida de este proceso el Supervisor de Calidad tomará una muestra y verificará en el laboratorio de calidad si la humedad de estos granos se encuentra entre $7-8 \%$ de lo contrario se procederá a eliminar el lote por no cumplir los requisitos mínimos de los compradores. A su vez, determinará que los niveles de HAP en los granos de cacao deben ser de 30 microgramos por $\mathrm{kg}$ de grasa y al mismo tiempo deben poseer entre $55-58 \%$ de grasa. 


\section{Anexo 8: Proceso de transformación de los residuos sólidos en el biodigestor}

Transformar: Una vez que el biodigestor haya recibido toda la merma del proceso de producción de cacao fino, se inicia el proceso de fermentación en el biodigestor. Este proceso descompone los residuos sólidos, produciendo biogás la cual luego se utilizará para crear el abono que se entregará a los agricultores como parte del subsidio que estos exigen para nuevas plantaciones (Martínez, 2003).

Ensacar: Luego de que los residuos sólidos se descompongan, se procede a ensacar el abono en sacos. Estos se llevarán directamente al camión que distribuirá el abono a los proveedores (Martínez, 2003) 
Anexo 9: Caracterización del Proceso de Producción

\begin{tabular}{|l|l|l|}
\hline & $\begin{array}{l}\text { CARACTERIZACIÓN DEL PROCESO DE PRODUCCIÓN DE CACAO FINO EN } \\
\text { GRANOS EN SACOS DE 60 KG }\end{array}$ & Código:ACM-1-PT \\
\cline { 2 - 3 } & & Versión: 01 \\
\hline
\end{tabular}

\begin{tabular}{|l|l|l|}
\hline $\begin{array}{l}\text { Nombre del } \\
\text { PROCESO / } \\
\text { SUBPROCESO }\end{array}$ & CACAO FINO EN GRANOS EN SACOS DE 60 KG & $\begin{array}{l}\text { OBJETIVO DEL PROCESO O SUBPROCESO: } \\
\text { Asegurar el correcto proceso de producción de cacao } \\
\text { fino en grano para obtener un producto saludable para } \\
\text { el consumidor. }\end{array}$ \\
\hline $\begin{array}{l}\text { RESPONSABLE } \\
\text { DELPROCESO }\end{array}$ & Supervisor de control de calidad & $\begin{array}{l}\text { ALCANCE DEL PROCESO } \\
\text { Desde el cortado de las mazorcas hasta el } \\
\text { almacenamiento de los sacos de } 60 \mathrm{~kg} \text { de cacao fino } \\
\text { en grano. }\end{array}$ \\
\hline
\end{tabular}

\begin{tabular}{|c|c|c|c|c|c|}
\hline | & ENTRADAS & RESPONSABLE & ACTIVIDADES & SALIDAS & CLIENTES \\
\hline \multicolumn{6}{|c|}{ CORTADO } \\
\hline $\begin{array}{l}\text { AGRICULTORES } \\
\text { DE SAN MARTIN }\end{array}$ & Mazorcas de cacao & 1 Operario & $\begin{array}{l}\text { 1. Se cortan las mazorcas y un } \\
\text { operario verifica que no } \\
\text { contengan Moho ni estén en mal } \\
\text { estado. } \\
\text { 2. Se tomará una muestra } \\
\text { representativa del lote. }\end{array}$ & $\begin{array}{l}\text { Almendra } \\
\text { mucílago } \\
\text { cacao, }\end{array}$ & LAVADO \\
\hline \multicolumn{6}{|c|}{ LAVADO } \\
\hline LAVADO & $\begin{array}{l}\text { Almendras con } \\
\text { mucílago y agua }\end{array}$ & 1 Operario & $\begin{array}{l}\text { 1. Un operario transporta las } \\
\text { almendras en jabas a la }\end{array}$ & $\begin{array}{lr}\text { Almendra } & \text { de } \\
\text { cacao lavada } & y \\
\end{array}$ & $\begin{array}{l}\text { ESCURRID } \\
\mathrm{O}\end{array}$ \\
\hline
\end{tabular}




\begin{tabular}{|c|c|c|c|c|c|}
\hline | & ENTRADAS & RESPONSABLE & ACTIVIDADES & SALIDAS & CLIENTES \\
\hline & & & $\begin{array}{l}\text { máquina de lavado por } \\
\text { inmersión para eliminar los } \\
\text { azúcares que deterioran el } \\
\text { grano. } \\
\text { 2. Un operario llevará la merma } \\
\text { al biodigestor. }\end{array}$ & $\begin{array}{lr}\text { agua } & \text { con } \\
\text { mucílago } & \mathrm{e} \\
\text { impurezas. } & \end{array}$ & \\
\hline \multicolumn{6}{|c|}{ ESCURRIDO } \\
\hline \multicolumn{6}{|c|}{ FERMENTADO } \\
\hline FERMENTADO & $\begin{array}{l}\text { Sacos de almendras } \\
\text { de cacao sin mucílago } \\
\text { y efluentes. }\end{array}$ & 3 Operarios & $\begin{array}{l}\text { 1. Tres operarios ingresan las } \\
\text { almendras a los cajones en } \\
\text { cascada, retirando el saco, y se } \\
\text { encargan de moverlos } \\
\text { diariamente por } 6 \text { días. } \\
\text { 2. En paralelo, uno de los operarios } \\
\text { monitoreará la temperatura } \\
\text { determinada, según el día ( } 36 \text {, } \\
40,49,49.8,46,45.5^{\circ} \mathrm{C} \text { por } 6 \\
\text { días). }\end{array}$ & $\begin{array}{l}\text { Almendras de } \\
\text { cacao } \\
\text { fermentadas }\end{array}$ & LAVADO \\
\hline \multicolumn{6}{|c|}{ LAVADO } \\
\hline LAVADO & $\begin{array}{l}\text { Almendras de cacao } \\
\text { fermentadas }\end{array}$ & 3 Operarios & $\begin{array}{l}\text { 1. Tres operarios transportan las } \\
\text { almendras en jabas a la máquina } \\
\text { de lavado por inmersión para }\end{array}$ & $\begin{array}{l}\text { Almendras de } \\
\text { cacao y } \\
\text { efluentes }\end{array}$ & SECADO \\
\hline
\end{tabular}




\begin{tabular}{|c|c|c|c|c|c|}
\hline | & ENTRADAS & RESPONSABLE & ACTIVIDADES & SALIDAS & CLIENTES \\
\hline & & & $\begin{array}{l}\text { eliminar las impurezas finales de } \\
\text { la almendra. } \\
\text { 2. Los residuos serán llevados al } \\
\text { biodigestor por un operario. }\end{array}$ & & \\
\hline \multicolumn{6}{|c|}{ SECADO } \\
\hline SECADO & Almendras de cacao & 3 Operarios & $\begin{array}{l}\text { 1. Dos operarios ingresan las } \\
\text { almendras al secador utilizando } \\
\text { jabas, mientras que un tercer } \\
\text { operario remueve las almendras } \\
\text { defectuosas para llevarlas } \\
\text { posteriormente al biodigestor. Se } \\
\text { utilizarán } 6.49 \mathrm{~kW} / \mathrm{hr} \text { para este } \\
\text { proceso. A la salida, un operario } \\
\text { mide la humedad de las } \\
\text { almendras para asegurar que } \\
\text { estas se encuentren a } 7 \% \text {. }\end{array}$ & $\begin{array}{l}\text { Almendras de } \\
\text { cacao secas y } \\
\text { almendras } \\
\text { defectuosas }\end{array}$ & $\begin{array}{l}\text { SELECCIO } \\
\text { NADO }\end{array}$ \\
\hline \multicolumn{6}{|c|}{ SELECCIONADO } \\
\hline SELECCIONADO & $\begin{array}{l}\text { Almendras de cacao } \\
\text { secas }\end{array}$ & 2 Operarios & $\begin{array}{l}\text { 1. Dos operarios insertan las } \\
\text { almendras secas a la máquina } \\
\text { seleccionadora en donde se } \\
\text { eliminan las almendras } \\
\text { defectuosas. }\end{array}$ & $\begin{array}{l}\text { Almendras de } \\
\text { cacao y } \\
\text { almendras } \\
\text { defectuosas }\end{array}$ & ENSACADO \\
\hline \multicolumn{6}{|c|}{ ENSACADO } \\
\hline ENSACADO & $\begin{array}{c}\text { Almendras de cacao y } \\
\text { sacos de yute }\end{array}$ & 1 Operario & $\begin{array}{l}\text { 1. Se trasladan las almendras de } \\
\text { cacao a la ensacadora. } \\
\text { 2. Una vez se cuente con el } \\
\text { producto terminado, un operario } \\
\text { se encarga de tomar una muestra } \\
\text { representativa del lote y procede } \\
\text { a trasladar los sacos al área de }\end{array}$ & $\begin{array}{l}\text { Sacos de } 60 \mathrm{~kg} \\
\text { de cacao fino en } \\
\text { grano }\end{array}$ & $\begin{array}{l}\text { ALMACÉN } \\
\text { DE } \\
\text { PRODUCTO } \\
\text { TERMINAD } \\
\text { O }\end{array}$ \\
\hline
\end{tabular}




\begin{tabular}{|c|c|c|c|c|c|c|c|c|}
\hline | & \multicolumn{2}{|c|}{ ENTRADAS } & RESPONSABLE & \multicolumn{2}{|c|}{ ACTIVIDADES } & \multicolumn{2}{|c|}{ SALIDAS } & CLIENTES \\
\hline & & & & $\begin{array}{l}\text { calidad } \\
\text { calidad } \\
\text { peso y } n\end{array}$ & $\begin{array}{l}\text { de el supervisor c } \\
\text { a la humedad, } \\
\text { de cadmio. }\end{array}$ & & & \\
\hline \multicolumn{9}{|c|}{ DOCUMENTOS ASOCIADOS } \\
\hline \multicolumn{4}{|c|}{ INTERNOS } & \multicolumn{5}{|c|}{ EXTERNOS } \\
\hline TIPO & NÚMERO & FECHA & TÍTULO & TIPO & NÚMERO & FECHA & \multicolumn{2}{|c|}{ TÍTULO } \\
\hline \multirow[t]{4}{*}{ Manual } & BYT 1 & $\begin{array}{l}05 / 07 / 20 \\
19\end{array}$ & $\begin{array}{ll}\text { Procedimiento } & \text { de } \\
\text { utilización } & \text { de } \\
\text { maquinaria } & \\
\end{array}$ & Norma & $\begin{array}{l}\text { NTP }- \text { ISO } \\
1114: 2016\end{array}$ & 2016 & \multicolumn{2}{|c|}{$\begin{array}{l}\text { Corte para granos de } \\
\text { cacao }\end{array}$} \\
\hline & & & & Norma & $\begin{array}{l}\text { NTP - ISO } \\
\text { 2292:2016 }\end{array}$ & 2016 & \multicolumn{2}{|c|}{$\begin{array}{l}\text { Muestreo de grano de } \\
\text { cacao en sacos }\end{array}$} \\
\hline & & & & Norma & $\begin{array}{l}\text { NTP }- \text { ISO } \\
2291: 2016\end{array}$ & 2016 & \multicolumn{2}{|c|}{$\begin{array}{l}\text { Humedad del grano de } \\
\text { cacao }\end{array}$} \\
\hline & & & & & $\begin{array}{l}\text { NTP } \\
\text { 208.017:2015/ } \\
\text { COR1:2016 } \\
\end{array}$ & 2015 & \multicolumn{2}{|c|}{$\begin{array}{l}\text { Humedad del grano de } \\
\text { cacao }\end{array}$} \\
\hline
\end{tabular}




\begin{tabular}{|l|l|}
\hline \multicolumn{1}{|c|}{ REGISTROS } & INDICADORES \\
\hline - Base de datos & - Eficiencia \\
- Informes de resultados de auditorias & - Eficacia \\
- Registro de acciones correctivas o preventivas & \\
\hline & \\
& \\
\hline
\end{tabular}

\begin{tabular}{|c|c|c|}
\hline \multicolumn{3}{|c|}{+2} \\
\hline HUMANOS & FÍSICOS & $\begin{array}{l}\text { TECNOLÓGICOS } \\
\end{array}$ \\
\hline $\begin{array}{l}\text { - } 10 \text { operarios } \\
\text { - } \quad 1 \text { supervisor de calidad }\end{array}$ & $\begin{array}{ll}\text { - } & \text { Máquina despulpadora de cacao \#1 } \\
\text { - } & \text { Máquina lavadora por inmersión \#2 } \\
\text { - } & \text { Máquina secadora de grano automática \#2 } \\
\text { - } & \text { Máquina seleccionadora por tamaño y } \\
& \text { condición \#2 } \\
\text { - } & \text { Máquina peladora \#2 } \\
\text { - } & \text { Máquina ensacadora \#1 }\end{array}$ & 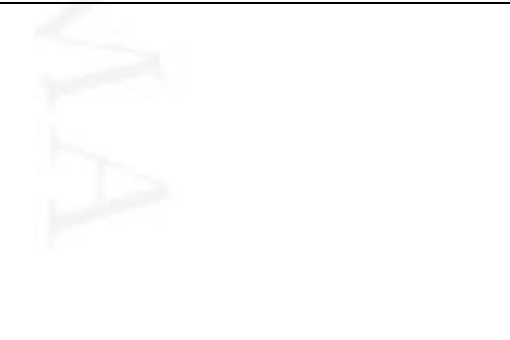 \\
\hline
\end{tabular}

Elaboró

Jefe de Turno

\section{Revisó y Aprobó}

Gerente de Producción 


\section{Anexo 10: Tamaño de muestra para inspección de Calidad}

A continuación, se presenta la ecuación para muestra de aceptación utilizada para inspeccionar la calidad del producto tanto al ingreso del producto al local como al final de la producción.

$$
n=\frac{N * p * q * Z^{2}}{N * d^{2}+Z^{2} * p * q}
$$

Donde:

$\mathrm{N}$ : Tamaño de Lote

p: Probabilidad de encontrar defectuosos

q: Probabilidad de encontrar no defectuosos

d: Nivel de Precisión

Nivel de Confianza: $95 \%$

$\mathrm{Z}=1.96$

Para hallar el lote de muestra para Producto Terminado se tomará del año de mayor producción (2024) y del mes de mayor demanda (Agosto) el tamaño de lote para determinar el tamaño de muestra, la cual se realizará cada dos semanas:

$$
n=\frac{975 \times 2 \% \times 98 \% \times 1.96^{2}}{975 \times 5^{2}+1.96^{2} \times 2 \% \times 98 \%}=29 \operatorname{sacos}
$$

De igual manera al ingresar la materia prima a la planta esta pasará a ser inspeccionada por lo que se realizó el mismo procedimiento

$$
n=\frac{148850 \times 2 \% \times 98 \% \times 1.96^{2}}{148850 \times 5^{2}+1.96^{2} \times 2 \% \times 98 \%}=30 \mathrm{~kg} \text { de Mazorcas de cacao }
$$

A su vez, como política de la empresa de ambas muestras si se encuentra que del producto terminado 4 sacos no cumplen con las especificaciones necesaria el lote será rechazado, de igual manera para la MP, si se encuentra que el $10 \%$ de la muestra no cumple los requisitos necesarios esta será devuelta al proveedor. 
Anexo 11: Logo y lema de la Empresa

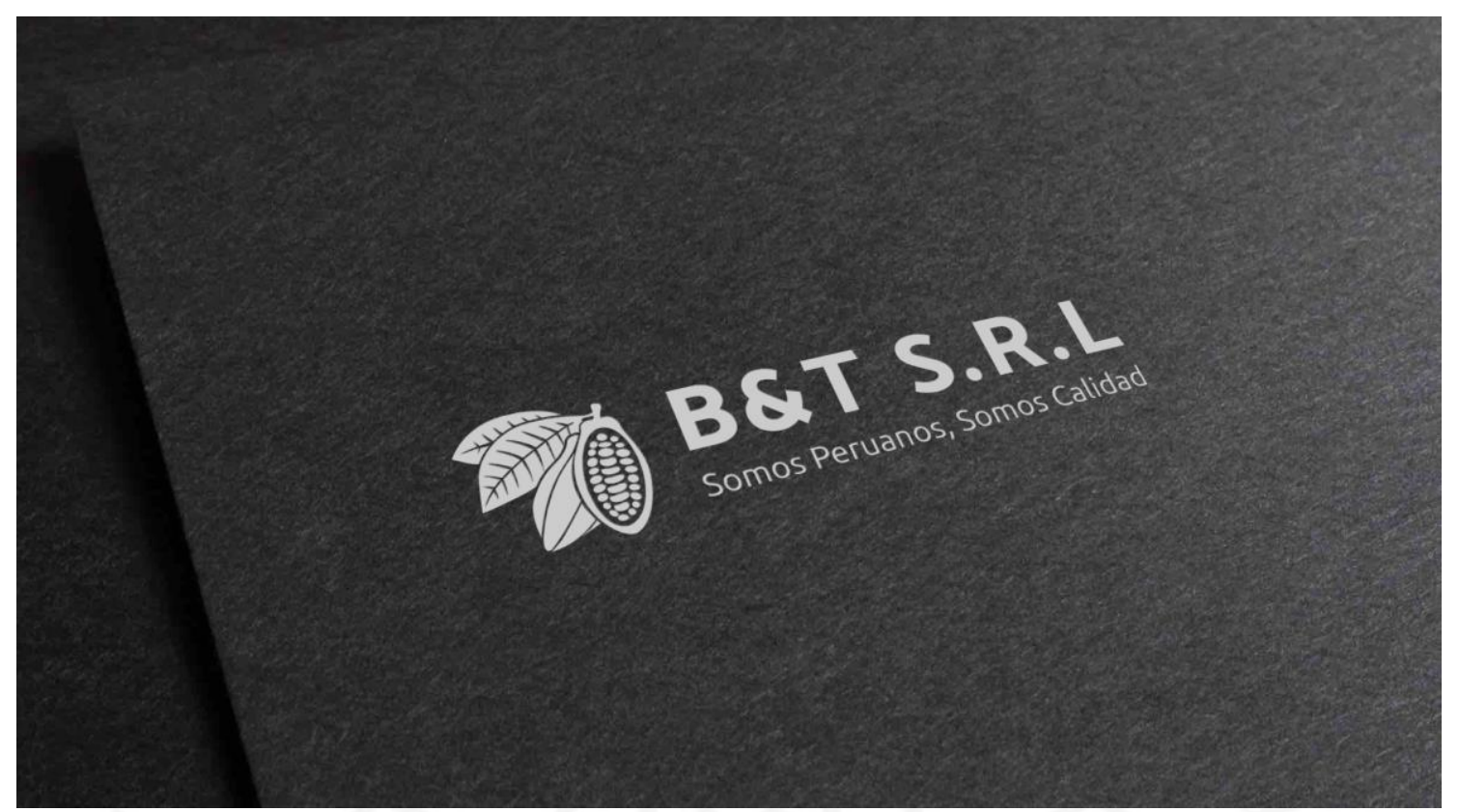

Elaboración Propia 